\title{
MANAGING TO COMPETE? EMPLOYMENT, WORK AND LABOUR RELATIONS IN THE HOSPITALITY INDUSTRY IN NEW ZEALAND
}

by

Rose Ryan

\author{
A thesis \\ submitted to the Victoria University of Wellington \\ in fulfilment of the \\ requirements for the degree of \\ Doctor of Philosophy
}

Victoria University of Wellington 


\begin{abstract}
This thesis outlines the nature of human resource management in the Accommodation, Cafes, and Restaurants industrial sector in New Zealand in the late 1990s. Using data collected through postal surveys, interviews and analysis of employment contracts, the thesis utilises Gospel's (1992) analytical framework (which suggests that labour, employment and work are the key areas in which managers must make human resource decisions) to describe prevailing patterns of management occurring in the industry. It suggests that stereotypical conceptions about the nature and structure of employment within the industry do not reflect current day reality, and that deregulation of licensing laws, a rapid rate of growth and the nature of customer demand within the industry have had a significant impact on human resource related decisions.
\end{abstract}

The thesis also attempts to uncover the rationales provided by managers for their employment related decisions. In doing so it finds that while some management decisions are clearly affected by market constraints, others appear on the face of things to be inconsistent with management's express view of their competitive strategy. This is explained with reference to Anthony Gidden's stratification theory of action to support the notion that managerial decision making is not a completely rational and market-related process, but that other factors, including ideology and manager's own conceptions of themselves as social actors, are influential in the decisions that are made. 


\section{Acknowledgments}

It is customary for authors of $\mathrm{PhD}$ theses to note that there are many people without whose assistance one could not have completed the task. The truth of this assertion means that acknowledging all those to whom I am indebted could easily have significantly extended the length of this thesis. Those who have offered professional support, advice and criticism of one type or another include:

- First, and most significantly, those managers in the hospitality industry who completed the survey, and most particularly those who also agreed to be interviewed;

- Officials and employees from the Hotel and Catering Industry Training Board, the Hospitality Industry Association and the New Zealand Tourism Board;

- Alistair Duncan, Ahlene McKee and Annie Newman from the Service Workers' Union of Aotearoa who kept my critical faculties honest;

- The Internal Grants Committee and Faculty of Commerce and Administration Research Committee of Victoria University of Wellington, for much-needed funding;

- Statistics New Zealand for work asociated with the postal survey; 
- Alistair Grey (ISOR) and Dave Mare for statistical assistance;

- The staff of the Alexander Turnbull Library and the National Archives of the National Library;

- The Staff of the Australian Centre for Industrial Relations Research and Teaching who welcomed me warmly during my period of research and study leave 1996/97;

- and last but in no way least, my supervisor, Dr Pat Walsh.

I am also in debt to many friends and colleagues who have offered personal as well as professional support. They include:

- Colleagues in the Faculty of Commerce at Victoria University of Wellington, particularly Gordon Anderson, Judy Brown, Pat Cumming, Lynny Groshinski, Prue Hyman, Janet Keilar, Sarah Oxenbridge, and Pak Yoong;

- My PhD support group - Jenny Neale, Jan Jordan, Devon Polascheck and Penny Fenwick - who have offered ideas and advice from beginning to end;

- Rosemary Lucas from Manchester Metropolitan University;

- and other friends not already mentioned who provided me with so much love and support and motivation at various times over the last 
four years - in alphabetical order Jane Benefield, Jane Bryson, Martha Coleman, Sue Hammond, Margaret Hanlon, Elizabeth Hartrick, Malcolm Menzies, Matthew Palmer, David Patten, Bill Ryan, Hilary Smith, John Tetley, Kurt and Eva Wetzel, and Amanda Wolf. And my cat, Rusty, whose expurrtise in Rogerian reflexivity was much (as ever) appreciated.

To those who have not been specifically mentioned, my gratitude is none the less.

Finally, I would like to dedicate this thesis, with the greatest of sincerity that I can muster, to my parents, Joan and Alf Ryan. In addition to making me stay at secondary school, I owe a particular debt of gratitude to my mother for keeping my garden weed-free during the past two years! At those times when I was most engrossed, my parents have served as a constant reminder of all that is most important in life. Their love, support and pride in this endeavour has been more than I could ever have hoped for. 


\section{Table of Contents}

Page number

\section{Chapter 1: Introduction}

1.0 Introduction 1

1.1 The framework for analysis $\quad 10$

\section{Part 1: Theoretical and Historical Background}

Chapter 2: Tourism and Hospitality Industry Development in New Zealand

2.0 Introduction

2.1 The development of the hospitality industry in New Zealand

2.2 The hospitality industry in the 1990s

2.3 Summary and conclusions

Chapter 3: Employment, Work, and Labour Relations in the Hospitality Industry

3.0 Introduction

3.2 Work relations

3.4 Summarising management practice in the hospitality industry

Chapter 4: The Framework for Analysis: Explaining Management Practice

4.0 Introduction 
4.2 The manager as agent: social relations and the construction of meaning

4.3 Bridging the gap: structuration and management practice

4.4 Explanations of management practice in the hospitality industry

\section{Part 2: Empirical Findings}

\section{Chapter 5: Research Approach and Methodology}

5.0 Introduction

5.1 Methodology

5.2 Limitations of the study

5.3 The respondents and their organisations

\section{Chapter 6: Employment Relations in the Hospitality Industry}

6.0 Introduction

6.1 Employment in the industry

6.2 Bringing them in: recruitment and selection practices

6.3 Training them up: induction, training and skill development

6.4 Summary and conclusions

\section{Chapter 7: Work Relations in the Hospitality Industry}




\section{Chapter 8: Labour Relations in the Hospitality Industry}

8.0 Introduction

8.1 Managers as employers - getting advice

8.3 Wages and conditions in the industry

8.4 Collective representation

8.5 Discipline, dismissals and personal grievances

\section{Part 3: Discussion and Conclusions}

Chapter 9: Labour-Management Practice in the Hospitality Industry: Managing to Compete?

9.0 Introduction

9.1 Reflections on management style 
9.5 Summary and conclusions 


\section{Chapter 10: Explaining Management practice: Strategy, Environment and Social Action}

10.0 Introduction

10.1 Markets and social action as determinants of managerial practice

10.2 Structuration and management action

10.3 Conclusion

Bibliography

\section{Appendices}

Appendix 1: Number of Licenses granted and average population per licensed house 1894-1938

Appendix 2: Questionnaire: Covering letter and reminder letter

Appendix 3: Questionnaire: Employment Relations in Hotels Cafes and Restaurants

Appendix 4: Survey Results - Frequency Tables

Appendix 5: Covering letter to interviewees

Appendix 6: Interview schedule

Appendix 7: Summary characteristics of interviewees 


\section{Tables and Figures.}

Page Number

\section{Chapter 1}

Figure 1.1: Structure of the thesis

\section{Chapter 2}

Table 2.1: Occupations of the non-Maori population engaged in hospitality 1874-1886

Table 2.2: New Licenses granted by the Liquor Licensing Authority since 1 April 1990

Table 2.3: Percentages of enterprises by employee size bands 19861996

Table 2.4: Enterprises and full-time equivalent employees by business type, ANZSIC Division H, 1996

Table 2.5: Numbers of full-time and part-time employees on hotels and restaurants, 1992-1996

\section{Chapter 4}

Figure 4.1: Features of a segmented labour market

Figure 4.2: Management approaches to labour relations

Figure 4.3: Management-employee relations and market power

\section{Chapter 5}

Table 5.1: Population and sample sizes

Table 5.2: Responses to survey

Table 5.3: Responses to the survey by size band 
Table 5.5: Interviews by industry sub-sector

Table 5.7: Second and third most crucial factors for competitive sucess by industry sub-sector

\section{Chapter 6}

Table 6.1: Proportions of full-time employees for selected industry sub-groups

Table 6.2: Proportions of permanent employees for selected industry sub-groups

Table 6.3: Methods of recruitment for filling vacancies and perceived success of method previous 12 months

\section{Chapter 7}

Figure 7.1: Methods of communication

Figure 7.2: Information provided to and sought from employees

\section{Chapter 8}

Table 8.1: Types of employment contract 
Table 8.2: Core employment conditions in employment contracts

\section{Chapter 9}

Figure 9.1: Dimensions of labour-management practice 


\title{
Chapter 1: Introduction
}

\subsection{Introduction}

\author{
Men make their own history, but they do not make it just as they please; they do \\ not make it under circumstances chosen by themselves, but under circumstances \\ directly encountered, given and transmitted from the past. The tradition of all the \\ dead generations weighs like a nightmare on the brains of the living. (Marx, 1870; \\ in Feuer, 1959:320)
}

The study of management sits somewhat uneasily within the industrial relations research tradition, as a number of writers have noted over the years (Clegg, 1979; Gospel, 1983; Gospel and Littler, 1983; Kaufman, 1993; Wright, 1995). As a result of the tendency of industrial relations researchers to focus on workers, unions and collective bargaining, managers as the subject of research are constituted largely as participants in collective bargaining or industrial disputes. The reasons for this orientation include the traditionally pro-labour stance of many industrial researchers, the reluctance of management to allow researchers access to their organisations for the purposes of research, and the perception that it is trade unions that have traditionally "driven" industrial relations activity (Gospel, 1983). While the management of people at work has "...always been a central problem and challenge for employers" (Gospel, 1992:1), it is only since the 1980s, as the balance of bargaining advantage has moved in favour of employers, that the subject of management has become more common as a concern of industrial relations researchers. This thesis aims to contribute to that 
body of research by analysing patterns of management in the hospitality industry in New Zealand in the 1990s.

That management has not been particularly visible in the industrial relations research tradition does not mean that recent work has not to some extent rectified this deficiency, nor that management has not been the subject of research in other disciplines. Research into a range of aspects of managerial behaviour and action has a history that dates back to the early years of this century, particularly in the United States. Within the economics tradition, John Commons analysed the importance of employers in shaping the development of the American industrial relations system (Gospel, 1983), and the work of Frederick Winslow Taylor (Taylor, 1947) was particularly influential in facilitating a more systematic approach to the management process. In the immediate post-war period, the insights of the Human Relations movement stimulated a greater concern with the management of labour (see for example Roethlisberger and Dickson, 1939; Chamberlain, 1948; Whyte, 1948). The post-war spread of collective bargaining as the primary means of regulating the employment relationship drew attention to changes in the sources and legitimacy of managerial authority (Bendix, 1956). Nevertheless, this period saw the beginnings of a "hollowing out" (Kaufman, 1993) of the field of industrial relations which eventually saw the discipline dominated by researchers whose prime concerns were with unions and collective bargaining, and the development of a separate management discipline. The publication of Dunlop's Industrial Relations Systems in 1958 (Dunlop, 1958/1993) accentuated these developments. While he pointed to the role of management as an actor along with unions and the State, emphasis was placed on 
the institutional and external influences on their behaviour, ${ }^{1}$ with little analysis of management processes or strategies (Gospel, 1983). Up until the 1980s, consideration of these questions was left to sociologists and organisational theorists (see for example, Simon, 1957; Chandler, 1962; Cyert and March, 1963; Child, 1972), who conversely did not always view labour-management ${ }^{2}$ as distinct from other management processes.

An institutional emphasis also dominated the thinking of industrial relations theorists across the Atlantic in the UK. While Marx and the Webbs provided some analysis of employer practices in the transition to industrialisation, these were otherwise ignored in British industrial relations up until the 1960s. This lacuna is reflected in Hyman's recent account of the historical development of British industrial relations, which jumps from the Victorian workplace to the 1960s within one paragraph (Hyman, 1995). The nature of the industrial relations system through much of the twentieth century, centred as it was on national industry bargaining by employer associations and trade unions, meant that most research focused on institutional factors and relationships. This changed from the 1960s for two reasons. The first was the rise in the level of shop floor activity in the postwar period, and the subsequent appointment of the Donovan Commission in 1965.

\footnotetext{
${ }^{1}$ Dunlop viewed management decisions as being made within an environmental context made up of the technical conditions of the workplace and the work community; the market or budgetary constraints and the locus and distribution of power in the larger society. Specific features of these and their influence on the industrial relations system are developed in some detail. Dunlop suggests that "While the full complex of rules of a workplace is to be regarded as influenced by the total context, some rules are particularly related to the technical and market context, and others to the power context and define the status of the actors" (Dunlop, 1958/1993:12). While this statement would seem to imply some degree of management autonomy, and a range of management styles discussed, no attention is paid to the influence on workplace rules of these alternative styles.

2 Throughout this thesis (and following Gospel), the term "labour-management" is used as a catchall to include all aspects of management activity in relation to employees.
} 
Fox's 1966 submission to the Donovan Commission, and his later work which stimulated the "frames of reference" debate (Fox, 1966b, 1974, 1979; Flanders, 1970; Wood and Elliot, 1977; Hyman, 1978; Clegg, 1975, 1979) were the first serious attempts to bring the study of management into the mainstream industrial relations tradition. In addition, the Commission itself (and its statutory successor, the Commission on Industrial Relations) was conscious of the need to establish an empirical base for discussions about the role of management in industrial relations. To accomplish this, it sponsored the earliest known British research designed to gather this data (Commission on Industrial Relations, 1973a, 1973b). The second development to draw attention to the role of management in industrial relations was the publication in 1974 of Braverman's Labour and Monopoly Capital which, drawing on Marx's Capital, focused on the control strategies utilized by management to transform labour power into surplus value. This publication resulted in an outpouring of articles in the labour process tradition, referred to at various points in this thesis.

Since the 1980s, management has become more commonplace as a focus for industrial relations research, which has considered important questions about patterns of management action, and explanations of management behaviour. The lacunae in our knowledge about labour management practices of the past have been partially filled by some important historical studies (Tolliday and Zeitlin, 1985; Gospel, 1992; Wright, 1995). Research into contemporary management practice is extensive and varied. Central themes have included analyses of the range and spread of employer practices (see for example Batstone, 1984, 1988; 
Millward and Stevens, 1986; Callus et al, 1991; Millward et al, 1992; Appelbaum and Batt, 1994; Millward, 1994), typologies of management style and theorisation about management strategy (Kinnie, 1985, 1989; Purcell, 1987; Capelli and McKersie, 1987; Storey and Sisson, 1993; Watson, 1994), and debates about changes in management practice, particularly the concept of human resource management (Guest, 1987, 1990; Marchington and Parker, 1990; Storey and Sisson, 1993; Legge, 1989, 1995; McLoughlin and Gourlay, 1994; Townley, 1995). The volume of work undertaken has added considerably to the broader body of knowledge concerned with organisational functioning. In addition, it fills a gap in the industrial relations literature about the functions and roles of managers, and provides a much needed critical perspective for scholars within the management discipline.

While an increase in the amount of work being undertaken on management is to be welcomed, along with the high quality of some individual contributions, a consideration of the literature as a whole reveals some gaps and weaknesses. The first is that it remains preoccupied with large organisations and those industries which drove the engine of the industrial economy - mining, steel mills, motor vehicle assembly plants, transportation, and in the New Zealand context, meat freezing works. ${ }^{3}$ Despite the massive changes in the structure of the world

\footnotetext{
${ }^{3}$ An indication of these preoccupations in found in a perusal of the indexes of leading industrial relations journals. The consolidated index for the Journal of Industrial Relations 1959-1990 includes within it numbers of articles on coal mining, metals and engineering, road transport, professional team sports, the waterfront, petroleum, iron and steel, shipping, electrical, and so on. A similar pattern is found when examining the consolidated index for the British Journal of Industrial Relations covering the first 19 volumes. Separate headings are found for agriculture and fishing, central and local government (including health and education services), chemicals, coal mining, construction, engineering and ship building, iron and steel, general manufacturing, paper, printing and publishing, public utilities, textiles, clothing and footwear, transport and
} 
economy away from its primary and manufacturing base, the discipline has been slow to adapt research strategies to these changes. ${ }^{4}$ The consequence of this concentration on primary and production industries has been that theories of management and industrial relations have been constructed on the basis of patterns which apply only to a specific segment of the economy, and are of limited generalisability. Beechey has argued that "...we need to develop an analysis of employment which does not take manual work in manufacturing as its model ... to pay more attention to forms of workplace other than factories ... and to small workplaces and work ... in other locations" (1987:191-192). It is notable that those industries where industrial relations have been studied in detail invariably employ large proportions of full-time male workers, are highly unionised, and have well-developed collective bargaining machinery. It is also notable that in these industries over the past two decades, major declines in employment have been experienced as a result of downturns in demand, technological change, and increased competition. Industrial relations as a discipline has yet to pay significant attention to workplaces within the service sector, where employment patterns are distinctively different (e.g., higher percentages of women workers, more part-time and casual workers), where union

communication, and vehicles (for which industry alone there are 28 entries). In contrast, in its entire 34 years of publication, the $B J I R$, has included only half a page on events related specifically to the hotel industry, and this was about an inter-union dispute (Palmer, 1968).

${ }^{4}$ It is true that this sometimes reflect ease of access for research purposes. It should be noted also that some information is available from large scale survey evidence and that some exceptions can be found in case studies that have been done in retailing (Marchington and Harrison, 1991; du Gay and Salaman, 1992; Marchington, 1996), the public service (Ferner, 1988; Winchester and Bach, 1995; Walsh, 1995), the travel industry (Williams, 1986; McGraw and Palmer, 1990) and insurance and financial services (Sturdy, 1992; Austrin, 1994). In addition, McLoughlin and Gourlay (1994) have made an important contribution in studying industrial relations in the nonunion sector of the economy. 
density is commonly considerably lower, where collective bargaining is often not as well entrenched, and where the notion of managerial prerogative is still strong. Riley (1993) notes that such patterns are often seen by industrial relations academics as being "traditional" in the sense of being historically antecedent to the pluralist tradition that has dominated industrial relations since the 1960s. Yet it is in the service sector that employment growth is the strongest, suggesting that these patterns may become the new "norm" for the future, despite their invisibility in the past. Writing in the hospitality industry literature, Riley notes that:

\footnotetext{
What we see in the hotel and catering industry is low unionisation, a good deal of self-directed learning, a dominant external labour market, and neo-classical economics aided and abetted by a rigid occupational structure. It is in fact a good example of an industrial relations system dominated by its economic system. If that looks like the past, it might also look a bit like the future. (1993:8)
}

A second weakness in contemporary research on labour-management is a narrowness of focus. Recent studies commonly examine the ways in which managers make decisions about wages and conditions, discipline and disputes, health and safety, collective bargaining and relationships with trade unions. Studies of job design and the control of work remain part of a separate, labour process, tradition, and with rare exceptions (see particularly Legge, 1995) these are not included within mainstream examination of industrial relations management. Even less frequently examined are the methods used by managers to recruit, train, appraise, and reward their employees. While Kaufman (1993) suggests that the reasons for this lie in the political and economic environments in which industrial relations systems have operated, resulting in an institutional orientation for the discipline, this focus may itself have been a casualty of the 
division between managers and unions on those subjects which were able to be the subject of bargaining and those which continued to remain within the domain of managerial prerogative. Nevertheless, as Gospel (1992) points out, the dynamic of the relationship between managers and employees cannot be so easily bifurcated, and contemporary studies of labour, employment and work must consider all aspects of labour-management. Several researchers have responded to this challenge, and apart from Gospel's own study, a more integrated approach been incorporated into both historical studies of management practice (Wright, 1995 ) and case studies of particular workplaces (Marchington and Harrison, 1991) and industries (Revelly, 1996).

A final weakness in the overall picture is an unfortunate tendency towards reductionism and positivism. In part as a consequence of large scale surveys as a research method, much current writing on management practice has explained management behaviour as contingent on organisational size, structure, ownership, product market environment or technology. Where managerial beliefs or ideologies enter the picture, they often do so as a simplistic search for increased control of labour with management viewed as an "agent of capital" (Sisson and Marginson, 1995). Yet the contradictions and ambiguities in management actions suggest the need for a more complex understanding of the relationship between agency and structure. Management research needs to incorporate a range of other perspectives and research methods, and in particular to take account of the meanings that managers themselves ascribe to their actions. Such an approach draws attention to managerial definitions of labour-management issues, and the ways in which they attempt to resolve them, while still allowing for the possibility 
of "competing systems of interpretation" (Silverman, 1970) about the motivations for and effects of their actions.

This thesis aims to make a contribution to the current stock of knowledge on managerial action through addressing these weaknesses. Its purpose is three-fold. The first is to describe patterns of labour-management in the hospitality industry in New Zealand in the 1990s. The findings suggest that popular stereotypes of the industry as involving low status, low skilled work, with high turnover and subject to capricious management control are too simple. As with most sectors of the economy, a range of management styles and a continuum of management practices exist, although general patterns may be discerned. A second purpose in undertaking this description is to explore some of the contradictions and complexities which provide exceptions to these general patterns and to consider why these anomalies exist. Thirdly, the thesis attempts to provide an understanding of management action, by looking at the interpretations that managers themselves provide. The general conclusion is that explanations of management behaviour can not be reduced to single factors, but that managers must be seen as social actors, operating within the constraints both of the objective realities of their economic, political, and organisational environment, but also their subjective interpretations of those influences on them and their employees. The quote from Karl Marx set out at the beginning of this chapter is particularly pertinent in light of the way in which the industry practice has been influenced by an industry culture which is closely associated with the emergence of the tourism industry in New Zealand in the post-war period, as well as in the slowly increasing status of service work. 


\subsection{The framework for analysis}

While, as noted earlier, the discipline of industrial relations has traditionally focused on those topics related to trade unions and collective bargaining, in recent times it has embraced a more inclusive definition which encompasses all aspects of labour-management. The research reported on in this thesis follows this approach, using Gospel's $(1983,1992)$ distinction between labour, employment and work relations. While, as Gospel notes, the distinctions between the three may be somewhat arbitrary given the degree of overlap between them, they provide a useful heuristic device for analysing the range of practices put in place by employers and managers at workplace level. Labour relations covers those aspects of the employment relationship related to employee input into management decision-making - whether management recognises (or not) the existence of collective employee interests, and whether it recognises and negotiates with employee representatives (either union or non-union) over wages, conditions, grievances, or any other matter. Employment relations refers to the relationship that the firm has to the labour market - the processes which are used to employ and reward employees, and the effect that these have on skill levels and turnover within the firm. Work relations, in contrast, deals with the internal and organisational aspects of the employment relationship - the way in which work is organised around the process of production or service delivery, including the ways in which the relationships between workers, managers and customers are constructed. 
Gospel's framework is not, however, simply a useful device for inquiring into and describing patterns of labour management. More importantly it has been utilised to consider the ways in which management decisions in these areas change over time and suggests a dynamic model in which firm and workplace strategy interact with structure and environmental variables (including historical, political, social, economic, legal, and technological contexts). Gospel's thesis rests on five distinct propositions:

- $\quad$ that in a market economy, the nature of markets will play a large part in shaping labour-management decisions;

- $\quad$ that market forces are mediated through the structure of the firm;

- that the nature of the managerial hierarchy is an important variable in influencing labour-management decisions;

- that the choice of production technology and the division of labour within the firm also shape labour-management decisions;

- that in making labour decisions, there are a number of choices open to the employer. (Gospel, 1992:6-8)

It is these key propositions that have formed the basis of the current study. In looking at management practices in the hospitality industry, the research considers how size, ownership, and market segment influence patterns of labour management. Gospel's model, however, does not propose a simple deterministic relationship between these variables. Following Child's (1972) view of 
managerial decision making, Gospel suggests that employers have a choice, and that one of the most significant is the extent to which decisions about the three aspects of labour management are determined by the external market, or according to administrative principles internal to the firm. Gospel argues that patterns of labour-management have shifted over time from a reliance on the external market to strategies of increased internalisation. If there is any weakness in his argument, it is that the reasons for this shift in emphasis are not adequately explored. While he recognises that labour and product markets are shaped by historical, cultural and political contexts, the effect of these factors is given less attention. In contrast, this thesis argues that non-market variables play an important role in determining managerial choices. The role of agency in relation to structure, is thus given greater emphasis in this study than in Gospel's analysis, and Part 3 of the thesis adopts Anthony Giddens' concept of structuration as a tool for examining the relationship between the two.

The thesis is divided into three parts as set out in Figure 1.1. The first provides a theoretical and historical background. Chapter 2 describes the development of the hospitality industry in New Zealand, and the regulation of employment within it. The chapter ends with a description of the sector in the present day, as an important centre of economic activity and source of employment growth. Chapter 3 goes on to summarise and review existing relevant literature on the hospitality industry, noting that insights from both industrial relations and hospitality literatures have rarely crossed disciplinary boundaries. The chapter concludes by noting that within this literature, little attempt has been made to explain the reasons for prevailing labour-management practices within the industry, nor to understand why firms adopt different practices despite operating in similar labour 
and product markets. Accordingly, Chapter 4 reviews the literature on explanations of management action, particularly focusing on the debate between those who see economic forces as a primary determinant, and those who allow a role for human action. In doing so, it suggests that the hospitality industry literature has been dominated by assumptions of rational employer responses to market conditions, and that alternative explanations for management practice have been inadequately explored.

The empirical findings of the research are set out in Part 2 of the thesis. It opens with a description of the methodology used to conduct the study and analyse the data. Chapters 6 to 8 explore the issues of employment, work, and labour relations in the industry, describing existing practice and the ambiguities and contradictions which exist within this.

The thesis then moves onto a discussion of the findings in Part 3. In particular, discussion draws out the ways in which understandings of managerial behaviour and action are affected by a variety of factors emanating from the political and economic environment as well as the structure and nature of the firm itself. This discussion emphasises, however, that these factors in and of themselves can not be used to explain away managerial action. Managers respond to constraints in different ways, and do so because of their multiple social identities, and their subjective (and intersubjective) interpretations of objective conditions. In particular, in the context of this study, changing understandings of the managerial role, the nature of service work and the status of the tourism industry are resulting in shifts in the prevailing style of management. The thesis concludes by arguing that a greater emphasis on interpretive analyses must be included within industrial 
relations and management research in order to reach a fuller understanding of the complexities of the employment relationship. 
Figure 1.1: Structure of thesis.

\section{Chapter 1: Introduction}

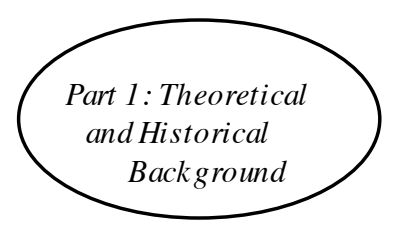

Chapter 2: Tourism and Hospitality Industry Development in New Zealand

Chapter 3: Employment, Work and Labour Relations in the Hospitality Industry

Chapter 4: The Framework for Analysis:

Explaining Management Practice

Chapter 5: Research Approach and Methodology

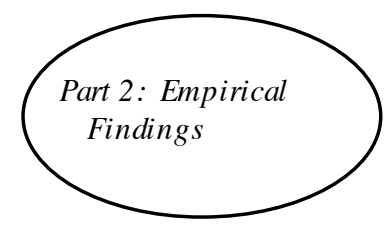

Chapter 6: Employment Relations in the Hospitality Industry

Chapter 7: Work Relations in the Hospitality Industry

Chapter 8: Labour Relations in the Hospitality Industry

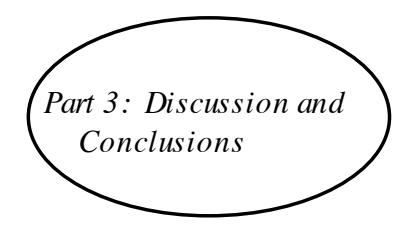

Chapter 9: Labour-Management Practice in the Hospitality Industry: Managing to Compete?

Chapter 10: Explaining Management Practice: Strategy, Environment and Social Action 


\section{Chapter 2: Tourism and Hospitality Industry Development in}

\section{New Zealand}

\subsection{Introduction}

The aim of this chapter is to describe the wider historical and social context in which managers in the hospitality industry conduct their business. It is structured in two parts. The first looks at the development of the hospitality industry in New Zealand, involving in particular the significance of "the pub" in New Zealand social life and the development of mass tourism in the post-war period. ${ }^{1}$ The chapter argues that the hospitality and tourism sectors in New Zealand evolved separately from each other, and developments in each were in conflict from the mid-1950s onwards. This was a consequence of the system of liquor licensing which had been designed to resolve domestic political concerns in the early half of the century. The boom in tourism in the post-war years, however, led to a perception that licensing regulations were in conflict with tourism interests and the desire to attract international visitors. From the 1980s, tourism interests played an important part in the deregulation of the licensing trade. In addition, changes in social attitudes have resulted in an integration of the two strands in the shape of the modern hospitality industry, in which domestic tourists and local residents are as critical to the continuance of the industry as international visitors. These changes themselves must also be seen in the context of the emergence of the so-

\footnotetext{
1 It must be noted that the chapter focuses largely on hotel accommodation and pubs. This reflects the importance of those two industry sub-sectors in New Zealand social life. While in the 1990s cafes, restaurants and fast food restaurants make up a numerical majority of enterprises in the hospitality industry, this is a relatively recent development. In addition, although cafes and restaurants have existed since the early settler period, almost nothing has been written on their history, except where this has related to licensing legislation.
} 
called "leisure society" in the western developed world, in which consumers spend increasing amounts of time and money on travel, tourism, accommodation and eating out.

The second part of the chapter describes the hospitality industry in New Zealand in the 1990s, including its structure, ownership and management, and patterns of employment. It suggests that while many of the regulatory problems that have constrained the development of the industry in the past have now been resolved, a set of new issues has arisen from the speed of development in the past decade.

\subsection{The development of the hospitality industry in New Zealand}

\subsubsection{Hotels and restaurants in New Zealand society}

The history of New Zealand is intimately tied up with the trade and supply of alcohol and the imposition of restrictions on the same. Whalers and traders in the early 18 th century brought rum and other spirits with them, and from very earliest times established a roaring trade in imported and locally distilled spirits and beer (Bollinger, 1959). “Grog shops” and hotels were a central feature of settler society - not just as places to obtain a drink, but also as general stores, places where food and accommodation could be obtained, and a meeting place and information centre. Few constraints were placed on early hotels. The 1842 Colonial Licensing Ordinance (the first liquor control regulation) required all persons selling liquor in quantities of less than 2 gallons to obtain a license, but these were unlimited in number and not difficult to obtain. Once licensed, a hotelier was simply required to observe the hours set out in the ordinance (6 a.m.-10 p.m. Monday-Saturday 
and 1-7 p.m. on Sunday) and to ensure that no patrons became drunk (Bollinger, 1959; New Zealand Official Yearbook, 1961; Hargreaves, 1992).

As the population of the new colony increased, the hotel was established as an integral feature of the new communities, in which there was otherwise little in the way of public facilities and social organisation. Hoteliers were supporters of public appeals for worthy causes (Hargreaves, 1992) and often played an important role in community affairs and local government (MacKay, 1992). Their premises were used for entertainment, sporting events, nursing of the sick, marriages and funerals, and as a departure point for coaches. The English custom of holding political and other meetings in pubs was a feature of the new colony. In 1851, Barretts Hotel in Wellington was the location for the first meeting of the Legislative Assembly (Bremner, 1990) and also hosted a meeting of trade unionists meeting to discuss a resolution that eight hours should be the length of the working day (Sutch, 1966:28). ${ }^{2}$ With no restriction on the number of licenses, and a largely single, male, and nomadic population, hotels flourished. The centrality of hotels in social life meant that they became important sources of employment in the new colony, particularly for women. A comment in the New Zealand Times in 1880 noted that a publican advertising for a barmaid had received 50 applications, this being attributed to the fact that wages being paid in hotels were significantly higher than those being paid to domestic servants. ${ }^{3}$ Early population censuses indicate that almost $10 \%$ of the total non-Maori resident

\footnotetext{
2 So accepted was the pub as a meeting place that even gatherings of the early temperance movement took place in hotels. More bizarrely, the 1867 Coroners Act provided for hotels to become a repository for any dead body awaiting an inquest (Baglin and Austin, 1984).

${ }^{3}$ Alexander Turnbull Library, Roth Files - Domestic workers.
} 
population were engaged in the provision of food and lodging (see Table 2.1), and these numbers continued to grow until the turn of the century. That hotels, coffee houses and other lodging houses were well patronised is suggested by reports from workers in early hotels. A day porter at the Excelsior in Dunedin complained of having to clean 60 pairs of boots before breakfast, and a worker at a temperance hotel reported an average of 250 people for lunch of three courses. ${ }^{4}$

Table 2.1: Occupations of non-Maori Population of the colony engaged in hospitality, 1874-1886.

\begin{tabular}{|l|c|c|c|c|}
\hline Occupation & 1874 & 1878 & 1881 & 1886 \\
\hline Hotel keeper or wife assisting in business & 1,537 & 1,690 & 1,890 & 1,682 \\
\hline Coffee, eating house keeper, or wife & 33 & 48 & 32 & 43 \\
assisting in business & & & & \\
\hline Boarding, lodging house keeper, or wife & 199 & 354 & 420 & 445 \\
assisting in business & & & & \\
\hline Cook (not domestic servant) & 256 & 439 & 726 & 589 \\
\hline Inn, club-house, eating house servant. & 1,939 & 2,887 & 2,471 & 2,579 \\
\hline
\end{tabular}

Source: New Zealand Censuses 1874-1886

Hotels also played an important economic function, particularly in gold-rush towns, as an entertainment centre in which diggers could spend their pickings. Of those who listed their occupation as hotel keeper in the 1874 census, 479 (including 71 women) were located in goldfields. An historian notes: 
The numbers of licensed hotels served as a rough indicator of the prosperity of a town. Most of the small settlements had at least three or four, while a medium sized gold-field town would have a dozen or so, and the largest centres, Thames and Hokitika, were to have more than a hundred hotels at their peak. Eight-four hotels were lined up cheekby-jowl along Hokitika's Revell Street, which was only a mile long. Each settlement and town also had an array of illegal drinking dens and illicit stills. The premises of slygroggers were normally crude, to say the least, but a good number of the hotels were spartan too. Some were merely wooden huts with a dirt floor, a bar made of planks, and a flap of canvas over the door. But the larger hotels of Thames and Hokitika were the zenith of gold-field grandeur: two-storied buildings, tastefully fitted out, offering fine meals and wines and accommodation for weary travelers, as well as evening entertainment of billiards and music (MacKay, 1992:84).

Hotels did a roaring trade, and residents of and visitors to gold towns consumed a considerable proportion of the amount of spirits imported into the colony (MacKay, 1992). At the same time, this resulted in unwelcome social problems, and excessive consumption of liquor was a major cause of crime, sickness and poverty. The emerging temperance movement appealed to the Victorian sense of morality in pressing for increased restrictions on the sale and supply of liquor. As a result, from the 1860 s onwards, the government became firmer in its resolve to deal with the issue. Drunkenness was treated severely, and in 187016.7 people per 1000 of the population were convicted for drunkenness (Justice Department, 1974). In addition, a series of legislative amendments designed to "clean up" hotels were passed. ${ }^{5}$ Local ordinances in Otago prohibited Sunday trading and dancing or playing music in bars, and hotel bars containing billiard or bagatelle tables were required to pay an additional fee (Hargreaves, 1992). The movement

\footnotetext{
4 "Before the Union was formed" by An Old Hand; The Recorder February 6, 1911. Alexander Turnbull Library, Roth Files.

5 This did not, however, extend to removing the provision of the 1852 Constitution Act exempting Parliament from the general law relating to liquor!
} 
towards wholesale regulation of the liquor trade and the separation of alcohol from other forms of social activity which was to later restrict the development of the industry had begun.

\section{$\underline{\text { Regulation, restriction and prohibition 1873-1948 }}$}

The first attempt to regulate hotels on a systematic basis was in 1873 , when the Licensing Act for the first time prevented the issue of new liquor licenses, and allowed locally elected Licensing Committees to opt for local prohibition. The Act was limited in its success, in part because the 395 local districts were so small that it was easy for would-be drinkers in a dry district to travel to another district to obtain a drink. In addition, the Act failed to provide for the cancellation of licenses (Justice Department, 1974). The increasing influence of the temperance movement was reflected in the passage in 1893 of the Alcoholic Liquors Sale Control Act which strengthened the system by restricting the number of available licenses across the country. New Licensing Districts reflected electoral boundaries, and "local option" polls were held at the same time as Parliamentary elections. In these polls, electors had the option of voting for continuance (the "top line"), or reduction or abolition in the number of licenses held in the district. The Act prohibited the granting of any new licenses anywhere in the country until such time as census results provided evidence of a $25 \%$ increase in population. It also introduced a new requirement for licensees to be certified by a local Magistrate as "fit" to hold a license (New Zealand Official Yearbook, 1894). In the first year of the Act, 1719 licenses were granted or renewed. At the time, the ratio of persons for each licensed premises was 391 (see Appendix 1). 
The first district to vote for prohibition was Clutha in 1899 by a majority of only 30 votes, and six months later, Invercargill's 16 hotels closed for business (Lind, 1994). While in a number of other districts more than half of all voters opted for the abolition of local licenses, in none was the $60 \%$ threshold reached. ${ }^{6}$ Over the years, most districts voted in favour of continuance, and in the eight polls that were held while the legislation was in force, only 12 districts in total voted for prohibition. ${ }^{7}$ In a number of other districts, however, electors voted for reduction, so over time, the number of licenses granted dropped off, and the ratio of licenses per head of population increased (see Appendix 1).

The turn of the century also saw the beginnings of employment regulation. Early attempts to form unions in Dunedin, Wellington and Auckland had not been successful, but the passage of the Industrial Conciliation and Arbitration Act in 1894 facilitated collective bargaining over wages and conditions of employment. The first Board of Conciliation hearing was in respect of hotel employees in 17 Wellington hotels and restaurants in 1901. The Board's recommendations included wages for cooks and waiting staff in hotels, restaurants, and oyster saloons; a prohibition on working more than 11 hours a day, a weekly half-day holiday; seven days annual holiday a year, and preference of employment for union members (Book of Awards, Vol. 2, pp 155-158). Dissatisfied employers, however, applied to the higher authority of the Arbitration Court, which issued an

\footnotetext{
6 While continuance or reduction of licenses was decided on the basis of a simple majority of voters, for prohibition to be implemented the local vote had to achieve a majority of $60 \%$.

7 Apart from Clutha in 1899; the others were Ashburton and Mataura in 1902; Grey Lynn, Oamaru and Invercargill in 1905; Eden, Ohinemuri, Masterton, Wellington South, Wellington Suburbs and Bruce in 1908. (1990 New Zealand Official Yearbook)
} 
award overturning the Board's recommendations by reducing wages and holidays and removing the preference provisions (Book of Awards, Vol. 3, pp 288-293).

Conditions of work for hotel and restaurant employees in the early years of the century were harsh (Ferguson, 1985). The majority of employees lodged at their premises of work, and provisions for accommodation and meals were rudimentary. A letter in the New Zealand Times of 31 January 1906, from one Edward O'Brien stated that:

In the majority of hotels in New Zealand there is no such room as a servant's dining room or sitting room of any kind, where we could get our meals comfortably, and the sleeping accommodation is simply disgraceful. In some places there are five or six men - waiters, barmen and porters - packed like sardines in a small unhealthy space not fit for human habitation at all, with no one to clean and tidy the place, and no time to do so themselves.

The area of biggest concern, however, was hours. It was not uncommon for employees to be required to work in excess of 90 hours per week (Fryer, 1976; Ferguson, 1985), and one employee reported working in a hotel kitchen from 5 a.m. to 8 p.m., with only a twenty-minute break for meals. ${ }^{8}$ From 1910 , the inclusion of restaurants within the scope of the Shops and Offices Act provided waiting staff with a weekly half-day holiday, but it was not until 1914 that the Arbitration Court granted a six-day week (of 62 hours) in hotel and restaurant

8 "Before the Union was formed" by An Old Hand; The Recorder February 6, 1911. Alexander Turnbull Library, Roth Files. 
awards. These hours of work remained standard until legislation imposed restrictions on hours of work in 1936 and $1945 .{ }^{9}$

The strength of the temperance movement increased after the turn of the century and led to heightened pressure for still more rigorous control of the liquor trade. After an amendment to the legislation in 1910, local option polls restricted voters to a choice between prohibition and continuance, thus removing the option of a reduction in the number of licenses. The amendment also provided for the introduction of a national poll, the first of which was held in 1911, in which 55\% of the population (just short of the $60 \%$ threshold) voted for national prohibition. It was not until 1919 that the anti-liquor lobby managed to persuade Parliament that the national poll (by this time also including a third option of state purchase and control) should be decided on the basis of a majority vote. The vote for prohibition was achieved on the night of the next election. The result was overturned, however, on the count of votes of servicemen overseas, and continuance won the day by the slim margin of 3,263 votes. This was to mark the zenith of support for the temperance movement, however, and the proportion of the population in favour of prohibition continued to decline over the years.

The anti-liquor lobby made other gains over the period, however. Concerns about the employment of women in hotel bars resulted in 1910 legislation prohibiting

\footnotetext{
9 The 1936 amendment to the Shops and Offices Act (which covered hotels and restaurants) reduced hours to 44 per week, although the Factories Act had reduced hours in these workplaces to 40. In 1945, hours of work were reduced to no more than 40 in all industries.
} 
the employment of barmaids. ${ }^{10}$ Women who were at the time employed in that capacity were able to register and continue with their employment as long as they did not leave the trade for more than two years. ${ }^{11}$ In addition, calls for strengthened regulation during the period of the 1914-18 war resulted in the passage of the 1917 Sale of Liquor Restriction Act. While the temperance movement had argued for complete prohibition "for the duration", this was met with resistance. The compromise that was reached was that hotel bars were required to close at 6 p.m. (Bollinger, 1959; Department of Justice, 1974). The legislation also prevented the serving of liquor with meals taken on licensed premises after 8 p.m. or at any other time when hotel bars were required to be shut.

While 6 o'clock closing was originally intended as a wartime measure, it became a permanent feature of the legislation from 1918. The effect of this was to cement the divorce between alcohol and other forms of social activity through increased restrictions on those activities that could take place in hotels. The earlier concept of pubs and hotels as a centre of community activity had changed irrevocably, as hotels were prevented from providing any service other than the sale of liquor and

\footnotetext{
10 This was based not so much on concern for the women themselves, but on their allure for hotel patrons. This was expressed most explicitly by the Hon Mr Callan in the Legislative Council debate on the 1910 Licensing Amendment, when he said that "The reason I support the abolition of barmaids is that in a long experience of life in various colonies my experience is this: that young men in large cities who are not inclined to drink at all, and who would not otherwise think of visiting hotels, are induced to do so simply for the purpose of having a talk with a pretty barmaid. Nobody will deny that, and the result is that they cannot go in and give themselves that pleasure without partaking of drink, and by constantly going in they are inclined to take drink to excess.” New Zealand Parliamentary Debates, November 10, 1910.

${ }^{11}$ At the time, it was anticipated that marriage, illness and death would reduce this number over time. This hope proved to be ill-founded however. Some 1500 barmaids registered at the time of the Act, but in the 1920s it was evident that similar numbers continued to be employed. A Police census in 1924 revealed that 220 of the original registrants continued to be eligible to work, but others were employed unlawfully. Police inquiries revealed that barmaid certificates were sometimes sold when the holder left the industry, or were forged.
} 
the provision of accommodation. As a consequence of restriction on numbers of licenses, however, their value significantly increased, ensuring high levels of profitability both for licensees and the breweries (Royal Commission on Licensing, 1946; Bollinger, 1959). A public backlash against industry profits resulted in the development of Licensing Trusts in the mid-1940s. When the Invercargill Licensing District voted for restoration in 1943, public concern was expressed that the sale of liquor would revert to private hands. The value of licenses was recognised as being considerable, and the public anxious that they should not simply be "given away" (Lind, 1994). Accordingly, the concept of an elected Board to control and supervise the selling and supply of liquor, with profits to be distributed to community organisations within the Trust area, was introduced through the Invercargill Licensing Trust Act of 1944 (Department of Justice, 1974). By 1949, more general legislation was passed which made permanent provision for the creation of Trusts in districts that had previously been no-license. ${ }^{12}$ The system allowed an exemption from the requirement for licenses to be granted by local Licensing Committees with Trusts themselves deciding on the number and type of outlets to be established. This was allowed on the assumption that if the electorate did not like the decision of the Board members then they would vote them out at the next election.

\footnotetext{
12 In the period between 1944 and 1977, 40 Trusts were established. Restrictions on their ability to raise capital, however, meant that a number never became operational, and others became insolvent over time. At the time of the 1983 review of Licensing Trusts, 26 remained (Bogle, 1983). The Sale of Liquor Act in 1989 made a number of amendments to the law related to Licensing Trusts, including opening Trust areas up for competition on a majority vote of electors living within the Trust area.
} 
Otherwise there were few amendments to the liquor licensing laws from 1919 till 1948. By 1945, however, it was widely accepted that the system was in need of review. The biggest problem was lack of legislative provision for the cancellation of unnecessary licenses or the issuing of new ones. Effectively, the distribution of licenses across the country reflected the population distribution of the late $1900 \mathrm{~s}$ and ignored significant demographic shifts during the first half of the twentieth century. In some areas there was little competition for customers, while in others too many outlets existed. The combined effect was that where competition was limited, there was no incentive to improve facilities (particularly accommodation and meal facilities), while in other areas profit levels were sufficiently low to restrict finance for facility improvement (Department of Justice, 1974).

Hotels also suffered problems in attracting labour. In 1939, hotel keepers in Central Otago petitioned Paddy Webb, as Minister of Labour, to allow immigration of female domestic workers to work in hotels. ${ }^{13}$ Statutory reductions in working hours had compelled city hotels to employ more staff, and as a result, hotel keepers had been unable to get the help that they required. The outbreak of war also caused labour shortages as available manpower was directed to the war effort. The perceived severity of the problem was such that in 1944, the Industrial Emergency Council approved the Licensed Hotels Legislation Modification Order, allowing hotel proprietors to employ part-time barmen to help them in busy periods. A discussion amongst members of the Council as to whether the order came within their remit to consider matters “... necessary for securing public

\footnotetext{
${ }^{13}$ Labour Department files, National Archives. File 31/88 B.164.
} 
safety, the defence of New Zealand, the efficient prosecution of war ... and maintaining supplies and services essential to the life of the community ..."; and whether the situation might be more properly resolved by an application to the Arbitration Court, was settled by agreeing that the situation had been brought about by the manpower shortage due to the war, therefore the problem was an indirect war emergency!

The establishment in 1945 of a Royal Commission on Licensing was an indication of continued concerns. Submissions presented in hearings of the Commission were largely critical of the industry, although the Commission accepted the argument that many problems arose because of the operation of the licensing system itself. The principal "mischiefs" identified by the Commission included after-hours selling, sly grogging, poor hygiene in bars and the re-sale of dregs. The physical aspects of hotel bars came in for particular criticism. Poor standards of residential accommodation were noted, as was the absence of seating resulting in "vertical drinking", and a general problem of overcrowding. The Commission noted that "There is little in the conditions in many bars that suggests they are places for the consumption of alcoholic liquor by persons who value their selfrespect.” (1946:278)

The Commission recommended wholesale reform of the industry. ${ }^{14}$ It argued for new legislation in accord with the principle that conditions in the industry should be "... consistent with the ... standards of self-respect which may reasonably be 
expected in the community" (1946:276); and that the law should ensure that the main feature of hotels was the provision of good accommodation rather than the supply of liquor. A considerable number of the Commission's recommendations were included in an amendment to the Act in 1948, and represented the first slow step in the direction of a more liberal approach to liquor licensing.

$\underline{\text { Towards liberalisation 1948-1989 }}$

The 1948 Licensing Amendment Act represented the beginnings of gradual liberalisation. While the Commission's recommendation for fundamental reform of the system was eschewed, a number of administrative issues were addressed. In particular, a newly established national level Licensing Control Commission, established to supervise the activities of Licensing Committees, was charged with the responsibility of prescribing standards for accommodation. In the mid-1950s, in a review of 1,098 established licenses, rebuilding of premises was ordered in 50 cases, and major improvements ordered in 290 others. ${ }^{15}$ As part of this new role the Commission also prescribed minimum general standards for new hotels, including bedroom facilities, numbers of bathrooms and lavatories, heating, bar cleanliness, and standards to be observed in hotel kitchens (New Zealand Official Yearbook, 1956).

\footnotetext{
14 To a large degree the Commission's findings were overshadowed by its recommendation in favour of nationalisation of the industry. The government of the day elected for a retention of private sector control however.

15 This proved to be costly to the Government when the Supreme Court increased the level of compensation paid to hotel owners whose licenses were cancelled because they were unable to meet the new standards set out in the Commission's regulations.
} 
The 1948 Act liberalised the system in a number of other ways. A new category of license for tourist houses (initially restricted to 25 across the country) allowed licensees to sell liquor to guests for consumption on the premises. The Act also removed restrictions on the sale and supply of liquor to Maori, in force since 1847. Finally, the Act provided for a referendum on the issue of hotel opening hours, held on 9 March 1949. Despite the available alternative of allowing hotels to open for a total of nine hours between 10 a.m. and 10 p.m., over three-quarters of the population voted for staying with 6 o'clock closing.

Despite these measures, problems continued. Protracted labour supply problems resulted in complaints from hotel proprietors about being able to get the "right sort" of employees, and pressure for an increase in immigration of domestic workers. Shortages of labour provided hotel workers with an opportunity to press for long-desired improvements in wages and conditions. Licensed Hotel award negotiations in 1948 saw bar staff in Wellington and Auckland attend stop work meetings in support of their union's claims and resulted in the introduction of a five-day working week and penal rates for Saturday and Sunday working. ${ }^{16}$

An increase in the number of overseas visitors resulted in increased awareness of the poor standard of drinking conditions available to the general public. The flavour of these is described most evocatively in a description of a public bar in the 1950s:

It is a long bare room with cold hard walls of tile or enameled timber, and a floor of concrete or rubberised material (rather like a public lavatory) so that it can be easily

\footnotetext{
${ }^{16}$ Labour Department files, National Archives. Series One, File 3/5/574.
} 
and cheaply cleaned out with a hose and a yard-broom. It opens on one side directly off the street pavement by a swing-door, and is lighted (so dimly as to require the aid of artificial lighting) by a row of windows which have been boarded up or painted over for most of their height with advertisements for various beverages (legible only from the outside). Women passing by in trams and buses are thus spared the sight of their husbands within.

It opens to the other side by another swing-door onto a gloomy and usually noisome yard, in which stands the most elementary sort of latrine. But it is not only the proximity of this feature which causes a "generally lavatorial atmosphere" to prevail throughout the whole bar.

The room is completely devoid of furniture, except for a long elliptical counter (or bar) down the centre of the room. Behind the bar, there may be a structure of timber (or chrome) and glass, to which are affixed a series of bottles of spirits upside-down on microscopic nip-meters, and rows of mass-washed glasses. Along the bar at regular intervals are attached half-a-dozen plastic hoses connected with the kegs or tank in the cellar, each hose terminating with a pressure tap through which one of the half-dozen barmen squirt a clear amber-coloured liquid with an alcoholic content of $6 \%$ proof, and the remnants of effervescence, into glasses go the refreshment of customers at eightpence (sixpence, ninepence, etc) a time. Each eightpence (sixpence, ninepence) is duly rung up on one of the half-dozen cash-registers, these most important of all the items of bar furniture.

Inside the unbroken ellipse of the bar, the barmen have a certain amount of space for movement. The customers on the outer bar are not so fortunate. They are packed into the area between bar and walls at a rate of about one person per square foot, and standing shoulder to shoulder, elbowing past one another, reaching over one another's heads, and spilling brimful glasses over one another's clothes they absorb glass after glass of the amber liquid, their natural thirst being intensified by their vertical position and the anxiety thirst induced by the certain knowledge that the moment the clock strikes six a harsh jangling of bells will signal the abrupt cessation of the flow of beer, and they will all be turned out unceremoniously upon the street. (Bollinger, 1959:1112)

Continuing criticisms resulted in further wholesale review of licensing laws in the late 1950s. A 1960 amendment first provided for a restaurant license - of which only ten were allowed across the country - allowing the licensee to sell wine, beer, 
and stout to persons dining at a restaurant for consumption with their meal. Hours were extended, allowing the sale of liquor up to 11.30 p.m. for diners and lodgers. For the first time in over half a century, dancing was allowed in premises that also sold alcohol, provided that those indulging in both were also partaking of a meal. The legislation was once again amended in 1961, and made a distinction between hotels and taverns which allowed the possibility, not contemplated before then, of premises selling alcohol without being engaged in the provision of accommodation. At the same time, there were fewer restrictions on the number of hotel and tourist house licenses, as long as the required standard of accommodation and meals were adhered to.

Six o'clock closing was finally abolished in 1967, following a national poll at which electors voted for 10 p.m. closing by a majority of $64 \%$. The Sale of Liquor Amendment Act 1968 saw hours extended to 11 a.m.-10 p.m. in hotels, taverns and clubs, and up till 11.30 p.m. in restaurants and tourist-houses. The issue of opening hours was not so easily resolved however, and was again debated during the 1974 Royal Commission on Licensing, at which representatives from the industry argued for a further extension in trading hours in hotels and taverns. In a compromise position, the Commission recommended extended hours for Friday and Saturday nights, and further liberalisation of hours in restaurants, tourist houses, theatres and cabarets, but these recommendations were not implemented by the Government.

The 1960s and 70s saw changing social attitudes to alcohol and wider acceptance of the 1946 Royal Commission view that pubs and bars should become pleasant 
places to socialise rather than drinking troughs. This period saw the introduction of dancing and live entertainment in hotels, increased availability of bar meals and counter lunches, and the emergence of the "lounge-bar" (Jurgeleit, 1973). There was a massive increase in the number of restaurants from 17, all of which had licenses to sell alcohol, in 1962, to 259 licensed and 450 BYO ("Bring Your Own") restaurants in 1980 (New Zealand Official Yearbooks, various years). A 1968 study of public opinion found a trend towards more liberal attitudes in relation to liquor and a desire for improvement in the standards of service in the industry (Jurgeleit, 1973). A follow-up study in 1972 found that respondents were overwhelmingly in favour of improved entertainment and recreational facilities, the provision of meals and snacks, and improvements in atmosphere and staff service. By this time, $52 \%$ of people had eaten out in the previous three months twice as many as in 1968. The changes were best exemplified by the comment from the then Director of the New Zealand Liquor Industry Council at the beginning of the 1970s, that liquor was no longer invested with the air of sinisterism or evil, as it had been in the past (Thompson, 1973:39).

In the 1980s, a combination of factors resulted in substantial deregulation of the liquor law. In addition to the changed social attitudes mentioned above, a considerably more liberal approach was being applied to all aspects of government regulation, and hospitality and tourism interests used this climate to press their case. In 1985, the government set up a working party to examine the law related to the sale and supply of liquor. Key issues related to restrictions on the hours during which alcohol could be sold, and the increasing complexities of the licensing system. By this stage legislative amendments over the years had 
resulted in a situation where there were 29 different types of liquor license, all with different conditions governing sales. The review resulted in the Sale of Liquor Act 1989, the most liberal licensing regime to exist in New Zealand since the turn of the century. The law and its operation are outlined in the final section of this chapter.

\subsubsection{The development of the tourism industry}

While the development of tourism as an industry is very much a twentieth century phenomenon, mass travel for the purposes of pleasure has a history which dates back to Roman times, during the two hundred years of peace brought about by the pax romanus, when for the first time Romans could safely travel to visit Egyptian obelisks, Greek statues, and the spoils of the conquests of Alexander the Great (Feifer, 1985). The next main stage of tourism development was in medieval times, during which pilgrims traveled in large numbers to visit relics and sacred sites, as a means of achieving indulgences for the after-life. Despite its religious motivation, the mass nature of pilgrimage led to the development of a tourist infrastructure comprising not only an industry network of monasteries and hospices for the provision of food and accommodation, but also facilities for the manufacture of souvenirs such as cockleshells (the sign of St James and the mark of the pilgrim). From Elizabethan times, the religious motivation for travel was overtaken by the notion of travel as a pleasurable activity, to complete the education of the sons of the wealthy landed classes. It was not until Victorian times, during which there were major improvements in roads, railways and other means of transportation that tourism became common. While travel was still generally the preserve of the wealthy throughout this time, the development of 
organised tours in the mid-1800s by Thomas Cook opened up travel to the increasingly large middle classes (Feifer, 1985). The 19th century "tour" was very much designed as an educational activity built around absorbing the culture of Europe - in particular walking in the Swiss alps and admiring Italian art and architecture. Far from its early religious connotations, the notion of travel came to be imbued with the notion of leisure in the early twentieth century and led to the development of resorts such as those on the French and Italian Rivieras to which tourists went simply to have a good time.

It was not until the second half of the twentieth century, however, that the "tourist explosion" became the phenomenon of the magnitude that it is today. In large part this has been as a result of the developments in aviation technology which have made travel easier and cheaper and has opened up tourism to a wider range of people than before. As MacCannell points out:

What began as the proper activity of a hero (Alexander the Great) develops into the goal of a socially organised group (the Crusaders), into the mark of status of an entire social class (the Ground Tour of the British "gentleman"), eventually becoming universal experience (the tourist). (MacCannell, 1976:5, emphasis in original)

MacCannell argues that this universalism is analogous in modern society to the symbolism of primitive religions, as it involves the tourist in a search for meaning and understanding. It is also intimately tied up with the development of modern mass leisure and reflects changing patterns of social behavior in respect of entertainment and eating out. However, the leisure and cultural aspects of the hospitality and tourism industries must not prevent us from seeing their development as a serious business. From experiencing annual growth rates of over $10 \%$ throughout the $1960 \mathrm{~s}$ and $70 \mathrm{~s}$, growth has slowed somewhat in the last 
twenty years. It is, however, forecast to continue, with current growth in tourism arrivals at around $3.9 \%$. Consequently, tourism has become an increasingly important part of the world economy, experiencing rates of growth far in excess of most other industries. According to estimates of the World Tourism Organisation, international tourism receipts in 1991 amounted to \$US259 billion (OECD, 1993); and in many countries tourism contributes a significant proportion of GDP.

\title{
Tourism development in New Zealand to 1960
}

Since the late 19th century, a number of scenic and social features in AotearoaNew Zealand have been recognised as having tourism potential. From soon after European settlement, publicity and educational material promoted New Zealand as "a scenic wonderland" (Ross, 1896). An early publication from the Department of Tourist and Health Resorts quotes a traveller as saying:

\begin{abstract}
Almost every New Zealander lives within sight of the mountains or the ocean or both. The landscapes show long ranges and solitary giants, tipped with alpine glow; there are waterfalls everywhere, some of them among the finest in the world; luxuriant countryside, golden farms, lakes, geysers, volcanoes, forests with miles of pink-, white-, and red-flowering trees in spring; and there are fiords of the sea threading their way around the feet of mountains crowned with glaciers and perpetual snow. The scenery is a synopsis of the best of Norway, Switzerland, Italy and England, with occasional patches of Gehenna in the pumice country around the hot lakes. (Cowan, 1907:9-10)
\end{abstract}

New Zealand had other features to attract the tourist. The newness of the colony, together with the progressive nature of much of its social legislation from 1891, were advertised as attraction enough for many people. The curative effects of mineral springs at Rotorua and Hanmer were also popular, and an early discussion of the attractions of Rotorua claimed that visitors to that area consisted of “... tourists, invalid-tourists, and invalids proper" (New Zealand Official Yearbook, 
1896). Hanmer Springs was described as holding first place among New Zealand's Health Resorts, attracting “... the physically weak and the mere seeker for pleasure ... the fagged brain-worker, the nerve-worn man of affairs, and the mechanic who "needs a spell"” (New Zealand Official Yearbook, 1898:547). The yearbook goes on to say:

The daily life at Hanmer is very pleasant. This is the daily programme for visitors to the Jolie's Pass Hotel, and it will be conceded that it admits no interval for yawning: Breakfast at 8 , first coach to the baths at 10 , bathing till 11.30 , croquet or bowls till the coach leaves at 12 , lunch at 1 , afternoon-tea at 2.30 , second coach to the baths at 3 , bathing, bowling, or croqueting till the coach leaves at 5 , dinner at 6 , coffee at 8 , drawing-room or smoke-room company conversation, music, cards, dancing, \&c., till bed-time. (New Zealand Official Yearbook, 1898:549)

The State took an active role in the development of the tourism industry. New Zealand was the first country in the world to establish a governmental structure for the development of tourism with the establishment of the Department of Tourist and Health Resorts in 1897. Its role in tourism promotion had begun in 1876 , however, when it took control of provincial railways and encouraged tourist travel through the issue of reduced rate tickets for excursion travel (Lloyd, 1964). The first National Park (Tongariro) was established in 1894, and a network of Travel Bureaux to promote tourist travel established in 1902. In addition to promoting New Zealand as a tourist destination, the Department also took an active role as a tourist operator through establishment of the Tourist Hotel Corporation (THC). It maintained national parks, reserves and gardens, and provided information for the tourist on scenic routes, spas and mineral waters, and costs of transport and accommodation. It also directly built and managed luxury hotels at key tourist resorts such as Rotorua, Te Aroha, Hanmer Springs, and Milford Sound. This latter function was in recognition of the fact that while the 
standard of New Zealand hotel accommodation was said to be "good", it was generally built to cater for domestic travellers, and a higher standard of accommodation was needed at some places in order to attract overseas visitors.

Despite a promising start in the late 1800 s, New Zealand's geographical isolation in a world dependent on shipping as a means of transportation, coupled with a series of economic recessions and two world wars, meant that the tourist industry saw little development over the next 50 years. From the end of World War II, however, the potential for growth in the tourist industry was recognised, and the Government embarked on a programme for expansion, based on the two-pronged strategy of getting more tourists to New Zealand and providing better facilities for them during their stay (New Zealand Official Yearbook, 1955:1145). The first part of the strategy was assisted by the development of air transportation. Air travel reduced the time that it took to get to New Zealand from London from 27 days to two days, from New York from 20 days to one day and from Australia from three and a half days to four hours. Not surprisingly, tourist arrivals increased markedly, with short-term visitor arrivals increasing from 31,00 in 1959 , to 132,000 ten years later. However, while the goal of getting more tourists to come to New Zealand was achieved, the second part of the strategy - providing better facilities for visitors once they got here - was less successful.

In large part, the problems experienced in the post-war period arose from a shortage of accommodation, particularly during the summer months. Not only were there not enough spaces to cope with the increase in international visitor arrivals, but domestic tourism was also increasing markedly with the 
popularisation of motor travel and in the wake of the 1944 Holidays Act which gave workers two weeks paid holiday (Lloyd, 1964). The Government and the Licensing Control Commission both attempted a variety of strategies throughout the course of the 1950s to stimulate the building of new accommodation facilities, but all proved markedly unsuccessful. As noted earlier, attempts by the Licensing Control Commission to impose higher standards for accommodation saw hotels close and licenses cancelled. Lack of investment in the industry was blamed on low levels of profitability, as a result of price controls that had been put in place during the second world war. ${ }^{17}$ A Price Tribunal was put in place to regulate increases in prices for a range of goods and services, holding public hearings on prices being charged both in specific industries and in the economy as a whole. In making its decisions, the Tribunal worked on the basis that charges should be "fair and reasonable", and allowed a 6-8\% return on investment (Lloyd, 1964). In addition, because the purpose of price controls was to maintain price stability in an environment of general shortage in the post-war period, the Tribunal also considered the extent to which price competition existed. Because of restrictions on the number of liquor licenses and concerns about high profits accruing to licensees and breweries, the Tribunal maintained strict controls on hotel tariffs. Increases were permitted in August 1950, May 1952, September 1953, and January 1954, but then were frozen until June 1960. The effect of tariff restriction meant that while most hotels made a profit on the bar, these were used to offset loss on the accommodation side (Lloyd, 1964). Given that wages continued to increase substantially over the period of tariff control, accommodation provision

\footnotetext{
${ }^{17}$ Hotel tariffs had been frozen when the war broke out in 1939, and remained at these levels until 1949.
} 
became less profitable, and hotels tended instead to focus their activities on liquor trading.

Licensing regulations were not the only obstacle for intended investors. Post-war building controls designed to ensure that construction activity met the urgent need for houses, hospitals and schools, restricted the development of a tourism infrastructure. Some increase in investment occurred when building controls were lifted in 1956. This led to an increase in the number of hotel beds, but the massive increase in tourist numbers continued to exceed available accommodation. In December 1958, there were 131 licensed hotels of tourist class standard across the country, with a capacity of 6,765 beds (New Zealand Official Yearbook, 1965), while short-term visitor arrivals in 1959 stood at 31,203. Few hotels had more than 100 rooms, and most had a private shower or bathroom attached to only a small proportion of rooms. As the New Zealand Official Yearbook wryly noted in 1965, "New Zealand hotels aim at producing good food and comfortable living, rather than the extra luxury services that are features of some American and Continental hotels" (p.1058).

The one area in which significant investment and growth occurred was in relation to motel accommodation. As noted earlier, the substantial increase in motor travel required a form of accommodation designed to meet the new needs of the domestic tourist. Once building controls were lifted in 1956, the number of motels increased rapidly. Catering to a mobile customer base, they were able to be built away from the most expensive inner-city sites. They were also cheaper to build than multi-storey hotels, and consequently had cheaper tariffs and higher 
occupancy rates. In addition, motels were not subject to government licensing or tariff controls in the same way as hotels. Consequently, where new beds were provided, they were in motels rather than hotels. While this met the needs of domestic tourists, it did little to provide additional facilities for the increasing number of overseas visitors, only $4 \%$ of whom were motel guests, according a study carried out by the Motel Association in 1963 (quoted in Lloyd, 1964).

The uneven pattern of growth in the industry stemmed from an indecisive and ambivalent attitude towards tourism on the part of the Government. Despite its explicit encouragement of tourism, a high degree of regulation restricted the ability of the industry to respond to the needs of international visitors, and limited growth in visitor numbers. ${ }^{18}$ Underlying this, Lloyd argues, was a deep suspicion of tourism and what it might mean for work and employment should the industry become a substantial part of the structure of the economy, including the "... antagonism of many proud New Zealanders towards providing any personal service to other persons which may in turn perhaps be traced to the egalitarian structure of New Zealand society since the founding of the colony" (Lloyd, 1964:49-50).

\section{Tourism development in New Zealand 1960 - 1990}

Since 1960, a more coordinated and consistent approach has been taken to development of the tourist industry. The lead was taken by the Government in

\footnotetext{
18 Lloyd (1964) suggests that this reflected ambivalence on the part of some officials about the impact of tourism on the economy. A 1958 Treasury report allegedly advised the Government against extensive development of facilities for overseas tourists, and there was some debate about the true amount of foreign exchange brought into NZ by tourists.
} 
building new THC hotels, and making amendments to licensing regulations. In addition, from 1962 the Government provided financial incentives, through the State Advances Corporation, for the construction of hotels and motels on main tourist routes where existing facilities were inadequate. Over the next ten years more than $\$ 17$ million was made available, resulting in the availability of an additional 2,866 first-class beds. Private sector investment also boomed, particularly in motel construction, as increasing numbers of people used motor cars. By the 1970s, the accommodation base of the developing tourism industry was in place with an inventory of licensed motel and hotel accommodation carried out on 31 March 1971 finding 6,541 motel units, 4478 first-class (i.e., all rooms with private facilities) beds and 6,760 beds in lower standard accommodation (i.e., not all rooms with private facilities). By 1982, this had grown to over 13,000 motel units, nearly 16,000 hotel beds, and an additional 12,000 beds in subsidiary forms of accommodation in facilities such as youth hostels, cabins, and home/farm stays (New Zealand Official Yearbooks, various years).

This increase in tourist accommodation was needed to meet the explosion in the number of international visitors. From fewer than 10,000 tourist arrivals in 1949, the next decade saw a steady increase, before exploding in the late 1950s. Throughout the next twenty years, annual growth rates of up to $25 \%$ were experienced and easily achieved the target growth rates set by the National Development Conference in 1969. In the year ending 31 March 1980, short-term (i.e., less than 12 months) visitor arrivals were 445,195 persons - representing more than a thousand-fold increase in visitor numbers in the twenty years since 1960. 
While constraints on the development of the tourist industry arising from limitations in the stock of tourist accommodation were resolved from the 1960s onwards, labour market problems began to be identified as a problem for the industry. As early as 1959, the Advisory Committee on Tourist Development noted that:

Generally there is a lack of qualification for the specialised job of management of tourist or residential hotels. Efficient bar management has been the main criterion for successful hotel management. The hotel licensee's interest in the accommodation side ... is often apathetic. ... The attitude of other staff reflects that of management which can permeate through the entire hotel. A further difficulty is the large turnover of staff in the hotel trade. The difficulty in introducing a planned hotel staff training scheme in the face of this is obvious (quoted in Tourist and Publicity Department, undated:3).

While the 1960s saw the establishment of cookery courses based on the City and Guilds of London Institute courses, increasing concern was expressed about the wider manpower and training needs of the industry. Shortages of staff and a high level of labour turnover resulted in the setting up of a scheme in 1962 whereby a return fare was paid to "Australian girls" (sic) on working holidays who worked in hotels for 12 months (Sheehy, 1971). The Staff Training and Recruitment Committee of the Hotel Association played an active role in stimulating the development of training courses and providing financial subsidies for trainees, but the industry was growing at such a rate that training provision could not keep pace with the demand for staff. The report of the Tourism Committee to the National Development Conference of 1969 expressed concern about the lack of management expertise in the industry and the need for an increased number of skilled workers given forecasts of growth. An estimated need for 12,000 additional workers in the industry led the committee to recommend that the 
industry pay greater attention to the recruitment of school leavers and provisions of pre-employment training schemes. Of particular concern was the low status accorded to service occupations:

\begin{abstract}
Some recent attempts to recruit New Zealand staff for waitressing and housemaid duties have proved disappointing, both in the number of applicants and their suitability. The committee ... recommends the adoption of a programme ... to stress the advantages and attractions of work in the hospitality industry. ... Much more can be made of the personal element which is so much a part of the industry; that is encounters with a wide variety of interesting people, and personal involvement in the international travel industry. (National Development Conference, 1969:57).
\end{abstract}

The most significant development in respect of industry training came with the setting up of a steering committee on training in 1971 leading to the Gazetting (under the Vocational Training Council Act) of the Hotel and Catering Industry Training Board (HCITB) in 1974. ${ }^{19}$ The objectives of the HCITB were to act as an interface between the industry and educational and training organisations in order to promote orderly training to meet the needs of the industry, and to identify and formulate industry career structures. Its formation stimulated the development of a wider variety of courses than were available previously, including a Chef Traineeship programme, the Diploma in Hotel and Catering Administration and the Certificate in Hotel and Catering Management. A variety of other short courses also became available, which provided training in specific technical aspects of hotel, bar and restaurant work.

Despite the increase in the number of courses available, a significant training gap in the industry was identified by the Personnel and Training Committee of the

\footnotetext{
19 Some representation had been achieved at an earlier date through Hotel Association of New Zealand (HANZ) and licensed restaurant involvement on the Tourist Industry Training Board established in 1972.
} 
Tourism Advisory Council in 1978. Quality of service within the tourism industry was felt to be sub-standard, despite a reputation for friendliness. A survey of tourism industry employees undertaken by the committee found that a high proportion of hotel staff did not receive any training at all and had not been asked by their management whether they wished to be considered for promotion (Tourism Advisory Council, 1978). Nonetheless, in both hotels and restaurants, management had difficulty attracting suitably qualified staff, and there was high labour turnover. The committee argued strongly for the development of an industry career structure in which workers could obtain a range of skills by moving from employer to employer and in which wage structures incorporated time off for training and recognition of skill. To ensure this they recommended that a levy be imposed on all employers in the industry to support the HCITB.

\subsection{The hospitality industry in the $1990 \mathrm{~s}$}

The 1980s and 90s have seen continued development of the tourism industry in New Zealand. World-wide, tourism has continued to grow, with New Zealand visitor arrivals growing at more than twice the world average (NZ Tourism Board, 1993) as result of changes in international tourism patterns. An emphasis on package tours and "seeing the sights" has given way to independent travel and a desire for a "total experience". Identified trends include an emphasis on interest in the environment, the demand for cultural experiences, and a world-wide increase in long-haul and short-break holidays. The effects in New Zealand are seen in the development of Maori tourism, increased use of National Parks and attractions off the mainstream tourist routes, adventure tourism, and use of a more flexible range 
of accommodation options such as farm stays and backpacker hotels. In addition, over the past two decades there has been a diversification of tourist markets with traditional markets such as Australia and the UK giving way to increasing numbers of tourists from countries such as Germany, Japan, Hong Kong, and Taiwan. Within New Zealand, tourism earns more foreign exchange than any other industry with $\$ 4.8$ billion generated from 1.6 million foreign visitors in the year to March 1996 (Ministry of Commerce, 1996; NZ Institute for Economic Research, 1997). In addition, it contributes over 5\% to GDP and is directly responsible for the employment of $9 \%$ of the labour force (New Zealand Tourism Department, 1990). The potential for growth in the tourism industry is still seen as being significant, with expected growth rates of $10 \%$ per annum over the next two decades. In the short term, growth is expected at an even higher rate as a result of the America's Cup Challenge and spin-off effects from the Sydney Olympics (NZIER, 1997). The NZ Tourism Board is aiming for 2 million visitor arrivals by the year 2000. Associated with this are the goals of achieving $\$ 9$ billion in foreign exchange earnings, and 180,000 full-time equivalent jobs (Ministry of Commerce, 1996). Nevertheless, caution must be exercised in this otherwise optimistic picture. Increasing emphasis on the need for sustainability has resulted in some backlash centred on the impact of increasing tourism numbers on the environment. In addition, international tourism is more volatile than the domestic and business market. For example, 1997 has seen a decline in tourism arrivals both as a result of the strong New Zealand dollar, and poor economic performance in a number of Asian economies. As a result, tourism profitability has fallen, and hotel occupancy rates have been under pressure particularly in centres such as 
Queenstown and Christchurch, which rely heavily on overseas visitors (NZIER, 1997).

Changes in patterns of tourism have required new strategies on the part of the tourism industry. Public sector reform has resulted in a refocussing of activity through privatisation of previously government owned hotels, the dismantling of the network of Government Tourist Offices, and decentralisation of tourism promotion to a newly established Tourism Board. The effect of these changes, in line with other Government reforms, has been to shift responsibility for tourism activity to the private sector. The new Tourism Board is primarily a marketing organisation, designing its activities to undertake market research into tourism and to promote New Zealand as a tourist destination using the concept of a "brand image". It does, however, retain a coordination role within the industry, developing strategic partnerships with the private sector to identify key tourism issues particularly the need for internationally recognised standards of performance, and effective industry training.

Attention to performance standards reflects the fact that quality has been identified as a critical factor for competitive success. Until recently there has been no system of classification or grading of $\mathrm{NZ}$ accommodation facilities, other than that operated by the Automobile Association (AA). In the 1990s a joint venture between the NZ Tourism Board and the AA resulted in the development and establishment of a common system of classification and grading for hotels and motels, known as Qualmark. This recognises not only the extent and quality of physical services but also service performance at the facility. Service audits with 
clearly identified quality benchmarks (including management of staff) are undertaken to ensure that standards are maintained. In addition, the establishment of the NZ Tourism awards organised by the NZ Tourism Board, with special categories for different grades of accommodation, has stimulated improved service performance. Criteria for the awards incorporate the application of quality principles to the running of the business, (including the physical product and innovation of its services and facilities and how well this has met the needs of customers), management of a customer focus and ongoing improvement of service, level and quality of environmental management, marketing; strategic management, and profitability (New Zealand Tourism Board, 1995).

The problem of industry training has not been so easily resolved. While the need for increased professionalism continues to be identified as a key issue, many employers do not undertake comprehensive training for staff (Ministry of Commerce, 1996). Despite developments in tertiary level tourism education, provision of training and the range of qualifications within the industry is characterised by fragmentation, duplication and inconsistency (New Zealand Tourism Board, 1993). While the industry and the Board aim for a coordinated approach to training, this conflicts with Government policy on industry training based on decentralised responses to local demand. Of particular concern is the need for a more professional service orientation. The nationally recognised programme of "Kiwihost" courses designed to improve standards of service and hospitality organised by the New Zealand Tourism Board has (ironically) been utilized by a wide range of organisations across a number of industry sectors, but 
has yet to be fully embraced by more than a small proportion of enterprises within the hospitality sector.

More generally, economic restructuring and deregulation of the economy has had a significant impact on the hospitality industry, and the role it plays in the tourism sector. The three key areas of change have been in respect of liberalisation of liquor licensing, the lifting of restrictions on inwards investment leading to a growth of Asian investment in the accommodation sector, and labour market deregulation. These are discussed further below.

\subsubsection{Liquor licensing}

Developments in tourism have been assisted by a liberalisation of licensing regulations. Following the report of the Working Party on Liquor set up in 1985 (The Laking Report), the Sale of Liquor Act 1989 deregulated the sale of liquor to a large extent, replacing the previous system of licensing with a new system in which the number of licenses is no longer limited. Premises may gain a license to sell liquor for either on-site or off-site consumption. The grant of a license is governed by the sustainability of the applicant, the nature of the business to be conducted, the manner in which the proposed licensee intends to operate the premises and the time during which that operation will be conducted having regard to the neighbourhood in which it is situated (Ministry of Justice, 1996). Deregulation has led to an enormous increase the numbers of licences granted from the 6,295 in force when the Act came into effect on 1 April 1990 (see Table 2.2) although the overall consumption of alcohol in New Zealand has steadily fallen by $22 \%$ since 1978 (ALAC, 1996). 
Table 2.2: New licences granted by Liquor Licensing Authority since 1 April 1990

\begin{tabular}{|c|c|c|c|c|c|c|}
\hline & $\begin{array}{l}1 \text { April } 1990 \\
-30 \text { June } \\
1991\end{array}$ & $\begin{array}{ll}\text { Year ended } \\
30 & \text { June } \\
1992 & \end{array}$ & $\begin{array}{ll}\text { Year ended } \\
30 & \text { June } \\
1993 & \end{array}$ & $\begin{array}{ll}\text { Year ended } \\
30 \quad \text { June } \\
1994\end{array}$ & $\begin{array}{ll}\text { Year ended } & \\
30 & \text { June } \\
1995 & \end{array}$ & $\begin{array}{ll}\text { Year ended } & \\
30 & \text { June } \\
1996 & \end{array}$ \\
\hline On-licence & 146 & 384 & 561 & 443 & 461 & 456 \\
\hline Off-licence & 332 & 276 & 318 & 223 & 204 & 218 \\
\hline Club licence & 23 & 122 & 176 & 95 & 73 & 82 \\
\hline $\begin{array}{l}\text { Wine } \\
\text { makers }\end{array}$ & 10 & 24 & 31 & 24 & 25 & 46 \\
\hline Total & 511 & 806 & 1,086 & 785 & 763 & 802 \\
\hline
\end{tabular}

Source: Liquor Licensing Authority

In 1996, a further review of liquor law was conducted by a three-member advisory committee appointed by the Minister of Justice to consider suggestions for improved operation of the Act (Ministry of Justice, 1996). The Report of the Advisory Committee, issued in March 1997, suggests that the last steps in the deregulation process are not far away (Liquor Review Advisory Committee, 1997). It recommended the abolition of club licenses, in effect suggesting that only two categories of license (on- and off-) should be recognised. In addition, the Committee recommended lifting existing restrictions on the sale of liquor on Sundays, and permitting supermarket sales of all types of liquor. Such moves will undoubtedly introduce further competition into what is already a very competitive industry. Further deregulation, however, is recommended to take place in the context of requiring those responsible for the sale of alcohol to recognise their 
responsibilities through the establishment of a national level industry qualification which would be required to be completed before the issue of a "Licence Controllers Certificate" to replace the current certificated manager system. At the time of writing, the recommendations of the Advisory Committee are under active consideration by Government, with amending legislation being anticipated for some time during 1998.

\subsubsection{Structure, Ownership and Management}

One of the key features of the Accommodation, Cafes, and Restaurants industrial sector is its diversity in terms of activity, size, and ownership. The industry (Division $\mathrm{H}$ in the Australian and New Zealand Standard Industrial Classification)

20 is made of up four groups, as set out below, with distinctive main activities:

- Accommodation: hotels, motels and other similar units (such as youth hostels, student residences, guest houses, caravan parks) engaged mainly in providing short-term accommodation;

- Pubs, Taverns and Bars: hotel bars and similar units (nightclubs, wine bars) engaged mainly in selling alcoholic beverages for consumption on and off the premises;

- Cafes and Restaurants: units engaged in providing meals for consumption on the premises, and including catering companies;

20 At the time of writing, Statistics New Zealand were in the process of moving from the old NZSIC, in which restaurants and hotels are included in Division 6 with Wholesale and Retail Trade, to the more recent ANZSIC. Thus the time series included here are based on NZSIC to 1995 and ANZSIC for 1996. While there are some slight differences between the two a comparison of the old and extended industry coverage (see Statistics New Zealand, 1996 Table 1.7) suggests that the only difference is in the accommodation area, with the new ANZSIC including 15 additional activity units and 18 additional FTEs. 
- Clubs: Associations engaged mainly in providing hospitality services to members.

The industry is of substantial economic importance in New Zealand. According to Statistics New Zealand, in the year to March 1996, ANZSIC Division H comprised 7,872 enterprises and 8,682 activity units, employing 58,086 full-time equivalent employees (FTEs). ${ }^{21}$ The industry has grown significantly over the past 25 years - the 1972 Census of Distribution recorded only 3000 workplaces engaged in the provisions of food, drink or accommodation. The vast majority of enterprises within the industry are small in size, and the size distribution in the industry has remained remarkably stable since the 1960s, although there would appear to have been a distinct increase in size over the past two years. ${ }^{22}$ Recent trends are illustrated in Table 2.3.

Table 2.3: Percentage of enterprises ${ }^{23}$ by employee size bands 1986-1996

\begin{tabular}{|l|l|l|l|l|l|l|}
\hline Year & $0-5$ & $6-9$ & $10-49$ & $50-99$ & $100+$ & Total \\
& employees & employees & employees & employees & employees & employees \\
\hline 1986 & 74.8 & 12.1 & 11.8 & 1.0 & 0.2 & 100 \\
\hline
\end{tabular}

\footnotetext{
21 Statistics New Zealand (1996) Business Activity 1996, (Table 1.2a Enterprises and Full-time equivalent persons engaged by NZSIC). The survey includes only workplaces in "economically significant enterprises" defined as those with greater than $\$ 30,000$ annual GST expenses or with more than two full-time equivalent employees. An activity unit is an operating unit engaged in economic activity from a single physical location, and generally corresponds to a single workplace.

22 Despite the fact that the comparison between NZSIC and ANZSIC shows only slight differences between the two, the inclusion of accommodation enterprises (which are more likely to be large in size) may partially explain the change.

23 It must be noted that from 1994 figures include only economically significant enterprises, while from 1986-1993 they are based on compulsory GST registrations.
} 


\begin{tabular}{|l|c|c|c|c|c|c|}
\hline 1987 & 74.0 & 12.8 & 12.1 & 0.8 & 0.3 & 100 \\
\hline 1988 & 73.1 & 13.1 & 12.6 & 0.9 & 0.3 & 100 \\
\hline 1989 & 75.7 & 11.8 & 11.4 & 0.8 & 0.3 & 100 \\
\hline 1990 & 76.7 & 11.3 & 11.1 & 0.7 & 0.2 & 100 \\
\hline 1991 & 78.8 & 10.3 & 10.1 & 0.7 & 0.2 & 100 \\
\hline 1992 & 78.3 & 10.7 & 10.2 & 0.6 & 0.2 & 100 \\
\hline 1993 & 77.8 & 11.3 & 10.1 & 0.6 & 0.2 & 100 \\
\hline 1994 & 73.2 & 14.2 & 11.8 & 0.6 & 0.2 & 100 \\
\hline 1995 & 74.2 & 13.2 & 11.7 & 0.6 & 0.2 & 100 \\
\hline 1996 & 68.2 & 16.2 & 14.2 & 0.9 & 0.5 & 100 \\
\hline
\end{tabular}

Source: Statistics New Zealand, Business Activity Statistics (various years)

Despite the fact that the industry is labour intensive, the capital outlay required to set up a business can be considerable. Finance is required on an up-front basis to establish premises before any income is generated, and in addition there is a generally accepted industry benchmark that $3 \%$ of revenue per annum is required for refurbishment (Duncan et al, 1994). As noted earlier, from the 1960s onwards the Government initiated a variety of schemes designed to provide for an increase in accommodation provision. Up until the 1980s these resulted in a significant amount of investment, but the outcome was a larger number of high quality hotels than was justified by demand considerations, and thus a low level of profitability. In consequence, investment dropped off at the end of the late 1980s. Profitability increased substantially in the mid-1990s (Statistics New Zealand, 1995), ${ }^{24}$

\footnotetext{
${ }^{24}$ For the industry as a whole net profit before tax increased from $\$ 158.9 \mathrm{M}$ in the 1990 -91 year to $\$ 315.4 \mathrm{M}$ in $1993-94$, and $\$ 344.7 \mathrm{M}$ in $1994 / 95$. The extent of competition in the industry is reflected in the fact that
} 
however, and as a result investment has once again increased in the areas in which tourism growth is increasing most significantly - particularly in respect of backpackers and mid-range accommodation.

The industry in New Zealand shows a distinct bias towards the North Island and urban centres. Almost $70 \%$ of activity units and employees employed are found in the North Island, and of these, almost half are in the Auckland and Wellington regional council areas (Statistics New Zealand, 1996). Not surprisingly, given the small size of many enterprises, most are privately owned. Table 2.4 shows that the vast majority of enterprises are limited liability companies, partnerships or privately owned, although in employment terms, private limited liability companies are by far more significant than any other business type. Only six companies involved in the hospitality industry are listed on the New Zealand stock exchange, ${ }^{25}$ although a number are subsidiaries of multi-national operations listed in other countries.

Table 2.4: Enterprises and full-time equivalents employees by business type, ANZSIC, Division H, 1996.

\begin{tabular}{|l|l|l|l|}
\hline & $\begin{array}{l}\% \text { of enterprises } \\
\text { (rounded) }\end{array}$ & of FTEs \\
employed
\end{tabular}

profit margin on sale in $1994 / 95$ was $7.6 \%$ in comparison to $11.4 \%$ for all industries. Return on equity increased over the early 1990s, and has remained stable since then, but at $15.9 \%$ in 1994/95, was higher than $13.3 \%$ accruing to all industries. (Statistics NZ, 1995, 1996). As noted earlier, profitability fell slightly in 1996/97, but is forecast to increase again in both the short and medium term.

25 These are CDL Hotels Ltd (the largest hotel owner in NZ with 19 hotels), Kingsgate International Corporation Ltd (50\% owned by CDL), Lion Nathan Ltd (Restaurant operations to supplement their brewing and soft drink operations), Manor Inns Group (motor lodge operators), Progressive Enterprises (Georgie Pie restaurant chain), and Sky City Ltd (344-bed hotel run as part of the Sky City complex). In addition, Fosters Brewing group, although Australian owned, is also listed on the NZ stock exchange. 


\begin{tabular}{|l|c|c|}
\hline & & (rounded) \\
\hline Individual ownership & 17.5 & 7.3 \\
\hline Partnership & 38.0 & 20.4 \\
\hline Private Limited Liability Company & 35.8 & 61.4 \\
\hline Public Company & 0.1 & 1.5 \\
\hline Central Government & 0.1 & 0.1 \\
\hline Local Government & 0.3 & 2.7 \\
\hline Incorporated Bodies & 6.4 & 5.3 \\
\hline Trust & 1.7 & 1.1 \\
\hline Other & 0.2 & 0.1 \\
\hline
\end{tabular}

Source: Statistics New Zealand, Business Activity Statistics, 1996 


\subsubsection{Employment and labour market deregulation}

Labour market deregulation has also had an effect on the industry. Under the industrial relations system operating up until 1991, a series of nationally determined wages and conditions of employment were negotiated by the union representing workers in the hospitality industry, and employers in the industry. Under this system, two main agreements, known as awards (one covering both licensed and accommodation hotels ${ }^{26}$ the other covering tearooms and restaurants) contained minimum wages and conditions of work which applied across the country. While the system was generally perceived as restraining employment choices, awards were limited in their scope to wages and conditions of employment, thus leaving a range of other employment related decisions (including staffing levels, work loads, hiring and firing decisions and work organisation), firmly within the realm of managerial prerogative.

From 1991, the passage of the Employment Contracts Act (ECA) resulted in radical transformation of the system. Key aspects of deregulation included removing the requirement that employers negotiate with unions and allowing employees the right to choose an alternative representative (or to not be represented at all) and replacing national awards with employment contracts. The key feature of these contracts is that all aspects are negotiable between employers and employees, including the fact of whether they are applied to single and individual employees, or across the workplace as a whole. In addition to these legislative changes, the ECA was seen as having a more pernicious effect in 
changing the "culture" of industrial relations in New Zealand by promoting a more market based approach to employment relationships based on the need for increased labour market and workplace efficiency. Critics of the Act argued that this would create an environment in which bargaining power would be placed firmly in the hands of employers, and that employees would be severely disadvantaged except in those parts of the economy where their skills and requirements were in short supply.

The impact of the ECA within the hospitality sector was immediate. The decline in union membership was estimated at 68\% from 1991-94 (Harbridge and Hince, 1994). Analyses of employment contracts suggested that conditions of work were being reduced to those required by legislation, and that penal and overtime rates of pay (for work at nights or weekend, or for working more than 40 hours a week) and allowances were virtually eliminated from the industry (Harbridge and Honeybone, 1994). In large part, patterns in wages and conditions of employment reflected those set out in a standard "pro forma" contract put out by the Hospitality Association of NZ (at that time named the Hotel Association) as guidance to their members. This standardised contract was controversial. While it went beyond those minimum conditions required by law, it was less beneficial to employees than the awards and agreements which had previously applied. From the point of view of the Association, it represented an attempt to provide their members with guidelines on their legal requirements under the Act, in a way which was simple to understand. From the union's point of view, however, the

\footnotetext{
26 Shortly before the Employment Contracts Act was passed in 1991, the hotel award was split into three - a pubs and taverns award, one covering major accommodation hotels, and a third applying only to Hancocks
} 
contract represented a reduction in wages and conditions of work for employees, and they were opposed to its introduction within the industry. They drew attention to a number of cases in which employees had their wages and conditions of work unilaterally changed by employers (unlawful under the legislation, which supposedly protects current conditions unless both parties agree to a variation), or were intimidated by their employers into agreeing to lesser conditions under the threat of job loss (Gosche, 1992).

Wages and conditions in the industry at the current time are undoubtedly below average in New Zealand. As discussed in Chapter 8, employment contracts are generally minimal both in their scope and in the level of conditions and allowances. Analysis of wage movements over time shows that although percentage movements slightly exceed the national average on an annual basis, the low level of wages in absolute terms means that the dollar amount of increase is just over half that applying in other sectors of the economy. These statistics are underlined by the fact that the minimum adult rate set out in hospitality industry contracts is lower than 24 out of 28 major industry divisions. Only three other industry divisions (agriculture, textile manufacture, and food retailing) have minimum adult rates which are lower (Harbridge and Crawford, 1996, 1997). As noted earlier, the hospitality industry is a significant employer in New Zealand and in 1995 employed 65,189 full-time equivalent workers (Statistics New Zealand, 1995). It is heavily reliant on the use of part-time workers and is one of the few industries in which the number of part-time employees exceeds the number of full-time workers. As can be seen from the table below, a high 
proportion of the increase in jobs in the industry has been in part-time work, which in the last four years has grown at a rate of just over $20 \%$, while full-time employment has been more stable.

Table 2.5: Numbers of full-time and part-time employees in hotels and restaurants, 1992-1996

\begin{tabular}{|l|l|l|l|}
\hline Year & Part-time & Full-time & $\begin{array}{l}\text { Part-time employees as a } \\
\text { proportion of total } \\
\text { employees }\end{array}$ \\
\hline 1992 & 39,945 & 36,564 & 52.2 \\
\hline 1993 & 40,929 & 36,477 & 52.9 \\
\hline 1994 & 44,983 & 38,528 & 53.9 \\
\hline 1995 & 48,253 & 41,062 & 54.0 \\
\hline 1996 & 44,325 & 35,922 & 55.2 \\
\hline
\end{tabular}

Source: Statistics New Zealand, Business Activity Statistics (various years)

Because of their part-time and sometimes casual ${ }^{27}$ nature, jobs within the industry are not high status. A high proportion of its employees work while participating in secondary or tertiary education, and their skills and experience are lost to the industry at the end of this time. Jobs are also often viewed as being low skilled, with even the Tourism Department noting that the industry is important as a creator of employment because it can utilise school leavers and others without requiring intensive prior training (NZ Tourism Department, 1990). Consequently, as noted earlier, training for both staff and managers remains probably the most

\footnotetext{
27 While there is no legal definition of "casual" employment, within the New Zealand context it is generally used to describe situations where there is no on-going expectation of employment. Nevertheless, the definition of "casual" employment is problematic. These issues are covered in further detail in the next chapter.
} 
important issue facing the industry. Two particular concerns have been identified. The first is simply that few managers in the industry outside specific sectors (notably in hotels and fast-food restaurants) recognise the importance and value of training and are prepared to make a substantial financial commitment to training other than very general on-the-job training (NZ Tourism Council, 1984). The second is that while a variety of courses in various aspects of hospitality management are available at Polytechnics around the country, in general, training provision is fragmented, inconsistent and characterised by duplication (New Zealand Tourism Board, 1993).

\subsection{Summary and conclusions}

Despite a promising start to the tourism industry in the first half century of the colony, a number of factors constrained the development of the hospitality industry in New Zealand through the most of this century. Chief among these was the system of liquor licensing which separated the consumption of alcohol from other social and leisure activities. In addition, the effect of price controls operating in the post-war period increased the profitability of liquor trading relative to accommodation provision. These problems have largely been resolved in the last decade through liberalisation of the liquor trading laws, but a whole new set of problems has arisen to face the industry. Exponential growth in both domestic and international tourism have resulted in massive growth in the hospitality sector. Quality, however, has not always been guaranteed. While the industry has in very recent times established a framework for assessing performance standards for hotel and motel accommodation, a coordinated approach to the training of 
employees and managers within the industry is one of the key challenges facing the industry as it looks towards the year 2000 . 
Chapter 1: Introduction

Chapter 2: Tourism and Hospitality Industry Development in New Zealand

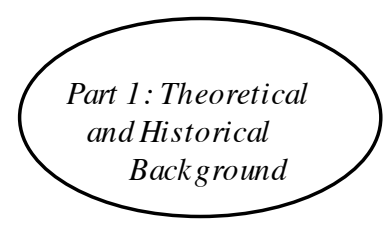

Chapter 3: Employment, Work and Labour Relations in the Hospitality Indus try

Chapter 4: The Framework for Analysis: Explaining Management Practice

Chapter 5: Research Approach and Methodology

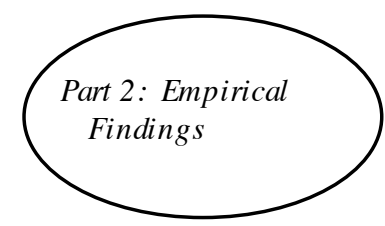

Chapter 6: Employment Relations in the Hospitality Industry

Chapter 7: Work Relations in the Hospitality Industry

Chapter 8: Labour Relations in the Hospitality Industry

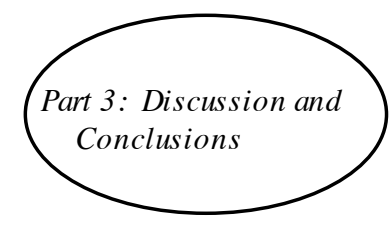

Chapter 9: Labour-Management Practice in the Hospitality Industry: Managing to Compete?

Chapter 10: Explaining Management Practice: Strategy, Environment and Social Action 


\title{
Chapter 3: Employment, Work, and Labour Relations in the Hospitality Industry
}

\begin{abstract}
The hotelier must have the diplomacy of a Kissinger, the social grace of the Queen Mother, the speed of a Concorde, the smile of a Greek God, the patience of a saint, the memory of an elephant, the thick skin of a rhinoceros, the strength of an Atlas, the staying power of a mother-in-law, the fitness of a centre forward, the grooming of a duke, the voice of an Olivier, the eye for profit of a Vestey, and last but not least, the hotelier must have a love of humanity, for humans show their worst side when they are tired and hungry. (Albert Elovic, Hotelier; quoted in Nailon, 1982).
\end{abstract}

\subsection{Introduction}

From the development of the hospitality industry in New Zealand, we now turn to international studies of labour-management issues in the industry. As noted in Chapter 1, the hospitality industry has been largely ignored by industrial relations and management scholars as an area of study. Its neglect has not been as total in other disciplines. As a central feature of social life in the late twentieth century, various aspects of labour and work within the industry have been examined since the 1960s in sociology, psychology and women's studies. Attention to aspects of labour-management issues began to be paid from the 1970s, when concern about industrial relations in the industry, notably low levels of unionisation and collective bargaining, and high labour turnover, were researched by a variety of governmental bodies in the UK (Hotel and Catering Economic Development Committee (HCEDC), 1969; Commission on Industrial Relations (CIR), 1971; Mars and Mitchell, 1976; Advisory Conciliation and Arbitration Service (ACAS), 
1980). ${ }^{1}$ Later, the emergence of tourism as a discipline also stimulated research on issues relevant to the hospitality industry, including aspects of employment and labour relations. Although many early studies focused on "problem issues" (Lucas, 1995), from the 1980s onwards researchers began to take cognisance of the debates taking place in mainstream industrial relations and management disciplines, particularly the vexed question of employment flexibility (Kelliher and McKenna, 1987; Guerrier and Lockwood, 1989a, 1989b; Bagguley, 1990; Rees and Fielder, 1992). In addition, the increased importance of human resource management in the industry was reflected in studies of industry experience in general (Boella, 1986; Kelliher and Johnson, 1987; Croney, 1988; Ralston, 1989; Baum, 1991) and specific human resource practices such as recruitment and training (Kohl and Stevens, 1989; Bonn and Forbinger, 1992). The 1990s have seen an explosion of articles on the "people management" side of the hospitality industry, particularly on issues related to "empowerment" (Jones and Davies, 1991; Bowen and Lawler, 1992; Wynne, 1993; Lashley, 1995a, 1995b); communication skills (Clark, 1993; Samenfink, 1994; Sparks, 1994; Nikolich and Sparks, 1995; Sparks et al, 1995), management (Chitiris, 1990; Dann, 1990; Brymer et al, 1991), and total quality management (Gamble and Jones, 1991,

\footnotetext{
${ }^{1}$ It should be noted that much of the material on which this chapter is based emanates from the United Kingdom. This reflects the location of much of the previous research in the industry. While a certain amount of work has been undertaken in the United States, this has generally had a prescriptive focus rather than relying on the gathering of empirical data. The exceptions are a few recent studies, approached largely from a sociological perspective. In addition, the recent growth in Tourism and Hospitality education at a tertiary level in Australia has also stimulated research in that country. Within New Zealand, the only research that has previously been carried out in the hospitality industry are two historical studies of the Auckland and Canterbury Hotel Workers Unions (Fryer, 1976; Ferguson, 1985); and a more recent analysis of the "Service First" programme at the Christchurch Parkroyal (Perry, Davidson and Hill, 1995). Other New Zealand research (for example on atypical employment, or levels of union density) is referred to where relevant in this chapter; but by and large these either focus on industries other than hospitality, or are multi-industry studies which do not disaggregate data to a level which allows details for the hospitality industry to be drawn out.
} 
Glennie, 1991; Saunders and Graham, 1992; Williams and Hunter, 1992; Coyle and Dale, 1993; Baldacchino, 1995).

This chapter summarises the existing stock of knowledge about managing employment, work and labour relations in the industry. This sets the scene for Part 2 of the thesis, which looks at current practices in hotels and restaurants in New Zealand set in the context of contemporary changes in labour markets, including changes in employment structures, work, labour relations and management practices. It also, however, draws attention to the limitations of hospitality industry research, which while describing management practice, provides an inadequate theorisation of differences and variations within the industry.

\subsection{Employment relations}

Not surprisingly given the considerable growth in tourism in the post-war period, the numbers of people employed globally in the hospitality industry has substantially increased over recent years (Riley, 1991; Wood, 1992a, 1995; Lucas, 1995; Boreham et al, 1996). Within New Zealand, the increase in employee numbers was noted in the previous chapter. This growth has not been seen in all quarters as entirely positive, however. Commentators from other countries have characterised the hospitality labour market as employing predominantly part-time and casual labour, with little skill, and providing little in the way of career structures (Ralston, 1989; Crompton and Sanderson, 1990; Timo, 1993). These factors, along with low wages, are argued to result in labour turnover rates that are higher than most other industries, with employers relying largely on the external 
labour market as their most common source of recruitment (HCEDC, 1969; Mars and Mitchell, 1976; Simms et al, 1988; Mitchell, 1988; Riley, 1991, 1993; Hotel and Catering Training Company (HCTC), 1994). These issues are explored below.

\subsubsection{Employment structure}

An often identified influence on the hospitality industry labour market is the nature of demand, which is commonly seen as unpredictable and irregular. Many hospitality industry workplaces are open for long hours, with peaks in demand at times such as morning checkouts or meal times, leading management to seek a high degree of flexibility in the way it deploys labour (Walsh, 1991; Riley, 1991; Timo, 1993). Under these conditions, the most suitable form of labour scheduling for many jobs is the employment of a large numbers of part-time and casual staff. While Walsh (1991) has argued that this employment pattern is for operational reasons, it is also clear that the employment of large numbers of part-timers has the advantage for management of restricting wage costs, particularly in those countries where indirect labour costs (such as National Insurance contributions and employment protection) are directly tied to the number of hours worked.

Estimates of the proportion of part-time staff in the industry vary, possibly reflecting different proportions of part-timers in different countries or a changing proportion over time. Although part-time employment has been a long-standing feature of employment in the hospitality industry (Walsh, 1991), evidence from both the UK and New Zealand is that proportions of workers employed part-time 
have increased since the 1970s. ${ }^{2}$ A survey carried out in the UK in 1984 found that $36.4 \%$ of managers reported an increase in the number of part-timers over the previous five years (Ralston, 1989), and 61.2\% of employees in 1993 were parttime (Lucas, 1995:52). Estimates for Australia suggest a somewhat lower proportion of part timers at $46 \%$ (Boreham et al, 1996). Figures from the British Workplace Industrial Relations Survey (WIRS) show that only 3\% of industry workplaces did not employ part-time workers, and in $48 \%$ of workplaces parttimers made up more than half the total number of employees (Lucas, 1995). A similar increase in part-time work occurred in New Zealand. Prior to the 1960s, a majority of hotel staff were full-time, lived in, and worked split shifts (Davidson and Bray, 1994). From the 1960s onwards, despite award restrictions limiting the number of part-time workers and introducing a 10\% loading onto the pay rates of part-time employees, numbers of part-time workers increased substantially. As noted in the previous chapter, by February 1996, part-time workers made up 55\% of the total number of workers in restaurants and hotels (Statistics New Zealand, 1996), up from 52\% in 1992.

High proportions of part-timers are not uniform across all workplaces in the industry. Within New Zealand, while only $55.1 \%$ of FTEs are part-time in workplaces with fewer than five employees, $90.7 \%$ of FTEs in workplaces employing 50-99 workers are part-time. A similar pattern has been noted for Australia where part-timers are more common in large workplaces (more than 75

\footnotetext{
${ }^{2}$ According to one estimate for the UK, part-time employment in hotels and catering increased from $39.2 \%$ in 1971 to $67.6 \%$ in 1981 (Bagguley, 1990), with part-time working accounting for $95 \%$ of new jobs in the industry over that decade (Ralston, 1989).
} 
employees) than small ones (fewer than eight employees) (Boreham et al, 1996). Part-time work is also a feature of particular industry sub-sectors. Organisations may adopt employment patterns which correspond to the niche or product market in which they seek to compete (e.g., fast foods vs. restaurants vs. cafes; high quality hotels vs. motels vs. backpackers). Walsh (1991), for example, found that the proportion of part-time employees in UK hotels in 1984 ranged from $13.9 \%$ to $28.9 \%$ depending on establishment size, full-time shift arrangements and the importance of business conferences in product demand. Hotels employ varying proportions of full-time and part-time workers depending on the level of service quality and professionalism which they aim to provide. Part-time work arrangements also reflect occupational, gender and age segregation in the industry. For example, part-time workers are most likely to be found in lower grade occupations or in lower status parts of the organisation (Walsh, 1991), women make up a much higher proportion of part-time workers than men (Bagguley, 1990; Lucas, 1995), and young workers (particularly those working in the industry while they complete their secondary or tertiary education) are more likely to work part-time (Worland and Wilson, 1988; Lucas, 1996)

Employment in the hospitality industry is also said to be highly casualised. Evidence to support this proposition, is however, debatable. Three distinct factors challenge the notion of a highly casualised industry. Firstly, the definition of casual work or casual workers is problematic and depends to a large extent on legislative or Court-determined definitions of casual employment. A general definition of casuals as employees who are employed "as and when needed" for short periods of time has been interpreted in the UK courts as meaning that casual 
workers are self-employed (Mitchell, 1988; Newman, 1993), and in Australia as employees who can be dismissed without notice (Boreham et al, 1996). Within New Zealand, although there is no legal definition of a "casual" worker, the Courts have generally drawn a distinction between casual and permanent employees on the basis of whether there is an on-going expectation of employment. Common usage of the term, however, (both in New Zealand and in other countries) often refers to employees whose hours of work vary, and parttimers are also sometimes included under the general heading of "casual" workers (see for example Worland and Wilson, 1988). This means that the number of "true" casual workers may in fact be smaller than is often assumed and that the extent of casualisation in the industry may be being confused with poor management practices in respect of managing part-time employees.

A second problem with the popular characterisation of work in the industry as highly casualised is that few attempts have been made to measure proportions of casual work in either individual workplaces, or the industry as a whole. Within New Zealand, there are no official statistics on the extent of casual work in the economy generally, although one large-scale survey found that $5 \%$ of the workforce were employed as casuals and a further 3\% were employed on a temporary basis (Brosnan et al, 1996). ${ }^{3}$ While Timo (1993) states that $65 \%$ of hospitality and tourism employment in Australia is part-time and "predominantly" casual, he offers no evidence to support this claim. Walsh's study of UK hotels

\footnotetext{
${ }^{3}$ In this survey, casual employees were defined as "employees hired on a periodic basis as need arises" while temporary workers were defined as "(those) taken on for a relatively short but unspecified time period". In addition, a further $3 \%$ of the workforce were employed under fixed term contracts (contracts with a specified expiry date, or point of completion).
} 
found that casual staff made up only a third to one-fifth of regular staff. In addition, case studies of employment relations in hotels and restaurants (see for example Chivers, 1972; Croney, 1988; Salmon, 1992; Newman, 1993) rarely make reference to casual workers as being a significant feature of employment.

Thirdly, a discussion of casualisation must take cognisance of the ways in which casual workers are deployed in the industry, and which relate to the fact that the hospitality "product" is consumed in a direct and instantaneous way. The employment of casual workers has been argued to be primarily a response to operational demands, rather than an attempt to lower wages or undermine employment protection arrangements (Walsh, 1991; Price, 1993). This is suggested by the distinct pattern in the use of casual labour in the industry. Findings from several studies (Ralston, 1989; Guerrier and Lockwood, 1989a, 1989b; Walsh, 1991; Rees and Fielder, 1992) note that casual work is of two types. The first is low-skilled work, for which little training is required, with casual workers brought in to cover for sickness or holidays, or for temporary increases in demand. Guerrier and Lockwood (1989a), for example, describe examples from hotels where a permanent pool of casual workers is available to provide housemaiding services in the event of sickness of permanent staff. The second type of casual work is for skilled and semi-skilled function or banqueting work, where workers are brought in on a "function by function" basis to supplement full-time staff capability. In both cases, however, the contract that is established is more like a short fixed term contract, and employees are often employed on a regular basis so that some might be considered "permanent casuals" rather than "casual casuals" (Walsh, 1991), with the former sometimes 
being employed under conditions similar to permanent workers (Rees and Fielder, 1992). Such workers are often a critical part of the workforce and are frequently highly regarded to the extent that one UK company has established a special programme for its temporary staff, which includes regular newsletters to provide advance notice of all functions, formal performance appraisals and a six-tier career structure (Pickard, 1995).

In addition to explanations based on operational demand, higher than average numbers of part-time and casual workers in the industry are suggested to be a consequence of the characteristics of those seeking work in the industry. Early studies hypothesised a "marginal worker" thesis (Wood, 1992a), suggesting a low degree of attachment to the labour market of industry employees. Workers were commonly characterised as "deviant" or marginal to society in some way (immigrants, vagrants, young people who have recently left home, and people with difficulty in forming social relationships) (Wood and Pedlar, 1978; Saunders, 1981; Shamir, 1981) or as individualistic and instrumental in their orientation (Wood and Pedlar, 1978; Butler and Skipper, 1981; Mars and Nicod, 1984). These explanations have been dismissed in recent years (Wood, 1992a) in favour of explanations of employment patterns based on labour supply. Continued high numbers of women seeking part-time work and the increasing costs of secondary and tertiary education ensure a ready supply of workers for whom part-time employment is preferred (Lucas, 1995). In addition, however, some research has suggested that characteristics of work in the hospitality sector, in particular the highly personal nature of many jobs, may provide an attraction to some workers. As early as 1975, Shamir's study of work attitudes found that hotel employees 
were much more likely to be motivated by a social and expressive motivation, with highest levels of job satisfaction being achieved through variety in their work, and in meeting people. A recent Australian study has also found female hospitality industry employees place greater importance on job satisfaction than financial rewards (Ross, 1995). While work in the industry is often characterised as low-skilled, as Riley (1993) notes, in many employees experience a degree of autonomy in that work is performed outside the direct control of management, which may be preferable to alternative available forms of employment.

In summary, employment patterns in the industry have been attributed to a range of labour supply and demand factors, with no one factor likely to provide a complete explanation. 


\subsubsection{Labour market dynamics - recruitment, turnover, and mobility}

In respect of labour market dynamics, the literature suggests high labour turnover and a heavy reliance on the external labour market. It is frequently commented on in UK studies (Shamir, 1981; Croney, 1988; Ralston, 1989; Macaulay and Wood, 1982; Bell and Winter, 1993; Wood 1995) and has also been noted in the US (Paules, 1991), Australia (Timo, 1993) Malta (Baldacchino, 1994) and Singapore (Yaw, 1994). Estimates of the rate of turnover, however, are less frequently provided, and when they are, fluctuate from single figures to those of several hundred percent. Variability has been explained with reference to both supply and demand factors. Differences in labour turnover have been demonstrated with reference to industry sub-sector (Croney, 1988; Crompton and Sanderson, 1990), occupation (Croney, 1988; HCTC, 1994), size of workplace (HCTC, 1994) and external labour market conditions (HCTC, 1994; Wood, 1995). Institutional catering in the UK, for example, has repeatedly been found to have lower levels of turnover than the commercial sector (Crompton and Sanderson, 1990; HCTC, 1994); larger workplaces have higher rates of turnover than smaller ones (HCTC, 1994), and turnover is said to have been reduced to $28 \%$ in the UK as a result of the recession (Wood, 1995; HCTC, 1994).

Non-market factors have also been suggested as an explanation for labour market volatility, but research is equivocal as to whether general perceptions of high turnover hold true in all cases. The managerial belief that part-timers are more likely to have higher levels of turnover than full-timers has been confirmed by one study (HCTC, 1994) and rejected by another (Walsh, 1991). Women have been found to have both higher (Brownell, 1993 cited in Wood, 1995) and lower 
(Timo, 1993) rates of turnover than men. In addition, some workplaces have been found to have low rates of turnover (Leonard, 1992) and several studies have pointed to the fact that even with high turnover, hospitality industry workplaces also employ a core of often long-standing employees (Ralston, 1989; Price, 1993). A study of two UK restaurants, for example, found that $54 \%$ of staff had been working at their jobs for more than three years, and some had been working considerably longer (Newman, 1993), while a survey of hospitality sector workplaces noted that more than half of the employees (including casual workers) of $55 \%$ of the respondent establishments had been in continuous employment for more than two years (Price, 1993).

A relationship between turnover and managerial practice has also been suggested. Early studies in both the UK and USA concluded that a more participative managerial style was critical in decreasing high levels of turnover (Whyte, 1948; Whyte et al, 1965; HCEDC, 1969), and more recent studies have also suggested that low levels of turnover in particular workplaces are attributable to good employment and human resource practices (Leonard, 1992; Rees and Fielder, 1992). While managers believe that turnover is inherent to the industry and largely a result of external labour market factors (HCEDC, 1969; HCTC, 1994), attitude surveys of past and existing employees in the industry point to dissatisfaction, unilateral decision-making by management, and lack of appreciation of work being well done as being more significant (Mars and Mitchell, 1976; Zacarelli, 1985; Hall and Jones, quoted in Worsfold and Jameson, 1991; Ross, 1995). Overall, findings from a variety of studies suggest a 
considerable gap in the expectations of employers and employees in the industry about the reasons for high turnover, and what can be done about it.

Recruitment and career management practices also have a compounding effect on labour turnover. In this area, research suggests a heavy reliance on external labour market and strategies for numerical flexibility (Simms et al, 1988; Mitchell, 1988; Riley, 1991, 1993). ${ }^{4}$ In the UK as few as $1 \%$ of hotels in 1975 used promotion from within as a method of recruitment (Mars and Mitchell, 1976), and as many as $75 \%$ of all vacancies (including senior positions) were filled from outside the organisation (Ralston, 1989). Simms et al (1988) have argued that there is little about the industry which suggests the development of an internal labour market, and this may contribute to high levels of labour turnover (Chivers, 1972; Bell and Winter, 1993). Two key factors influencing this are the multiple points of entry to most hospitality sector workplaces and the lack of any specific hiring standard or promotion criteria. Few workplaces have formal recruitment guidelines, and even where these exist (such as in large hotel chains) they are not always used in practice, despite management rhetoric affirming the importance of selecting the right staff (Croney, 1988; Worsfold and Jameson, 1991; Riley, 1993). Recruitment is often ad hoc and informal, with word-of-mouth and recommendations from existing staff the most common source of recruitment (Ralston, 1989; Bonn and Forbinger, 1992; Baldacchino, 1994). Other recruitment

\footnotetext{
${ }^{4}$ Use of the term "numerical flexibility" refers to the use by firms of practices which allow them to respond to changes in demand by altering the number of staff employed and/or the hours for which they work. It is contrasted with use of "functional flexibility" strategies in which employers achieve flexibility through deploying their staff in a variety of capacities, for example through multi-skilling across occupational classifications.
} 
methods include job centres and newspaper advertising but this depends on the nature of the vacancy (Price, 1993; Kelliher and Johnson, 1987; Ralston, 1989).

While concern about high levels of mobility is predicated on the assumption that low turnover is important for employers to maximise their investment in training and to minimise the costs and disruption of replacing staff who leave, a recent survey of 2,472 British workplaces found that $89 \%$ of mangers reported that high turnover was not of great concern to them (HCTC, 1994). In addition while high turnover is generally viewed as negative, another perspective suggests that it is functional for the industry. As Riley $(1991,1993)$ points out, the industry is structured according to a hierarchy of consumer standards representing a pecking order of skills. While employees may move frequently from workplace to workplace, mobility outside the industry is limited. A recent UK study found that $57 \%$ of joiners were from the hospitality industry, and $60 \%$ of leavers went to another job in hospitality (HCTC, 1994). Figures were even higher in hotels and for managerial employees, $80 \%$ of whom were recruited from within the industry. Thus high levels of mobility may act as a mechanism for skill accumulation in an industry in which the predominance of small workplaces limits the opportunity for employee development. Under these conditions employees may stay in a particular occupation but move from workplace to workplace to develop specialist skills or to experience a different type of product environment.

It must also be noted that heavy reliance on the labour market external to the firm may be giving way in the 1990s to increased emphasis on functional flexibility under pressure from demographic considerations, continued growth in the 
industry, and changing customer expectations. A worldwide reduction in the number of new entrants onto the labour market is creating conditions of scarcity in an industry heavily dependent on younger workers. Few managers in the industry have given conscious thought to the implications of decreasing labour supply (Worsfold and Jameson, 1991) although a handful of organisations have responded by increasing the proportion of older employees that they hire (Lucas, 1993). Others (generally larger workplaces where emphasis is placed on quality management) are bettering employment conditions and instigating internal labour markets to provide development opportunities for employees as a means of improving employee retention rates (Williams and Hunter, 1992). An indication of these changes is seen in the increasing emphasis on opportunities for employee training and skill development. While the majority of jobs in the industry have been seen as low skilled (with Riley (1993) putting this as high as 64\%) industry demand for tertiary trained employees in the Asia-Pacific region outstrips supply by a factor of ten (Craig-Smith and Fagence, 1995). The increasing importance of quality as a source of competitive advantage has resulted in a re-thinking of the "value" that is attached to many of these jobs and is reflected in an increasing amount of investment in training provision. For example, the Mirage Hotel in Las Vegas spent over \$5.5 million in 1993 on training its 7,000 employees (Tracey and Tews, 1995), and a commitment to service quality at the Ritz-Carlton in Australia involves training each employee for 126 hours as a "quality engineer".

Despite increased attention to training by some high profile employers, the picture across the industry as a whole is less rosy. While greater numbers of catering and hospitality employers than other industries in the UK have been found to have a 
training budget, much of this training is on-the-job, and a smaller proportion of employees have received training than in other industries (Lucas, 1995). Similarly, in Australia, industry employers have been found to provide fewer hours of training than other industries and invest only $1.6 \%$ of gross wages on training. A survey of 76 hospitality industry workplaces in Queensland found that while $84 \%$ of workplaces provided informal on-the-job training, in only just over $40 \%$ was this training formalised, and only a third provided training outside the workplace. An increased likelihood of training was associated not only with size, but also to a progressive approach to management; and training expenditure was consistently lower in workplaces employing a high proportion of casual workers (Boreham et al, 1996).

One of the specific changes that has taken place is the focus on training for service quality. In particular, the interpersonal skills which have traditionally been seen as an "inherent" part of an employee's personality have come to be recognised as a valued skill, and therefore as one in which employees can be trained. Employees may be provided with skills in service provision customised to individual need, with employees at the Ritz-Carlton being empowered to "move heaven and earth" to satisfy customer needs (Watkins, 1992). Whether these skills, however, guarantee improved service is a matter of some conjecture. In some workplaces, customer service training has resulted in what has been described as the "routinisation" of service work (Leidner, 1993) in which service standards are closely prescribed. The implications of this for work in the industry are discussed in the next section. 
In summary, the literature on employment relations within the hospitality industry suggests two images. The first, and most traditional, is that of an industry employing low-skilled and largely casual workers drawn largely from the external labour market, and where jobs are characterised by low pay, long hours, and high labour turnover. The second is more complex and suggests that work is permanent (albeit often part-time), that flexibility may suit employees as much as employers, and that high turnover and mobility provides a means of skill accumulation in an industry dominated by small workplaces. The two images are not, of course, mutually exclusive. They may co-exist at the same time in different industry segments, with individual workplaces displaying a tendency towards one or the other. Some literature suggests, however, that the balance within the industry as a whole is moving away from the external labour market model towards one which places increasing emphasis on human resource development, and the formalisation of an internal labour market. The truth of this suggestion for the New Zealand situation is examined in Chapter 6 of this thesis. We turn now to examine the nature of work relations in the industry. 


\subsection{Work relations}

As noted in Chapter 1, work relations include the way in which work is organised and the deployment of workers around technology and production processes. In the hospitality industry, these are fundamentally affected by the way in which the service that is being provided is an integral part of the product purchased, and the centrality of interpersonal relationships between managers, workers and customers. This feature is addressed after consideration of the continuing segregation of work in the industry.

\subsubsection{The nature and segregation of work}

The nature of work in many workplaces has traditionally been subject to a specialist division of labour. While in many industries this was as a result of the application of management techniques based on the adoption of Taylorist principles (described in Chapter 4), in the hospitality industry it has also been affected by social norms handed down from domestic service and the technology of food production. In an earlier era, domestic staff were arranged in a hierarchy of occupations, with chefs and cooks at the apex, maids and dressers in the middle and cleaning staff at the bottom. Intra-occupational hierarchies were also important, with status often deriving from the status of the master or mistress for whom one worked. Within the kitchen, the partie system which evolved in France during the eighteenth century saw each chef specialise in a particular category of food and perform all work related to food in that category, independently of other chefs in the same kitchen (Chivers, 1972; Urry, 1990). Escoffier broke down these demarcations by reorganising kitchens so that work centred upon processes (such 
as sauce-making, grilling, etc), with success of the final product dependent on a high degree of cooperation between chefs.

These traditional demarcations and status differentials have continued into the present day, and are commonly noted within hospitality industry research (see for example Whyte et al, 1965; Chivers, 1972; Cobble, 1991; Paules, 1991; La Pointe, 1992; Salmon, 1992). Work in hospitality industry workplaces is highly demarcated into kitchens, housekeeping and cleaning, waiting, and reception. ${ }^{5}$ Within these functional areas, men have higher status than women, ${ }^{6}$ employees providing customers with a direct product or service have higher status than those who do not, and those who make or prepare food and drink have higher status than those who simply serve it, or clean up afterwards. There is very little horizontal mobility between these groups, and an employee seeking a change in job is more likely to transfer their employment to another employer while

\footnotetext{
${ }^{5}$ The exact line of demarcation may vary from workplace to workplace; and some workplaces may also include other areas - e.g., portering, leisure facilities etc.

${ }^{6}$ Gender segregation in the industry has been frequently noted, with men and women being employed in different occupations. The employment of men is often associated with more exclusive and higher status establishments. Whyte's (1965) study of the Tremont hotel, for example, records female waitresses being displaced from the silver service Zebra Room in favour of servicemen returning from the war, and were sent instead to the less prestigious King Cole room. Even where men and women perform the same work gender-specific titles (such as cook/chef, waiter/waitress) are used. This reflects more than simply the sex of the person undertaking the job, but also connotes aspects of the job itself. LaPointe (1992), for example, has noted how while one restaurant employed both waitresses and waiters, the waiters refused to do perform tasks other than serving tasks, such as side-work or making desserts, because this was perceived as women's work. More significantly perhaps, Hall (1993a) found that while two thirds of the restaurants which she studied employed both males and females as serving staff, the gendered meanings of "waiter" and "waitress" were carried through into the integrated organisations. In more exclusive restaurants, both female and male staff wore the traditionally male penguin suit, and were referred to as "waiters"; while in less formal and family style restaurants, employees wore gender-specific uniforms, and the term "waitress" was used, even when the individual referred to was male. "To be a waiter means the server interacts in a charming and professional manner, engages in 'selling', but remains reserved and 'professional'. The kind of work a food server performs is generally called waitressing by other respondents" (Hall, 1993a:339).
} 
continuing to work in the same occupation, than to change occupations but continue to work for the same employer.

The question arises as to whether these demarcations are immutable or are being broken down under pressures for functional flexibility. The need for greater flexibility in labour deployment in the industry was noted as early as the early 1970s (Pickering et al, 1971). Although it noted that this was less likely to be a problem in small firms, Pickering et al noted that departmentalisation limited efficient utilisation of staff, leading to inefficiency and too much idle time on the job. The increasing application of new technology, including the use of automatic dishwashers, microwaves and convenience foods, has reduced the need for some categories of labour (particularly specialist cooks and some categories of unskilled staff) and involved re-thinking the content of many jobs. More generalist staff were employed, such as sous chefs and "functionally flexible" chambermaids. A typical day for the latter occupation is described in a Department of Employment research report as including:

...make and serve early morning teas; assist in preparation and service of breakfast; make beds and clean bedrooms and bathrooms, and after an afternoon break, assist with the preparation and service of the evening meal; or part-time staff might be engaged for evening duties. (Department of Employment, 1971:31 quoted in Urry, 1990: 79)

Research on labour deployment in hotels is equivocal as to whether any significant change has been experienced in the 1980s and beyond. Partly as a result of a high level of occupational segregation, success depends on recognition of interdependence and a high level of coordination between departments. Shamir 
(1978) argues that this has resulted in a tendency towards cooperation and a willingness (at least for some groups) to cross occupational boundaries. Thus, hospitality industry workers may traditionally have been more flexible than their counterparts in other industries. Several studies have found mechanisms such as job rotation, enrichment and enlargement to be relatively common, and practiced in between $50-60 \%$ of hospitality industry workplaces (Hales, 1987; Ralston, 1989). Those findings have been subject to cautious interpretation however. Hales (1987) suggests that where changes in job design have been put into place, it is used as an ad hoc way of providing individual workers and managers with extra responsibility, rather than a general means of redesigning work. In particular, where individuals are undertaking a range of work outside their job descriptions, this commonly involves managers "helping out" as a means of covering for sickness and absenteeism, and to this extent represents flexibility downwards (Guerrier and Lockwood, 1989b). Such practices may not vary significantly from traditional means of overcoming operational constraints in the industry.

The practice of functional flexibility as a deliberate strategy appears to be limited to large hotels. Management development programs frequently are based on the principle that junior managers are rotated around all important aspects of hotel operations. At an operational level, workplaces in large hotel chains in Australia and New Zealand have moved towards cross-training of staff in order to promote flexibility (Perry, Davidson and Hill, 1995; Nankervis, 1993), although this crosstraining is often limited to jobs with low skill levels rather than providing a career path for employees. More significantly, it has been argued that while some opportunities for functional flexibility exist there are considerable barriers to its 
wholesale introduction in the hospitality industry including occupational identity and orientation, the nature of work and level of skills for different functional groups and management practice in the industry (Guerrier and Lockwood, 1989b; Riley, 1992). These are explored in further detail below.

Differences in occupational identity within the hospitality industry were clearly identified by Shamir's (1975) study of employee attitudes in British hotels. This found that orientations to work differed across hotel departments, with kitchen staff placing greatest value on creativity and expression, reception and restaurant staff being more interested in the social and expressive nature of their work, and housekeeping staff having a higher instrumental orientation. Not only do these differences create the basis for occupational identification based on group membership, but the nature of hotel work generates conflict between groups (Riley, 1992). The desire of waiting staff to fulfill a customer desire for a Lobster Royale in Butter Sauce sandwich may offend the chef's sense of cuisine, ${ }^{7}$ while the requirement that housekeeping staff follow strict guidelines for the make-up of rooms may cause difficulties for the receptionist who has undertaken to meet a specific request for a guest. ${ }^{8}$

\footnotetext{
${ }^{7}$ This comment is in reference to a popular New Zealand television advertisement for butter, in which a group of well-known rugby players order such sandwiches, much to the outrage of the chef (played by Lenny Henry).

${ }^{8}$ Such a situation is reflected in the well-known and apocryphal story of the guest at a London hotel who requested that he not be provided with soap as he had brought his own. Due to miscommunication between reception and housekeeping departments and management, he ended up with 67 cakes of soap of three different brands and sizes.
} 
The nature of occupational identity and orientation is not simply an indication of personality differences between individuals but also reflects contrasts in the nature of the work that they undertake; and variance in the skill levels utilized in the performance of this work. The work of a chef is recognised as involving a considerable degree of expertise and allowing room for the expression of individuality and the creation of variety (Chivers, 1972). Fine (1996) describes how cooks use "occupational rhetorics" of artistry and professionalism to maintain a sense of occupational skill. Housekeeping, on the other hand, while commonly thought of as menial, requires an essential amount of attention to detail and speed in order to ensure that all tasks are performed in a short space of time. The work of front-of-house staff, involving a high level of customer contact, is largely made up of emotional labour, as employee service forms an important part of the product that is being purchased by the consumer (Wood and Pedlar, 1978; Urry, 1990; Leidner, 1993). Accordingly, such staff are commonly required to demonstrate a high level of interpersonal skills, and frequently accomplish job satisfaction through their exercise (Paules, 1991; Salmon, 1992). The variations between the different types of work being undertaken in the industry and the different types of skills needed to perform them thus serve to maintain demarcations between occupational groups in the industry.

A final barrier to the adoption of functional flexibility arises from the nature of the hospitality labour market and the way in which managers have traditionally achieved flexibility. While functional, rather than numerical flexibility practices offer hospitality industry managers greater assurances of quality (Guerrier and Lockwood, 1989b), the reality is that managers have been able to achieve 
adequate operational flexibility through increased use of part-time and casual employees. A ready supply of workers, and a focus on learning management skills by experience, means that few managers have felt the need to adopt new means of achieving flexibility. Nevertheless, changing customer expectations and the decrease in supply of new entrants to the labour market mentioned earlier may provide a new stimulus to the adoption of functional flexibility.

\subsubsection{Controlling the labour process}

A central feature of work relations involves the mechanisms used by management to control the labour process. In addition to specialisation in the division of labour discussed above, the way in which management directs work performance provides an important element of control. The hospitality industry has been described as relying on hierarchical and authoritarian managerial style, despite a self-image of being consultative and open (Croney, 1988; Worsfold, 1989; Guerrier and Lockwood, 1989c; Wood, 1992a). More recently, management journals in the industry have argued the need for improved communication, employee empowerment and a concern for employees that mirrors the approach to customers. The adoption of these practices has been stimulated by an increased emphasis on customer and service quality as critical for business success. Research on the implementation of quality management has drawn attention in turn to the way in which in service industries, the presence of customers complicates the basic dynamic of competition for control over the labour process (Leidner, 1993). 
In many hospitality industry jobs, the labour process is undertaken under significantly different conditions than production related work, where this takes place under the direct control of management. Key differences are: the service provided is indistinguishable from the product that is being consumed, it is consumed directly by the hotel or restaurant guest and cannot be stockpiled, service is supplied directly from the employee to the customer and satisfaction is highly dependent on the nature of the relationship constructed between them, and the encounter takes place largely outside of the direct control of management. ${ }^{9}$ In essence, workers in hospitality industry jobs are serving two masters - their employer and those to whom they provide a service. In addition, work is often carried on at a hectic and even chaotic pace necessitated by customer demand (Fine, 1990; Paules, 1991). ${ }^{10}$ As Leidner (1993) observes, the interests of managers, workers and customers may conflict in this interaction and the desire of management to control the service encounter in the interests of efficiency and profit may run counter to its more general goal of keeping the customer satisfied. At the same time, employee focus on the customer may serve to undermine

\footnotetext{
${ }^{9}$ It is important to note that physical proximity, social relationships and direct provision of service will vary considerably from employee to employee depending on their position in the hierarchy. The relationship between a customer and the hotel porter, for example, will be very different to the relationship which that customer has with the hotel receptionist, the hotel manager, or the head cook. Conversely, the relationship between the cook and the customer may have more similarities than differences to the relationship between a customer and a supervisor in charge of a motor vehicle assembly line. While an industry itself may be relatively easy to define as involving service, the nature of service work is extremely diverse.

${ }^{10}$ Paules has suggested that the fact that waitresses are required to work at this pace actually contributes to their job autonomy. Firstly, argues Paules, waitresses will have to improvise in order to find creative solutions when, because of pace, organisational systems break down (e.g., when the coffee has run out, or when customers are waiting for tables that have not been cleared). Secondly, the fact that waitresses work efficiently during busy times (and often do not take the breaks to which they are formally entitled) is part of the exchange of reciprocal obligations that also allows them to be unproductive (e.g., read books, take unscheduled breaks) at times when the restaurant is not busy.
} 
managerial authority. Tipping, for example, can have the psychological effect of placing the customer in the position of proxy employer, and be viewed as a form of performance pay. Customers may be supplied with larger than specified portions and other management determined standards breached in order to maximise chances of receiving a tip, and serving staff may refuse to serve customers who do not fit the profile of those who tip well (Paules, 1991). The attitude of workers to customers may focus less on serving their needs than on "processing" them in as large a number as possible. This is reflected in the language used by serving staff, for example, in objectifying customers by referring to them as "tables". Similarly, Paules (1991) waitresses talk about "making" a tip, suggesting a process of extraction from the customer rather than personal service.

Increased focus on the customer has drawn attention to the peculiarities of the labour process in service work. The service being provided for customers in the hospitality industry is more than simply supplying them with a product but involves the provision of "emotional labour" (Hochschild, 1983). Customers pay not only for the food or accommodation which they are consuming but also for the experience of being attended to and looked after. The provider is being paid to attend to the customers' emotional needs for gratification and attention, as much as their physical needs for accommodation, food and drink. In providing this emotional labour, the employee is often required to conform to a particular demeanour, established by restaurant managers or owners as the appropriate image for their particular establishment. Such images may range from the formal, being friendly and knowledgeable but reserved, through to a more familial style, 
in which service employees are expected to display an outgoing and extroverted personality. In other situations, waiters and waitresses flirt with customers, so that assurances of sexual attractiveness are part of the service that is being provided and paid for (Hall, 1993a, 1993b; La Pointe, 1992).

Other developments have changed the nature of work relations in the industry in a way which often reduces direct contact between customers and service providers. Technological change has resulted in a standardisation of hotel and restaurant products such as rooms, dishes and drinks (Shamir, 1978) and has employed the customer as "unpaid" or "involuntary" labour in the provision of service. This can be seen, for example, in automatic billing, dispensing machines, and self-service restaurants in which customers serve their own food, carry their own trays and clean up after themselves. In addition, under the guise of quality management, work in the industry has been routinised or "McDonaldized" (Ritzer, 1993). This strategy is particularly prevalent in workplaces which are part of multiestablishment firms or chains and in which the provision of food or accommodation is standardised according to a concept developed at a corporate Head Office. In these organisations, standardisation of the product also involves routinisation of the service to be performed. Job descriptions and organisational structure are accordingly determined outside the workplace itself; as are uniforms, layout and physical environment, and logos. Customers are educated to expect and conform to this standardisation. As Leidner notes (1993:45), no-one ever walks into McDonalds and says "So, what's good today?" Thus in workplaces which rely heavily on standardisation, the job of unit managers is to maintain uniformity with corporate standards rather than to manage innovation. 
Routinisation often moves beyond standardisation of product and provision of a uniform or dress standards to prescribing appropriate behaviours and attitudes towards customers. ${ }^{11}$ Workers are provided with "scripts" for dealing with specific service delivery situations, and the importance of guest recognition, eye contact, and body language are emphasised. Salmon (1992) for example describes the "Doing It Right" programme of a bar/restaurant owned by a brewery chain in which workers were trained how to welcome and bid farewell to customers, to acknowledge people at the bar within thirty seconds and to recognise regulars. Such training requires workers to perform a role as part of their job. This is seen most clearly in "theme" type restaurants in which the adoption of roles as an integral part of the service provided is taken to an extreme. At a London restaurant, for example, workers are hired after an "audition" in a theatre and are provided with two-three weeks training before they come into contact with customers (Gardner and Wood, 1991). Workers are hired for their "personality" rather than for their technical skill, and the work that they perform is of a theatrical nature:

Barmen can free-pour a drink into a glass, throw it over their shoulder and catch it behind their backs. Bartenders are also encouraged to juggle together, using bottles, glasses and fruit ... Waiting staff are required to act together as a team for a variety of special services such as a "train" where for large parties waiters gather to collect the food, form a train and run into the restaurant with the food. "Crazy carries" are also

\footnotetext{
${ }^{11}$ It should be noted of course that proscriptions on certain types of behaviour are not limited to those workplaces in which work has been standardised. The fact that workers are supplying "emotional labour" means that it is common for workers to be prohibited from performing any activity in front of customers that does not involve service tasks (Paules, 1991). For example, employees are frequently prohibited from eating, drinking, smoking or having personal conversations in front of customers; they take their breaks out the back, out of the sight of customers; and frequently have separate toilet and bathroom facilities.
} 
delivered where two waiters carry in a horizontal waiter laden with food (Gardner and Wood, 1991:272)

The routinisation of hospitality work is a key means by which managers in the industry seek greater control over the labour process. It is put in place when the employer believes that the quality of the interaction between worker and customer is critical to the success of the business, when workers are unable or unwilling to conduct the interaction appropriately on their own, and where routinisation will guarantee quality control (Leidner, 1993). The process of routinisation nevertheless has significant consequences for both employees and customers. Recourse to the justification of maintaining quality standards as a legitimation for specifying worker looks and behaviour allows employer intervention into areas of individuals' lives usually considered to be a feature of individual personality. Playing a role may require workers to take on personality traits which they would not otherwise choose, leading to possible confusion in self-identity. In addition, there is an inherent contradiction between the routinisation of service standards and the notion of good service as treating the customer as an individual. Consequently, good service is redefined by how successfully the worker can persuade the customer that they are being authentic rather than playing a role. In the same way as workers on an assembly line become alienated from the production process, routinisation may alienate employees from their own emotions and thoughts (Leidner 1993).

Two caveats may be placed against this general concern about routinisation in the industry. Firstly, several studies have pointed to the fact that despite a requirement to adhere to standards, workers may contest this as demeaning or may use routines 
as a way of resisting demands put upon them by either managers or customers (Paules, 1991; Salmon, 1992; Leidner, 1993). Employees may refuse to adopt required scripts and use their interpersonal skills to provide standards of service that are superior to those set out in the corporate manual. The limited capacity for managers to control the encounter in such situations is underlined by a reluctance to reprimand workers for a breach in policy (Paules, 1991). In this way, workers can defy management while unwittingly enlisting the customer in support. Alternatively, slavish adherence to corporate requirements can act as a form of "work-to-rule", by complying to management directives in the face of customer requests to the contrary. Routines also allow workers to resist customer demands which the employee is unable or unwilling to meet when these fall outside the range of possibilities allowed for, and to "educate" the customer about appropriate codes of behaviour or dress. Thus, the standardisation of work may in some situations, allow hospitality industry workers to regain some measure of control over the labour process.

Secondly, while routinisation has been an important influence on the changed nature of work in the industry, evidence also suggests that customisation and niche markets are equally important (Lyon, Taylor and Smith, 1994; Taylor and Lyon, 1995). Quality distinctions between hospitality industry workplaces are frequently based on the extent to which services are customised for the individual. Technology has played an important part in this customisation. The Ritz-Carlton, for example, (along with many other first-class hotels) maintains computerised guest history profiles on the likes and dislikes of more than 240,000 repeat guests (Watkins, 1992). The pursuit of improvements in service quality has been based 
on the claim that the best predictor of satisfaction for hotel guests is the quality of service that they receive from front line employees (Barbee and Bott, 1991; Bowen and Lawler, 1992; Leonard, 1992; Cavaness and Manoocherhri, 1993). ${ }^{12}$ Given that service is often delivered by employees at the lowest levels of hospitality industry organisations, management advisers in the industry have argued the need for renewed attention being paid to motivating employees to provide an improved level of service, through organisational development programs which include team working, suggestion schemes and employee empowerment programs. An important precondition is providing workers with the autonomy to meet guest needs. Accordingly, some workplaces refrain from closely prescribing employee conduct and instead provide training around "principles" or "basics" of service provision which act as a guide to behaviour. The Ritz-Carlton, for example, has 20 basic service steps but empowers employees to "move heaven and earth" in order to provide a guest with "instant pacification" (Watkins, 1992). Similarly, Scott Hotels entitle their training programme "Whatever it takes", reflecting the fact that the work of their employees consists of meeting guest needs (Lashley, 1995a). The importance of customisation and meeting guest needs as a selling point is reflected in an advertisement for Marriott hotels, where a satisfied guest describes how a hotel porter traced a wallet lost at some unknown time and place in the previous hours. It concludes:

\footnotetext{
${ }^{12}$ While few would question the importance of good service, studies of customer expectations suggest that the definition of "quality" is subjective and that customer service may not be the defining feature of satisfaction as is sometimes assumed. Factors such as physical environment and quality of facilities are also important in defining customer satisfaction. See for example, Gilbert and Joshi, 1992.
} 
I was astounded that he went out of his way so much to help me. But, as I now know, everyone at Marriott works this way. Personally assuming responsibility for the needs of every guest. It's called empowerment. And thankfully, they never seem to find anything too much trouble. (Quoted in Lashley, 1995a)

In summary, the picture of work relations that arises out of the literature has similarities to that which was painted in respect of employment relations. The traditionally hierarchical and segregated industry has responded to increased competition and changing customer expectations by the adoption of two alternative strategies for organising work. The first of these is continued occupational segregation and either selective or wholesale routinisation of work. The second alternative is the breaking down of barriers between functional areas through multi-skilling and cross-training, a move to team based working and employee empowerment as a means of meeting guest needs. The extent to which these have been adopted in New Zealand is explored in Chapter 7, while the literature on the nature of labour relations in the industry is now explored. 


\subsection{Labour relations}

Outside the mainstream industrial relations literature, the limited amount of research on labour relations in the hospitality industry that has been conducted (mainly in the UK) has focused on the two areas of union membership and the establishment of wages and conditions of work. While increasing levels of unionisation and the establishment of a collective bargaining framework were evident in most industries in the developed world in the post- World War II period, the hospitality industry in many countries stood aside from this general trend. Instead, management has by and large adhered to traditional methods of managing employees and determining wages and conditions of employment. More recent research has suggested the adoption of the rhetoric of the "new" industrial relations but with management retaining firm control over pay levels and the centrality of managerial prerogative as a prime determinant of labourmanagement relations.

\subsubsection{Representation}

In contrast to other industries which unionised at an early stage, and in which levels of union density generally increased through the course of the twentieth century, the hospitality industry has generally remained unorganised. Despite attempts in most countries to stimulate the growth of unions and collective bargaining, membership has remained low, and in most cases estimates of density have been in the single figures (Chivers, 1972; Wood and Pedlar, 1978; Macaulay and Wood, 1982; Ralston, 1989). Most recent and reliable figures on the basis of data from the British Workplace Industrial Relations Survey (WIRS) suggest that 
in the early 1990 s, only $3 \%$ of the industry's workforce were unionised and $92 \%$ of workplaces employed no union members at all (Lucas, 1995). ${ }^{13}$ Pockets of union strength can nonetheless be found. In the United States, although overall union density is low, in some centres such as San Francisco and New York, hotels have been organised since the beginning of the century (Cobble, 1991), ${ }^{14}$ and unions continue to have an active role in bargaining on behalf of their members. Similarly, in the UK, despite low overall levels of density, 16.4\% (mainly industrial catering establishments and former British Rail hotels) have 100\% membership (Ralston, 1989) and density in workplaces employing more than 100 employees, at $19 \%$, is only slightly lower than the $23 \%$ density in large workplaces in all industries and services (Lucas, 1995).

The low level of union density would, on the face of it, represent something of a conundrum for industrial relations researchers. Given evidence of arbitrary management action, low levels of job security, and poor wages and conditions, workers in the hospitality industry would appear to have more to gain from unionisation than most. Explanations for why this has not occurred have made reference to industry fragmentation, the nature of the hospitality labour market, and characteristics and attitudes of employees, unions and employers.

The influence of industry structure on low level of union density is often noted (Mars and Mitchell, 1976; Wood and Pedlar, 1978; Macaulay and Wood, 1992;

\footnotetext{
${ }^{13}$ These figures contrast with a figure of $48 \%$ union density across the economy as a whole; and only $36 \%$ of workplaces which employed no union members.

${ }^{14}$ Cobble (1991) explains this with reference to historical factors, particularly the fact that the union developed as a craft, rather than an industrial union.
} 
Riley, 1993). The majority of workplaces are small, and apart from major tourist centres are frequently geographically scattered and in isolated locations. In addition, seasonal variations in demand means that some workers may be employed for only a short period of time with high turnover undermining union organisation. High proportions of part time workers and shift workers are also argued to make it more difficult for unions to recruit members, in part because of the difficulty of establishing any sense of workforce solidarity.

Unions themselves have been criticised for failing to take a more active role in recruiting hospitality industry employees. They have been argued to show little understanding of the industry (Macaulay and Wood, 1982), and consequently have had limited success in marketing themselves to hospitality workers (Wood and Pedlar, 1978; Johnson and Mignot, 1982; Gabriel, 1988). In the UK, unions took a more active recruitment role in the 1970s than earlier, but these efforts met with little success, despite an increase in industrial militancy (Johnson and Mignot, 1982; Wood and Pedlar, 1978; MacFarlane, 1982).

While industry structure and inactive unions provide a partial explanation, research on the views of employers and workers suggest that prevailing attitudes within the industry are inimical to unionisation. Employees have been argued to be individualistic and to have a preference for individual contracts (Mars and Mitchell, 1976; Riley, 1985). The culture of the industry is also said to be reliant on the existence of a set of mutual obligations and reciprocity whereby employers are dependent on the good will of employees in order to achieve flexibility in the 
face of irregular customer demand. This gives workers a degree of individual influence with management which mitigates against the development of a collective consciousness. Other research has suggested a more positive attitude towards unions (Chivers, 1973; Macaulay and Wood, 1992). A study of 60 employees in Scotland suggested a high level of awareness about trade union activity in the industry, and $80 \%$ reported largely positive views of trade unions (Macaulay and Wood, 1992). ${ }^{15}$ In addition, there were no differences between women and men, and full-time and part-time workers in their attitudes to unions. The fact that these positive views were not translated into union membership was attributed to the fact that workers did not believe that unions would be able to make a difference and therefore perceived that the investment in union membership fees was not worth it. Others said that they would join a union only if their employer was happy for them to do so and were skeptical of the ability of a union to survive in the industry in the face of employer opposition.

These findings underscore the importance of employer attitudes as a determinant of low levels of trade unionism and collective bargaining. The hostility of employers to trade unions in the industry has been noted in several studies (Wood and Pedlar, 1978; MacFarlane, 1982; Macaulay and Wood, 1992; Wood, 1995). The reasons for this stem from management reluctance to accept constraints on their authority and concern about third party involvement in the management of their units (Aslan and Wood, 1993). However other findings suggest the need for

\footnotetext{
${ }^{15}$ It should be noted, however, that the fact that the study was carried out in Scotland where more favourable attitudes to unions exist than in other areas of the UK, may have influenced the large number of positive responses.
} 
more detailed research. WIRS data suggests that almost three-quarters of managers in the industry were neutral in their view of trade unions, and fewer managers held unfavourable attitudes than in other industries (Lucas, 1995). In addition, while anti-union attitudes are common, some employers also display positive attitudes to unions. For example, Aslan and Wood's (1993) study of management attitudes to unions found that while employers generally accepted the need for unions in the industry, in order to curb exploitative practices, employee desire to unionise in their own hotels was seen as reflecting negatively on their own management ability and interpreted as a sign of personal failure.

In the face of anti-union attitudes, in the 1990s it has become more common for employers in the industry to establish alternative representative structures, such as joint consultative committees, to achieve employee involvement in the working of the business. These are, however, most likely to be found in larger organisations. Representation is generally non-union, with only $2 \%$ (in comparison with $10 \%$ of organisations in other industries) having all or some representatives chosen by trade unions (Lucas, 1995). In addition, while hospitality industry organisations are as likely as workplaces in other industries to operate joint consultative committees $^{16}$, other research suggests that managers establish committees in line with corporate policy rather than as a means of genuinely ensuring employee influence in decision-making (Croney, 1988). Consultative mechanisms are, in general, management initiated and controlled, concerned with communication

\footnotetext{
${ }^{16}$ Although given that the British WIRS excludes workplaces employing fewer than 25 employees, and given the tendency for JCCs to be associated with larger workplaces, this may overstate the incidence of committees in the hospitality industry.
} 
downwards rather than consultation, and are designed to reinforce a sense of common interest between management and their employees.

\subsubsection{The determination of wages and conditions of employment}

Unsurprisingly, given the low level of unionisation, collective bargaining in the industry is poorly developed. Within the UK, despite supportive public policy since 1918 designed to encourage collective bargaining, little progress has been achieved in hotels and restaurants. In 1943 the Catering Wages Act established the Licensed Residential Establishment and Licensed Restaurant Wages Council, and this effectively set the wages and conditions of work for workers in the hotel and catering industry until its disestablishment in 1986 (Lucas, 1991b). In the absence of collective bargaining wages and conditions are determined unilaterally by management. A study of British hotels found that pay rates were settled this way in $56 \%$ of independent hotels and $73 \%$ of hotel chains (Lucas, 1991a). A minority of hotel chains engaged in voluntary collective bargaining, and in a few small (less than 25 bedrooms) independent hotels pay was determined as part of employee participation mechanisms. In multi-establishment firms, starting salaries and rates of increase are frequently determined by Head Offices, although unit management may have some discretion in relation to individuals (Croney, 1988; Paules, 1991; Ralston, 1989). The only area in which individual bargaining is common is in respect of skilled staff, most notably, cooks and chefs.

The industry is notorious for the low levels of its wages and conditions (Chivers, 1973; Wood and Pedlar, 1978; Croney, 1988; Newman, 1993; Wood, 1992; Lucas, 1995). In the UK, until 1986, prevailing wages in the industry were at the 
level of or close to those set by the relevant wages council, although hotels in chains paid slightly more than independent hotels (Lucas, 1991b). The low level of pay is commonly put forward as a prime explanation for high turnover within the industry. Management have more recently become conscious of and sensitive to their reputation as low paying, and may emphasise the need to pay competitive rates to attract good staff (Croney, 1988). Despite this, however, payment systems are relatively minimalist with most hotels paying a basic hourly rate and overtime but rarely making use of schemes such as profit sharing or employee share ownership (Walsh, 1991; Lucas 1991a) or undertaking skills analysis or job evaluation (Croney, 1988).

In addition to poor wages, conditions of work in the industry are harsh. The nature of demand for hotel and restaurant services means that employees work long and anti-social hours, commonly working split shifts necessitated by fluctuations in workload during the day. The pressure of work and the nature of customer demand means that breaks can not always be taken (Paules, 1991; Newman, 1993). Conditions of work are often minimal and do not extend beyond annual holidays, free meals, the provision of a uniform (and laundry facilities) and transport home when working late (Lucas, 1991a). In addition, workers are frequently subjected to a series of rules which would be considered oppressive in many other industries, including the requirement that staff make up any shortfall in takings at the end of a shift, to cover for example for customers who have left without paying, constraints on the type of food and beverages that may be consumed during a shift, and restrictions on personal behaviour (Croney, 1988; Newman, 1993). 
That employees have not seen collective bargaining as a way of improving their wages and conditions has been suggested to be a result of complex reward systems. Mars and Mitchell (1976) have suggested that from the point of view of employees, the payment system is made up of a variety of elements including more than just pay. Tips are the most obvious example of this and can considerably augment take-home income (Paules, 1991; Newman, 1993). In addition, employees may have access formally to subsidised accommodation and food, and informally to "fiddles and knock-offs" or "perks" which have some economic benefit to the employee. ${ }^{17}$ Employers and employees may collude in the development of these systems to their mutual benefit. The extent to which employees can make use of perks may depend on the nature of labour market conditions at the time. At times when sufficient employees are readily available for work, more emphasis is placed on the formal payment system. When, however, labour market conditions are tight, or in situations where the organisation has difficulty recruiting staff (e.g., hotels and restaurants in remote locations) then greater flexibility can be expected, without increasing the wage bill over the longer term. On the other hand, taking advantage of perks may also be an expression of employee discontent and resistance. An employee who feels underpaid, for example, may consume prohibited food as a means of restoring an economic imbalance in employment, as in a case described by Newman (1993)

\footnotetext{
${ }^{17}$ Such activities may be against the policies of the organisation, or even illegal. They range from taking home food, beverages or other items from the hotel or restaurant, giving free meals or drinks to friends, not charging items on the bill, overcharging the bill and pocketing the difference, taking a commission from prostitutes using the hotel, and so on. See Hawkins, 1984 and Prus and Vassilakopoulos, 1979 for an examination of this sort of behaviour in two different settings.
} 
where an employee helped herself to cappuccino coffees, despite regulations restricting employees to filter coffee.

\subsubsection{Management style in the hospitality industry}

An important aspect of labour relations is the prevailing style used to manage employees. The 1980s saw increasing interest in management within the hospitality industry. In general, studies have focused on two themes. The first argues that management is unsophisticated and ad hoc in its approach to personnel and human resource management, resorting instead to an operational management style. The second suggests that in the absence of a systematic approach to management, the prevailing approach relies heavily on a unitarist style, emphasising managerial rights and prerogative. The combination of these two has led two commentators to characterise the prevailing style of management as involving " ... a high level of activity, a bias towards the practicality of the operation linked to an emphasis on technical and craft skills and a benevolent and autocratic style of staff management" (Guerrier and Lockwood, 1990:163).

Despite the development of the personnel management function in the twentieth century, few hospitality industry establishments adopted formalised labour relations or work related policies and procedures (CIR, 1971). In the UK, even in large organisations, fewer than half of all workplaces in the industry employed a personnel specialist. Even when they did, this person was unlikely to be trained in personnel, and often relied frequently on manuals issued by a corporate office (Kelliher and Johnson, 1987; Ralston, 1989). The personnel management function in the industry is largely perceived as being about recruitment (Ralston, 1989), 
and higher proportions of personnel and human resource managers in hospitality than in other industries reported that their two most time-consuming activities were recruitment and selection, and training (Lucas, 1995). In the absence of formalised policies, management style has tended to be reactive and unsophisticated. An early study characterised management as "abdicating" their responsibility by leaving new employees to sink or swim, and as being reluctant to intervene in conflicts between employees and customers (National Economic Development Office (NEDO), 1969). Since that time, despite increased emphasis on the importance of management, there is little to suggest that managers practice a leadership role. Instead, the management function is largely concerned with operational tasks, including filling in for sick or otherwise absent employees, dealing with customers, and responding to crises. Their role has been most aptly described as a "being there" style of management (Guerrier and Lockwood, 1989c).

A second theme arising out of research has been the way in which managers approach their relationships with employees. Overwhelmingly, this has been described as "unitarist" (Mars and Mitchell, 1976; MacFarlane, 1982; Croney, 1988; Aslan and Wood, 1993; Lucas, 1991a, 1995), connoting a reluctance to take account of worker interests in decision-making; and a belief in the centrality of managerial control in the employment relationship. This approach is demonstrated in management attitudes to both workers and their representatives. As noted earlier, managers are reluctant to admit trade unions a say in their workplaces because of concerns that this will reduce their operational flexibility (Macaulay and Wood, 1992; Aslan and Wood, 1993). In addition, the arbitrary nature of 
managerial action in relation to employees as a feature of the hospitality industry has been noted since the very earliest studies (Whyte, 1948; NEDO, 1969; CIR, 1971) and continuously since then (MacFarlane, 1982; Croney, 1988; Worsfold, 1989; Guerrier and Lockwood, 1989c; Wood, 1992). This is exhibited not only in low rates of pay and lack of job security for employees, but also in the "rules" by which the employment relationship is constructed. Despite having few other formal personnel procedures, hospitality industry workplaces are as likely as workplaces in other industries to have written procedures in place for the discipline and dismissal of employees (Lucas, 1995). In addition, the nature of the rules for which disciplinary action can be taken frequently relate to personal behaviour or trivial breaches, such as personal use of the telephone, refusing work offered at short notice, standards of dress and appearance, smoking or eating in sight of customers or general behaviour which might reflect on the employer (Croney, 1988; Paules, 1991; Leidner, 1993). The low-trust approach taken by employers is evidenced by the nature of seemingly arbitrary rules which for example, allow consumption of soft drinks but not "Coke", or some menu items but not others (Newman, 1993). It should be noted also, that even those managers who perceive themselves as adopting a consultative style are described by their employees as autocratic (White, 1973; quoted in Guerrier and Lockwood, 1990).

Prevailing management style has been explained with reference to the nature of managerial careers in the industry. In particular, the industry has been described as "insular" (Wood, 1992) with few managers having experience of work outside the industry. In part, this is a consequence of the relatively youthful age at which workers are promoted to senior management positions, and the considerable 
mobility within the industry. Guerrier (1987), for example, found that the average age for obtaining an initial senior post was 30 , while Baum notes that although half his sample were under the age of 40 , three-quarters had been employed in the industry for more than ten years. Similarly, Riley and Turam's 1989 study of 155 hotel managers in the UK established an average of eight to ten years for a 21year old to become a general manager, moving from position to position on average every three years (quoted in Guerrier and Lockwood, 1990). The fact that few managers have experience in other areas of the economy means that the prevailing culture of the industry is likely to take hold at an early stage, with little opportunity for a transference of new ideas or practice from workplaces in other industries.

Despite this, recognition of the need to adapt the prevailing style of management in response to changing circumstances is increasing. As noted earlier, industry management advisors promote the adoption of human resource management practices such as employee involvement, team work and improved communications with employees. In doing so, they frequently stress the need for managers to re-think their roles and behaviour to ensure that labour-management practices meet the needs of employees (Bowen and Lawler, 1992; Heymann, 1992; Bell and Winter, 1993; Caveness and Manoochehri, 1993). Evidence on the take up of these ideas, however, suggests that employers are cautious in their adoption of new styles. WIRS data suggests that fewer hospitality industry workplaces than other industry sectors had introduced management change with the view of increasing involvement in the previous three years (Lucas, 1995). Where changes were introduced, they were most likely to involve the provision of 
information from the top down than to provide a forum for real employee participation. Even in the $25 \%$ of workplaces where a functioning joint consultative committee was in existence, managers in the hospitality industry saw it as having less influence on decision making than managers in other industries.

In summary, the general picture painted by research on aspects of labour relations in the industry is one in which managerial prerogative remains extremely strong. Unlike other industries, this has never been tempered by union or worker opposition or collective bargaining. While in more recent times some employers have adopted practices associated with the "new" industrial relations, including increased emphasis on communication and employee involvement, mechanisms which recognise and meet employee needs separate to those of employers are rare. In this way, the pattern of labour relations practice varies somewhat from other labour-management practices. They exhibit a degree of uniformity across the industry, in contrast to patterns of employment and work which show divergent trends. The lack of debate on possible reasons for these differences and similarities are discussed below.

\subsection{Summarising management practice in the hospitality industry}

In summarising existing research on employment, work and labour in the hospitality industry it must be said that the research that has been undertaken has been largely descriptive. ${ }^{18}$ That description paints a picture of an industry in which labour-management practices are variable, but in general, unsophisticated,

\footnotetext{
${ }^{18}$ A limited number of studies attempt to analyse the industry within a broader theoretical or sociological context. See for examples, Nailon, 1982, Slattery, 1983, Wood, 1994b.
} 
ad hoc, and largely reactive. Two problems with the research to date may be isolated. Firstly, the literature reveals a considerable disjuncture between management rhetoric and practice. While managers stress the importance of people skills in managing their employees, they are generally charactarised as autocratic; while they emphasise the need to pay salaries to attract good staff, wages are poor. This gap is very rarely noted and even less commonly is any attempt made to explain it. The second problem is that these descriptions rarely attempt to analyse the rationale for management practice, and in particular, why firms in similar labour and product market positions adopt quite different strategies. Where explanations for management practices are mentioned, these usually refer to market factors, such as the nature of demand in the industry, or customer expectations. No attempt has been made, however, to consider the extent and direction influence of these factors; or indeed any other factors that have been used to explain management behaviour.

The next chapter of this thesis attempts to go some way to addressing this gap in the literature. It considers the influence of a range of factors used to explain labour-management practices, and uses these to draw attention to the assumptions which underlie descriptions of management practice in the hospitality industry. These issues are picked up again in Chapters 9 and 10, in considering potential explanations for industry practice in New Zealand in the 1990s. 
Chapter 1: Introduction

Chapter 2: Tourism and Hospitality Industry Development in New Zealand

Chapter 3: Employment, Work and Labour Relations in the Hospitality Industry

Chapter 4: The Framework for Analysis: Explaining Management Practice

Chapter 5: Research Approach and Methodology

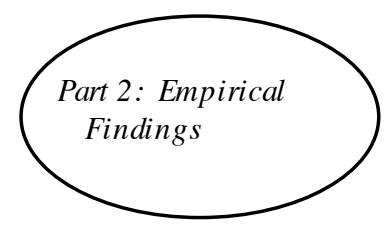

Chapter 6: Employment Relations in the Hospitality Industry

Chapter 7: Work Relations in the Hospitality Industry

Chapter 8: Labour Relations in the Hospitality Industry

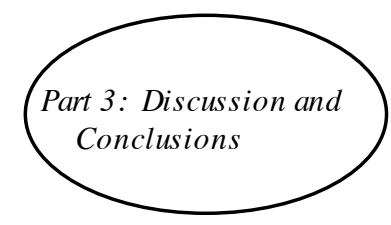

Chapter 9: Labour-Management Practice in the Hospitality Industry: Managing to Compete?

Chapter 10: Explaining Management Practice: Strategy, Environment and Social Action 


\section{Chapter 4: The Framework for Analysis: Explaining Management Practice}

\subsection{Introduction}

The management of people at work has always been a central problem and challenge for employers. It is a universal problem, but it has been tackled in different ways, at different times, in different countries. ... The management, and mismanagement, of labour has had profound consequences for ... society and national competitiveness. (Gospel, 1992:1)

An explanation of labour-management practice $^{1}$ in the hospitality industry must take account not only of existing research on the industry itself, but also explanations of management practice in other industries. This chapter examines relevant literature in the context of Gospel's contention that the subject matter of industrial relations must consider all aspects of labour-management and the key influences to which it is subject.

To briefly re-cap the framework for analysis set out in Chapter 1, Gospel's thesis suggests that in a market economy, the nature of both labour and product markets predetermine labour-management practices. In particular, employment, work and labour relations practices vary according to the extent of competition, whether the market is homogenous or fragmented into segments, and the relative size of the

\footnotetext{
${ }^{1}$ The term "practice" is used here very deliberately. The thrust of the chapter (and the rest of the thesis) is that both objective material conditions, and subjective interpretations of social and cultural norms, are important influences on managerial behaviour. As Clegg (1994:34) notes, the term "practice" transcends the traditional division between objectivism and subjectivity, and seeks to integrate both in its framework. Both this chapter and Chapter 10 emphasise the importance of
} 
market. However, market forces are mediated through other aspects of the firm, including:

- its structure, and in particular its size and ownership;

- the nature of the hierarchy within the firm, particularly the degree of integration or segmentation within the hierarchy, and the competence of managers to manage;

- production processes, involving not just production technology but also the way in which the work process is organised.

While these contentions suggest a largely contingent approach to employer decisionmaking, Gospel also argues the availability of choices for employers and managers in respect of their decisions about employment, work and labour relations. However, he displays an ambivalence about the extent of choice available, noting that "... markets do not determine behaviour, but are a powerful constraint on choices" (Gospel, 1993:7) (emphasis mine). While he also admits to a role for non-market factors, including historical, cultural and political contexts, the influence of these factors is not considered in any detail. Coming from an institutional perspective, he argues that choices are not limitless and are by and large explained through the influence of markets, as mediated through firm structures, managerial hierarchies and the division of labour.

this in exploring patterns of labour, employment and work which arise out of managerial decisionmaking. 
It is in this area that Gospel's analysis suffers the weakness displayed by many other institutional and economic theories of firm behaviour. In particular, it reifies the effect of economic factors and neglects to examine fully the ways in which managers themselves (either individually or collectively) act autonomously to constrain the operation of market forces or alternatively make choices in response to non-market factors. As Child (1972:16) notes, the very notion of choice implies “... the operation of an essentially political process in which constraints and opportunities are functions of the power exercised by decision-makers in the light of ideological values". This chapter considers a variety of explanations for labourmanagement practices. It begins by looking at those which suggest that economic factors have a commanding influence. These suggest that market considerations and productive capacity are decisive in determining firm structure and size, which in turn affect patterns of employment labour and work relations. Labour market imbalances have also been found to influence management practices. However, the fact that organisations operating in similar product and labour markets demonstrate differences points to the necessity of considering managers as social agents, influenced by non-market factors. Managers adopt different practices because they have choices, and these choices are influenced by socially and culturally determined ideologies which serve to legitimate them. The relative influence of economic circumstances and social values on management practice has been the subject of debate for many years. ${ }^{2}$ These competing explanations are

\footnotetext{
${ }^{2}$ It must be noted that few commentators resort solely to either economic or non-economic factors in providing explanations of firm behaviour. However, while most will admit a role for both, it is common to place emphasis on one or the other, and in general non-market factors are seen as being subordinate to the economic. For example, in what is still the most comprehensive theoretical attempt to explain industrial relations systems, Dunlop (1958/1993:109) comments that
} 
discussed in the second part of this chapter. Section 4.3, argues that both material and subjective explanations must be seen as important and interrelated and explores Giddens' concept of structuration as a means of resolving the perceived conflict between the two. Finally, the chapter ends by suggesting that the explanations which have been used (or assumed) in specifically considering hospitality industry practice have been limited in their focus to economic, rather than social explanations.

\subsection{Economic determinants of labour-management practices}

Economic perspectives on a range of labour-management practices have a long history arising from institutional and economic theories of firm behaviour. These have resorted to explaining the growth of large scale firms as a distinctive organisational form associated with the development of twentieth century capitalism. While space precludes a systematic review of these theories, the general argument is that the growth of mass markets and mass production was closely associated with the development of large scale firms. This occurred through processes of vertical and horizontal integration, requiring increasing specialisation and integration of the management function, and gave rise to the modern corporation with a different form and structure than the small familyowned firms which predominated at the turn of the century (Chandler, 1962; Williamson, 1975).

"It is well understood that economic development changes the technical and market context but it brings just as pronounced changes in the status of the actors. Economic development changes the rules of the industrial workplace through recasting all three features of the context of an industrial relations system." 
Industrialisation and the development of capitalism drew attention to implications of these processes for the management of employment, labour and work. Early views of the operation of labour markets assumed perfect competition, where the price of labour with identical skills and perfect information was determined by supply and demand. ${ }^{3}$ In the early industrial period, management decisions on employment matters were based on the efficacy of these assumptions. In early British factories, for example, employment decisions were the responsibility of sub-contractors who took on or laid off workers as demand varied (Gospel, 1992). As firms grew in size, however, changes in practices to recruit and retain labour developed. These included the establishment of bureaucratic rules for employee selection and promotion within the organisation. An increase in firm size was thus associated with a move towards administrative rules, rather than market mechanisms, as a means of making employment-related decisions (Williamson, 1975; Chandler and Daems, 1980).

The nature of work processes has also been argued to have changed with the development of modern capitalism. Because, by paying wages, the capitalist buys

\footnotetext{
${ }^{3}$ Over time the classical view of labour market operation was challenged by the development of institutional economics based on the assumption that labour markets did not operate under perfect conditions. In this alternative view of the world, economic theory needed to take account of the reality that product and labour markets were imperfect and that firms had some degree of power which they used to exploit both consumers and workers who were economically insecure as a result of their inequality in bargaining power. Accordingly, labour market institutions were required which would level the playing field through the operation of the "common rule" - a floor of labour standards under which no employer could fall (Kaufman, 1993).
} 
only the potential for workers to transform their labour into productive activity, ${ }^{4}$ in order to maximise profits capitalists must control work effort to ensure that labour performs to its maximum potential. While direct control by an entrepreneur was sufficient while the workplace was of a size that the employer had personal power and authority over members of the workforce, large-scale organisation required more sophisticated systems and resulted in the beginnings of alternative hierarchical and structural forms of control. Structural control could be either technical (determined by machine pacing or the way in which machinery is designed and work flow planned), or bureaucratic, where impersonal rules are established as an integral part of socio-organisational structure to routinise management procedures and functions, and institutionalise the exercise of hierarchical power within the firm (Edwards, 1979). The most significant shift towards structural forms of control came with the development of Scientific Management (see Taylor, 1947). Whereas previously employers had maintained control of work by purchasing agreed labour outputs in terms of quantity (for example through the "putting out" system in which piece rates were paid or by subcontracting agreed outputs within the factory system), Scientific Management focused instead on close control of job design and increasing specialisation in the division of labour. The managerial specification of the work to be done and the manner of its execution had two consequences for the labour process. Firstly, as jobs became more specialised, control over the labour process was transferred from craftspeople to managers resulting in a tendency towards de-skilling

\footnotetext{
${ }^{4}$ This idea is based on Marx's argument that a distinctive feature of the labour process in capitalist societies was the way in which labour power was transformed into surplus value, thus increasing the potential for capital accumulation.
} 
(Braverman, 1974). Secondly, the increasing importance of this new class of managerial workers, together with a growth in the size and complexity of organisations, resulted in new managerial hierarchies, in which occupations were designed not around productive processes but the flow of paper:

The concept of control adopted by modern management requires that every activity in production have its several parallel activities in the management centre: each must be devised, precalculated, tested, laid out, assigned and ordered, checked and inspected, and recorded throughout its duration and on completion. The result is that the process of production is replicated in paper form before, as, and after it takes place in physical form. ... The novelty of this development during the past century lies not in the separate existence of hand and brain, conception and execution, but the rigor with which they are divided from one another, and then increasingly subdivided, so that conception is concentrated, insofar as possible, in ever more limited groups within management or closely associated with it. (Braverman, 1974:125)

Industrialisation also resulted in the establishment of a new form of relationship between master and servant. Initially, and in accordance with the individualist philosophy prevalent at the time, the terms of this relationship were determined by the external market. This meant that workers were paid according to their output, had little security of employment and were responsible for their own training. In the early twentieth century, however, the emergence of trade unions established a collective basis to the employment relationship. Within those countries that industrialised at an early stage, employers began to negotiate with trade unions on behalf of their employees. While it is sometimes assumed that employer participation in collective bargaining occurred as a response to the emergence of trade unions, evidence from the UK suggests that employers and employer associations played an important role in establishing collective bargaining as a 
means of regulating wage competition in some industries (Flanders, 1970; Clegg, 1979).

In summary, therefore, discussions of early labour-management practices have been grounded in suggestions that they evolved in response to changes in the structure and nature of the firm, which was in turn an adaptation to the prevailing labour and product market environment. The influence of these explanations has continued, particularly so with discussions of employment and work relations. More recently, industrial relations theories have also suggested a closer relationship between firm size and market competition than previously. These arguments are discussed below. 


\subsubsection{Managing employment and work relations: theories of labour market}

segmentation

The early 1970s saw increased awareness, particularly in the United States, of continuing labour market inequalities. While some firms had developed comprehensive bureaucratic mechanisms for guiding their employment decisions, these firms tended to be those operating in the prosperous core of industrial production, and employing white and male workers. Black, immigrant and female employees were more likely to be employed in smaller firms, with little access to training or promotion, fewer material rewards and little employment security. Job tenure was short and workers tended to move from firm to firm in response to the dictates of the external market. In contrast, studies of the US manufacturing sector found that some firms developed an internal labour market from which they recruited senior employees in preference to competing on the external labour market (Doeringer and Piore, 1971; Reich et al, 1973; Piore, 1973). The idea that labour markets were "segmented" suggested not only that there were internal and external markets; but also that the benefits attached to a particular job varied according to where in the labour market it was located. While the concepts of segmented labour markets and internal labour markets developed separately from each other, they shared the idea that wages and conditions, security of tenure, and career prospects were better in some jobs than in others, and that not all workers had access to "good" jobs.

Theoretical developments suggested that historical processes divided the labour market into different segments distinguished by different labour market 
characteristics and rules (Reich et al, 1973). The primary labour market was characterised as comprising stable workers with good wages and conditions of work, security of employment, and the potential for advancement through promotion. The secondary labour market, conversely, was argued to be made up of workers employed in jobs with poor wages and conditions and who moved frequently and randomly between jobs. Apart from these general differences, several factors were isolated as being critical to the distinction between primary and secondary labour markets. One of these was the question of stability. Workers in the primary labour market, it was argued, were expected to develop stable work habits in contrast to a tolerance of lateness or absenteeism in the secondary sector (Edwards, 1973). Turnover and job tenure in the primary labour market were said to constitute a mobility chain by which workers could progress into higher paying and higher status jobs. Conversely, workers in the secondary labour market were said to switch jobs frequently to achieve variety but without achieving any improvement of conditions or status. Thirdly, the nature of managerial control in the two segments was very different. Organisations offering jobs in the primary labour market developed bureaucratic systems of control which ensured equity and due process for their employees, while in the secondary market, employees were subject to highly personalised management control, in which dismissal was the most common disciplinary tool (Edwards, 1973).

The notion of internal labour markets has many similarities to the idea of primary and secondary labour markets. In place of recruitment from the external labour market, it is suggested that under certain conditions, organisations will develop 
administrative rules (set out in management manuals and traditionally through collective bargaining) for determining decisions about recruitment, promotion and layoff within the firm (Doeringer and Piore, 1971). The development of these rules is closely associated with mechanisms for training workers and providing them with a career structure within the firm. In contrast, in firms without a developed internal labour market, employment decisions are made according to criteria based on economic efficiency and in relation to the external labour market. While research was conducted predominantly in the manufacturing sector and led to the concept of enterprise based internal markets, the original formulation also envisaged internal labour markets that operated on an industry or occupational basis (Doeringer and Piore, 1971).

The concepts of segmented and internal labour markets have developed over time, in part in response to criticisms that a dichotomy of "good" and "bad" jobs oversimplifies labour market operation. The positive characterisation of internal labour market jobs, for example, was challenged in the face of empirical evidence from the manufacturing sector that a majority of workers had limited career prospects and earnings potential. In the face of these critiques, the model has undergone refinement. The need to distinguish between an upper and lower tier in the primary labour market, on the basis of different patterns of mobility and turnover between operator and managerial positions in the manufacturing sector has been noted (Piore, 1973). Similarly, Loveridge and Mok (1979) have argued that both primary and secondary labour markets must be seen as bifurcated, on the basis of skill, earnings, and span of discretion (see Figure 4.1). They suggest that 
labour markets may be differentiated vertically on the basis of the jobs that people do, and the rewards and mobility patterns associated with those jobs and horizontally on the basis of their skills and place in the organisational or industry hierarchy.

\section{Figure 4.1: Features of a segmented labour market}

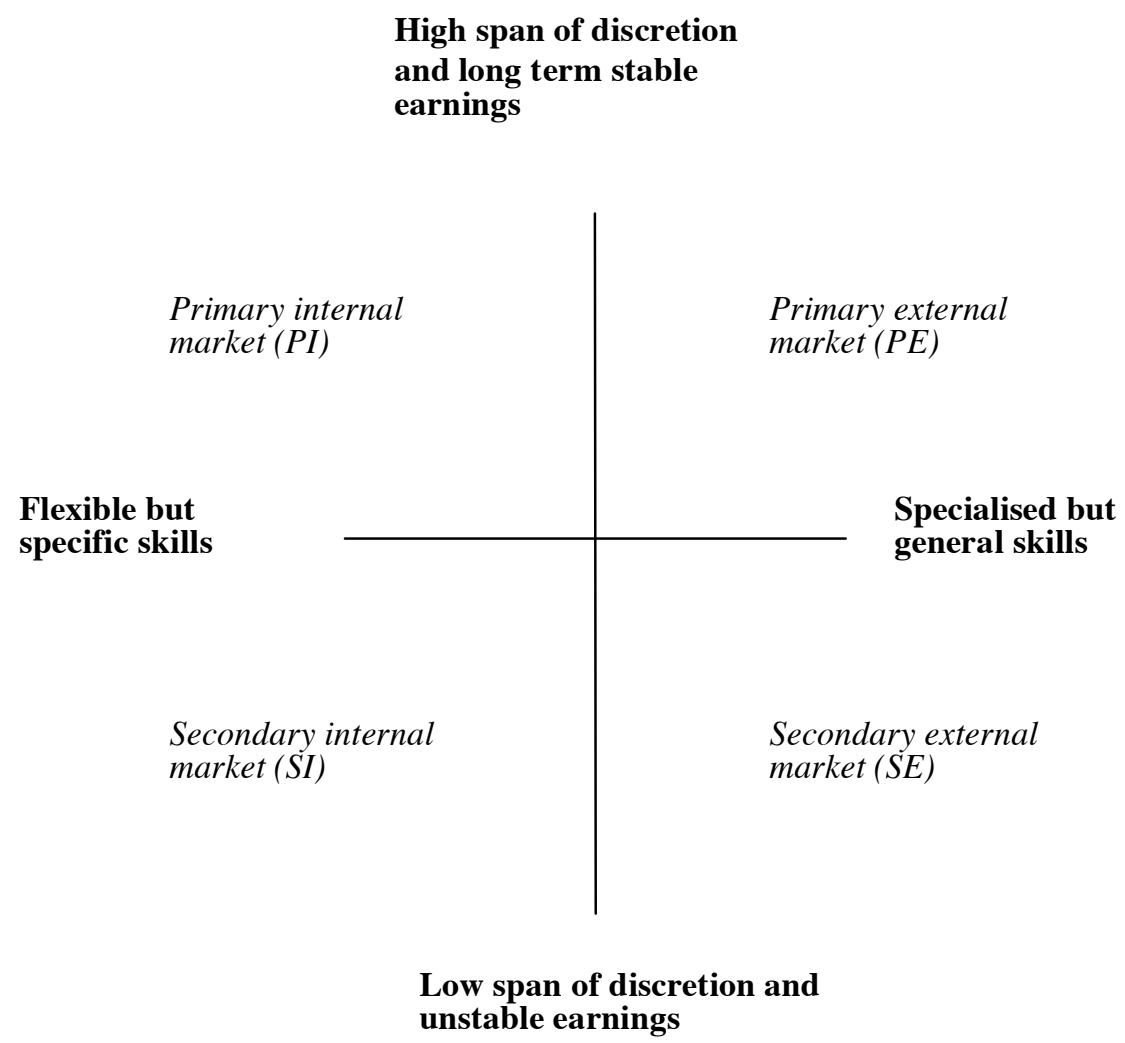

Source: Loveridge 1983

Within each segment of the model, different patterns, rules and customs exist in respect of the employment relationship. In the primary internal market (PI), jobs fit the classical internal labour market stereotype. They are wellpaid, require a high level of skill, and have good internal promotion prospects. Work in these positions is characterised by a high degree of autonomy and responsibility and isoften managed according to a set of administrative rules governing recruitment, 
promotion, and day-to-day operation. The primary external market (PE) differs from the primary internal market largely in terms of mobility. Jobs in this segment often have a craft or professional standing, with a relatively high degree of autonomy and reasonable material rewards. Career structures within the organisation are, however, limited, so workers must seek skill increases and promotion on the external market.

The secondary market contains jobs at a lower level of skill, and at a lower level in organisational hierarchies. Although within the secondary internal market (SI) there is a degree of on the job training and the potential for internal promotion, skills are often manual and easily acquired. Employees often have little responsibility and autonomy, relatively low material rewards, and poor wages and working conditions. Jobs in the secondary external market (SE) are the complete opposite of those in the primary internal market. Employment fits the neoclassical view of labour market operation, in that it is based on market demand, with little security of tenure, and poor wages and working conditions. The jobs in which workers are employed have a low level of skill specificity, require little onthe-job training, and allow little autonomy or responsibility.

As noted earlier, differences in the nature of managerial control strategies are seen as critical in the distinction between primary and secondary labour markets. Edwards (1979) points to the persistence of "simple control" techniques in small businesses and in the peripheral economy, and suggests that variations in control systems underpin segmentation of the labour force on the basis of sex and race. 
His analysis extends beyond identification of largely mutually exclusive labour market segments in which pay and conditions vary markedly from each other, to suggest that the control systems utilized by an organisation firmly establish it in a particular segment of the labour market. Firms choose the control mechanisms which they put in place, and their choices will be dependent on the relative profitability of alternative strategies. While education and skills affect the sort of work that individuals seek "...it is the system of control that creates the context within which experience, training, schooling, skills, and other attributes assume their importance" (Edwards, 1979:179). Thus, where there has been no need for a firm to make use of anything other than direct control, the result is that most of the jobs provided by the firm are in the secondary labour market. Technical control is a compromise response to worker resistance, through the establishment of an internal labour market which shares some of the characteristics of primary labour market employment; but leaves intact a hierarchical management structure. Bureaucratic control is instituted and leads to independent primary labour market jobs in those situations where employer profitability requires a relatively high level of skill, education or experience. Thus, these factors become screening devices for employers, who are able to promise job security and a career structure for those who adhere to organisational rules. While the establishment of alternative methods of structured control come about as a result a managerial choices, these choices are made partly as an accommodation to the needs of workers which may have been expressed through a variety of forms of resistance. 
As noted earlier, explanations of the historical shift from external to internal labour markets rely upon the suggestion that managerial hierarchies and administrative mechanisms became a more efficient means of regulating employment (Williamson, 1975). The question remains, however, as to why internal labour markets have not evolved in all areas and why firms adopt different labour market arrangements. Osterman (1987) argues that this variability results from responses to external economic circumstances. Changes from time to time (such as the development of new technology, or a change in labour supply patterns) may create problems with existing labour market arrangements and force management to adopt alternative employment systems. In making these choices, firms will aim for maximum cost effectiveness, flexibility and predictability. However, there are often trade-offs in meeting these goals:

A firm which seeks to maximise flexible staffing levels and deployment may reasonably seek to rely on the external market for its labour supply. ... When the external market functions well, skilled workers can be obtained without sacrificing flexibility. The external market does not always work well, however, and hence this strategy comes at some sacrifice of predictability. Under many circumstances, skill shortages may develop; so, too, may sharp and unforeseen wage movements. A firm which is committed to maximising predictability will prefer to develop internal job ladders and on-the-job training systems. ... In this way, labour supply is under the firm's control. The cost is limited flexibility. (Osterman, 1987: 58-59)

Osterman goes on to note that four main sources of constraint exist when managers are considering changes to their employment practices. The first arises out of the physical technology and in particular the degree of skill required to operate the technology, the risks and costs of employee error, and the relationship of technology to work organisation. For example, while some technology may be simple to operate (e.g., pressing a button which launches a nuclear reaction), and 
jobs might be easily filled from the external labour market the risks associated with its operation, including the consequences of employee error, might result in the position being designated as a key position within the organisation. The "social technology" of the firm also acts as a constraint on management. Tasks which are central to the firm's operation (such as customer service roles in service organisations) are more likely to be performed by employees who have more regularised employment arrangements. A third set of constraints arises from aspects of labour supply. Secondary labour market jobs do not offer job security, adequate wages, or the chances of advancement. If insufficient labour is available to the employer from the secondary labour market, the firm may have to respond by improving employment arrangements to attract workers. Lastly, the role of government in regulating labour markets may also constrain the ability of employers to adopt certain labour market arrangements. Minimum wage laws and protection against arbitrary dismissal, for example, provide a floor of employment rights which limit the operation of the secondary labour market. Conversely, regulatory requirements that firms provide training for employees, for example, promote the development of internal labour markets on a craft or industry basis.

\subsubsection{The model of the "flexible firm"}

The debate on segmented labour markets was re-stimulated with the emergence of the debate on labour market flexibility from the 1980s onwards. This centred on the question of whether firms were seeking to adopt more flexible employment practices as economic and regulatory conditions changed and product markets became more competitive. The model of the "flexible firm" put forward by the 
Institute of Manpower Studies (Atkinson and Meager, 1986) suggested that firms were seeking cost savings and increased operational flexibility by deliberately segmenting their workforce into a "core" and a "periphery". The core group (conceptually equivalent to those in the primary internal labour market) would enjoy high wages, job security and access to training in exchange for being functionally flexible, that is, being prepared to undertake a range of tasks within the organisation. In contrast, peripheral groups (including, according to the model, trainees, part-timers, temporary workers and those on short-term contracts, and subcontractors), would have little opportunity for advancement, no job security, and less beneficial wages and conditions.

While in many respects the model was no more than a restatement of longstanding and well regarded theories of labour market segmentation, it sparked a heated debate that has lasted now for close to a decade (see for example Pollert 1987, 1988a, 1988b, 1991; McInnes, 1988; Hunter et al, 1993; Nolan and Walsh, 1995; Legge, 1995). Criticisms have centered on whether employers could be said to have followed a deliberate strategy for segmentation and flexibility, the extent of empirical support for the model, and its internal contradictions. In particular, although some evidence of a change in employer practice has been found, the extent to which this represents a deliberate strategy must be questioned. ${ }^{5}$

\footnotetext{
${ }^{5}$ The literature contains substantial debate about the concept of strategy which will not be reviewed here. Key points in this debate include the definition of the notion of strategy, and in particular whether strategy should be conceived as deliberate or emergent; the levels at which strategy is formulated and the linkages between business strategy and industrial relations strategy. For discussion see Chandler, 1962; Mintzberg, 1978; Thurley and Wood, 1983; Kochan, McKersie and Cappelli, 1984; Deery and Purcell, 1989; Legge, 1995.
} 
Similarly, a considerable amount of data analysis has uncovered only partial support for the contention that employment practices have changed significantly over the course of the 1980s (Millward et al, 1986; Dey, 1989; Hakim, 1990; Legge, 1995; Nolan and Walsh, 1995). While growth in numbers of part-time and self-employed workers in the UK has occurred, use of other types of non-standard work has not increased significantly. In addition, analysis suggests that change has not resulted from wholesale change in employment practices in response to external economic circumstances, but as a result of both structural change away from manufacturing and towards the service sector, and changed management practices in the public sector.

In addition to mixed empirical support, attention has been drawn to many of the internal contradictions of a model which equates organisational flexibility with increased use of market mechanisms to determine employment arrangements, and which sees "peripheral" workers as being unskilled and unessential or marginal to organisational functioning. The considerable number of part-time workers in the service sector, for example, suggests that this "peripheral" group does in fact perform many "core" customer service tasks. Similarly, many highly skilled and well-paid tasks (e.g., accounting, computer programming) are commonly performed on a contractual basis by people outside the group of "core" employees. Case studies have also pointed to situations in which the use of socalled "flexible" employment practices has resulted in rigidities or disadvantages for the organisation (Dey, 1989; Geary, 1992; Hunter et al, 1993). For example, increased use of temporary employees may result in poorer quality in products or 
service delivery and may require a greater amount of management supervision. Conversely, while the employment of permanent employees may be construed as resulting in rigidities, such employees may have more loyalty and a longer term commitment to the organisation and engage in behaviour which contributes to organisational flexibility.

In summary, much research has suggested the external economic environment as a key determinant of the way in which firms elect to construct their employment and work relations. Firms may choose to internalise or externalise aspects of these, but those choices will be determined by economic conditions. In addition, changes in employment arrangements are made within environmental constraints and will inevitably result in trade-offs. The labour market changes that have occurred over the past two decades (including increased segmentation of the labour force, an increase in secondary labour market jobs and a greater reliance on the external labour market in the determination of employment practices) can be more readily explained with reference to structural change in the economy than a reversal of employer practices of the past. In addition, there is some evidence that employers may have continued employment practices of the past because of undesirable consequences of increased flexibility.

\subsubsection{Markets and labour relations}

As noted above, early economic theories drew attention to the development of trade unions and collective bargaining as a consequence of the development of twentieth century capitalism. Although theories of labour relations have 
traditionally paid greater attention to the role of power and ideology than have explanations of employment structure, the influence of market factors (and in particular the effect of increased product market competition) has been particularly influential in explaining changes in labour relations since the 1970s. The discussion below considers the way in which economic change, and firm responses to these have been suggested to contribute to changed employer approaches to collective bargaining and the management of employees within the firm.

A decline in collective bargaining has been experienced in most Western countries from the 1970s (Katz, 1993). Explanations for this frequently refer either directly to increased product market competition being experienced by firms as a result of both economic and regulatory changes, or indirectly to changes in firm structure which have been adopted as firms seek to respond to these changes. Kochan and Capelli (1984), for example, suggest for the US that a more competitive product market environment has reduced the benefits of the stability offered to employers by collective bargaining, while Purcell and Sisson (1983) argue that consequent changes in the size, ownership and control of firms in response to product market change has forced changes in the structure and nature of industrial relations in Britain. Over the course of the 1980s and 90s, research has focused more specifically on the nature of the changes, including a shift from multi-employer to single-employer bargaining, a decline in collective bargaining coverage in favour of individually negotiated pay, declines in trade union recognition, a decentralisation of the management function, and the redesign of 
work rules (see for example Kinnie, 1985, 1987; Capelli, and McKersie, 1987; Batstone, 1988; Marginson et al, 1988; Ahlstrand and Purcell, 1988). In general these studies have confirmed earlier findings that industrial relations changes are a business response to increased competition, a new focus on quality and innovation in product markets, and an oversupply of labour. Organisational factors such as size and structural form, as well as industry sector and extent of product diversification have been found to have a significant effect on the extent of collective bargaining, the existence of industrial relations policies and whether trade unions are recognised. In addition, re-organisation of company structures, in particular the increasing importance of multi-divisional firms arising from a spate of company mergers and takeovers, has resulted in distinctive patterns of labour relations (Ahlstrand and Purcell, 1988; Marginson et al 1988). Overall, research has suggested that changes in industrial relations practices can, to some extent be explained with reference to a small number of characteristics associated with organisational responses to external economic conditions. In summarising the considerable body of empirical research undertaken in the 1980s, Legge (1988) has concluded that the most convincing explanations of industrial relations changes are those based on the need for firms to respond to changed economic conditions, but that change had been incremental rather than revolutionary.

In addition to research on the formal aspects of labour relations, research has also suggested that changing economic circumstances have resulted in the adoption of diversified patterns of management style, and several typologies of management practice have been developed (see for example Purcell, 1987; Guest, 1990; 
Marchington and Parker, 1990; Purcell and Ahlstrand, 1993). Again the explanations for these different approaches have suggested that industrial relations practices vary according to workplace size, ownership, product market conditions, and technological and operational considerations. While many commentators have commented that the 1980s saw a shift from collectivism to individualism and a corresponding decline in trade unions and collective bargaining, Purcell and Sisson (1983) have argued that some employers adopted policies which promoted the interests of employees as individuals, while still working with trade unions. Conversely, continuing collectivism has not guaranteed protection of worker interests. This argument has formed the basis for several further typologies of management practice which make a distinction between management approaches to employees as individuals (specifically the extent to which employees are treated as a valued resource or as a commodity) and as a collective (particularly whether a cooperative or adversarial approach is adopted). This may be represented diagrammatically as seen in Figure 4.2.

The possibility that employers may adopt a variety of approaches to employees as individuals and as collectives gives rise to the likelihood of a wide range of managerial practices. At the extremes, employers may adopt an exploitative approach which is essentially anti-union and based on reducing labour costs as much as possible. Alternatively they may recognise collective interests and negotiate agreements with unions which include provisions which primarily

Figure 4.2: Management approaches to labour relations

\begin{tabular}{l|l} 
Employee as resource $_{\text {development }}^{\text {Employee }}$ & $\begin{array}{l}\text { Sophisticated human } \\
\text { relations }\end{array}$ \\
132
\end{tabular}




\section{INDIVIDUALISM}

Paternalism

Labour control

and cost

minimisation commodity
Traditional

paternalism

\section{Bargained \\ constitutional}

Modern paternalist

\section{COLLECTIVISM}

Source: Adapted from Purcell, 1987; Purcell and Ahlstrand, 1993; Storey and Sisson, 1994

(although not solely) benefit individuals (including, for example, child care provision, and skill development). In between these extremes an almost infinite variety of types is possible. A refusal or reluctance to recognise collective interests may be based either on a paternalistic approach which regards management as being in a better position to promote the interests of employees, or an ideological opposition to trade unionism. Where the collective is recognised, employers' approaches to bargaining may fit anywhere along a continuum between adversarialism and cooperation, and the content of the contracts which are negotiated may similarly range from minimalist to being comprehensive and generous in nature. 
The hypothesised emergence of changes in management style is often linked to discussions about the emergence of human resource management (HRM). ${ }^{6}$ This has been said to represent a new attempt to align labour-management practices with business strategies, in which employees are recognised as "assets" and "strategic resources" whose talents can be utilised by the organisation for competitive advantage. Despite the suggestion that a "hard" calculative approach may be distinguished form a "soft" employee development model (Guest, 1987), the defining characteristics of HRM are said to involve recognition of the importance of employee involvement in the firm and the development of mechanisms to achieve this, better communication between management and employees, and increased emphasis on training and development, all with the aim of ensuring greater employee commitment and improved levels of productivity within the firm. Debate on HRM had been extensive, with arguments centred around whether it involves a distinctively different approach to labourmanagement, and the extent of change. Despite suggestions that it involves a rejection of the traditional model of labour-management (and in particular a move away from a collective to an individual approach to the employment relationship), the extent to which practices associated with HRM have been adopted across the economy has been found to be limited and are more commonly found in union than in non-union firms (Ichniowski et al, 1989; Guest, 1990; Sisson, 1993). The suggestion that adoption of HRM practices can improve organisational performance has also been questioned. Both the nature of the competitive process

\footnotetext{
${ }^{6}$ For the most comprehensive reviews of the debate on HRM, see Storey and Sisson, 1993; Legge, 1995.
} 
and the huge array of factors which have been found to create competitive advantage have led one commentator to note that "...the assumption that HRM can be easily linked to competitive performance is misplaced" (Whipp, 1992:52).

While labour relations research in the 1980s drew attention to the way in which practice appeared to change in response to economic pressures, Marchington (1990) quite correctly points out that it has not provided an adequate theorisation of the linkages between product market considerations and labour-management. He and Parker (1990) have provided the most substantive attempt to construct a model of employee relations management based on an analysis of competitive pressures (or degree of monopoly) and customer pressure (or degree of monopsony). Key aspects of competitive pressure include the number of competitors in relation to existing demand, barriers to market entry of new competitors, and whether demand is growing or declining. In situations where competitive pressures are intense, managers may feel that the market constrains the extent of choice available to them, in terms of influencing the direction of the market and adopting appropriate responses to market pressures. Customer pressure may also influence the environment in which the organisation operates. If demand fluctuates or is unpredictable, this exerts more pressure on management, as does the number of customers in the markets and the ease with which they can switch their business from one transaction to the next. Of particular importance is the acknowledgment that employees perceive the effects of the customer demand not only through management pronouncements but also directly through contact with customers, media influences and the flow of work. The direction of influence 
of market pressures on employees and management is reflected diagrammatically below:

Figure 4.3: Management, employee relations and market power

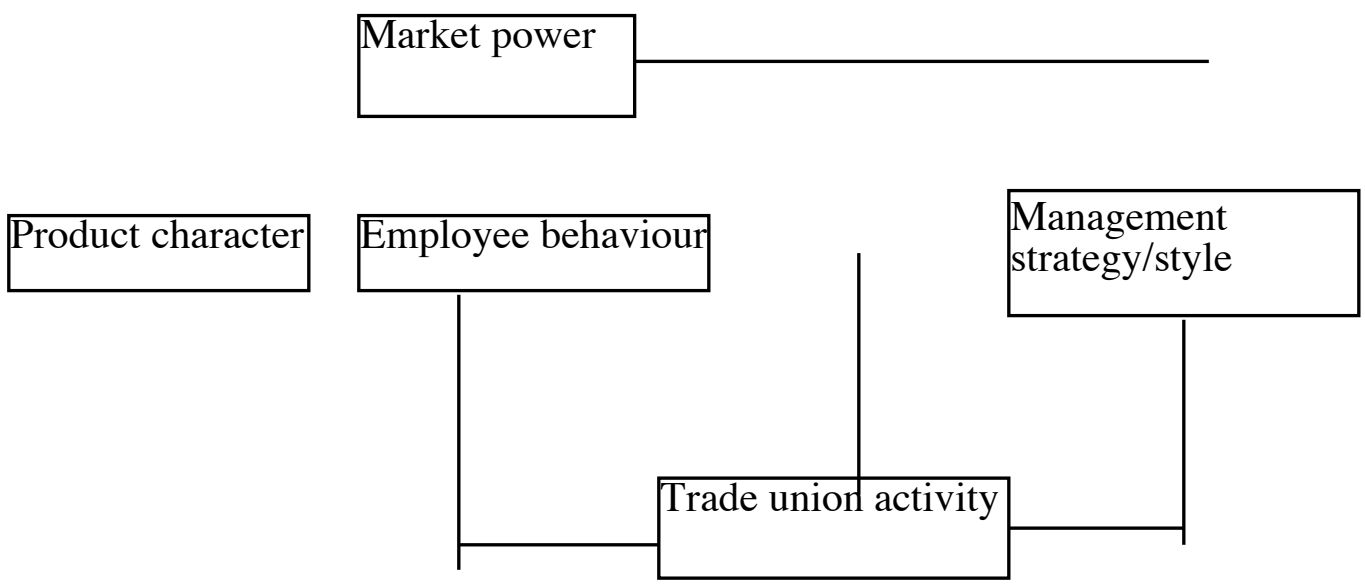

Source: Mar hington and Parker, 1990
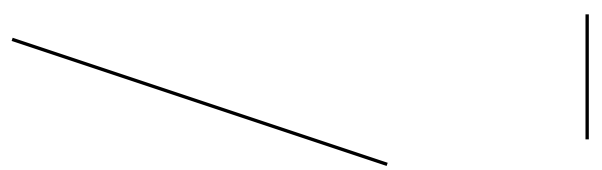

Marchington and Parker suggest that the more intense the degree of pressure experienced from customers and competitors, the less choice managers have in labour-management practices, and the more control managers feel that the market has over their actions. Conversely, where market pressure (particularly customer pressure) is low (for example, where demand is stable, regular and predictable, or where customers have few choices for available supply) managers have more room for manoeuvre in their approach to labour-management. The model put forward by Marchington and Parker represents a considerable advance on previous work, but still suggests the exercise of a significant degree of influence by the market. Although they accept that even when faced with the possibility of 
choice managers may continue to "blame" market forces to legitimise decisions which it wishes to make anyway, it does not suggest why they would wish to do so. Similarly it provides no convincing explanation as to why other managers in the same situation adopt a consultative and high-involvement approach. In addition, they suggest that in situations where pressures are intense managers " ... see little option but to adopt a more aggressive employee relations approach" (Marchington, 1990:129). This is based on the untested assumption that a more aggressive response places the firm in a more competitive position, and fails to examine the efficacy of these perceived linkages.

In summarising considerable body of research on management systems and structures during the 1980s, Sisson and Marginson (1995) have argued that despite variety in industrial relations practices among firms, many variations can be explained with reference to size, ownership and business strategies, and that industrial relations strategies “... are increasingly business-led" (Sisson and Marginson, 1995:107). Nevertheless, other findings suggest that such conclusions provide only a partial explanation. Firstly, in noting general patterns of labour relations, exceptions are commonly noted. Industrial relations researchers are generally reluctant to offer completely deterministic explanations of labour relations patterns and commonly note that economic variables constrain or shape, but do not determine practice (see for example Purcell, 1987; Batstone, 1988; Kinnie, 1989; Marchington and Parker, 1990; Sisson and Marginson, 1995) In addition, some studies have noted differences in labour-management practices between firms despite operating in similar product market environments. 
Marchington and Harrison's (1991) study of three food retailing stores, for example, found that the labour relations strategies adopted by each of the firms varied, despite similarities in work and employment relations. Nevertheless, alternative influences on the determinants of choice within the constraints of market forces are seldom explored. Secondly, it must be noted that research questions and methodology may have a significant effect on findings. A number of studies that have been conducted on labour relations practices in the 1980s and 90s have aimed to explore the relationship between such practices and economic variables, using survey questionnaires and structured interviews. It is thus not surprising that a relationship of some kind should be recognised, but its relative importance in comparison to other non-economic variables has rarely been examined through intensive case study research. The view that labourmanagement practices must also be seen as being influenced through the operation of managerial agency and social action is considered in the following section.

\subsection{The manager as agent: social relations and the construction of} meaning

Non-economic explanations of management practice arise from organisational theories built around the importance of social and cultural values and beliefs in determining behaviour. These theories vary in the extent to which they see action as determined by social norms and ideologies which influence behaviour at a general level, as opposed to more interpretive approaches which argue the 
importance of individual action arising out of interaction with others. ${ }^{7}$ They share, however, the belief that economic and institutional explanations of management practice are too simplistic. Hyman notes that such explanations fail to locate economic factors in their structural context and treat market forces as "... autonomous, immutable, irresistible" (Hyman, 1974:183). Similarly, more recent approaches within critical economics have argued that economic forces must be seen as embedded in (rather than distorted by) social institutions (Maurice et al 1986; Rubery, 1994). Nowhere is this more apparent than in comparative analyses of labour-management practices which have traced the differences between firms to the cultural beliefs of the societies in which they operate (Bendix, 1956; Wood and Kelly, 1982; Rubery, 1994). Accordingly, explanations of labourmanagement practices must also take account of social values, and in particular the ideologies which support and constrain management action, most particularly in respect of work and labour relations. In addition, the multiple social identities which managers from diverse backgrounds bring to the managerial task draw

\footnotetext{
${ }^{7}$ The approach at the most subjectivist extreme is social interactionism, which suggests that in providing explanations for behaviour, the meaning which social actors attribute to their actions must be taken into account. Its most cogent application to organisation theory may be found in the work of Silverman (1970) who argues that in analysing organisational behaviour, researchers must take account of the extent to which behaviour is determined by "social expectations" which lead social actors to act in response to their past experience and in relation to the probable reactions of others. He suggests that people are socialised into roles, and expectations that form part of those roles (such as, for example, expectations that form part of the managerial role) become internalised as "typifications". It is these typifications which provide the individual with a "...frame of reference which he (sic)can use to shape his own actions and to make sense of the acts of others " (Silverman, 1970:132). The social interactionist approach is not considered in any detail here for two reasons. The first is that no accounts of its application in the field of labour-management practices can be found. The second is that Silverman himself has suggested in more recent writings that his 1970 book was a reaction to the positivist tradition applying in organisational studies at the time, and that its approach underestimated the importance of social and cultural factors. (See Silverman, 1994).
} 
attention to the way in which the interpretation of meanings may vary from individual to individual.

\subsubsection{Values and attitudes in management actions and reactions}

The importance of values and attitudes in determining management action has been central to discussions of labour-management practice. Such interpretations assume the possibility that managers act, not simply in response to economic forces, but as reasoning and intentioned agents. ${ }^{8}$ This is seen most particularly in discussions of the concept of managerial prerogative which legitimates the exercise of managerial authority at the workplace. The emergence of industrialism as a new form of economic activity necessitated the emergence of new ideologies to support both entrepreneurial activity, and the need for these entrepreneurs to obtain labour for productive activity (Bendix, 1956). ${ }^{9}$ The right of employers to direct and control workers evolved as the law of domestic service was applied in early factories and established a distinctive relationship between employer and employee in which the employer was granted the right to act not only in respect of

\footnotetext{
${ }^{8}$ It must be noted that explanations vary in the way in which the concept of agency is conceived. Philosophically, the conception of agency rests on the assumption solely that agents act with intent. Giddens (in Cassell, 1993:96) argues however, that it must also include the notion of capability; i.e., that the individual could have taken an alternative course of action. Giddens' explanation for why individuals select one course of action over another is discussed later in this chapter.

${ }^{9}$ It should be noted that Bendix' discussions of managerial prerogative is not altogether clear as to whether he sees the use of managerial prerogative as an act of agency or an inexorable consequence of the emergence of industrialism. While on the one hand he suggests the importance of a materialist analysis; his main conclusion (that ideological appeals in support of managerial prerogative varied in the US and England in comparison to Soviet Russia and Eastern Germany) points to the centrality of cultural values in shaping alternative forms of practice.
} 
their capital investment but was also accorded authority over those whose labour was employed.

The exercise of managerial prerogative rests on three distinct justifications (Storey, 1983). Firstly, owners are authorised to act to protect their property rights. Given that capital investments commonly require labour input in order to make them productive, the doctrine of managerial prerogative allows employers to direct employee action in respect of their labour in relation to plant and equipment. A second justification rests on a broader notion of ownership and allows employers to decide the future of their investment. Lastly, the authority of managers over employees is legitimised with reference to notions of economic efficiency - the suggestion that managers and owners possess expertise or superior ability, either inherent or as a product of training or education. As with all ideologies, the importance of these justifications lies in the way in which they are part of the fabric of the workplace, and have a taken for granted nature which is not subject to challenge. The notion of managerial prerogative has in fact become the "ideological lens" (Fox, 1974) through which the employment relationship is viewed. Reproduction of this ideology occurs through the establishment of "hegemonic regimes" (Burawoy, 1979) based on persuasion, in place of more coercive forms of control. As a result, it is recognised not only by employers and managers but also workers. Socialisation through families, schools and the media is essential in ensuring that workers accept as legitimate cultural norms centred around a work ethic, respect for private property, the desirability of a private sector motivated by profit as necessary for economic growth, the inevitability of 
hierarchy and the rights of management to direct workers (Burawoy, 1979; Littler and Salaman, 1982; Brown, 1992). For managers themselves, assumptions about a “manager's right to manage" are not only embedded within management textbooks and periodicals but are also part of the pattern of responses "learned" from senior colleagues (Fox, 1966a). The unconscious adoption of behaviour which reflects the ideology of managerial prerogative thus become an important part of the construction of what a manager "is" and form such an important part of selection, socialisation, appraisal and promotion as a manager.

The importance of managerial control strategies has been emphasised by a number of writers in the labour process tradition. The publication of Braverman's seminal Labour and Monopoly Capital in 1974 and the ensuing development of labour process theory drew attention to the methods used by managers to direct work relations (Littler and Salaman, 1982; Thompson, 1989; Brown, 1992). ${ }^{10}$ According to Braverman, management's need to control labour in the more elaborate production processes associated with the development of twentieth century capitalism required a new approach to management which was best

\footnotetext{
${ }^{10}$ Again, the extent to which labour process theory adopts a materialist as opposed to an agency perspective has been the subject of considerable debate. Braverman himself has been criticised for his neglect of agency (see for example Littler, 1987; Thompson, 1989; Willmott, 1994). However, later commentators in the labour process tradition have drawn attention to the variety of ways in which individuals define themselves in terms of group membership, and the implications that this has for the workplace (see for example Jermier, Knights and Nord, 1994). Such analyses have pointed out for example, that such factors as (inter alia) gender, ethnic group membership, occupation and sexual orientation may play a complex and contradictory part in constituting the identity of the subject as a "worker" or a "manager". While those case studies contained in Jermier at al's collection focus mainly on the ways in which subjective identities affect strategies of resistance, a logical extension of these studies is to hypothesise that such identities would equally influence not only the ways in which workers consent (or accommodate) to their subjugation, but also the way in which control strategies are implemented by managers with a variety of subjective identities.
} 
achieved through the adoption of principles of Scientific Management. ${ }^{11}$ The deskilling and degradation of work which allowed greater control of workers involved replacement of skilled workers by machines, fragmentation of jobs to enhance standardisation and replaceability, and the allocation of any remaining tasks involving skill to a small number of specialist and managerial workers (Brighton Labour Process Group, 1977). Other writers who have affirmed the importance of managerial control have challenged the idea that Scientific Management was the only strategy adopted by management (Friedman, 1977a, 1977b; Edwards, 1979; Burawoy, 1979; Thompson, 1989; Brown, 1992). Friedman (1977a, 1977b) for example, has suggested that as an alternative to direct control of work activities, management may adopt a strategy of "responsible autonomy" in which workers are provided with considerable job autonomy and relationships between managers and workers are constituted on the basis of "high-trust". The adoption of such strategies does not, however, imply a lack of concern with the operation of managerial prerogative. Rather, managers adopt such strategies either because they give them greater control over the labour process as a whole or because they are forced to as a result of worker resistance.

While the concept of managerial prerogative is integral to the application of Scientific Management, it is also the foundation of other approaches to

\footnotetext{
${ }^{11}$ This idea has, however, been a source of considerable contention. One strand of the debate has been the conflicting evidence on the extent to which Taylorism was adopted through the Western world (Burawoy, 1979; Thompson, 1989). This is, however, less relevant to the current research than two other streams of writing over the years centred on alternative management control strategies and the extent to which employees participate in their own subjugation in the labour process.
} 
management. For example, while the Human Relations school of thought which developed in opposition to Scientific Management recognised the complexity of organisational social structures, it was still based on the view that the organisation should be organised around a single source of authority (Fox, 1966a). The key distinction between the two approaches is not the extent to which employees should be subject to managerial authority, but the way in which this authority can be achieved. While Scientific Management believed that authority should be imposed on workers, the Human Relations School viewed it as a relationship which had to be developed and accepted by the subordinate.

The ideology of managerial prerogative also acts as a powerful force behind management action in the labour relations area, where it has commonly been used to limit the scope of collective bargaining. While employers have (sometimes reluctantly) conceded the negotiation of wages and conditions of work as areas in which employees have a legitimate interest, other decision making processes have been protected as matters for management determination. These include, for example, investment decisions, output, layout and staffing levels. In between these two extremes lie a range of areas over which bargaining may be allowed in some situations and prohibited in others. This demonstrates that the boundaries of managerial prerogative are in some senses contested and may change from time to time and place to place, depending on the ability of workers to infringe upon these boundaries and the ability of managers to resist encroachment. The strength of the ideology and its taken-for-granted nature, however, is underlined by the fact that although the scope of bargaining has been extended since the 1970s (Storey, 
1976/77), there are many areas which continue to be regarded as "off-limits" for bargaining purposes.

Nonetheless, the exercise of managerial prerogative has been constrained. The view of the employment relationship as simply a market transaction has been modified by state regulation of a range of employment related matters, including encouraging the development of trade unions and collective bargaining (Dunlop, 1958/93; Flanders, 1970). Over the course of the twentieth century, collective bargaining became the primary means of regulating wages and conditions of employment, particularly in the post-World War II era as the move to a new style of economic management in the Western world saw its institutionalisation both in Europe and North America. Although the specific features of different national systems varied, they shared in common the move to collective representation by unions and bargaining over the terms and conditions of employment. According to Fox (1974), the consolidation of collective bargaining represented a move away from a contractual approach to the employment relationship to one in which workers were once again accorded dignity and social identity. He states that:

Through trade unionism and collective bargaining, status is restored to this unpredictable, capricious and non human world of contract. The occupational group or category secures for itself a bundle of rights and protections, and a worker taking up membership in the group automatically becomes entitled to claim them. They are "givens" which transform his employment situation from an individually negotiated contract to an established status to which is already attached an array of rights and obligations. From this he derives security, social identity, and a sense of meaning, while from membership of the collective itself he gains fellowship and support in place of competitive individualism. (Fox, 1974:246). 
The significance of the institutionalisation of collective bargaining was thus not economic but political (Flanders, 1970; Blain and Gennard, 1970). As Flanders has noted, the process of negotiation is not a market activity, and trade unions do not sell the labour of their members. Rather it is a rule-making process which determines the conditions under which individuals work. The primacy accorded to collective bargaining as a method of job regulation reflected a particular philosophy about the nature of the employment relationship (Flanders, 1970), based on both liberal collectivist and corporatist views of the world (Legge, 1995) in which the necessity for institutional management of conflict between employers and employees was seen to be desirable; and in which the state was seen to have a legitimate interest in performing this role.

Collective bargaining developed in quite different ways in Europe and North America. In the United States, bargaining took the form of "job regulation" in which negotiations settled disputes not only about wages and conditions, but also staffing levels, seniority, and occupational demarcations. In Europe, on the other hand, bargaining a national or industry level has been more common. In the UK, for example, national multi-employer bargaining by industry was the primary means of determining wages and conditions from the 1940-60s. The nature of these agreements however, was more limited than their North American counterparts. Apart from settling wages to be paid within an industry and hours to be worked, a key feature of British collective agreements was that they were based on procedural rather than substantive rules (Flanders, 1970), setting out processes to be used in the event of a dispute arising. Such rules were used as a 
means of regulating conflict between the parties and again emphasise the political, rather than the economic nature of collective bargaining.

Where collective agreements emphasise procedural rather than substantive concerns, many aspects of job regulation are left to be determined by management itself at the workplace. Flanders (1970) draws the distinction between internal and external job regulation to consider the ways in which management has traditionally taken a key role in controlling the work behaviour of employees, through the development of substantive rules covering work rules and domestic procedures. Clegg (1979) also draws a distinction between those functions carried out by employer associations in relation to collective bargaining, and those undertaken by managers at firm level, including work study, job evaluation and job design.

More importantly, it is recognised that managers approach industrial relations with different assumptions which affect their attitudes to trade unions and collective bargaining. In the "spaces" created in the gaps between collective bargaining and the operation of managerial prerogative, worker resistance has also been important in constraining managerial action. According to Edwards (1979) increasing levels of industrial activity in the US at the turn of the century, as workers reacted to harsh and arbitrary nature of managerial control as well as low wages and long working hours, resulted in managerial experiments with welfare capitalism, scientific management and works councils. At an individual level, resistance may also take the form of "games" or informal rules aimed at reducing 
tedium, making work more tolerable or reasserting some degree of control over earnings (Burawoy, 1979). Worker resistance requires management to gain "consent" to the exercise of their authority (Burawoy, 1979). ${ }^{12}$ While managers may be required to adjust their strategies as a result, their tolerance of resistance strategies occurs not because they are unable to enforce compliance with the formal rules, but because relaxation of these rules brings with it increased control and worker integration (Thompson, 1989).

In explaining changes in labour-management practices over the last two decades the adoption of an alternative ideological framework and its consequent influence on social attitudes and values has been noted. Nowhere is this seen as much as in the change in regulatory environment surrounding collective bargaining. A move away from state support for a regulatory framework for collective bargaining has been evident in most western countries (Katz, 1993; Kochan Katz and McKersie, 1994) and has been replaced by the adoption of a liberalist and individualist approach to the employment relationship (Legge, 1995). Several studies have suggested that in developing new approaches to labour and work relations, employers and managers have been influenced by a re-formulation of the philosophy of managerial prerogative as much as they have by economic conditions. Kochan, McKersie and Capelli (1984), for example, argue that the extent and incidence of concession bargaining in the US in the 1980s can not be explained purely with reference to the external environment, and the rise of a

\footnotetext{
${ }^{12}$ Although it has been suggested that the terms "accommodation" or "compliance" are more appropriate than "consent" (Knights and Collinson, 1985; Thompson, 1989; Sturdy et al, 1992).
} 
"macho management" style in the UK has been said to reflect the desire of employers to engage in work intensification practices wherever possible (Legge, 1995).

The adoption of HRM practices has also been argued to have occurred for symbolic, rather than business reasons. Despite the rhetoric which suggests that HRM represents a more strategic approach to labour-management in order to improve competitive advantage, its adoption may simply be an ideological legitimation for new managerial practices. Whittington (1993:37) argues that "... the point about the formally rational apparatus of classical strategy-making is that it cloaks managerial power in the culturally acceptable clothing of science and objectivity". While HRM is said to be the means by which organisations achieve greater competitiveness, there is little evidence to suggest that it has done so, or that the adoption of HRM practices has radically affected labour-management practices. While $84 \%$ of corporate managers in multi-establishment firms in the UK reported the existence of corporate philosophies and styles for the management of employees, these were frequently not written down, nor communicated to employees, nor used as a guide for managerial behaviour in these firms (Purcell, 1987; Marginson et al 1988). However, the importance of HRM is not the way in which it represents a business response to new market conditions. As a modern ideological legitimation of managerial prerogative, empirical refutations of the spread or efficacy of HRM practices have been argued to be irrelevant to the debate (Keenoy and Anthony, 1992). The significance of HRM is as a "cultural construction" which "... attempts to redefine both the 
meaning of work and the way in which individual employees relate to their employers" (Keenoy and Anthony, 1992:234).

In addition to a reformulation of traditional forms of control, new ones have developed which have an important effect on work relations. Among the most important of these are the importance of quality assurance and the customer. The latter has been established as a new form of employee surveillance (Heery, 1993), through, for example, information systems which monitor customer response times, proactive surveys of customers on levels of service received, and appraisal of employees by managers who are disguised as "anonymous customers". The inclusion of the customer in the labour-management relationship has radical implications for work relations, as has the emphasis on quality (du Gay and Salaman, 1992; Heery, 1993). Ritzer $(1993,1996)$ has argued that it has led to the reorganisation of work according to the principles of "McDonalization" in which efficiency, calculability, predictability, and control are the guiding principles of job design and work organisation. The emphasis on quality and total quality management (TQM) in the 1980s involved a re-working of the notion of quality so that "conformance to specifications" rather than "excellence" became its defining feature. TQM contains contradictions in that while it has adopted the rhetoric of "worker empowerment", it has also required the implementation of work systems which ensure that processes are the same whenever they are performed. Control of work and individual workers has been an important part of this. Routinisation requires workers to perform tasks in a specified way, reminiscent of Taylorism, in which jobs are designed in such a way as to limit 
discretion in their performance. These processes are not limited to the manufacturing sector. Workers engaged in service provision, not only in retail stores and hotels, but also in hospitals and educational institutions, are increasingly being directed in the way they relate to customers/clients, appropriate standards of behaviour and dress, and so on. This has resulted in a huge growth in the number of jobs in the service sector in which work is routinised and monotonous (Wood, 1989; Legge, 1995). A key influence on the nature of these jobs is a rewriting of the notion of quality service, so that customer expectations as well as employee work are subject to organisational control. The new emphasis on customer focus is based not so much on meeting the individual needs of customers or clients, but rather establishing "contracts" between the organisation and its customers so that the customer knows what to expect. Predictability and conformity are at the heart of the control systems that are part of reorganised systems of work, and rely on workers following precise operational instructions for making a hamburger, admitting a patient in a hospital, assembling a car, or processing frozen vegetables.

The question of managerial agency has received increasing attention over recent years (see for example Pettigrew, 1985; Clegg, 1989; Whittington, 1992, 1994; Wilmott, 1994; Watson, 1994) and has drawn attention to an aspect of management which cannot be ignored. Managerial behaviour is constituted by individuals with multiple identities, only one of which is their organisational position. The category of "manager" is not homogeneous, but is made up of increasingly diverse groups of individuals with a variety of values and beliefs. As 
Whittington $(1992,1994)$ notes, this increases the possibility of agency, as individuals adopt patterns of behaviour which draw on rules embedded in a variety of sometimes conflicting social systems. For example, a woman manager may act in ways which draw as much on her experiences as a woman worker, as it does on her managerial training and experience, and this may differ in significant ways from other managers of a different age, ethnicity, gender, or social background:

... managers are not only managers, but may also be patriarchs, patriots and professionals, capable at work of drawing resources and inspiration from all their social identities. Managerial agency derives from the simultaneously enabling and contradictory nature of the structural principles by which people act. Strategic choices are not merely idiosyncratic, because informed and empowered by the prevailing social systems of their society. Choices are real, because involving both the interpretation of internal contradiction within capitalist structures and the reconciliation of the alternative 
structural principles which managerial cosmopolitanism and reflexivity make available (Whittington, 1994:72).

The way in which management action is influenced by multiple social identities however, brings us full circle in the discussion of management practice. While managers must be seen as agents, capable of acting independently of structural (particularly economic) forces, they are also clearly influenced by them. An attempt to reconcile the two has been undertaken by Giddens in his theory of structuration, discussed below.

\subsection{Bridging the gap: structuration and management practice}

The debate about structure and agency (or determinism and voluntarism) as a determinant of social life has been one of the central strands of organisational theory since the challenge to the predominant structural-functional paradigm in social theory by humanist and critical approaches from the 1960 s onwards (Burrell and Morgan, 1979; Astley and Van de Ven, 1983). Giddens' theory of structuration, developed in the 1980s, has been an explicit attempt to overcome the perceived conflict between the two, through the development of "...an ontological framework for the study of human social activities" (Giddens, 1991:201). His approach has been based on the hypothesis that the reproduction of social relations and practices is not the mechanical outcome of external forces but rather involves active subjects. The debate over structuration has been considerable and this synopsis can not hope to do more than set out those key points relevant to the subject of this thesis. Giddens rejects the idea of an opposition between structure and action, arguing that the two must be seen as 
acting in constant interplay, and that (in an oft-quoted summary of the essence of structuration) "... the structural properties of social systems are both the medium and the outcome of the practices that constitute those systems" (Giddens, 1982:36-37; 1984, in Cassells, 1993:122). In arguing this he uses the concept of a "social system", as a set of recurrent social practices, to link together the concepts of structure and agency. Giddens' rejects the traditional concept of structure as consisting of organisational frameworks, in favour of one built on patterns of interaction and social relationships. He argues that the concept of structuration depends not only on making distinctions between structure and system “... but also involves understanding each of the terms differently from the characteristic usages of both structuralism and functionalism" (Giddens, 1984, in Cassells, 1993:114). Structuration involves the conditions under which structures and systems are reproduced and changed over time, and involves a duality of structure in which rules and resources (as structural properties) are drawn upon in the production of interactions, but are also re-constituted by such interaction. System change can be explained with reference to the fact that structural properties may result in "unintended consequences" and which later become the acknowledged conditions of further action.

A number of elements of the theory of structuration are important for considering approaches to labour-management practices. These relate both to the structures within which action takes place (and in particular their enabling as well as constraining role) and the way in which patterns of managerial action are reproduced over space and time. In relation to structures, Giddens argues that 
social systems are not structures themselves, but rather exhibit structural properties. Here he refers to the "rules" by which social interaction proceeds and the resources which allow social actors to act in the way that they do. In doing so, Giddens aims to restore the concept of power to a central place in social theory. He argues that "...resources are the media whereby power is employed in the routine course of social action; but they are at the same time structural elements of social interaction" (Giddens, 1982:39). While a structuralist perspective sees social structures as constraining action, Giddens' use of the term also emphasises their enabling role. The relevance of this for management practices lies in the fact that while organisational forms and prevailing patterns of social interaction may constrain labour-management practices in various ways, other aspects provide a legitimation for management action.

In relation to action itself, one of Giddens' key contributions has been his insistence on the incorporation of a temporal and spatial dimension into the concept of agency. He argues that time and space are inherent in the constituting of social relations, and that social systems are produced and reproduced within a specific context. Social life is inherently and fundamentally recursive; and consists of routines which provide an "ontological security" for social actors. By adhering to the rules of social life, actors not only act with the conviction that they "know" what they are doing but also contribute to reconstituting the circumstances that generated them in the first place. Thus the adoption of employment practices that have been used in the past, with known consequences, contributes to the likelihood that they will continue to be used in the future. 
This is not to suggest, however, the impossibility of change in social practices. Because patterns of action must be contextualised, changes in context (either internal or external to the actor) become part of the process of action. Giddens is explicit in his conviction that social actors are knowledgeable about the social systems in which their actions are enmeshed and that conscious reasons for their behaviour are crucial in the sustainability of those actions (1982:29). While social actors may rationalise and monitor what they do, they may also be unconscious of their underlying motivation. Thus, Giddens suggests a "stratification model of action" in which three levels of consciousness influence social practices. At the level of "discursive consciousness", actors reflexively monitor their actions, and can provide explanations of their behaviour and intentions. Below this is "practical consciousness", where actors know tacitly about the conditions of their actions, but may not be able to articulate them. At this level, action is rationalised by actors "knowing" what to do, without being able to explain why except in terms of the "rules" of the social system. Finally, actions are underpinned by unconscious motivation, or "wantings which prompt action" (1982:31), and the permeability of the boundary between the conscious and the unconscious is limited. Thus, Giddens argues that while actors are knowledgeable, this knowledgability must be seen as bounded by unconscious motivations which constitute the unacknowledged conditions for action.

The importance of unacknowledged conditions means that actions may have unintended consequences about which actors may become aware. In this way, 
because of the recursive nature of social interaction and the reflexive nature of actors, agency and structure interact. An example in relation to the subject at hand may illustrate the point. In constituting their employment relationships, management may opt for the recruitment of a large number of part-time staff. At the level of discursive consciousness, the intent of this act may refer to operational reasons such as daily peaks in demand. At a practical level, the manager may rationalise that most other employers deal with the situation in the same way, but below this may lie a desire not to have to put in the effort to deal with the perceived additional demands of managing full-time staff. In employing part-time staff, however, the manager finds that those staff bring with them multiple social identities (they are students, or parents with domestic responsibilities) and that the actions of these employees are determined as much by these other identities as they are by their status as employee. This may mean, for example, that they place greater priority on activities related to these other identities than their employment. Thus the manager's actions have had the unintended consequence of providing him/her with employees who do not meet other needs of which he/she was not previously aware. By reflecting on these consequences, the manager may make an alternative choice in the future or alternatively, may choose to live with those consequences.

While Giddens' ideas have had some influence on discussion of the determinants of organisational structure (see Ransom et al, 1980; Wilmott, 1981), no attempt has been made to apply his ideas to the construction of labour-management practices. Nevertheless, the empirical evidence presented in Chapters 6-8 suggests 
that interpretive as well as materialist approaches are required to uncover the motivations for management action in the hospitality industry. These are set out in further detail in Chapter 10.

\subsection{Explanations of management practice in the hospitality industry}

Finally in this chapter, we return to the findings of the previous chapter considered in relation to the literature examined in this. Two weaknesses were revealed in the review of hospitality industry literature undertaken in Chapter 3. Firstly, the content of research suggests a preoccupation with particular themes and issues, while other areas are left unstudied. For example, food service workers are studied more frequently than accommodation workers (Lennon and Wood, 1989); hotels are studied more frequently than workplaces in other industry subsectors (with the possible exception of fast food restaurants); work is described as unskilled and casual with little analysis of how this is exhibited, and labour relations research has rarely moved outside of a concern with low wages and levels of union membership. A second problem is that much writing is prescriptive or normative. Many researchers have been content either to describe existing practice or to exhort managers to change practice in line with other industries with no critical focus on whether these practices are appropriate or not. The research that has been undertaken is rarely underpinned by a theoretical perspective and usually occurs when researchers from other disciplines (such as sociology or psychology or organisational behaviour) undertake research within the industry. In short, much mainstream hospitality industry research is 
characterised by a marked tendency towards pragmatism, description, and a lack of reflexivity. ${ }^{13}$

The consequences of these two problems are clearly seen in the literature related to labour-management within the industry. The two areas in which studies of management have been undertaken have been in relation to managerial careers, and the nature of managerial work in the industry. Management style is characterised as ad hoc and unitarist. This view, however, like many others in the industry (such as the idea that chefs hate waiters and the customers enjoy themselves more in luxury hotels), is based on a "commonsense" view (Slattery, 1983) rather than being empirically grounded. Explanations for or determinants of managerial behaviour have not been explicitly undertaken. Nevertheless, it is clear that the literature makes two underlying assumptions about the reasons for management action, and prevailing patterns of labour-management. By far the most important of these is that patterns of labour-management are a consequence of imperatives arising from the nature of customer demand in the industry. Management's requirement for maximum flexibility in labour usage in order to respond to supposedly erratic demand in a competitive environment is constantly emphasised (see for example Mars and Mitchell, 1976; Shamir, 1978; Guerrier and Lockwood, 1989a; Walsh, 1991; Riley, 1993). The desire for as few constraints on flexibility as possible is justified as creating the conditions for the

\footnotetext{
${ }^{13}$ There are some notable exceptions to this, as was noted in Chapter 3. Wood's work, for example, makes many sociological insights which are missing from other research. Riley also incorporates more in-depth analysis, and makes some useful observations on the economic environment in which hospitality industry workplaces operate. Other studies from a more critical
} 
adoption of a largely unitarist management style (MacFarlane, 1982; Aslan and Wood, 1993), to create pressures for reductions in labour costs (Mars and Mitchell, 1976, Newman, 1993), and to establish an environment in which numerical flexibility is most effective way of achieving organisational flexibility (Riley, 1993). Labour market characteristics are also invoked to explain management practice. The employment of relatively high proportions of young people, "marginal" workers and part-timers have all been used to justify a unitarist style of management as somehow appropriate. All in all, prevailing views of the hospitality industry suggest that it is “... a good example of an industrial relations system dominated by its economic system" (Riley, 1993:8).

While explanations of management practice arising out of economic and organisational factors are most common, other studies consider the influence of managerial and employee attitudes and beliefs. Managers may be more insular than those in other industries as a consequence of managerial career patterns. They stress the industry's uniqueness in relation to others (NEDO, 1969; MacFarlane, 1982) suggesting the existence of a distinctive culture or ideology of work within the industry. The way in which these attitudes are adopted by managers is an important direction for further research. One of the few studies to question managers directly suggested that managers' reluctance to allow trade union influence in the workplace was associated not so much with anti-union attitudes per se, but a perception that employees' desire to join a trade union reflected badly on them as a manager (Aslan and Wood, 1993). This suggests that 
management practices are determined not simply by influences arising from external economic forces but also the prevailing culture within the industry, and the conceptions of "good management" that are passed on to those entering a managerial career within the industry.

A number of problems with prevailing explanations of management practice in the industry may be suggested. Firstly the assumption that labour-management practices are a reflection of erratic demand is a "commonsense" view which is largely untested. The fact that despite facing similar product market environments, some firms in the industry do in fact adopt quite different practices suggests that alternatives are available. In addition, explanations for management practice need to consider the ways in which social and cultural values influence management practice, the ways in which practice is linked into wider social structures and how these are reproduced over time. A number of questions arise when these factors are taken into account. How does increasing professionalism within the hospitality industry and increased economic importance influence the way in which managers treat their employees? Given that managers move into managerial positions from within the industry, how do their prior work experiences influence their management style? How do managers perceive their management role? How do managers ensure that employees deliver the service they require? To what extent do managers reporting to corporate managers at a higher level have autonomy in their approach to labour-management? These and other questions are covered in the next section of this thesis.

(1993) examination of routinisation in service work). 
Chapter 1: Introduction

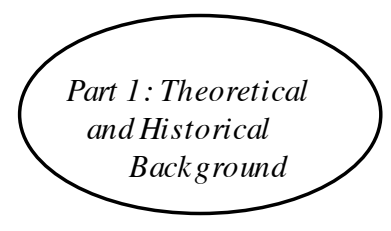

Chapter 2: Tourism and Hospitality Industry Development in New Zealand

Chapter 3: Employment, Work and Labour Relations in the Hospitality Industry

Chapter 4: The Framework for Analysis: Explaining Management Practice

Chapter 5: Research Approach and Methodology

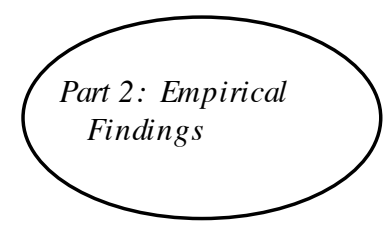

Chapter 6: Employment Relations in the Hospitality Industry

Chapter 7: Work Relations in the Hospitality Industry

Chapter 8: Labour Relations in the Hospitality Industry

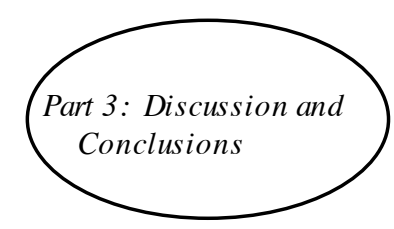

Chapter 9: Labour-Management Practice in the Hospitality Industry: Managing to Compete?

Chapter 10: Explaining Management Practice: Strategy, Environment and Social Action 


\section{Chapter 5: Research Approach and Methodology}

\subsection{Introduction}

Having turned from the theoretical to the empirical sections of this thesis, we begin by outlining the methodology used in the research. As will be seen below, this consists of a multi-method approach based on both quantitative and qualitative analysis of data obtained through a postal survey, supplemented by follow-up interviews. The use of these methods must be seen in the context of the prevailing empiricism of industrial relations research. Within the US, this tradition in large part arises out of the discipline's evolution out of labour economics, and its emphasis on policy and practical concerns (Kerr, 1978; Strauss and Feuille, 1978). Across the Atlantic, in the UK, empiricism has been associated with case-study analysis of shop-floor behaviour (Brown and Wright, 1994; Cully and Marginson, 1995), stimulated by the Donovan Comission's theorisation of an informal system of industrial relations underlying the formal. More recently, a distinct trend towards large-scale surveys has been evident, associated with quantitative and statistical analysis and attempts to draw directional and causative relationships between variables.

While industrial relations scholars have periodically bemoaned the lack of a "general" theory of industrial relations, less self-conscious thought about methodological issues has been apparent. The discipline by and large has not participated in the methodological and epistemological debates that have characterised other social sciences, and the positivist underpinnings of empiricism 
remain largely unchallenged. ${ }^{1}$ This is not to say, however, that industrial relations researchers are unaware of the limitations of the methodologies that are used. Morris and Wood (1991) have drawn attention, for example, to the way in which interviews with managers who had earlier participated in the Warwick Enterprise Survey painted a different picture of the nature of workplace industrial relations, and attribute this in part to the different nature of the research instruments. Similarly, a recent debate on the limitations of large-scale survey research in comparison to small scale case studies (McCarthy, 1994; Fernie and Woodland, 1995; Millward and Hawes, 1995) has promoted an understanding amongst researchers of the comparative benefits of both, with general acceptance of the need for research to make use of "... the full variety of intensive and qualitative methods ... (and) extensive and quantitative methods ... So far as is possible, 'multiple triangulation' should be the aim" (Millward and Hawes, 1995:71).

In general, the desirability of triangulation to support conclusions reached has been adopted as a principle in this research, and multiple data sources, where available, have been used. The conclusions rely equally on both quantitative and qualitative material. A description of the process used for collecting this data, and the limitations of the research, are outlined below.

\subsection{Methodology}

\footnotetext{
1 "Positivism" is used here in the sense of referring to the belief that science and application of the scientific method can un-cover or dis-cover "truth(s)" which are in some way external to the researcher. In this way it refuses to accept any explanations or principles which are in any way beyond experience or unobservable. This traditional notion of science has been undermined throughout the course of the 20th century by a variety of scholars and philosophers ranging from those writing from a hermeneutic perspective, to those adopting a post-modernist philosophy. For further discussion see Manicas (1987).
} 
A multi-method approach to the research was adopted for reasons related to the research objectives outlined in Chapter 1. Given the lack of knowledge about labour-management practices in the hospitality industry generally, a large scale survey was appropriate in order to be able to describe patterns and to examine whether these varied according to size, ownership, and industry sub-sector. However, it was recognised at an early stage that the insights related to the second research question (the reasons for the patterns that exist) were unlikely to arise from survey data alone. While some broad associations with measurable variables might be established, it was also necessary to establish whether responses might vary for managers according to their individual characteristics. Accordingly, the survey was followed up by a smaller number of interviews which sought more qualitative information than was able to be collected through the use of a survey.

\subsubsection{Survey development}

The construction of the survey instrument took place over the three months from April - June 1995. Two sources of data were drawn on for determining question content. The first was a series of eight semi-structured exploratory interviews with representatives from several major accommodation hotels, the Hotel Association, the Hotel and Catering Industry Training Board, the Service Workers Union, and the Tourism Industry Association. ${ }^{2}$ These interviews were general in nature, and covered nine predetermined areas (nature and role/competitive position of the organisation, employee profile, hours of work, recruitment strategies, skills and training, mechanisms for employee communication and involvement, human

\footnotetext{
${ }^{2}$ Interviews were sought with other individuals and industry associations (e.g., Motel Association; Chartered Clubs Association) in an attempt to get as wide a coverage across the industry as a whole. However several declined to be interviewed or were unavailable.
} 
resource policies and practices, and industrial relations). These areas had been isolated as important from background reading on the industry, and from knowledge of the context of industrial relations in the 1990s in New Zealand. Their purpose was to draw a general picture of human resource and employment practices and to identify some key themes to be covered in the survey. These exploratory interviews were invaluable for gaining an overview of the current state of play in labour-management practice in the industry, and were particularly useful for the questionnaire design - for example, in determining use of appropriate language and the relevance of particular issues.

The questionnaire design was also influenced by work being undertaken in Australia on data items being developed for the second Australian Workplace Industrial Relations Survey (AWIRS) being undertaken in the second half of 1995. The benefit of doing this was two-fold. Firstly, this research was covering similar issues as the AWIRS and could benefit from the prior expertise that had been brought to bear in question design. Secondly, given that both surveys were conducted within roughly the same time period, question replication provides a basis for comparative analysis at a later date. At the same time, it was clear that replication could only be partial for three particular reasons. The main AWIRS questionnaire is delivered to workplaces which employ more than 20 people, and consequently tends to focus on "formal" labour management practices. Although a secondary questionnaire is delivered to workplaces employing between five and 20 employees, this is much less extensive. Because of the small average size of workplace of the hospitality industry in New Zealand, it was necessary to ensure 
that questions were asked in such a way as to be relevant to these workplaces. Secondly, a number of data items used for the AWIRS reflected the different regulatory environment existing at the time in Australia, particularly in respect of collective bargaining and union membership. New questions were required to be constructed to reflect both the nature of industrial relations in the hospitality industry, and the more voluntaristic legislative framework operating in New Zealand. A third problem was that while AWIRS is administered on a face-to-face basis, time and resources did not allow this to be done in this case. Thus the way in which the AWIRS data items were used as a resource was confined to repeating data items that were relevant, using the same question wording with appropriate adaptation if necessary for the New Zealand context. Of the 51 questions included in the final questionnaire (included as Appendix 3), about half were adaptations of AWIRS questions, ${ }^{3}$ with the remainder being specifically developed for this research.

After several re-workings, a final draft of the questionnaire was sent for comment to 12 people. These included academic colleagues selected for their expertise in questionnaire design and others with industry knowledge, including representatives from the main industry associations. In addition, the draft was

\footnotetext{
${ }^{3}$ Of these about half involved very minor or slight adaptations, while other were more significant changes to wording. Minor changes involved, for example, changing "Australia" to "New Zealand" when asking about ownership (question 3); or using industry specific, rather than general occupational descriptions (question 23). More major changes were made in other areas. For example, AWIRS (Employee Relations Management Questionnaire, Questions A.11 - A.15) asks a series of questions about membership of employer associations and the advice that is sought from these and other external consultants and agencies, with a wide range of fixed variable responses. The exploratory interviews conducted in the hospitality industry suggested that a more limited range of options (reflecting both the nature of the industry and different national conditions) were utilised. Accordingly, the question wording was changed significantly, although ostensibly asking about the same subject matter.
} 
tested on two managers from the industry to ensure that the questionnaire was readily understandable, that instructions were clear and easily followed, and that the questionnaire would not take more than about 30 minutes to complete. Following these final amendments, the questionnaire was ready for piloting.

\subsubsection{Sample selection}

The sample frame used for the survey was the Statistics New Zealand Business Directory, ${ }^{4}$ as the most comprehensive listing of businesses in New Zealand. It comprises information on all "economically significant enterprises", defined as those with more than $\$ 30,000$ annual GST (Goods and Services tax) expenses or with more than two full-time equivalent (FTE) employees. Information on employers is obtained through an Annual Business Directory Update Survey. In addition, the database is amended by receiving feedback from other economic and financial surveys (e.g., the Retail Trade Survey), by a monthly birth survey of all compulsorily GST registered businesses (the prime source for adding new businesses to the frame) and by media and Building Permit information to capture significant new business starting up (e.g., new shopping malls). While the sample frame was considered to be the only reliable one available, it is not without its limitations. In particular, given that the Directory only includes businesses with an annual GST turnover or expenses of greater than $\$ 30,000$, it may miss out on failing businesses or extremely small ones. This will be more of a problem if the level of business turnover in the industry is higher than in others. ${ }^{5}$

\footnotetext{
${ }^{4}$ While other surveys in the industry have used phone books and accommodation guides as sample frames, this was rejected as excessively time-consuming and not allowing the survey to be stratified by size.

${ }^{5}$ While "conventional wisdom" in the industry suggests that business start-ups and failures are
} 
Statistics New Zealand was asked to randomly select three samples from the data base for the study, consisting of a pilot sample of 50 firms, the main sample of 1,000 firms, and a third sample of 100 firms to be used in the event that surveys were returned as "gone no address" (GNAs). All samples were selected in the same way and were stratified by size $(5-19,20-49,50-99,100+$ full-time equivalent employees). ${ }^{6}$ Details about the sample in relation to the total population of activity units in the industry is contained in Table 5.1.

The pilot survey was conducted in the week beginning 1 August 1995. Twenty-six responses were received (a response rate of 52\%) with no reminder letter and no refusals. $^{7}$ The main survey was sent out at the beginning of October 1995.

Table 5.1: Population and sample sizes

\begin{tabular}{|l|c|l|l|l|l|c|}
\hline Size (FTE & Population size \\
employees) & Pilot & Main & Sub-total & GNA & Total \\
& & survey & & replacement & \\
\hline $5-19$ & 2,420 & 38 & 760 & 798 & 76 & $\mathbf{8 7 4}$ \\
\hline
\end{tabular}

more common than in other areas of the economy, there is no evidence to either support or refute this hypothesis.

${ }^{6}$ Given that employers employing fewer than five FTEs were unlikely to use anything either than completely ad hoc methods for labour management, these were excluded from the survey, and the covering letter allowed respondents who employed fewer than five employees to indicate this and to return the questionnaire without having completed it. As Table 5.2 indicates 14\% of respondents fell into this category. This was considered to be high given that these employers were supposed to be excluded from the population sample, and may reflect rapid changes in business size, or inaccuracies in the population data. Alternatively, some respondents may have ticked the box to save themselves the trouble of responding to the questionnaire.

${ }^{7}$ As a result of the pilot, changes were made to question wording (only one which was of any significance) and to the question order. Because the changes made were so minor, and because the pilot sample was selected in the same way as the main sample, in the analyses contained here, the pilot sample has been included in the results. 


\begin{tabular}{|l|c|c|c|c|c|c|}
\hline $20-49$ & 557 & 9 & 175 & 184 & 17 & $\mathbf{2 0 1}$ \\
\hline $50-99$ & 154 & 2 & 48 & 50 & 5 & $\mathbf{5 5}$ \\
\hline $100+$ & 54 & 1 & 17 & 18 & 2 & $\mathbf{2 0}$ \\
\hline Total & $\mathbf{3 1 8 5}$ & $\mathbf{5 0}$ & $\mathbf{1 0 0 0}$ & $\mathbf{1 0 5 0}$ & $\mathbf{1 0 0}$ & $\mathbf{1 1 5 0}$ \\
\hline
\end{tabular}

This time was deliberately selected as a relatively quiet period prior to the seasonal rush from mid-November until Xmas, as a means of maximising response rates. Each questionnaire was identified by a unique code number and accompanied by a covering letter explaining the purpose of the research (included as Appendix 2), and a reply paid envelope. Because of confidentiality restrictions all mailouts were sent out by Statistics New Zealand. The survey was anonymous and the researcher at no time had access to the addresses of the workplaces to whom the survey was sent. As completed surveys were received, their unique identifier was deleted off a master list. This meant that as the date at which surveys were due to be returned approached, the master list was sent back to Statistics New Zealand, which then sent out a reminder letter (Appendix 2) and a new copy of the survey to those workplaces for whom surveys had not been received. This process substantially increased the response rate for the survey.

Unfortunately, however, because of administrative blunder, surveys were sent not only to the main sample, but also to the supplementary list (those that were intended to be sent out to the GNAs) in the main mail-out. Thus 1100 surveys were sent out rather than the 1000 as originally intended. Accordingly, all 
calculations done as part of the research have been based on a sample size of 1,150 (including all three selected samples).

Of the 1150 questionnaires distributed, 702 were returned. This represents a response rate of $61 \%$ which is very good for a postal survey of this type. Only 560 of these responses $(48.7 \%$ of the total sample) were usable, however, as is indicated in Table 5.2 .

Table 5.2: Responses to survey

\begin{tabular}{|l|c|}
\hline & Number \\
\hline $\begin{array}{l}\text { Employed fewer than 5 staff or had gone out of } \\
\text { business }\end{array}$ & 98 \\
\hline Returned incomplete or not completed & 11 \\
\hline Declined to respond $^{8}$ & 14 \\
\hline Gone no address & 19 \\
\hline Usable responses & 560 \\
\hline Total & $\mathbf{7 0 2}$ \\
\hline
\end{tabular}

Response rates varied according to workplace size. As can be seen from Table 5.3 large organisations (those employing more than 100 employees) and medium sized organisations (employing between 20-49 employees) had the highest response rates, while medium to large sized organisations (employing between 50

\footnotetext{
${ }^{8}$ This included respondents who objected to completing this particular questionnaire as well as those where the organisation had a policy of not doing so. It also included 2 organisations who declared that they were not engaged in the hospitality industry.
} 
to 99 employees) had the lowest. This is consistent with patterns of questionnaire response found in other recent New Zealand surveys. ${ }^{9}$

Table 5.3 Responses to survey by size band

\begin{tabular}{|l|c|c|c|c|c|}
\hline Size band & Usable responses & $\begin{array}{l}\text { Usable responses } \\
\text { as \% of size band } \\
\text { sample }\end{array}$ & $\begin{array}{l}\text { Returned } \\
\text { incomplete }\end{array}$ & $\begin{array}{l}\text { Employed fewer } \\
\text { than 5 staff or } \\
\text { had gone out of } \\
\text { business }\end{array}$ & $\begin{array}{l}\text { Total returns as } \\
\% \text { of for size } \\
\text { band sample }\end{array}$ \\
\hline $5-19$ & 391 & $44.7 \%$ & 9 & 49 & $51.4 \%$ \\
\hline $20-49$ & 114 & $56.7 \%$ & 1 & 2 & $58.2 \%$ \\
\hline $50-99$ & 21 & $38.2 \%$ & - & 1 & $40.0 \%$ \\
\hline $100+$ & 11 & $55.0 \%$ & - & 1 & $60.0 \%$ \\
\hline Unknown $^{10}$ & 23 & & 1 & 45 & \\
\hline
\end{tabular}

While the number of usable responses for the two larger size bands is small in absolute terms, the relatively small size of the total population means a small sampling error. Consequently, the results analysed here are still considered to be

\footnotetext{
${ }^{9}$ Two patterns of response have been found in surveys of New Zealand organisations in the 1990s. In some, response rates increase with increasing organisational size (See for example Ryan, 1992; Anderson, Brosnan, Rea and Walsh, 1992). The pattern found here is more consistent with that found by Brosnan and Walsh (1996), where response rates were lower for medium to large sized organisations (employing 50-99 employees). There may be several reasons for this. Brosnan and Walsh suggest that a possible reasons is complexity - i.e., the organisation is large enough to make filling in a questionnaire such as this a more time consuming task than in less complex organisations, but often not large enough to employ a specialist personnel or human resource person for whom such an exercise would be easier. An additional explanation may also be that surveys have become a more common means of collecting organisational data over the course of the 1990s, and several of these surveys have excluded organisations of fewer than 50 employees or have focused on industries in which larger than average workplaces are common (see for example Gilson and Wagar, 1996). Given the relatively small population of workplaces in New Zealand, and the large samples selected in some surveys, it is highly probable that some workplaces received more than one survey in a short period of time. This may have contributed to respondent burden and resulted in a lower level of response for organisations employing between 50 and 100 employees than would normally be the case, all other things being equal.
}

${ }^{10}$ The unique identifier on the surveys allowed identification of the size band into which each respondent fell (according to the Statistics New Zealand Business Directory). The size band which respondents belonged to became unknown if they had removed their unique identifier from their completed survey; or alternatively if they simply sent back the covering letter declaring that they employed fewer than 5 employees or had gone out of business without returning the survey itself. 
valid for the population as a whole, despite the inevitability of non-calculable non-response error. In order to partially compensate for this, weightings were applied to ensure that responses were proportionate to their size grouping in the population as a whole. The formula used to establish the weighting was as follows:

weight $=\frac{\sum^{H}\left[\frac{M_{H}}{m} \frac{\widetilde{m}}{m_{h}}\right]}{\sum \frac{M_{H}}{m} \frac{\widetilde{m}}{m_{h}} \cdot m_{h}}$

where:

$\mathrm{H}=$ size band

$\mathrm{M}=$ group population and

$\mathrm{m}=$ sample

The following table sets out the weights applied as a result of the application of this formula, with weighted and unweighted response numbers. The base for all analyses included in the thesis is the total number of weighted responses. 
Table 5.4: Weighted and unweighted responses

\begin{tabular}{|l|c|c|c|}
\hline Size band & Usable responses & Weighting & $\begin{array}{l}\text { Weighted responses } \\
\text { (rounded })\end{array}$ \\
\hline $5-19$ & 391 & 1.088 & 425 \\
\hline $20-49$ & 114 & 0.859 & 98 \\
\hline $50-99$ & 21 & 1.290 & 9 \\
\hline $100+$ & 11 & 0.864 & 23 \\
\hline Unknown & 23 & 1 & 582 \\
\hline Total & 560 & & 9 \\
\hline
\end{tabular}

Details about the survey respondents and some background on their organisations is set out in Section 5.3. Survey data was coded and analysed using SPSS (Statistical Package for Social Sciences), and frequency tables for each of the survey questions are included as Appendix 4.

\subsubsection{Follow-up interviews}

The survey provided for two types of follow-up. Firstly respondents could opt to be supplied with a summary of the survey results after initial analysis. Secondly respondents were asked if they would be willing to be interviewed regarding the issues raised in the questionnaire. Both types of follow-up elicited a high level of response with 259 respondents wanting summary results, and 111 being prepared to participate in a follow-up interview.

Follow-up interviews were conducted at 38 workplaces between August and October 1996. In selecting workplaces for interview particular efforts were made 
to ensure that interviews included managers in a range of different workplace types, sizes and locations. Final selection, however, was also partly determined by convenience and the limitations of research funding. The total interview sample eventually included 19 small (fewer than 20 employees), 16 medium (20-99 employees) and three large (more than 100 employees) workplaces; in rural, provincial and urban settings. In addition, Table 5.4 shows the range of industry sub-sectors in which interviewees worked. ${ }^{11}$

Table 5.5: Interviews by industry sub-sector

\begin{tabular}{|l|c|}
\hline Industry sub-sector & Number of interviews \\
\hline Restaurant / Bar & 8 \\
\hline Cafe/ Bar & 7 \\
\hline Accommodation Hotel & 5 \\
\hline Motel/Motor Lodge & 4 \\
\hline Licensed Club & 4 \\
\hline Catering Company & 3 \\
\hline Pub & 2 \\
\hline Fast Food Restaurant & 2 \\
\hline Other & 3 \\
\hline
\end{tabular}

The interviews were organised by telephone contact with the manager concerned, to confirm that a follow-up interview would still be convenient, and to organise a specific interview time. Following this, a letter was sent (included as Appendix 5)

\footnotetext{
${ }^{11}$ In some cases, workplaces could conceivably fall into more than one category and many workplaces provide a range of services. A clear distinction between industry sub-sectors is not always easy to make in practice. For example, the distinction between a cafe and a restaurant; or a motor camp and a motel, are not always easy to make. The classification here represents my own judgement, and the 3 workplaces that have been included in the "other" category have been so placed as to prevent identifiability.
} 
to confirm interview arrangements, set out confidentiality provisions, and to explain details of the interview process, including the range of issues to be covered.

The interview process was not designed to obtain statistically valid and reliable data in the same way that the questionnaire had been. Its purpose was to obtain more qualitative insights, and in particular to explore some of the rationales which managers use to explain patterns of labour management. Accordingly, the interviews were largely unstructured, although the range of areas addressed in each interview (set out in Appendix 6) was similar. Interviews ranged from 45 minutes to an hour and a half, with most taking 55-60 minutes. All interviews were audio-taped and fully transcribed. Summary characteristics of the workplaces are included in Appendix 7.

The collection of interview data was less straightforward than the postal survey and drew attention to the volatile nature of employment and work in the industry. Of the 60 workplaces contacted, interviews were unable to be arranged in 18 because the establishment had gone out of business (five workplaces) or because new managers or owners were in place and did not wish to participate in the study (13 workplaces). Even when interviews were arranged, the immediacy of work demands frequently required interviews to be postponed and re-arranged at short notice. Two interviews that had been arranged and confirmed did not take place. In one case this was because I was told that the manager had left the previous week with no notice. In a second instance I arrived at the pre-arranged interview time, to find the premises closed and a notice on the door saying that the lease on 
the property had been terminated through non-payment of back rent of $\$ 25,487.95$ ! The interview process was also affected by the nature of managerial work in the industry. The fact that all interviewees were interviewed at their workplaces meant that interviews were commonly interrupted, as managers dealt with the immediacy of dealing with staff, customers and suppliers. Rather than being a problem, however, these interruptions were frequently used by managers to illustrate points that they were making and made an important contribution to an understanding of the context in which management decisions are made.

\subsection{Limitations of the study}

As with any research, limitations are inevitable. As noted earlier, although sampling error was reduced as much as possible through the use of stratified random sampling from a reliable sampling frame, the Business Directory is not perfect in its coverage. Non-response error may also limit the generalisability of the findings. In this particular study, respondents could conceivably differ from non-respondents in attitudes and behaviour. Those managers placing higher priority on good management of employees may have been more interested in the subject matter of the survey and more willing to reply to it. If this bias is present in the data, then the findings here will possibly present a more optimistic view of the state of labour-management in the industry than that applying more generally. Nevertheless, in general the survey data is considered to have a high degree of statistical reliability and validity. This is not the case for the interview data, as noted earlier, but this data is used in the study to provide insight and illustrate issues arising from the survey data. 
One issue which has arisen in the study is the extent to which the findings identified here represent "truth" about patterns of labour management in the hospitality industry in New Zealand in the 1990s. A particular criticism that might be directed towards the study is whether it is valid to rely on only one party to the labour-management relationship (in this case management) in describing employment, work and labour relations practices. The answer to the concern is, of course, that this study presents only a partial view of industry practice, and that the picture painted here constitutes subjective reality from the point of view of owners and managers in the industry. Nevertheless, the second aspect of the research question required the approach to be taken. ${ }^{12}$ In attempting to uncover management reasoning for their actions, managers themselves are the only actors able to articulate these rationales. Even when their employees disagree (and perhaps disagree violently) with their reasoning, subjective perceptions constitute a reality which guide actions and practice. If the study presents only the views of managers, this is because that is what it set out to do. The fact that the intent was to reach a better understanding of managers' actions, however, does not mean that their rationales were not subjected to critical analysis. Firstly, reasonably regular contact (both formal and informal) was kept with officials from the Service Workers Union of Aotearoa during the research, who had the opportunity to read drafts of the findings. ${ }^{13}$ Their comments were frequently valuable in providing alternative explanations and pointing to contradictions which had not previously

\footnotetext{
${ }^{12}$ The connection between research questions and methodology is not always paid the attention it requires. For example, if the research question had been phrased in terms of examining the dynamic of labour-management relations, this would have required a consideration of the subjective perceptions of both employees and managers.

${ }^{13}$ In the event the union did not come back with comments owing to the constancy of work pressures.
} 
been considered. Secondly, during the course of the research, I spent many hours observing hospitality industry workplaces and talking informally to friends, acquaintances, and anyone else I could find who worked in the industry. These contrary perceptions, as well as my own sympathies for the "labour" side of the labour-management equation, all played a part in developing the picture that is drawn in the findings as presented here.

It must be said however, that in seeking to understand the actions of my research subjects, an empathy has developed. As the study progressed I developed a greater feeling for the dilemmas in which managers found themselves, and the ways in which they responded to these. Certainly the findings are a more optimistic assessment of the quality of human resource management practice than is suggested by stereotypical conceptions of an industry in which management practice is authoritarian and arbitrary, and employees are poorly paid, work long hours and provided with little training. The data also conflict with anecdotal evidence collected from employees in the industry and their union representatives (see for example Gosche, 1992). How can this gap between popular conception and the interpretation given here be explained? The account offered in this study is of an industry increasingly cognisant of the need to improve its practice in the direction of greater professionalism. There is some suggestion in the data, however, and discussed in further detail in Chapter 10, that managers may offer a more favourable account of their practices than may be experienced by the employees working for them. This is not to suggest that managers "lie" about their practice, but rather that their accounts involve what was described in the previous chapter as "discursive consciousness", below which unconscious 
motivations may be operating (Giddens, 1982). In addition, as Watson (1995) notes, when managers report on their actions, their words do not always reflect an objective assessment of their attitudes and behaviour, but are uttered in a context in which the researcher is a part:

...every person will frame their answer in the light of circumstances unique to themselves: their attitude to the interviewer, the particular overtones for them of any given word, the time of day, their personal background, priorities, and current state of mind, and so on. (Watson, 1995:40-41)

It is inevitable that when asked about their behaviour in any area of activity, research subjects will offer an account which portrays themselves in the best possible light, and according to rationales which make sense in their own terms. A study such as this, making use of survey and interview data, can simply report these perspectives. While contradictions in behaviour and ambiguities may be drawn out, the possibility of unconscious motivations cannot be explored in the same way as a more in-depth case study is able to do. While it is a limitation of the study, the findings also provide a solid foundation for more in-depth research to be undertaken. 


\subsection{The respondents and their organisations}

Completed questionnaires were received from a wide range of workplaces. In terms of location, just under half were located in a main city, $11 \%$ were located in rural areas and the remainder were evenly split between smaller cities and towns. Responses were also received from a range of workplaces (as can be seen from Figure 5.1) and included all major industry sub-groups. ${ }^{14}$ It is impossible to definitively establish whether the sample is fully representative of the industry as a whole, as the ANZSIC classification used by Statistics New Zealand differs from that used in the industry and adopted in this study. However, estimates from the Business Activity statistics published by Statistics New Zealand suggests that the sample is reasonably representative, although with a slight over-representation of Accommodation Hotels and Pubs; and a slight under-representation of Motels and Cafes. ${ }^{15}$ The reason for this is likely to be the different response rates from workplaces of different sizes, so that those parts of the industry in which workplaces are medium and large sized are likely to be over-represented. Given the close association between size and industry sub-sector, however, this distortion is likely to have been corrected for by weighting.

The survey asked whether the workplace was part of a larger business or organisation, and whether it was New Zealand or overseas owned. Just over $70 \%$

\footnotetext{
${ }^{14}$ While educational institutions are not generally thought of as part of this industry, the industry classification from which the sample was drawn also includes organisations providing student hostel accommodation.

${ }^{15}$ Capital letters are used for all industry sub-sectors to draw attention to these as an analytical category.
} 
of the workplaces were independent - that is they were not part of a larger organisation. Those that were part of a larger organisation were most likely to be 
Figure 5.1: Respondents by industry sub-sector

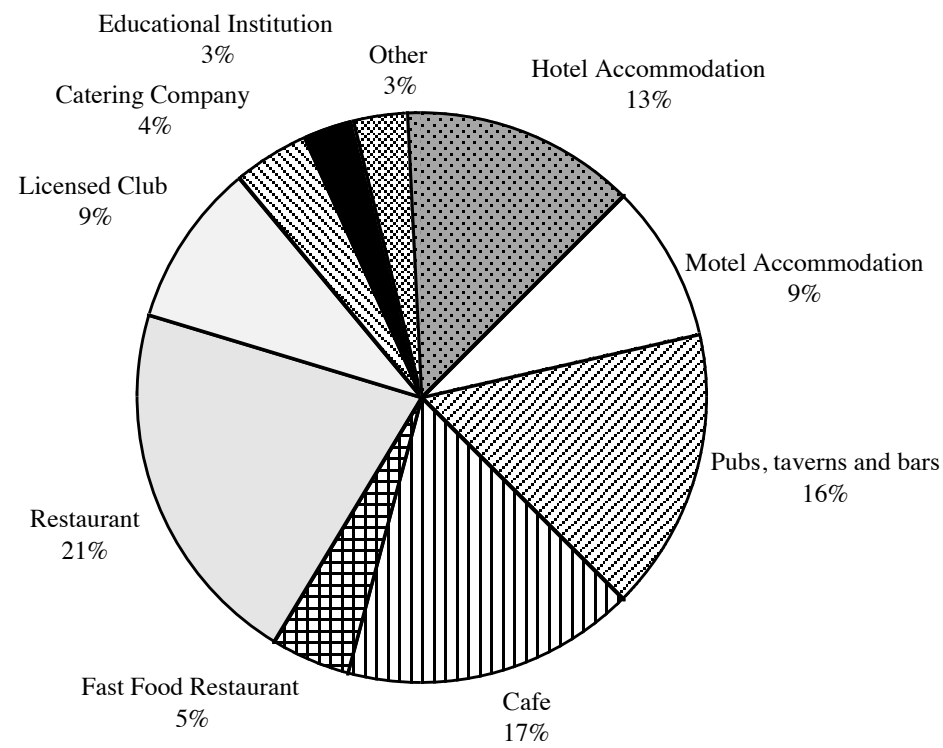

Accommodation Hotels, Catering Companies, and Fast Food Restaurants, reflecting the fact that these workplaces are likely to be part of chain operations, or subsidiaries of multi-national organisations. Not surprisingly, workplaces which were part of a larger organisation tended to be larger than average, with nearly $20 \%$ employing more than 50 employees (in comparison to only $6.9 \%$ of all respondents and less than $1 \%$ of the industry as a whole) and over $50 \%$ employed more than 20 employees (in comparison to only $25.9 \%$ of all respondents). In respect of ownership, over $90 \%$ of the workplaces were wholly New Zealand-owned, but some of these workplaces included New Zealand-owned franchises of multi-national organisations. Those workplaces that were wholly or 
predominantly foreign-owned tended to be larger than average and half were Accommodation Hotels.

The people who answered the questionnaire were mainly owners $(56 \%)$ or the most senior manager $(33.2 \%)$ in the workplaces that received the questionnaire. Collectively, they had a lot of experience in Hotels and Restaurants - nearly half had been working in the industry for ten years or more. The average length of time that the respondents had been working in their current organisation was between two and five years, reflecting the high level of mobility of managers within the industry.

The questionnaire asked a range of questions about demand and competition in the industry, summarised in Table 5.6. The industry is generally viewed as one which is highly competitive and where demand is unpredictable and somewhat volatile. This picture was only partly supported by the survey results, and responses revealed some surprising patterns. There is no question that managers in the industry see it as being highly competitive, with $71 \%$ of respondents agreeing that they had many competitors. Levels of competition varied, however. Above average proportions of Pubs, Fast Food Restaurants and Restaurants reported high levels of competition, while the least competitive sector was the provision of accommodation in educational institutions. The extent of competition was also affected by location. Workplaces in cities were slightly more likely to report competition than were workplaces in towns or rural areas. However, even this varied by industry sector. In the main cities, competition is most likely to be 
reported by Fast Food Restaurants, Pubs, Restaurants and Cafes, while in smaller cities it most significant not only for Pubs and Restaurants, but also for Motels and Catering Companies. The most competitive place to be overall was for Fast Food Restaurants in one of the five main cities, over $90 \%$ of which reported a high level of competition. 
Table 5.6: Demand and competition levels by industry sub-sector

\begin{tabular}{|c|c|c|c|c|c|c|c|}
\hline & \multicolumn{2}{|c|}{$\begin{array}{l}\text { Predictability of Demand } \\
\qquad\left(\mathrm{N}=\mathbf{5 7 3 ^ { 1 6 }}\right)\end{array}$} & \multicolumn{3}{|c|}{ Level of Demand ( $N=577$ ) } & \multicolumn{2}{|c|}{$\begin{array}{l}\text { Level of Competition } \\
\qquad(\mathbf{N}=\mathbf{5 8 0})\end{array}$} \\
\hline $\begin{array}{l}\text { Industry sub- } \\
\text { sector }\end{array}$ & Predictable & $\begin{array}{l}\text { Not } \\
\text { predictable }\end{array}$ & Expanding & Stable & Contracting & $\begin{array}{l}\text { Many } \\
\text { competitors }\end{array}$ & $\begin{array}{l}\text { Few or no } \\
\text { competitors }\end{array}$ \\
\hline $\begin{array}{l}\text { Hotel } \\
\text { Accommoda- } \\
\text { tion }\end{array}$ & 67.0 & 33.0 & 48.7 & 40.2 & 11.1 & 70.4 & 29.6 \\
\hline $\begin{array}{l}\text { Motel } \\
\text { Accommoda- } \\
\text { tion }\end{array}$ & 70.4 & 27.5 & 53.6 & 44.3 & 2.1 & 71.5 & 28.5 \\
\hline $\begin{array}{l}\text { Pubs, } \\
\text { Taverns and } \\
\text { Bars }\end{array}$ & 70.3 & 29.7 & 37.5 & 53.5 & 9.0 & 75.0 & 25.1 \\
\hline Cafes & 65.3 & 33.5 & 42.6 & 49.6 & 7.8 & 71.9 & 28.0 \\
\hline $\begin{array}{l}\text { Fast Food } \\
\text { Restaurants }\end{array}$ & 79.9 & 20.1 & 52.0 & 31.7 & 16.3 & 83.0 & 16.9 \\
\hline Restaurants & 59.6 & 38.6 & 35.7 & 53.3 & 10.1 & 76.3 & 23.7 \\
\hline $\begin{array}{l}\text { Licensed } \\
\text { Clubs }\end{array}$ & 87.8 & 12.2 & 44.3 & 43.7 & 12.0 & 63.6 & 36.4 \\
\hline $\begin{array}{l}\text { Catering } \\
\text { Companies }\end{array}$ & 63.0 & 37.0 & 48.4 & 43.0 & 8.5 & 68.0 & 31.9 \\
\hline $\begin{array}{l}\text { Educational } \\
\text { Institutions }\end{array}$ & 87.9 & 12.1 & 34.1 & 55.9 & 10.0 & 25.7 & 74.3 \\
\hline
\end{tabular}

While the popular impression of a highly competitive industry was confirmed by the survey results, that of an industry where demand is unpredictable and volatile was not. While demand may be seasonal, and fluctuates by the time of day, day of

\footnotetext{
${ }^{16}$ Note that totals are slightly less than $100 \%$ for Motels, Cafes, and Restaurants as 5 respondents in these areas made responses which were coded as "other".
} 
the week or season of the year, these fluctuations were thought to be predictable by over two-thirds of respondents. As with levels of competition, however, the predictability of demand varied from workplace to workplace. The industry subsectors most likely to say that demand was unpredictable were Restaurants and Catering Companies, while those with the most predictable demand were Licensed Clubs and to a lesser extent, Fast Food Restaurants. Predictability of demand was also associated with location. Over three-quarters of those operating in the main cities agree that demand is predictable, while workplaces in rural areas were more than twice as likely to assess it as unpredictable. Finally, workplaces with fewer than 10 employees were considerably more likely to see demand as being unpredictable (although this effect was less marked in the five main cities and for Fast Food Restaurants), but it is difficult to explain why market demand should be influenced by workplace size. This suggests that assessments of demand may be influenced by management skill in analysing longer-term trends or alternatively that marketing and reputational factors may be more significant in contributing to stable demand than managers themselves think.

A question was also asked about whether demand was generally expanding, stable or contracting. In general, the vast majority of respondents agreed that it was either expanding $(43.1 \%)$ or stable $(47.4 \%)$. While in general the tourism industry (of which the hospitality sector forms a significant part) has expanded considerably over recent years, the end of 1995 saw the beginnings of a decline in consumer spending which is reflected in the survey results. Those sub-sectors of the industry most dependent on domestic demand (e.g.; Restaurants, Cafes, Pubs) 
were more likely to report that demand was stable and were possibly also affected by the fact that the survey was carried out at a time of year which is often relatively quiet in the industry. ${ }^{17}$ In contrast, those sectors which also or predominantly provide services for international visitors were more likely to report expanding demand. Despite these seasonal variations, the survey data suggested that demand in some industry sub-sectors tended to be more stable than in others. Pubs and Restaurants were more likely to report stable demand, while Motels and Fast Food Restaurants reported an expansion in demand in higher proportions than other industry sub-sectors. The fact that a higher proportion of Fast Food Restaurants than any other industry sector also reported a contraction of demand and the high level of competition in the industry noted earlier suggests that demand in the industry is not inelastic and that competition is largely based on increasing market share in a limited market.

Given the level of competition in the industry, management assessment of the factors important for competitive success of their business were of particular interest. Respondents were asked to indicate what they saw as being the most crucial and second most crucial factors for competitive success from a list which included quality of product or service, quality of staff, pricing strategies, responsiveness to customer requirements, location, providing a distinctive service or product, and advertising/marketing. Several respondents noted on their comments to the survey that it was difficult to draw a clear distinction between

\footnotetext{
17 As noted earlier, the quiet period that occurs immediately prior to the Xmas rush was deliberately chosen as one of the strategies to maximise survey response.
} 
these. For example, the nature of the service industry means that it can be almost impossible to draw a clear line between the quality of the product (which frequently includes the service being provided by employees), quality of service, and responsiveness to customer requirements (which may be a measure of service quality).

Despite these difficulties, quality of product or service was identified by $49.7 \%$ of respondents as the most crucial factor for competitive success, and by $72.7 \%$ as either the most or the second most crucial factor for competitive success. The graph on the next page shows the percentage of respondents indicating that the factor was one of the two most important factors for competitive success. As can be seen, while quality of product or service was seen as by far the most important factor determining competitive success, a cluster of four other factors also emerged as being important - price, responsiveness to customer requirements, quality of staff and location. 
Figure 5.2: Most/second most crucial factors for competitive success

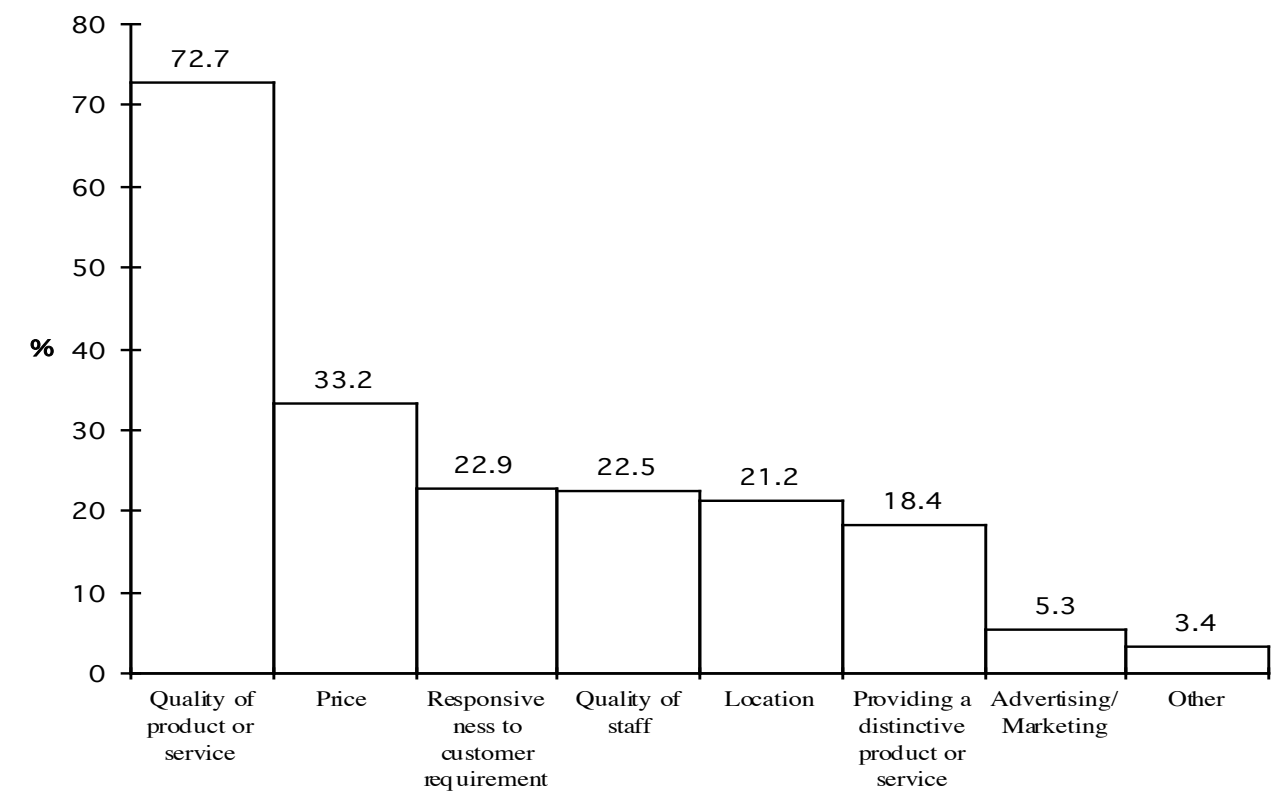

$\mathrm{N}=581$

In all but one industry sub-sector quality was the most important consideration, ${ }^{18}$ but other factors weighed more heavily in some sectors than others. For example, higher than average percentages of respondents in Motels, Clubs and Catering Companies reported that price was important. Interestingly, while in most subsectors of the industry one or two competitive success factors stood out as being more critical than others (e.g., price for Motels, quality for Restaurants, quality and location for Cafes), responses in the accommodation sector indicated a focus on all four of the most commonly identified factors.

Table 5.7: Second and third most crucial factors for competitive success by industry sub-sector 


\begin{tabular}{|l|l|l|}
\hline Industry sub-sector & Second most crucial competitive & $\begin{array}{l}\text { Third most crucial competitive } \\
\text { success factor }\end{array}$ \\
\hline Success factor & Price (39.6\%) & Quality of staff (29.9\%) \\
\hline Motel Accommodation & Price (46.4\%) & Location (36.8\%) \\
\hline Pubs, Taverns and Bars & Price (35.3\%) & $\begin{array}{l}\text { Responsiveness to customers } \\
(34.3 \%)\end{array}$ \\
\hline Cafes & Location (35.1\%) & Providing a distinctive product or \\
& & service (25.3\%) \\
\hline Fast Food Restaurants & Price (35.5\%) & Location (24.5\%) \\
\hline Restaurants & Price (26.7\%) & Quality of staff (24.8\%) \\
\hline Licensed Clubs & Quality of product or service & Responsiveness to customer \\
& $(47.6 \%)$ & Requirements (35.3\%) \\
\hline Catering Companies & Price (49.9\%) & Providing a distinctive product or \\
\hline Educational Institutions & Price (35.5\%) & customer \\
& & \\
\hline
\end{tabular}

$\mathrm{N}=581$

Other workplace characteristics were also associated with the critical success factors. Not surprisingly, workplaces which experienced a high level of competition, and where demand was contracting placed more emphasis on price as a source of competitive advantage. Workplaces where price was important were also less likely to employ workers under the age of 20. But had employed an increased number of part-time and casual workers in the previous five years. A concern with quality increased with increasing organisatijnal size, and those

\footnotetext{
${ }^{18}$ The one exception was Licensed Clubs, where price was identified as the most critical factor for competitive success by a majority of respondents (51.8\%); closely followed by quality of product or service by $47.6 \%$ of respondents.
} 
workplaces which placed emphasis on quality were more likley to have provided training for employees and had a higher proportion of employees engage in training.

The survey results also confirmed the popular perception of an industry in which long hours are worked seven days of the week. Fewer than a third of the workplaces were open for less than 12 hours a day, $46.1 \%$ were open from 12 to 20 hours, and slightly under $20 \%$ were open for more than 20 hours per day. $8 \%$ said that their hours varied from day to day. Just under three-quarters of the respondents operated for seven days a week.

We turn now to an examination of patterns of employment, labour and work in the industry, and how these are shaped by the variables (such as size, industry, subsector and product market considerations) discussed in this chapter. 
Chapter 1: Introduction

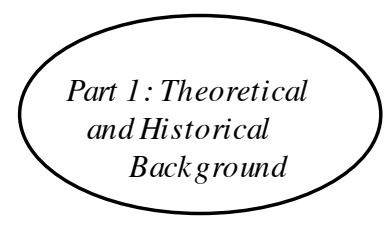

Chapter 2: Tourism and Hospitality Industry Development in New Zealand

Chapter 3: Employment, Work and Labour Relations in the Hospitality Industry

Chapter 4: The Framework for Analysis: Explaining Management Practice

Chapter 5: Research Approach and Methodology

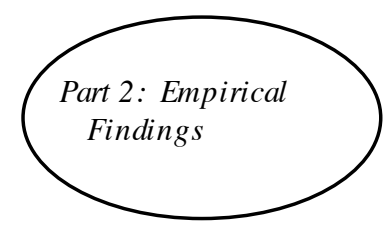

Chapter 6: Employment Relations in the Hospitality Industry

Chapter 7: Work Relations in the Hospitality Industry

Chapter 8: Labour Relations in the Hospitality Industry

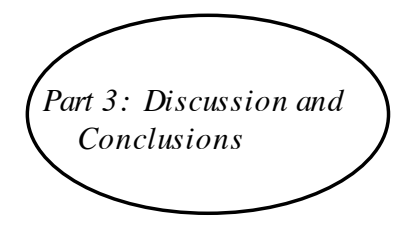

Chapter 9: Labour-Management Practice in the Hospitality Industry: Managing to Compete?

Chapter 10: Explaining Management Practice: Strategy, Environment and Social Action 


\section{Chapter 6: Employment Relations in the Hospitality Industry}

\subsection{Introduction}

This chapter outlines the nature of employment relations in the industry. The first section looks at the nature of employment itself - the type of people that are employed and the structure of employment. It considers also the way in which operational demands affect employment patterns and addresses the question of turnover and mobility within the industry. The second and third sections of the chapter go on to look at how new recruits are selected and trained at the workplace.

\subsection{Employment in the industry}

As noted in Chapter 3, the hospitality industry is an increasingly significant employer of labour in New Zealand. A profile of the industry's employees and the nature of their employment is set out below.

\subsubsection{The nature of employment}

The respondents to the survey employed between them a total of 11,500 staff, with a mean workplace size of 22.5 employees. Many respondents, however, were at pains to point out that employee numbers could vary significantly in response to seasonal demand. This was confirmed in interviews, particularly in those geographical locations which were either summer or winter holiday destinations, or alternatively where demand was affected by seasonal events (including, for example, sports bars which employed more people during the winter rugby 
season; Restaurants, Cafes and Catering Companies, which were busier at Christmas time).

Both the survey and follow-up interviews asked respondents about the nature of employment in their workplaces, in terms of whether employees were permanent or casual; and full-time or part-time. As noted earlier, employment in the hospitality industry has been characterised as "atypical" in nature (Walsh, 1991; Lucas, 1995). The findings presented here suggest that this characterisation is only partially accurate. It is certainly common for workplaces to employ casual and part-time staff. Over $60 \%$ of the survey respondents had employed at least one casual worker in the week of the survey, and 95\% had employed at least one part-time worker. However, it would be inaccurate to suggest that part-timers and casuals dominate the industry, and caution must be exercised to ensure that the two types of employment are not conflated. While there is some overlap in the two categories, the data suggests that clear distinctions must also be made and that the two are utilized by employers in very different ways. In addition, patterns of employment follow some distinct patterns associated with size, industry subsector and occupation.

As noted in Chapter 3, part-time employment is prevalent in the industry. ${ }^{1} 72.5 \%$ of surveyed workplaces had employed more part-timers than full-timers in the

\footnotetext{
${ }^{1}$ The survey did not use the term part-time or full-time worker, but rather asked how many employees had been employed for less than 30 hours, or 30 hours or more (the Statistics New Zealand distinction between full-time and part-time employment). Interviews suggested that a different definition of part-time is commonly applied in the industry. Asked what they meant by a part-time employee, interviewees commonly suggested that it was someone working fewer than 40 hours a week, and some included as part-timers employees who worked between 30 and 38 hours per week. When asked how many hours part-time
} 
week of the survey, and in $58.5 \%$ the proportion of part-timers exceeded $50 \%$. Not altogether surprisingly, greater proportions of full-timers were found in workplaces with more then 50 employees, and in the Accommodation and Catering industry sub-sectors. However, it must also be noted that a calculation of the ratios of full-time and part-time staff shows that in a majority of workplaces the proportion of employees employed on a part-time basis falls between 40-69\%. Thus a mix of part-time and full-time employees is engaged in most workplaces. Nevertheless, these proportions vary across the industry. As can be seen in Table 6.1, over $50 \%$ of Motels and Fast Food Restaurants are dominated by part-timers (that is, more than two-thirds of their employees are engaged on a part-time basis). Conversely, organisations engaged in accommodation provision employ a high proportion (more than two-thirds) of full-timers. Employment patterns are also associated with size. Both very small organisations (employing fewer than 10 employees) and larger than average ones (employing more than 40 employees) are more likely to employ either high proportions of part-timers or high proportions of full-timers, while medium sized businesses were more likely to employ a more even mix of full-time and part-time staff. In relation to market

Table 6.1: Proportions of full-time employees for selected industry subgroups

\begin{tabular}{|l|l|l|}
\hline Industry sub-group & $\% \quad$ of & $\% \quad$ of \\
& workplaces & workplaces \\
& employing & employing \\
& more FT than & more than \\
\hline
\end{tabular}

employees would "typically" work, responses ranged from 2 hours to 30 . However, the vast majority of responses fell in a range between 15-25 hours. 


\begin{tabular}{|l|c|c|}
\hline & $\begin{array}{l}P T \\
\text { employees }\end{array}$ & $\begin{array}{l}70 \% \text { FT } \\
\text { employees }\end{array}$ \\
\hline All sub-sectors & 27.5 & 8.8 \\
\hline Fewer than 15 employees & 25.4 & 10.9 \\
\hline $15-49$ employees & 26.0 & 8.4 \\
\hline $50-99$ employees & 54.3 & 21.9 \\
\hline 100+ employees & 47.5 & 8.1 \\
\hline Hotel accommodation & 46.3 & 15.1 \\
\hline Motel Accommodation & 17.8 & 2.3 \\
\hline Fast Food Restaurants & 15.2 & 0 \\
\hline Cafes & 30.2 & 8.0 \\
\hline Catering Companies & 35.9 & 9.5 \\
\hline Predictable demand & 26.6 & 10.7 \\
\hline Not predictable demand & 23.0 & 7.9 \\
\hline Expanding demand & 27.8 & 9.9 \\
\hline Contracting demand & 21.2 & 7.0 \\
\hline
\end{tabular}

factors, there was no association between the level of competition and the proportions of part-time staff, but organisations where demand was expanding and those where it was predictable were slightly more likely to employ high proportions of full-time staff. In addition, those workplaces where quality of staff had been identified as a critical success factor were more likely to engage fulltime employees. 
Interviews confirmed the patterns identified by the survey and shed further light on the nature of part-time employment within the industry. Both full-timers and part-timers were employed in all the workplaces where interviews took place, but some occupations (management grades, trained kitchen staff, and hotel and restaurant receptionists) were likely to be employed on a full-time basis. The majority of cleaners, however, were employed part-time. Waiting staff, and lower level kitchen staff could be employed on either basis, and many workplaces had a mix of the two.

As noted in Chapter 2, part-time employment has increased significantly in New Zealand over recent years. $28.1 \%$ of workplaces surveyed reported employing an increased proportion of part-time workers than five years previously. Increases were most likely to have occurred in larger workplaces, Accommodation Hotels, Catering Companies and Licensed Clubs. It is notable that in these industry subsectors, registered awards containing restrictions on the employment of parttimers existed until 1991, and the increase may in part be related to their demise. A range of other reasons for the increase in part-time work were suggested in interviews. These included factors related both to labour supply and operational demands. Several interviewees mentioned the importance of using a core of fulltimers supplemented by part-timers to cover peak periods as a way of keeping labour costs as low as possible. Many employers did not specify hours of work when recruiting staff, and employed either full-time or part-time workers for any particular vacancy. Some employers also noted that changes in patterns of customer demand (specifically more continuous demand through the afternoon in 
between lunch and evening peak times) had resulted in a change from deploying staff on split shifts to full-time employment. Some of the quotes below demonstrate the influences on whether staff are recruited full-time or part time: It's really up to them actually. We obviously put (ads) in the situations vacant for fulltime employees. Quite often out of those you'll get also part-time employees who come in. And we always have a need for part-time employees as a good back up scenario, and so we always look at them as a definite prospect. (Restaurant)

\begin{abstract}
At first we tried to find a range of part-time staff. ... It worked out good for a while, we could be more flexible but we just couldn't hang on to them. They were either students or only there for a short time trying to get that extra money or they had a relationship and the hours were too hard. So it worked out better to have full-timers where they are working five shifts, five nights a week for the kitchen and bar side of it. (BarRestaurant)
\end{abstract}

We don't need so many full-timers. We need people more during the weekend and not during the early part of the week. So we have one full-time dish washer and one fulltime front person who can do waitressing and maitre d'ing every night. (Restaurant)

It's really budget. The thing is that in the service industry, when you're only busy 3 or 4 nights a week, then you don't require someone 5 or 6 days a week. It's really due to budget. The full-timers tend to be the chefs and the bar managers who you need fulltime. And the casuals fit around that, boosting it over peak periods. (Restaurant)

Sometimes we might be looking for a full-timer and end up hiring part-timers; or looking for part-timers and end up hiring a full-timer .... usually it's a question of what's available really, what you can find. (Cafe)

The fact that employers made little distinction between part-time and full-time workers extended to their expectations. While the industrial relations literature tends to view part-time work as a peripheral form of employment that is less secure, the majority of employers interviewed saw part-timers as the "core" of their workforce. Part-timers were provided with regular shifts, and with training, 
and were expected to be as committed to the organization as full-time employees. A number of interviewees spontaneously drew the distinction between "true" casuals and permanent part-timers. As far as the latter group were concerned, the number of hours for which they were employed was of little relevance:

\begin{abstract}
Our true part-timers get regular work, and we have the same level of commitment to all of our staff. And the part-timers, their entitlements are the same as the full-time staff. They still get sick leave, they still get annual holidays. They get all the training obviously. We need them to be trained. The only difference with their annual leave and their sick leave is that it's on a pro-rata basis. (Accommodation Hotel)
\end{abstract}

The use of casual employees in the industry is much more complex in comparison. The survey asked employers to define casuals as "employees hired on a periodic basis as the need arises". 2 Neither the survey nor follow-up interviews wholly supported the contention that the industry is highly casualised. As can be seen in Table 6.2, more than $70 \%$ of workplaces employ more permanent than casual staff, and in more than $50 \%$ of workplaces the number of casual staff does not exceed $30 \%$ of total staffing. In addition, the use of casual staff follows some distinct patterns. Casual staff are more commonly employed in very large and very small organisations, and are more likely to be employed in workplaces where demand is expanding and unpredictable. The employment of casuals was only loosely associated with critical success factors. While those workplaces where quality (both of product and service) was identified as being a critical success factor employed the highest proportions of permanent staff, those where price was identified as important also employed above average numbers of

\footnotetext{
${ }^{2}$ As noted in Chapter 3, no standard definition of "casual" exists in NZ law. This definition was developed in the light of a general understanding (in light of Court interpretations) of the difference between casual and permanent employment as involving an expectation of continuing employment, even if hours change from week to week. This distinction was used as the basis for the definition of permanent employees.
} 
permanent staff (although these workplaces were more likely to have increased their proportions of casual workers in the previous five years). The highest proportions of casual staff were employed in workplaces where advertising and marketing, and location were identified as the most critical factors for competitive success. 
Table 6.2: Proportions of permanent employees for selected industry sub-groups

\begin{tabular}{|c|c|c|}
\hline Industry sub-group & $\begin{array}{l}\% \text { of } \\
\text { workplaces } \\
\text { employing } \\
\text { more } \\
\text { permanent } \\
\text { than casual } \\
\text { employees }\end{array}$ & $\begin{array}{l}\% \text { of } \\
\text { workplaces } \\
\text { employing } \\
\text { more than } \\
70 \% \\
\text { permanent } \\
\text { employees }\end{array}$ \\
\hline All sub-sectors & 70.7 & 53.7 \\
\hline Fewer than 15 employees & 67.9 & 49.4 \\
\hline 15-49 employees & 74.0 & 62.5 \\
\hline 50-99 employees & 74.6 & 54.2 \\
\hline 100+ employees & 100.0 & 81.8 \\
\hline Hotel accommodation & 81.9 & 69.8 \\
\hline Motel Accommodation & 52.6 & 28.2 \\
\hline Fast Food Restaurants & 58.7 & 41.0 \\
\hline Cafes & 79.1 & 59.1 \\
\hline Catering Companies & 68.2 & 58.1 \\
\hline Predictable demand & 67.5 & 56.1 \\
\hline Not predictable demand & 63.5 & 60.4 \\
\hline Expanding demand & 60.0 & 53.6 \\
\hline Contracting demand & 75.0 & 57.7 \\
\hline
\end{tabular}

Casual staff are most commonly used either for specific functions or one-off events (most commonly in Catering Companies and Accommodation Hotels) or in 
case of emergencies and absences of rostered staff. Typical are the responses below:

That's important because we could have someone sick in any of those areas; so you need to have people that can come in at short notice. (Cafe)

They are more an emergency scenario. At the end of the day it is terminology as such really. But at the end of the day I would say the casuals are there more just as a backup, and that's how they want to work too. (Restaurant)

I have three full-time and then I have whole lot of casuals. What happens is when it's just a normal cafeteria day and there are no other functions, then it's the three of us, so I work in the cafeteria, washing dishes, and things like that. And then when we have functions on, which is most days, I do the functions and I bring in one or two of my guys to work in the cafeteria and then I'll have helpers for me with the function and waitering staff. I mean we can have sometimes, you know, we've had ten, twelve people. It changes daily. (Cafe-Catering)

We have a permanent staff of 8 , and an on-call staff of up to $50 \ldots$ We actually have a roster up in the office. And it goes up every time we have work come up, which is a week in advance. People come in ... all we do is write up the number of people required, the hours that we envisage that the function will go for, and the person then puts their name up against it. (Catering company)

While the survey provided a definition of "casual" employees, interviews provided an opportunity to explore whether the unprompted understanding that employers had of the term coincided with juridical ones. In interviews, employers who stated that they used casual employees were asked what they meant by the term casual. This revealed a wide misunderstanding of the nature of this type of employment, in almost all sectors. The definition of "casual" workers provided by interviewees included those employed on an hourly basis, those whose hours changed from week to week, those who solely worked weekends and those who resigned after a short period of time. Other interviewees were clear about the 
definitional distinction between part-time and casual workers, but noted that in practice, there was often an overlap between the two :

Well they are generally people who have come to us and just said "Have you got anything?" and we say "Not right now, but if you want to do some shifts when we're short we'll train you up in the meantime. And then when one of the part-timers or fulltimers fall off, then we will give you some regular hours." And it is quite surprising just what regular hours those people get actually. Not regular in terms of a particular shift, but regular in terms of the number of hours. (Cafe)

It's become a difficult definition. It used to be that under the Award, it was pretty strictly defined, what was part-time and what was casual but I think the words are probably being treated generally interchangeably in the restaurant business. My notion of what a casual is, is that it's somebody who works only on call, not regular hours. In fact, everybody tends to be a mixture of both. You'd have one regular day that they're always scheduled for, and then other days that they do as well, so they're really casuals and parttimers. (Restaurant)

Despite concerns about casualisation in the industry, there does not appear to have been any dramatic spread in the extent of their use. The $22 \%$ of workplaces where use of casual staff had increased in the previous five years was exceeded by the $28 \%$ where the proportion of casual workers was about the same, and an additional $14 \%$ who employed casuals less frequently than in the past. ${ }^{3}$ Analysis suggested that those areas with the greatest increases in the use of casual staff over the previous five years were in Motels and Catering Companies, in workplaces employing more than 40 employees, where demand was expanding, and where price was viewed as being critical to competitive success. Use of casual employees was not, however, associated with the extent of competition or predictability of demand. Interviews suggested that the employment of casuals 
was viewed as an undesirable necessity, and many employers preferred to offer additional shifts to regular part-timers wherever possible. Casuals were commonly perceived to not offer the quality of service that was desired, ${ }^{4}$ and to adopt an instrumental approach to work that was at odds with the employers' desire for committed employees:

It's my perception that it would be hard to find people who are able to be on-call I've never had good experience with that. Especially when we are employing primarily younger staff - they're students or young people. It seems to me that they don't really need the work, because they certainly don't put in any extra effort. Very rarely will I come across staff who will work any time and anywhere and who want the money. They tend to be working because they have to and they'll fit it around their social life. (Cafe-Restaurant)

To be quite honest, if you're running your business efficiently and effectively, you shouldn't require casual staff. I don't think it benefits either party. Not in an operation this large anyway. (Accommodation Hotel)

Most of our part-timers are casuals, but there are more casual people that are parttimers, if that makes sense. So in essence we've got some permanent casuals and casual casuals. Not everyone is able to work as a part-timer on specific days that we need them. So they are then casual casuals. (Motor Lodge)

\subsubsection{Employees in the industry}

Associated with issues about the nature of employment in the industry are those concerning the employee profile. The gender and ethnic profile of employees in the surveyed workplaces is not surprising given both observation and available

\footnotetext{
3 Although this finding is contrary to what might be expected, it is similar to the pattern uncovered by Brosnan, Horwitz and Walsh (1996). Their multi-industry surveys carried out both in 1991 and 1996 also found a decrease in casual employment over this time period.

${ }^{4}$ In one of the quotes here, the interviewee went on to comment on the quality of work supplied by casuals. His comment was underlined most appropriately when the interview was interrupted by a waiter bringing in a plunger of coffee for us. The waiter said as he poured the coffee "I don't know what the coffee will be like. I didn't know how to make it. I just tipped some instant into it and stirred it up." At the end of this interchange, as the employee left the room, the interviewee remarked "He's casual"!
} 
statistics. Women are employed in greater numbers than men, and in $37.7 \%$ of workplaces, women comprise more than three-quarters of all employees. Men are employed most commonly in Restaurants and Pubs, and larger workplaces. In terms of ethnicity, the vast majority of employees in the industry are European/Pakeha. Although numbers of Maori employees are small, just on $60 \%$ of workplaces employ Maori staff. Fewer than $20 \%$ of workplaces employ either Pacific Islands, Asian staff, or those of other ethnicities. Other variables suggest that the degree of ethnic segregation in the industry is considerable. The employment of non-Pakeha employees is closely associated with size of workplace. Maori, Pacific Islands and Asian staff are more likely to be found in workplaces employing more than 30 employees, and are considerably more likely to be found in workplaces employing more than 50 employees. Ethnicity is also associated with industry sub-sector. Maori are more likely to be employed in Accommodation Hotels, Pubs and Catering Companies, Pacific Islands staff in Fast Food restaurants and Catering Companies, and Asian staff in Hotel Accommodation, Fast Food Restaurants and Restaurants. In addition, non-Pakeha employees are most likely to be employed in lower paid occupations in the industry, such as housekeeping, cleaning, and low-level kitchen work. In interviews, little reference was made to Equal Employment Opportunities (EEO), ${ }^{5}$ and only one manager had a policy of ensuring workforce diversity:

We purposely targeted a mix of people. So if you look in our lobby, you'll see that ladies are older, we've got some older women here, we've also got a couple of older

\footnotetext{
${ }^{5}$ The operation of EEO programmes is voluntary in the private sector in New Zealand (although required by legislation in the public sector). The EEO Trust is the body which has been established and partially funded by Government to promote EEO development in workplaces. Two hotels/hotel chains and two Fast Food Chains (all very large organisations in the industry) are members of the EEO Trust (EEO Trust, 1997), although membership does not require any action beyond payment of a membership subscription.
} 
men here. We try and get a cross section. Because in fact what happens is the older people provide life, life experience for the younger people and the younger people provide, I guess, energy for the older people and it really works in very well. Our policy is that your employment should mirror your community. Okay, so we have a cross-section of ethnic people in our business, but we also have a cross-section of ages. Because we find that in our experience that that sort of thing fits very well and that people communicate and get on a lot better when there's a mixture as opposed to everyone being the same. (Fast Food Restaurant).

The hospitality industry is perceived, both inside and out, as one in which the average age of employees is younger than in the paid workforce as a whole. The industry constitutes an important source of employment for younger workers, and $14.4 \%$ of workers in Hotels and Restaurants are under 20 years of age, in comparison to only $7.1 \%$ of those employed in all industries (Statistics New Zealand, 1993). Of the workplaces responding to this current survey, $56.4 \%$ employed under-20 year olds. However, these workers were usually less than $40 \%$ of the total workforce, and the vast majority of employees under the age of 20 were aged 18 or 19 . In addition, a number of interviewees noted that they had a policy of not employing workers under the age of 20 where the work involved the sale of alcohol. ${ }^{6}$ Under 20 -year olds in the industry are considerably more likely to be employed in organisations which employ more than 20 employees, and in specific industry sub-sectors. For example, 95.9\% of Fast Food Restaurants, $78.7 \%$ of Catering Companies and $73.4 \%$ of Accommodation Hotels employed

\footnotetext{
${ }^{6}$ Under the Sale of Liquor Act 1989, the minimum drinking age is 20 (although exceptions are provided for accompanied minors, and within "supervised" areas such as restaurants.) Minors can, however, sell alcohol (for example, when employed in supermarkets or cafes). Nevertheless, public concern about access to alcohol by teenagers (in part because of the difficulties of age-identification) has led a some of employers in the hospitality industry to adopt the policy mentioned here. Although this has never been tested in the Courts, it is likely that this discrimination is unlawful under the Human Rights Act which prohibits discrimination on the grounds of age, except where age constitutes a "genuine occupational qualification" (S.30).
} 
under-20 year olds, in comparison with only $16.5 \%$ of Licensed Clubs and $28.5 \%$ of Pubs. In addition, fewer than $10 \%$ of workplaces have increased their numbers of under-20 year olds in the past five years. Employment of higher proportions of under-20 year olds was not associated with any demand or competition factors, although those workplaces where quality of staff was perceived as important for competitive success were slightly more likely to employ younger staff.

Qualitative analysis suggested that managers view employees as falling into three broad groupings based on their motivation for working in the industry. The first includes those who work for a short term basis for instrumental reasons, including people wanting a second job to save for a particular purpose or as a form of temporary employment (such as travelers and recent graduates). The second are those who are clearly committed to the industry and looking for a career within it. In between these two groups lay those who work in the industry on a long-term basis and who are financially reliant on their earnings but who for various reasons do not wish to work full-time or regularly. Included here are those whose main career offers only intermittent employment (such as actors and dancers), students, and women with dependent children. These three groups are viewed and valued very differently. Transient workers are not highly regarded. Although frequently undertaking essential tasks, they are often seen as providing a source of operational flexibility, and as being easily replaceable and therefore readily dispensable. Those working in the industry on a long-term basis however, whether as trained chefs or as casual waiting staff, are highly regarded and valued employees. The difference between the two groups was frequently described in 
interviews as being a matter of attitude and the extent to which they would "go the extra mile".

The chefs tend to be more committed. They will not get sick, considering the pressures and the hours that they tend to work which is always quite long hours.... And they will work any time; they'll cover for each other; they'll say "Look, I'll cover for you tomorrow if you want to have a day off'. The front staff tend ... to work what they need to work and no more than that. On the odd occasion they'll fit around each other, and they'll be flexible with each other and help each other out if necessary; but on the whole people work extra hours only begrudgingly whereas in the kitchen there's a stronger work ethic. There is a culture in the kitchen; there isn't quite so much the same culture on the floor. (Cafe)

The people that work here are very good. And they work quite hard, but they're not interested. When they finish their shift, they finish their shift. They're not particularly interested in whether things are set up for the next person coming on. ... It's probably a lack of co-operation I think, in the people that are transient. They're here to earn the money while they're here. And they work quite hard when they're here, and they do a good job. But a lot of time they only do the bare minimum. What they can get away with. Whereas the full-time people, I find that they're more .... I suppose there's more of an incentive. They want to get promoted, they want a really good reference in the end, so they're watching themselves to see that they get that. These people don't even particularly care whether they get a good reference, because they're not going to be working in the industry. So there's not that underlying incentive. (Cafe)

We've got some older people in our housekeeping. Especially middle aged ladies who are great. The backbone ... they are the most experienced people and the most reliable and we'd be just about almost dependent on them. We've got a lot of younger ones as well. We've got two who are about 17 years old. Our experience shows that they aren't the most reliable and so we tend away from them. If we have the choice between an older person and a younger person if we're taking people on, the young one's probably at a disadvantage. They have to shine through in an interview for us to think that we'll take them on. (Accommodation Hotel)

\subsubsection{Employment and hours of work}

Both the nature of employment and the type of employee engaged in the industry are commonly explained as being warranted by operational attributes of industry. 
Nearly three-quarters of the survey respondents reported that their workplaces were open seven days a week, and more than half were open from 12-24 hours a day. Hours and days of operation are closely associated with workplace size and industry sub-sector (with larger workplaces and Accommodation Hotels and Motels being open for longest hours). This reflects the fact that work in the hospitality industry commonly involves the provision of a service to customers engaged in a leisure activity. A consequence of this is that employees are customarily required to work at nights and on weekends. The issue of employee availability for work at these times was contentious in many workplaces. It is common for employers to impose requirements about availability as a condition of employment, whether this is expressed in terms of the numbers of hours that employees are expected to be available for work, or the days on which they are prepared to work.

We're never closed, we're a hotel. We're open twenty four hours a day, seven days a week, three hundred and sixty five days a year .... When we employ people we say to them, you know, "What is your availability, are you able to work weekends?" And if they say "No" well we say to them "You must remember that we are a seven day a week operation, so you could be required to work a weekend". (Accommodation Hotel)

They come here on an availability basis. They have to be prepared to work a minimum of sixteen hours a week. (Fast Food Restaurant)

She's been used to working Monday to Friday and now I'm saying that if (the new supervisor) wants to roster you on Saturday and Sunday, then you have got to work it and have Monday and Tuesday off, or Thursday, Friday off. I said if you went to a big hotel, only the Executive Housekeeper I would think would have that luxury of perhaps weekends off. But the Samoan girls have church commitments on a Sunday, so it makes it a bit hard for them. (Accommodation Hotel) 
Hours of operation can cause difficulties for rostering arrangements as a result of the need to balance customer demand and employee availability, as employers seek to roster their best employees at busy times, or a mix of experienced and inexperienced staff at the same time to provide training for the latter. Fluctuations in demand are seen as creating havoc with rostering arrangements. Nevertheless, as noted in Chapter 5, more than two-thirds of respondents reported demand as being predictable. In addition to the size and industry differences noted earlier, interviews lent support to the notion that ability to predict demand is a function of management skill as much as it is to industry characteristics. In particular, newer managers and those in small workplaces were more likely to see demand as unpredictable. Those with more experience were aware of patterns from the past:

\footnotetext{
We know our patterns through history, and we use history a lot. And that tells us that .... we look back on last year and we know that Melbourne Cup day today will be that from 5 or 6 o'clock onwards we'll have people swinging through. Rugby weekends we know, other things. We also know that weather is a big factor for us. Great weather in mid-summer gets our outside area really busy. So we use a lot of history and also common sense. (Restaurant)
}

We know that Monday and Tuesday are dead. Unless we've got something that we've generated on the side, other sorts of activities. Wednesday is always a good night for us, and Thursdays. Fridays is always our busiest. So we pick up for that. Weekends are quiet, so you just drop it down. Unless there is something on like a rugby match. Things like that, but you've got plenty of time to plan for, you know you're going to be busy from historical factors. (Licensed Club).

While predictability of demand allowed advance scheduling in rosters, variability in hours of work was common. In over $50 \%$ of workplaces, employees work regular hours, or hours might vary only on occasion. Several interviewees reported that this was important for ensuring orderliness and quality of service for 
customers. Employee hours were most likely to vary regularly or to be completely irregular in workplaces employing more than 40 employees and in Accommodation Hotels and Fast Food Restaurants. Employees in workplaces where demand is stable and predictable are also more likely to have regular hours of employment; while those in workplaces where demand is either contacting or expanding are more likely to work irregular hours. In most cases, hours of work and rostering are determined by employers after consultation with employees as to their availability. While in $69.3 \%$ of workplaces employees had at least some flexibility to choose the hours and days on which they worked, this was most limited in larger organisations. The range of ways in which rosters are negotiated within the bounds of demand and availability are typified by the descriptions below:

We do a shift plan for every shift, which is all fully itemised, who's going to do what. And there's a lady that does the roster, which is a massive task here because we like to fit in with people's lives. We don't say, "that's it". We discuss it with every individual what their needs are and their roster. Now occasionally the tail starts to wag the dog, and then you say that "Well, we fit in, and we're more than fair, but you've got to fit in with us to". But once she's done the roster the manager's expected to transfer the roster on to their shift plan two to three days ahead. So they're planning ahead, and they don't come in on a Sunday morning and say "Oh shit, I haven't got enough staff'. (Restaurant)

It's left to department managers. In Portering the Head Concierge puts up the roster every week and she says to the part-time people, "These are the shifts available, you choose what you want to do". Providing all the shifts are full, if they are not, then she obviously says "Well come on, you know that we need to fill these shifts, fill them." But she allows them first in first serve basically. Whereas, for example, in the restaurant its a little bit more structured, basically because there's a high number of people there. And in the part-time area the shifts are handed out. (Accommodation Hotel) 
They have a choice by electing their availability. Their availability is put into the computer. Now from time to time when their circumstances change, they could put in a change of availability. Now providing that it's not totally different from that they originally were employed in, we don't have a problem generally. We try and help them as much as we can. But we also are aware, and they're also aware that sometimes they are employed based on their availability. If we're looking for specific people for specifics areas or times, then if we need to, we basically say "Well look, you know, this doesn't meet our requirements." We need to at least come to some sort of an arrangement and we compromise. (Fast Food Restaurant)

There are 3 rosters - 1 for the front, 1 for the chefs and 1 for the kitchenhands. And then once a week, every Thursday, for the week beginning the next Monday, everybody has got their name on the roster, and at the end you've got a comments section. And in the comments section they put on if they'd like days off the next week, like if they want to go away for the weekend, or if exams are coming up. But they've got the option to do that. Basically they work around the same number of shifts and they're expected to .... like if they want Friday night off, they're expected to do something else instead. But a lot of them change ... the full-timers are pretty much set, but the part-timers will change a lot. (Cafe-Restaurant)

The need to balance operational demands with a desire for flexibility means that rostering arrangements are an intensely political process in many workplaces. They are used by managers not only to provide the necessary quantity and mix of workers, but also as a means of control. Employers who have given away some power through allowing employees to elect their availability use rostering arrangements to establish an equilibrium in the labour-management relationship. Although this is clearly in their favour, managers also see it as counterbalancing their preparedness to be flexible in respect of employees:

Sometimes ten people ask for the weekend off, and then we have to say to a few of them that they can't. And usually the people that are the most co-operative with me get the first pick on having the weekend off. While the people who are never happy to cover shifts usually don't. And I say that to them, that's just how it works - it's very much you scratch my back and I'll scratch yours. (Cafe-Restaurant) 
The way that the roster works, if you get somebody and they're not particularly good, you just don't roster them on. So then therefore they start looking elsewhere for work. (Accommodation Hotel)

The favoured ones get called first. And they have the first right of refusal. ... The roster is a very powerful tool for management. Because it's a way of giving away something that is not very valuable to me, but is valuable to them. (Cafe)

(Some people are) losing a little bit of enthusiasm and interest. Exams are coming up, we have a lot of students here. And it's a give and take situation, at least that's certainly the way I see it. We expect them to come to work, that is part of the process when we employ them. We also don't overdo it. I mean if someone has got an exam or test coming up we don't give them work the night before. However, because of so many people having time off lately, or not willing to work, in order to promote a bit more competition amongst the staff, and make them sort of think about having time off, for various reasons we decided maybe let's try and employ a few more part-timers and just see if the situation changes. And its interesting because it has actually changed, we seem to have more people that want to work. (Accommodation Hotel)

Even where rosters are well-organised in advance, sickness or an unexpected absence can cause difficulties. This was easier to manage in larger workplaces, where employees could be shuffled around if necessary. It was also common for managers to regard themselves as an additional pair of hands. At other times, bringing in employees on call was regarded as a necessity, and required additional negotiation:

I grovel! Please, please!!! I'll do whatever. I'll drive them in. Sometimes I'll pay them cash to come in on their day off. That's why I've got so many part-timers actually. In the beginning, when we started, most of them were full-timers and we had just a few back-up part-timers. But there were so many people calling in sick. ... And I found that with full-timers who only had 2 days off a week, you pretty much couldn't convince them to come in on their day off. Whereas part-timers who are only doing 2 or 3 shifts anyway might want to earn a bit more money. Or they might want a favour out of me next week. So they think "All right, I'll do that and then when I want the night off I'll get it." And I'm a floater too. I don't put myself on any 
shifts. I just float and cover shifts if its needed. And for the front managers, and the Head Chef, it's understood that if no-one can cover, even if they've been working all day then their responsibility is to cover. (Cafe-Restaurant)

We've got 6-10 on-call employees like that. We ring them up and say "Hi, I'm sorry to get you up at 8:30 on a Sunday morning, but I was wondering how do you feel about doing some work today??!! I always call you first, but no pressure if you don't want to!" (Cafe)

\subsubsection{Turnover and Mobility}

As noted in Chapter 3, the hospitality industry is one in which levels of labour turnover are perceived as high. The findings from this study confirm this perception only in part. $94 \%$ of survey respondents had had at least one vacancy in the previous year, and turnover rates did not vary notably with respect to alternative competitive strategies, demand or competition variables. Vacancies were, however less common in workplaces where fewer than 10 employees were engaged, particularly in Licensed Clubs. Several caveats must be placed on the general pattern however. Firstly, turnover is higher for some groups within the industry than others. Secondly, turnover is relative. Less than $10 \%$ of the survey respondents had a complete turnover of staff in the course of a year. In $35 \%$ of workplaces turnover was fewer than a quarter of all employees, and in a further $32 \%$ between a quarter and a half of staff changed in the course of a year. Although turnover may be higher than in other industries, ${ }^{7}$ in many instances managers do not perceive high turnover as being a problem. Lastly, despite high turnover, many workplaces have a core of extremely long-serving staff.

\footnotetext{
${ }^{7}$ It must be noted that although there is a perception that levels of turnover are higher than in other areas of the economy, as no published figures on employee turnover are available in New Zealand, it is difficult to assess the truth of this assertion. In addition, the wide range of comparable figures in the hospitality industry literature (see Chapter 3 ) does not provide a particularly useful basis for comparison.
} 
It was clear from both the survey and interviews that some occupations and groups have a higher level of turnover than others, and that these patterns are clearly understood and accepted by managers within the industry. As noted in Chapter 3, managers do not necessarily see high turnover as a problem to which a solution should be sought. Service and sales staff were the occupational group where turnover is highest, with $51 \%$ of survey respondents indicating that they had had vacancies in this area in the previous year. While this is not surprising given the sheer volume of service and sales workers in the industry, there is also a clear perception amongst managers that this group is more transient in their employment patterns than, for example, reception or kitchen staff, who are seen as having a longer term commitment to the industry, and steadier employment. In large part, this was put down to the individual characteristics of employees. Young workers, students, and travelers, often employed as waiting and front-ofhouse employees, were perceived as having less employment stability than older workers, workers with families, and those working in the industry on a full-time basis (such as kitchen, housekeeping and reception staff):

I think (turnover) would be more in the restaurant than it would be to the kitchen. The kitchen staff would stay longer, because the hours are good, the conditions are good, it's a very organised kitchen. The nature of the work tends to suit the type of employees that we have. They don't want to go anywhere else. (Restaurant)

Well the managers are usually fairly stable. ... It's more the younger people who tend to move, more than the older ones who have more stable family, more financial commitments and a bit more responsible about their jobs I suppose. The young ones tend to come and go a bit much. (Bar-Restaurant) 
We actually have quite a high turnover ... well I think it is high. But I think its the nature of the people we attract. We have a large student base here. The hours suit them, the employment, because they can come and go, and it suits them. It's students that are casuals, so when exams are on, we don't see them. (Catering Company)

In addition to the fact that turnover varies for groups within the industry, it was not uncommon for workplaces to have a core of long-standing employees. The vast majority of interviewees noted that they employed staff who had been with them for the entire time that their business had been open. In three cases, length of tenure extended to over 20 years. This pattern of a core of long-standing employees and a satellite staff with high turnover raises interesting questions about employment patterns within the industry. The most common explanation for the existence of long-serving employees was provided in relation to women with families, usually employed in work such as housekeeping or cleaning, which is similar to the unpaid work they perform at home:

These ladies that I've got working for me that have been working for me for a long time have got families. That's the extra income they need, as they say, it buys the things they couldn't have on the one income. So they're working because they bloody well have to. (Pub)

On the housekeeping side, we've just lost a part time employee who has been here 23 years, and her off-sider has been here a similar number of years, so that's been great. They live in the area, so its handy for them to do that 8 a.m. till 12 p.m. shift. She's only left because her husband has retired and she's moved out of the area. (Licensed Club)

Most of them are secondary income earners, or they are the second income earners for their family, or their home unit. And the hours suit their family situation. ... Husband is earning the major income, this is their spending money, but it also gives them hours a day to do either what duties they have at home or what any other interests they have. Now that sounds a very sexist comment, but it is a reality. So that's the reason why those people stay. (Motor Lodge) 
Explanations for people leaving the industry were many and varied. Students might move from school to University, change educational establishment or move into the full-time workforce. Travelers might move on to their next destination. For those people moving on to other jobs in the industry, reasonably frequent changes of scene are felt by managers to be necessary to prevent "staleness" and to experience a variety of hospitality industry locations. In addition, the industry is perceived internally as being made up of a recognisable hierarchy of establishments, and some employees might move onto a better "quality" of work in terms of service standards, pay and hours of work. Teams, particularly of kitchen staff, will sometimes move together from workplace to workplace. The understandings managers had of the reasons for high turnover were crucial in whether they perceived it as a problem or not. While it might cause operational problems, they did not always see as one which they needed to be overly concerned about:

I generally find that we don't lose people that we want to keep to other restaurants. Not much. Now that would probably be a bit of a concern if that happened. Overseas travel is quite a big thing. Sometimes it's "I know what I want to do, I want to get a proper job". You get people who have sometimes got out of their (main job) ... we've got someone who finished sales repping, and something didn't go right, and she's been looking, but she seems to have settled in and has done us great service. (Restaurant)

Sometimes I see it as a problem if they stay too long. Some people stay too long, and they're sick of it, and always looking for the easiest way to do it. (Cafe-Restaurant)

In a year, we would have between 15 and 18 leave out of 95 employees. Now half of these would be leaving because their basic term's up. You know, they've concluded their degree, it's time to go into the big world and find a job or whatever they want to do. Or their circumstances may have changed, they may be shifting to University 
somewhere else or something like that. Half of them would leave for whatever reason, I don't know, although we ask them. (Fast Food Restaurant)

Moving overseas is high on the list, more for our younger workers. And some of them have left for reasons of dissatisfaction, because the expectations given to them weren't met. But generally it's to improve themselves. (Catering Company) 


\subsection{Bringing them in: recruitment and selection practices}

\subsubsection{The process of recruitment and selection}

Given the extent of turnover within the industry, it is not surprising that recruitment and selection is a common activity for many workplaces. The processes used for recruiting staff, and the perceived success of those methods are set out in Table 6.3. As can be seen, word of mouth is the most common source of recruitment, and is generally perceived as the most successful. Even where a range of recruitment methods had been tried, when asked to describe how they went about filling vacancies more than half the interviewees referred to word of mouth recruitment, and people walking in off the street. The frequency with which this happened was underscored by the fact that three research interviews were interrupted by potential employees coming in to ask if work was available. Several explained what they saw of the benefits of employing people this way: Because you don't have that problem of .... the initial thing of people ringing up about the job, hassling you and so on. (Motor Lodge)

I find that if I need anybody its through people what work here. They recommend a friend who needs work, and usually because they are recommending someone, they're not going to recommend somebody who doesn't know what they are doing. (Bar-Cafe)

What I like best is to ask the existing staff do they know of anybody who wants a job. People know the person that's coming along, how reliable they are, are they a good worker, what their standards are. And that's important in this job. (Conference Centre)

I've never advertised for staff. It's a combination of people coming and asking me or people phoning me up and saying "I'm a friend of such and such". It's a pretty casual way of getting to meet the people and then I just make my judgements from there. (Pub) 
Table 6.3: Methods of recruitment used for filling vacancies and perceived success of method

\begin{tabular}{|c|c|c|}
\hline Recruitment method & $\begin{array}{l}\text { \% of workplaces using } \\
\text { method }\end{array}$ & $\begin{array}{l}\text { \% of workplaces } \\
\text { considering that } \\
\text { method to be } \\
\text { successful }\end{array}$ \\
\hline Word of mouth & 77.0 & 60.9 \\
\hline Advertising in local paper & 61.3 & 40.1 \\
\hline NZ Employment Service & 49.6 & 25.2 \\
\hline Internal promotion & 23.6 & 12.4 \\
\hline Advertising in national paper & 18.2 & 8.5 \\
\hline Recruitment agencies & 11.7 & 4.5 \\
\hline Other & 10.0 & 5.3 \\
\hline
\end{tabular}

Word of mouth recruitment is particularly common for medium sized organisations. Because their staff do not turn over as frequently, small organisations have less need for an established recruitment practice, whereas larger organisations are likely to rely on formalised methods, in part because they are more likely to employ professional and trained staff which are perceived as being much harder to find. Nevertheless, many employers have established and systematic processes for selection of staff. This commonly involves asking potential recruits about their previous experience, what sort of work they are after and work availability. Few, however, outside the very largest organisations, have formal application forms, systematic criteria for guiding selection decisions, or 
undertake reference checks. The two most common ways for new employees to be selected is for employers to consult the list of people who have come in asking for work and to interview the most promising; or for those people to be brought in on a casual basis and offered more regular work if they work out. Typical of the processes used are the following descriptions:

We find that a lot of it is word of mouth, you know, friends of friends, who've worked somewhere else. If you don't know the person, and if they're not extremely good, then we'll probably trial them for a week or two anyway. We try to give them busy shifts, and just see if they fit in. And if they fit in then we'll look at training them. (Cafe)

We've got different people applying all the time. We normally ... if they sort of fit the bill that we require we'll keep them on record. If a position comes up we'll give them a ring, get them in and train them up. (Licensed Club).

It will occasionally happen that somebody who has been working casually will go into full-time, and chances are when they start with us casually they would have been hired just on the basis of coming through the door. We do tend to have a list of people who come in and have asked about casual work, and we keep that on file, and if something comes up we give them a ring. (Restaurant)

The selection process is not considered to be complete until the completion of a trial period, even though most employers who make use of trial periods are aware of the legal difficulties in so doing. The rationale for doing so was commonly expressed as being a check on their judgement, and to ensure that the new employee "fitted in":

I know that with the industrial law trial periods are now getting to be a bit of a no-no, but we still have to have time where they can ... you might get someone who's quite intelligent that can't handle the stress. Or will panic when there's four people demanding attention at once. (Accommodation Hotel)

If someone gets past (the interview) stage I'll bring them into the restaurant, on the floor, on a trial basis. I know that a trial is illegal but on a trial basis. Even to the extent 
that I'll bring someone in for the first shift as a freebie. Y'know I wont pay them and they'll come in and we'll just sort of look at each other. But because I'm not employing a lot of people I would tend to have a good feeling about them after the first shift, and would tend to put them on a roster for the rest of the week. And I say to them, its not a trial, obviously legally they're employed, but we give each other a two week stand-down period, and at the end of the two weeks we'll reassess it. I've never had any problems with employment relations - legally. And I know that its not $100 \%$ kosher, but that's what I do - I say let's give each other two weeks and re-assess it. And I think 9 times out of 10 I've always employed them. And I don't give them a contract until that period. (Cafe-Restaurant)

\subsubsection{What do employers look for?}

Given that few employers had formal criteria for the selection of staff, an interesting question arises as to how they decide which of many applicants will be the most suitable employee. Interviews revealed a heavy reliance on "gut reaction" as an influence in decision making:

The initial interview is only fifteen minutes long. And to be honest with you, you can tell in five minutes whether they're going to be suitable. (Fast Food Restaurant)

You can pretty much gauge people, when you first meet them. You have a few words with them, you don't have to ask them pointed questions. You just get a feeling - gut feeling. (Licensed Club)

Well in the end it comes down to gut reaction, when it comes to choosing people. (Restaurant).

Beyond this, however, two key considerations stand out as being critical for managers as qualities which they look for in applicants. The first is loosely described as "personality". The characteristics which employers spoke of repeatedly in interviews were good communication and interpersonal skills, confidence and assertiveness, an extrovert nature, and an ability to put aside one's 
own problems and to appear (if not actually be) happy. A particular facet of this mentioned by a significant minority of interviewees (and discussed further in Section 7.3) was that good staff have an ability to "read" customers. This involves an ability to discern when customers want to chat or be left alone, when they want another drink or their next course, whether they are having a good time or a bad one. Most managers believed that these skills were not ones that employees could be trained for. Most were of the opinion that "you either have it or you don't". Given that these qualities can only be accurately be assessed over a period of time the demeanour of applicants during the interview was crucial in determining whether they were offered a job or not:

Pretty much by just watching how they act. I mean, we don't, we're not big on big interview scenes. So if the person looks like they're a party sort of person, bubbly, happy all the time, can cope with anything, that's pretty much it. (Bar-Restaurant)

I tend now from experience to employ people based on personality. ... An ability to communicate easily, with me. If they can communicate with me in an interview then they should be able to communicate with customers. Very much an aura of friendliness and a little bit of confidence and ... niceness is I guess is what I'm saying. (CafeRestaurant)

First of all we're interested in people that can serve customers, so communications becomes very important to us. All you need is a bit of practice and you'll make (the product) quite well, but can you serve customers, have you got communication skills to look after customers? (Fast Food Restaurant)

What we look for is personality, that's the main thing. We believe you can train people but you can't train the personality. And if they've got a good personality, they can smile, they're bubbly - well that's the sort of person that we're looking for. And then we'll worry about the rest later on. (Bar-Restaurant) 
A second key consideration for many managers was expressed in words such as "hard-working", "punctual", "honest", "reliable", and "willing". Again, proxies (such as whether the applicant had turned up on time for the interview, and their general demeanour) were used by managers to assess these qualities. A variety of views were expressed on the desirability of industry experience or qualifications in the selection of staff. Chefs or receptionists are frequently required to have formal qualifications. However, not all qualifications are viewed positively and a number of interviewees noted that they did not necessarily provide an advantage for a job applicant. ${ }^{8}$ Some employers look to previous industry experience (or experience in other service occupations) as guaranteeing a minimum level of skill in customer service. However, comments from some managers suggested that previous experience could be a disadvantage if it meant that employees were not able to adapt to another way of doing thing, or had picked up bad habits:

I used to prefer to train cooks from scratch because a lot of people had some very bad habits, which you had to break before you can trust them. (Restaurant)

I'm not really fussed on experience, I don't have any catering quals, I think, you know, it's just common sense and work ethic. Come in and you do your days work and you go home. That's what I really want. (Cafe-Catering)

They often have been trained the wrong way. There are a lot of people with very bad habits. (Restaurant)

I look for industry experience for reception work, and in the kitchen area, for the chefs, yes. But I'm still prepared to look at someone who hasn't got any qualifications. If they've got enthusiasm, and it just beams out, I'm quite prepared to give that person a chance. (Motor Lodge)

\footnotetext{
${ }^{8}$ Regional patterns suggested that some tertiary institutions are perceived as providing employers with high quality graduates, while others are seen as mediocre. However, the small numbers involved do not allow this
} 


\subsection{Training them up: induction, training and skill development}

\subsubsection{Induction and initial training}

While the survey asked separately about the processes of recruitment, selection, induction and training, interviews suggested that these processes are more continuous than discrete. Potential employees are frequently given information about the organisation and a physical tour of the property at the interview stage. As noted earlier, the prevalence of trial periods means that the selection process does not end at the point at which a contract of service is entered into. Thus induction, common in all size groups and industry sub-sectors, may begin at the interview stage and spill over into an initial training period. This will customarily take the form of giving employees a variety of information about the organization, providing them with a physical tour of the property and specifying details about their job. Table 6.4 shows the range of information provided to employees when they are newly recruited.

to be assessed with absolute reliability. 
Table 6.4: Information provided to newly recruited employees

\begin{tabular}{|l|c|}
\hline Information provided to newly recruited employees & $\begin{array}{l}\% \text { of workplaces } \\
\text { providing this } \\
\text { information }\end{array}$ \\
\hline Information about their job & 97.5 \\
\hline Information about employment conditions & 91.5 \\
\hline Information about uniforms and appearance & 89.0 \\
\hline Information about the company or business & 67.5 \\
\hline Information about the geographical layout of the & 57.6 \\
\hline work area & \\
\hline Other & 6.8 \\
\hline N=530 & \\
\hline
\end{tabular}

In about a third of the interviewed workplaces, employees are provided with written material prior to their commencing work. This sets out (inter alia) expected standards of dress and behaviour, work rules, health and safety procedures, use of telephones, pay and rostering arrangements, and details about their conditions of work. Three managers describes the process here:

We normally just give them a quick run-down on the Club history, show them through. Where we would be looking for them to work. What sort of hours, run through it from there. We'd then get them on in a practical sense, just to -y'know - say they are on a bar position, get them behind a bar while we're open, show them different things - till layouts, prices, glasses, go right through everything. And then sort of schedule them on for shifts from there. (Licensed Club)

If they've accepted the job ... I would get them in before their first day on the roster, I would give them the manual, I would give them our rules and regulations which are contained in that, I would give them a tour around the place so that everything is familiar on their first day, and I would say to them that it is very important that they 
read and digest the manual before they come in. It covers rules and regulations, our ethos, who is involved, its a very simple structure but try to give them an outline of the ranking as it were, codes of behaviour and what is expected of them, fire regulations, wages, holiday pay ... all the stuff that's contained in the contract. Plus for the floor staff there's a whole section on service. What I actually expect of them right down to the tone of how they would say things and suggested ways of talking to the customers. (Cafe-Restaurant)

We talk about the company that we work for, ... how they got started, who they are, their management philosophy. We talk about the hotel as an individual unit amongst the chain. We talk about the structure. ... We go through the staff handbook and outline our policies and we go through that very, very thoroughly. That covers things like grooming standards for males and females. Things like our smoking policies, basic things like how to get into the building, security doors and those sorts of things. Start times, we talk about the benefits, like staff discounts. We talk about the staff cafes, the staff transport, how their wages are paid. (Accommodation Hotel)

Following induction, new employees are put through an initial training process. In $69.8 \%$ of workplaces, this training is undertaken by the manager or supervisor of the department or area concerned, except for Motels, where training was more usually performed by another employee. In other cases it is performed by a senior employee, or by another employee and a manager jointly. While a small number of workplaces adopt the "throw them in at the deep end" method of training, most apply some degree of systematisation. The structure of this varies significantly. At one end of the scale, new staff are employed as a supernumerary and "buddied" by a more senior employee who demonstrates the performance of tasks. In other workplaces a more formal training programme is in place, in which employees progress through a range of tasks, and are required to demonstrate their competence in one area before they move on to the next. The most structured are those operated by large organisations, such as multi-establishment firms and 
branches of multi-national companies. Typical examples of both types are described below:

Most training is on the job. I mean I sit down and explain everything to them, but there is only so much explaining you can do, you just have to do it. So I give them to the manager, or the person who's in charge of the kitchen. And every shift there's a shift manager, who's in charge of cashing up, and making sure everyone's working on their shift. They usually get 5 or 6 shifts being an extra person. And then I start them on the very slow days, and I do that for about 2 or 3 weeks. And then once I can see that they're okay, then they turn into what I call a real person. (Cafe-Restaurant)

There is a set training procedure for front of house, where they start off as drinks runner. There's 75 tables, and just to understand that I think is a big task. So I just don't believe in that "here's a docket book" when you're an inexperienced waiter. So they work through food runner, drinks runner, at a pace that suite us and them. And then they go to waiter assistant, working with a waiter, but with less customer contact, a commis runner. Then they have about 4 sessions in waiter training, getting full knowledge of the menu, the questions they get asked, how to write dockets, how to deal with the kitchen. (Restaurant)

Both the survey and interview asked how long on average it took new employees to work to the standard expected of other employees in that job classification. Table 6.5 on the next page shows that the level of skill perceived as necessary to perform the job varies significantly by industry sub-sectors. In addition, initial training time increases with increasing workplace size, but does not differ across other variables.

Table 6.5: Average time taken for a new employee ${ }^{9}$ to work to the standard expected of other employees in that classification

\begin{tabular}{|l|l|l|l|l|l|l|}
\hline Industry sub-sector & 1 day or & Less than & Between & Between & 3 months & Other \\
\hline
\end{tabular}

\footnotetext{
${ }^{9}$ Given that the time taken to work to the required standard is likely to vary from occupation to occupation, the question asked about the occupation for which the respondent most frequently recruited.
} 


\begin{tabular}{|c|c|c|c|c|c|c|}
\hline & less & a week & $\begin{array}{l}\text { a week } \\
\text { and a } \\
\text { month }\end{array}$ & $\begin{array}{l}\text { a month } \\
\text { and three } \\
\text { months }\end{array}$ & or more & \\
\hline $\begin{array}{l}\text { Hotel } \\
\text { Accommodation }\end{array}$ & - & $12.9 \%$ & $65.9 \%$ & $15.7 \%$ & $4.2 \%$ & $1.4 \%$ \\
\hline $\begin{array}{l}\text { Motel } \\
\text { Accommodation }\end{array}$ & $2.1 \%$ & $28.7 \%$ & $56.9 \%$ & $6.3 \%$. & $6.0 \%$ & - \\
\hline $\begin{array}{lll}\text { Pubs Taverns and } \\
\text { Bars }\end{array}$ & $2.4 \%$ & $26.3 \%$ & $58.7 \%$ & $12.6 \%$ & - & - \\
\hline Cafe & $3.4 \%$ & $20.2 \%$ & $62.1 \%$ & $11.9 \%$ & $1.1 \%$ & $1.1 \%$ \\
\hline Fast Food Restaurant & $3.4 \%$ & $21.2 \%$ & $48.7 \%$ & $22.5 \%$ & $4.3 \%$ & - \\
\hline Restaurant & - & $13.4 \%$ & $59.5 \%$ & $20.1 \%$ & $5.3 \%$ & $1.8 \%$ \\
\hline Licensed Club & - & $18.5 \%$ & $68.7 \%$ & $12.8 \%$ & - & - \\
\hline Catering Company & - & $17.6 \%$ & $55.9 \%$ & $17.6 \%$ & $8.8 \%$ & - \\
\hline
\end{tabular}

Managers recognise that initial training involves comprehending a variety of details, and that degrees of competence varied according to the individual. Some individuals could perform the job satisfactorily in a month, but it might take longer for them to become expert at it. Similarly, in the same way that managers believed that prospective employees either had it or didn't, some individuals, it was argued, would pick things up almost immediately, while others would never come up to scratch:

Some people really click. On average, about a month. But then there are people that can do it after three days and there's people that still won't make it after a month. (Cafe-Restaurant) 
The right type of person will pick it up and run with it quite adequately in that time.

(Motel)

People either get it or they don't. (Cafe).

\subsubsection{On-going training and career development.}

The research also looked at the question of on-going training of staff within the industry. Table 6.6 sets out the percentage of workplaces providing on-going training during the year prior to the survey.

The percentages of employees participating in on-going training are highest in Restaurants and Fast-Food Restaurants and in organisations employing more than 50 employees. The propensity to provide on-going training for employees is also associated with demand and competition variables. Above average proportions of employees are provided with training when demand is expanding and in workplaces where the quality of staff or providing a distinctive product or service had been identified as critical success factors. Conversely, in workplaces where demand is contracting, smaller proportions of employees are engaged in on-going Table 6.6: Percentage of employees participating in on-going training in the previous 12 months.

\begin{tabular}{|l|c|}
\hline Proportion of employees provided with & Proportion of workplaces \\
training & \\
\hline None & 13.8 \\
\hline A quarter or less & 21.5 \\
\hline Between a quarter and a half & 10.6 \\
\hline
\end{tabular}




\begin{tabular}{|l|c|}
\hline About half & 9.1 \\
\hline Between a half and three quarters & 11.5 \\
\hline More than three quarters & 10.5 \\
\hline All & 23.0 \\
\hline
\end{tabular}

training. The vast majority of on-going training involves general on-the-job training, undertaken in $79.2 \%$ of workplaces. Fewer than a quarter of workplaces provide training at external institutions (such as Polytechnics), with specialist training (such as wine waiting), or with supervisory skills training. Interviews reinforced the notion that the provision of on-going training is informal and general. It most commonly involves providing individuals with skill enhancement on an on-the-job basis. Nevertheless, some employers increasingly recognise the importance of on-going training and have made efforts to ensure that employees are provided with training opportunities such as KiwiHost and Food Hygiene courses. Training sessions as part of staff meetings (including sessions on coffee making, wine appreciation, health and safety, fire evacuation procedures, cocktail making, host responsibility and licensing laws) were also frequently mentioned. Those workplaces in which higher than average numbers of employees are provided with training are more likely to provide training across a range of areas, suggesting that provision is better integrated into some, but not all operations. Several interviewees, however, pointed to difficulties in providing on-going training. These ranged from cost considerations, the culture 
of the industry, the likelihood that trained staff would move on quickly, and a perceived lack of interest in training from staff:

People do tend to departmentalise themselves, this is what I want to do, and I don't want to learn anything more. (Restaurant)

We try to push people to get their certificates, like the Bar School ones. But it's very hard, given the hours, and the split shifts and the budgets in a small organization to do anything other than on-the-job training. We attempt to at least once a month have some staff training. And what we do is things like fire evacuations, first aid, bar procedures. (Bar-Restaurant)

But for ongoing training its usually little bits and pieces, just keeping an eye out when you're working, if you see somebody not presenting a wine, and you want them to present the wine, this is the reason we want to present it, and we present it this way. So its just always keeping an eye on and that way you keep the restaurant and bar running the way you want it to, and everybody is doing it the same way. (Bar-Restaurant)

\subsection{Summary and conclusions}

In summary, it is useful to compare and contrast the employment relations practices uncovered by this study with those suggested by other research. The absence of detailed studies of contemporary employment practices makes it impossible to compare these findings with practices in other industries in New Zealand. However, a comparison with the hospitality industry literature outlined in Chapter 3 draws attention to some interesting similarities and differences. In relation to employment structure, the findings of the current study are in line with those elsewhere which point to the prevalence of part-time employment, but with pockets (such as particular occupations and industry sub-groups) where full-time employment is more common. Questions have been raised, however, about whether employment is as casualised as it is sometimes characterised as being. Casuals tend to be used in specific circumstances and were not viewed altogether 
favourably except where they were brought in to meet particular operational needs. Whether this finding holds true for the hospitality industry in other countries would be an interesting question for further examination.

In respect of the labour market dynamics of recruitment, selection, induction and training, the findings here also show considerable similarities with those found in other countries. The industry experiences a reasonably high level of labour turnover, and most workplaces are reliant on the external market to fill vacancies. This study supports Riley's $(1991,1993)$ argument, however, that high levels of mobility are regarded as functional by managers, and operate as an important mechanism for skill accumulation. Other areas of similarity with previous hospitality industry research lie in the largely ad hoc and unsophisticated approach to employment practices such as recruitment and promotion, and the increasing attention being paid to the necessity of training of staff.

The more interesting question for assessment from this material is what it tells us about the variables which affect the manner in which employers and managers conduct their employment relations. It is clear that workplace and organisational size have a considerable impact. Increasing size was associated with greater systematisation of practice and development of a rudimentary internal labour market. While these patterns were also loosely associated with industry subsector, commonsense suggests that this association may be a consequence of size (i.e. the fact that Fast Food Restaurants and Accommodation Hotels are on average larger workplaces than Restaurants and Cafes). Demand and competitive 
success strategies (but not the level of competition) were also found to be associated with employment structure and the level of investment in on-going training. Nevertheless, these market related variables do not entirely explain the range of employment practices which are put in place. Firstly, while firms may adopt employment practices that correspond with the factors on which they seek to compete, this does not explain why firms operating in similar markets choose to compete on different strategies. This suggests that employer perceptions of the market in which they are operating play at least some role. Secondly, underlying (at various levels of consciousness) a number of the comments made by managers about their employment practices was a focus on their ability to control employees through the nature and quality of their personal relationships. This can be seen in the way in which potential applicants were assessed by "gut reaction", the way in which rostering arrangements were used as a means of control and to reward "cooperative" employees, and the fact that training is offered only to selected employees. The ways in which personal relationships at the workplace are a central control tool in the industry is developed in further detail in the next chapter. 
Chapter 1: Introduction

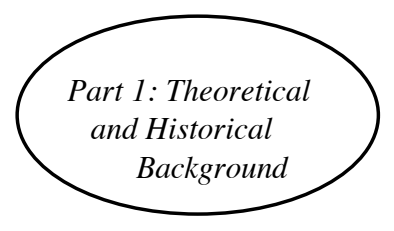

Chapter 2: Tourism and Hospitality Industry Development in New Zealand

Chapter 3: Employment, Work and Labour Relations in the Hospitality Industry

Chapter 4: The Framework for Analysis: Explaining Management Practice

Chapter 5: Research Approach and Methodology

Chapter 6: Employment Relations in the Hospitality Industry

Chapter 7: Work Relations in the Hospitality Industry

Chapter 8: Labour Relations in the Hospitality Industry

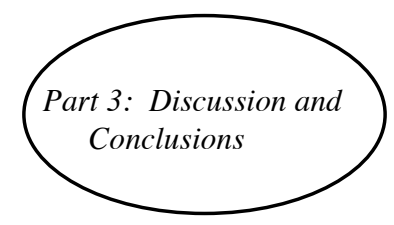

Chapter 9: Labour-Management Practice in the Hospitality Industry: Managing to Compete?

Chapter 10: Explaining Management Practice: Strategy, Environment and Social Action 


\section{Chapter 7: Work Relations in the Hospitality industry}

\subsection{Introduction}

Following on from the previous discussion about the ways in which managers control employees through employment relations, this chapter considers the nature of work relations. By virtue of the character of the processes involved, it relies more heavily on the qualitative material gathered in interviews than survey data. It begins by looking at the nature of hospitality work and the extent of work routinisation, before moving on to look at continued occupational segregation and the spread of multi-skilling or "cross-training". The third and fourth sections of the chapter consider the importance of interpersonal relationships in the workplace, firstly between staff and customers, and secondly between employees and managers.

\subsection{The nature of hospitality work}

\subsubsection{Key features of work in the industry}

The nature of work in the hospitality industry is described by competing stereotypes. One of these is that hospitality work is dull, boring, repetitive, dirty and demeaning. A second, and possibly more recent, stereotype is more positive. It replaces the old image with portrayals of work as fun, glamorous, exciting and sophisticated, and has developed as the industry has become increasingly associated with travel, eating out, and a new urban environment. Comments made by managers in the course of interviews suggested that they felt that this new 
representation was exaggerated, and that the old stereotype was perhaps closer to the truth:

If you talk to all my friends, they all want to work in a restaurant. And I'm just like: "Why?" But to people that don't know, it seems to have this sort of glamorous quality for some reason. I can't say I think like that myself, but I think maybe that's what attracts a lot of people. They think "Oh, it would be really neat to work in a bar", they forget that you're working you don't get to stand around drinking with people. (Cafe-Catering)

There's a lot of people when you advertise, especially for reception they think it's a glamorous thing, and even though you say hotel experience, you get all these people that have been (working) nine to five and they've got no idea. It's five days, it's shift work, so it can be $7-3$ or it can be $3-11$. And if you're on the $7-3$ shift, then you can't go out partying all night because you've got to be back for 7 o'clock. Then you've got 3 - 11, and by the time you've finished at 11, you're too tired. (Accommodation Hotel)

Managers' view of work in the industry was that it was physically hard, emotionally demanding, and involved an ability to deal with complexity not recognised by outsiders (including customers), who commonly perceive work in the industry as unskilled and low-status. As one restaurant manager noted "It's like anything - the most skilled people are the ones that make it look easy."

Long hours, and the sometimes pressured and frantic nature of performing work within time constraints, create physical demands in many hospitality industry jobs. Many require a degree of physical strength, endurance and dexterity to shift furniture, lift kegs of beer and cases of wine, transport bulk quantities of food, and balance numbers of plates and glassware. When staff are not busy with the job at hand, they are expected to undertake additional work, such as cleaning shelves, polishing glassware, and clearing tables. Many jobs involve considerable attention 
to detail. Cleaning staff, for example, may be expected to check $200-250$ items within a 25-30 minute time period, for each of the 13-14 hotel rooms or motel units they clean in an eight-hour day. Hotel receptionists are required to retain and recall vast amounts of detailed administrative information, including information on tourist activities, destinations, transport and accommodation. Waiting staff must correctly locate up to 75-100 tables, be able to discuss details of wine lists and menus, and serve the correct meal to the right person, ensuring that any specific requests made by the customer (e.g., no dressing on the salad) are met. A number of managers admitted in interviews that staff are poorly paid for the work that they do, and that their skills often go unrecognised:

The skills that they use and that we are training them in are amazing and they're not given much credit in our world for them. (Restaurant)

\begin{abstract}
The perceived view of waiting and service staff in New Zealand is that there was a time not so long ago where people looked down upon those sorts of positions and they were considered servile. Whereas today, that's all changing. We're realising that this can be a career for a lot of people, and if you are qualified at doing something that your pay level should be higher. (Accommodation Hotel)
\end{abstract}

While some interviewees promoted a view of the industry as increasingly cognisant of the skill involved in many jobs, others argued that many hospitality jobs continue to be extremely boring and repetitive. As two managers noted: I mean it is basically a dead-end job. If I wasn't doing it as part of my own business I wouldn't do it by choice. I'd do it if I was desperate. (Motel)

It gets boring. I mean a lot of the work is boring. There's probably 2 or 3 positions here that are interesting and really the rest are boring. They're quite repetitive. (Cafe-Restaurant) 
In addition to the physical demands, work in the industry involves "emotional labour" and putting aside one's own needs in order to service the customer. Although issues relating to customers are dealt with in considerably more detail in Section 7.3 , it must be noted here that many managers saw hospitality industry jobs as being emotionally exhausting, even where customer contact was indirect (as in the case of kitchen and housekeeping staff). This emotionality arose out of the constancy of meeting customer needs, often in a very immediate way, and to keep smiling at the same time:

You ask someone to do a Sunday brunch, from 9 a.m. until 4 p.m., and (the customers) are just coming all day. ... Our managers should recognise when someone's flagging and say, "Hey, why don't you go on the food counter" and just get them away from direct contact, and put someone fresh on there. (CafeRestaurant)

I mean my industry is run like "Fuck this, fuck that" "Do it now". ... Our industry works on conflict, so you've got to be thick-skinned. If you burst into tears every time someone says "Just do it"... especially in a kitchen, kitchens are very feudal. (Restaurant)

It's constant. And sometimes you just think go away, I don't care! People complain about trivial things and you know that you're supposed to listen to them. (Cafe-Restaurant) 


\subsubsection{The routinisation of hospitality work?}

As noted in Chapter 3, some studies have suggested that hospitality industry work is being routinised (Salmon, 1992; Leidner, 1993). Interviews with managers looked at the extent to which workplaces have adopted standardised processes for job performance and the service of customers. Their answers suggest that standardisation has increased primarily as a means of achieving greater consistency of service, but that only in Fast Food Restaurants (and not surprisingly there) can the provision of products and service be seen to have reached the extreme of "McDonaldisation".

In a number of small workplaces, the tasks to be performed are not recorded in any way, and job descriptions are lacking. In these workplaces, employees are left to "get on with it" and the job receives their personal imprimatur. In others, tasks are specified and demonstrated as part of the initial training process, but the manner of their accomplishment is flexible. Individual personality and skills are integral to job performance, although these will frequently be "checked" by a manager or supervisor, to ensure adherence to a minimum (but unspecified) standard. Details of tasks and service standards are set out in about half the medium sized workplaces and all the large sized ones, and in all industry subsectors. These frequently involve requirements for table settings, how people should be greeted, recognition of regular customers or guests, what music should be played at what time of the day, how orders should be taken and served, and how bills should be processed. While standardisation is not uncommon, in only one case did a manager emphasise the need for employees to rigidly adhere to 
requirements. In most cases they are an operational framework, which serves to ensure a consistent quality of customer service, and also makes things easier for staff. They are not intended as a constraint, neither are they intended to prevail over individual personality characteristics:

There is a service procedure, but it doesn't try to take away personality. What you've got to do is get them into the habit so they don't have to think about it. The personality side is hard enough. So they come in and they say "Hullo, how are you? Smoking or non-smoking? Would you like a drink to start? How are you off for time today?" (Restaurant)

They do have 15 steps that give them the guidelines of just what steps to go through for the whole evening, as far as meeting and greeting, to presenting the menu, to presenting the drink menu, to getting the drinks, to getting the food, to check on the food. And that all comes with their training any way. It is written down, but there's no set way to address a person. We believe in saying to them everybody's an individual ... don't use the same sort of tack as somebody else because it may not work for you. (Bar-Restaurant)

Other managers saw disadvantages in standardised service:

I don't have formal procedures about how they do the job. I wouldn't really like to see it get that way. I prefer them to be themselves to a certain extent, and always be polite. I don't like going to places where everybody is uniform. I wouldn't like to see this place get so that everybody was treated exactly the same. I would find that a shame. (Cafe-Restaurant)

There are quality standards in the service that must exist, but that there is scope for personality to come through there. We're not interested in the plastic smile, we're interested in people interacting with people. (Accommodation Hotel)

Why do some workplaces choose to adopt standard service requirements while others do not? Workplace size is a notable influence on this. In small workplaces managers can directly control their employees, while larger workplaces are considerably more likely to insist on adherence to written service standards. Even 
some smaller workplaces have adopted standardised practice, however, and set these out in manuals which they provide to employees. For many employers, standardisation of service provides their customers with a guarantee of quality or distinctiveness in service standards. Specific service requirements might be put in place because they establish an operation in a particular market niche or for other business related reasons. One restaurant owner, for example, explained that his staff were trained to offer espressos cappuccinos or lattes (rather than filter coffee) because it provided a higher profit margin. A final reason for standardisation related to the turnover of staff, as a motel owner outlines below:

\footnotetext{
We expect certain standards and we will go out and inspect things ourselves. We are lucky again because we've got a small group of long term staff members and they provide that standard. (Without that) then without a doubt I would move to a more standardised situation because it's a better way of guaranteeing it, especially if you've got a more higher staff turnover. But because our staff turnover is less it gives us the freedom to be more flexible. (Motor Lodge)
}

\subsection{Occupational segregation and multi-skilling}

As noted in Chapter 3, studies of the hospitality industry show a continued high level of segregation between occupations. Four occupational groups predominate front-of-house or waiting/service staff, kitchen staff, housekeeping and cleaning, and management. Some (usually larger) workplaces also employ people in other occupations such as reception, porters, door staff, trades employees, computer operators, and administrative staff. In general, the findings of this research found that the tradition of strict demarcations between occupational groups in the industry had continued relevance in New Zealand in the 1990s. 
The culture of the industry ensures that traditional occupational hierarchies continue to be potent in limiting the extent to which individuals cross occupational boundaries within the same workplace. Interviewees were asked about their policies on internal recruitment and the possibility of staff moving from one occupational group to another. While few were opposed to the idea, a number of reasons were advanced which suggest that they view the suggestion as having limited practicability. In many cases the reality of workplace size means that opportunities for multi-skilling are extremely limited beyond the general principle that "everyone has to pitch in and help when necessary". In addition, interviewees alluded to occupation-specific nature of the skills required for some jobs in the industry, (e.g., reception and kitchen work) which made it difficult to transfer staff. Beyond this, however, two other rationales for the lack of movement between occupations were commonly put forward. The first was a belief by managers that employees are not interested in moving, attributing this to a lack of ambition on the part of employees. For example, several managers associate this pattern with an instrumental work motivation on the part of employees and argued that employees just want to come in, do their work and go home again. While this perception was frequently expressed, few managers offered supported evidence to back up their claim, except for their "knowledge" of employee ambitions. In addition, managers frequently attribute occupational segregation to personality preferences. Chefs are characterised as creative, passionate and somewhat impulsive, while front-of house staff are extroverts, gregarious and people-oriented. In contrast, housekeeping staff are often seen as careful, painstaking and providing a good deal of attention to detail. In the minds 
of many managers, choice of jobs reflects immutable individual personality characteristics which limit the extent to which employees wish to move, even if it were possible to provide greater ranges of career choices.

Despite this, multi-skilling (or "cross-training" as it is known in the industry) has become increasingly common over recent years. Most large organisations (generally either Accommodation Hotels, Fast Food Restaurants or Catering Companies) include provision for cross-training in their employment contracts, and some smaller workplaces also make an attempt to provide employees with a broader range of experience where practicable and desired. Training opportunities are frequently provided through internal training programmes offered by the organisation. At managers' own admission, most moves, when they occur, are at the initiative of employees themselves, and will frequently be "rationed" to those who they consider have the potential to have a longer-term career in the organisation or the industry. The rationale for this is often argued on the basis of organisational imperatives, particularly the need to retain skilled staff and the limited availability of training funds, as the following quotes demonstrate:

We have a lot of movement (internally). Because ... we are supporting each other whereas in some hotels, they won't let them move from their area, because they're losing an experienced trained person. And as an HR person you're trying to say, "Yes, but you're going to lose them anyway". ... Because ultimately, if you don't move people they will go somewhere else. (Accommodation Hotel)

We offer subsidised training. $100 \%$ subsidy in the majority of cases where people are taking relevant training to our industry. Provided of course that they stay within the same role. And there is a limitation of how much we are prepared to put in our budget and spend on training, or external training. (Catering Company) 


\subsection{Dealing with the customer}

The interviews made it clear that interactions between employees and customers are possibly the most critical influence on work relations in the industry, and that many employers see it as crucial for their business success. This is underscored by the fact, as noted in Chapter 5, that quality of products and service was viewed by $72.7 \%$ of the survey respondents as being either the most important or second most important factor for determining competitive success. Interviews explored this issues further by asking managers and employers about how they expected their employees to treat their customers, whether the customer was always right, and whether there were any limits to behaviour that would be tolerated in customer treatment of employees. 


\subsubsection{Dealing with the customer - service or product?}

When asked how they expected employees to behave towards customers, interviewees showed a remarkable degree of solidarity and unity in the words used to describe their expectations. Words such as "friendly", "personable", “professional”, "polite”, "sociable", and "charming” were frequently used, serving to emphasise the importance of emotional labour for much front-line work in the industry. Several were explicit in their adoption of the "customer as employer" metaphor and suggested that the service standard of "giving the customer what they want" sometimes requires going to extremes in some way:

I expect them to provide the best service they possibly can. And that means that if a person is unhappy with their meal or their coffee then it's replaced and they get their money back. ... The people that come here pay their wages, and I make that point very clear to all the staff. It's not me that pays their wages, it's the people that come in here. So what I expect is that they treat the customers as kings. Or queens. (Cafe)

So I try to say to the staff, look, you have to go to what you might consider to be an extreme of service before they get the benefit. Like if someone is asking where the local dairy is, so they can buy cigarettes ... if you've got the time, go down the road and get them for them. It's extreme, but you make a difference to that person. And people mentally keep a score of the places they go to. (Cafe-Restaurant)

There is nothing that we cannot give, cannot supply, would say no to. It doesn't matter what it is - if they want to eat something and we've got it in the kitchen, why can't they have it? If they want to play with a sheep, you get a sheep in! ${ }^{1}$ (Accommodation Hotel)

\footnotetext{
${ }^{1}$ This comment refers to an earlier interchange in which we had discussed a documentary screened on television the previous month, on the operation of the Ritz-Carlton at which the 1995 Commonwealth Heads of Government meeting was held. Among the guest requests which hotel staff had been asked to meet at various times were playing with a sheep, buying a car for a guest who was unable to find the time to do it himself, and completely remaking a set of curtains to ensure that city lights could not penetrate a VIP room at night. More commonly undertaken services in luxury hotels include buying presents for family members, finding lost luggage, and cleaning up vomit, excrement, and general mess after guest parties.
} 
The concept of "quality service" does not lend itself to objective definition. Rather it very much depends on the market niche in which the business chooses to operate, and the style or "culture" which is being created. In some workplaces, quality service involves a degree of formality, and is characterised by adherence to service performance standards such as greeting the customer in the specified way, accurately describing the menu, correct presentation of wine, and general attentiveness to customer requirements. In other workplaces, the atmosphere which is being created is more relaxed, and informal service may be a deliberate attempt to meet customer desire for a more anonymous environment. Even within an establishment, service may vary in different places. Bars may provide less formal service, for example, than fine dining areas. That service may vary with the nature of the service site is described most clearly by the manager of a business which undertook commercial catering as well as managing two cafes:

(Service standards) depend on the different areas that people are working in. For example, we've got two cafes. This cafe is more refined ... and there will be a friendlier attitude, where they've got time to spend with people. As opposed to our other cafe where it's more jovial and moving. And in the functions area it's sort of very formal, it's "sir" "ma'am", and you don't speak with anyone unless you're spoken to. (Cafe-Catering)

As noted in Section 7.1, standardisation and routinisation are commonly utilized as a tool to ensure consistency in service quality. Nevertheless, it was clear that many managers feel ambivalent about these processes, and believe that taken to extremes, can have the opposite effect from the one they are trying to achieve. Even when standards are explicit and formalised, a critical aspect of good service is seen to involve an element of authenticity in terms of personality. After explaining in detail what he required of his staff in terms of how customers are 
approached, and the sequence in which orders are taken from customers, one manager went on to say that:

But we are a very informal place, and we emphasise that to them when they start.... So we do want they to relate to customers as individuals, and to have their own sort of style. Within the balance of making sure that they work efficiently, that we get the information from the customer that we need in order to give them what they want. ... You have people that relate in different ways for different people, so we might have one waitress who's very reserved and what she does is smile at people and say good morning to them. And there'll be somebody else who is much more gregarious who will listen to people's life history and then when they come in the next time, say y'know "How's your sick pet doing?" and things like that. (Restaurant)

While staff are expected to be individuals, there are some aspects of their personalities which they are prohibited from exhibiting at work. The imperatives of good service allow only the agreeable aspects of individual personality to be expressed. As with other workers providing emotional labour, employees are expected to discipline their other impulses in order to minister to customers. As discussed in the next section, although employees are not expected to put up with unacceptable behaviour from customers, a required aspect of their expected professionalism is the extent to which they are able to deal with difficult customers and to leave their personal lives behind:

They know the routine, they know what's expected. They're always punctual, they're always polite, they know they have to leave their baggage at the door. Those are the rules and if they don't do it then they go home. And one girl was sent home one night, she wasn't in a good mood and it showed and I said "you need some time out". She agreed and off she went. She knew the rules. (Restaurant)

Comments which managers made about their expectations suggested that employees are required to "play a role" in providing customer service. As noted in 
Chapter 3, customers are also "product", and success in "processing" the product is a key element in how good service is defined by managers. Two particular aspects of this were referred to in interviews. The first of these was the skill required in "reading" customers and providing them with what they wanted, but had not specified, or anticipating their needs:

I want them to try to read the client, so that if the opportunity arises i.e., if people are interested in having some kind of dialogue with the staff, that they impart a sense of personality with the client. ... Because I want my clients to feel that when they come here they have some sort of experience other than just consuming food and drink. I want them to be able to read the client. If someone is sitting there on their own, or there is a couple who are obviously having a slightly difficult evening, they should just be able to act appropriately. (Cafe-Restaurant)

One of our key tasks is to read body language and to read the unsaid things. (Restaurant)

Because our customers have different expectations depending on where they are from, I want them to understand their wants. Like you know, some people want fast service, and others want like some relaxed and slow service. I want them to understand that they have to give them what they want. And also I want our staff to be attentive and caring. If you see someone's beer is nearly empty, to ask them if they want some more beer. Some people can do it without you telling them, some people just don't recognise it. (Restaurant)

There are certain subtleties that not everyone picks up on. I always try to explain to people that some people want to talk and others don't. And leave them alone if they don't! And you can pick up it, you can pick up on their body language. (Cafe)

The second aspect of "the customer as product" was the way in which managers described the satisfaction experienced when they were able to "turn the customer around" or rescue a difficult situation:

Some of our customers are extremely demanding. ... But that's part of life, you'll always get those people, and we'll go out of our way, and if they're coming back, 
we know, we're ready for them! We're ready to turn on the charm the next time! It's almost like a challenge, to see whether they can find something to complain about. (Accommodation Hotel)

It's easy to be nice to the $95 \%$ who are nice - the test of your professionalism and your skill is how you deal with the other 5\%. And if you use good skills you can turn them round. ... If there's a table of 8 , there'll be one arsehole. And you look round the table and there'll be at least one person who'll be sympathetic. Who is looking at you and saying "Don't take his bait, don't wreck our night". And we see it so often. And they'll come up at the end of the night and thank you. And what they're really saying is "Dad was an arsehole, we know it, you know it, but thank you for keeping it right.". You know people who big-note in restaurants...and there're a lot of them. Who come in and complain for the sake of it. They're a bit too full. And that's where we get our pleasure is in turning it round. (Restaurant)

\subsubsection{When the customer isn't always right}

Establishing routines congruent with the culture of the workplace is as much a question of educating customers as it is of controlling employees. Customers learn to expect different levels and standards of service in different establishments. While customers would not expect to wait more than two minutes for a Big Mac, this speed of service would be rushed in a high quality restaurant. Several managers in interviews mentioned the need to "educate" customers about what they should expect from their service experience. The range of areas included guidance on wine appreciation, drinking habits, realistic expectations, the way staff are treated, and the way in which they treat premises. Two managers here talk about the range of difficulties in providing good customer service when the customer is a source of difficulty:

I've had somebody loud and obnoxious trying to push in. So I say to my staff, treat people politely but expect politeness back from them. Even to the stage where if they are very, very blunt in the way that they order their drinks you go, "Hey, you're missing a word there mate!" Some people are not used to using manners to bar staff. 
I personally do not think that bar staff should be exposed to the rudeness of some clientele. And that's part of my job as publican, I think to train my clientele to let them know that they will be treated politely and efficiently, but that they have also got to show a bit of decorum as well. (Pub)

(We ask them) do you have any time constraints? ... And they say, "Thanks for asking" , or "No we've got plenty of time, and we're going to have three courses" or "Yes, we've got to be at the movies in half an hour". So then we have to educate them and say, "Well, that's pretty quick, as soon as you've decided we'll be right there and we'll achieve what you want." (Restaurant)

These quotes demonstrate a widespread ambivalence in the industry about whether the customer is always right. While some interviewees were adamant that they were, the majority took the view that was best expressed by a motel manager who commented that "The customer is always right even when they are wrong"! Underlying these attitudes is an evident inconsistency in employer attitudes. On the one hand, many voiced the view that their workplaces had to provide what customers (the market) wanted in order to be successful. On the other hand, many had established themselves in a market niche and aimed to provide services to attract discerning customers seeking to purchase an experience rather than a product. In many cases this involved not providing services which some customers might want and educating the market about which services they were and were not prepared to provide. The way in which some managers spoke about "educating" the customer clearly demonstrated that they sought some influence over the market, and did not solely respond to customer demand. For example, one cafe owner spoke of the need to educate his customers about coffee in order that they might have a greater appreciation of the quality with which they were being provided. Similarly, one restaurant owner with two dining areas actively 
encouraged customers into the more informal area if they had time constraints because she did not believe that the dining experience that she sought to provide in the formal area could be enjoyed otherwise. In this way, the relationship that managers have with customers is seen as being considerably more complex than one in which they simply provide a service to meet customer demand.

Interpersonal problems between customers and staff are another common source of difficulty, particularly when they escalate upwards. Frequently, the necessity of immediacy in dealing with an unpleasant situation results in customer pacification. However, many managers suggested that they were aware of the fine line between customer and employee fault, and that honest mistakes could happen. In addition, many interviewees accepted that dealing with customers was a stressful part of the job, and expressed some understanding and sympathy for what employees have to put up with:

There's no point arguing with customers. When they ask for things, they demand really rather than ask. And they see you as the bottom rung on the ladder and they're having a bad day so, you know, I'll be rude to the girl in the cafe and you haven't got a rung underneath. You have to be nice to everybody, you can't have a bad day. (Cafe-Catering)

Some of our customers are painful, I say that myself. I have trouble dealing with some of my customers. Some of my customers are very monotonous, boring people. And the reason they come to a pub is because the staff have got try and be cheery and talk to them. They've got to do their best and they've got to handle things the way they see best. (Pub)

Our busiest days are Saturday and Sunday. We do an awful lot of breakfasts all day. And quite often people are coming in, and they're hung-over, and they can be a bit feral! You know until they've been fed. And you know that as soon as they've got food and a coffee in front of them, they'll settle down. (Cafe) 
Staff are expected to tolerate and deal with a wide range of difficult situations which arise with customers. Interviewees had a general expectation that as an industry in which customers were at leisure, and frequently consuming alcohol, some degree of customer volatility was only to be expected. While most suggested definite limits to what staff should be expected to what up with, drawing the line is not always easy:

And some of them are relative pigs, the people that we deal with, they're all used to getting their own way, They all come up in their Beeemas, and they're difficult to deal with and you've got to be able to deal with them at a level. And also ride with the punches that you get, the verbal punches that you have to deal with. It's horrific what people have to deal with in this industry. (Restaurant)

You can only take so much, and I think everybody has their own boundaries. (Licensed Club)

I don't expect them to stand for a lot of shit from customers and I will defend my staff to the hilt. If they've done their job properly and if they're being abused by a customer ... The old adage, "The customer is always right" is not necessarily so. I mean the industry doesn't pay a lot of money now, ... so I will not put up with people working for me being abused by guests. (Accommodation Hotel)

The situations in which conflicts between staff and customers are most likely to occur are in relation to sexual harassment and enforcement of the Liquor Licensing laws. Both situations are fraught with difficulties, as the following quotes suggest:

It can be a bit of a lonely hearts club here. We had a particularly nasty one where a member was making comments about having slept with one of our female bar staff in the past. Because she turned him down and that was why she was providing bad service to him. It was all so far from the truth and we had to take steps as employers to protect the employee obviously, otherwise we were going to be in trouble. And that member was eventually thrown out. (Licensed Club) 
You get customers that start to get intoxicated and get more obnoxious. There's no set way of dealing with the person. There are certainly some set ways of not dealing with the person and one is being confrontational. All you're going to do is straight away get the hairs up on the back of their neck. You can do it politely. Sometimes they won't listen, that's when you've got to go over there, you've just got to say, "Look mate, I'm sorry, it's against the law to serve you alcohol. You're over the limit, do you just want to cruise for a while and we'll get you a coffee or something like that." (Pub)

In all workplaces where interviews took place, procedures existed for staff members to pass over responsibility for difficult customers to a senior staff member or manager. Most had no compunction about asking people to leave their premises, even to the extent of issuing trespass notices where required:

We have a rule here that our staff are not here to take shit from customers. And from time to time a customer's going to be grumpy because that something has gone wrong with their experience, and that's fine, we have to deal with that. But if it's, say a straight abusive thing, then I have to deal with it, and I'll do whatever's required. Like we've had one particular guy that's been coming in and he's always abusive to staff. Very abusive. And in fact the guy's normally tanked most of the time, even in the morning at nine o'clock. So this last time he caused a bit of stink, I just had him evicted and issued with a trespass notice. ... Why the hell subject your staff to that sort of insult? (Fast Food Restaurant)

We ask them to leave straight off. I don't put up with any of that. The customer was upset that he hadn't been served, and I told him to leave. And if it's someone that has been served and they become obnoxious, I just give them their money back and ask them to leave and tell them not to come back. (Restaurant)

\subsection{The workplace dynamic}

Beyond the dynamic that is created by the centrality of the relationship with customers, work relations are also intensely affected by interpersonal relationships between those working at any particular workplace. This includes both the 
relationships between staff themselves, and the relationship that those employees have with employers and managers. These issues are examined in further detail below.

\subsubsection{Workplace relationships}

When asked about the workplace dynamic, most employers described this in a positive and even enthusiastic manner. The terms that were commonly used to describe the "culture" of the workplace included "open", "easy-going", "relaxed" and "fun". There were two features which are seen to contribute to this atmosphere. The first is that in running a business in which customers enjoy their leisure time, managers view it as important that they create an integrated operational and work environment which is congruent with their business goals. As will be discussed in further detail in Section 9.2, this requires them to adopt a management style and an attitude towards employees which is consistent with the way in which they require employees to treat customers. This belief was common among interviewees, although many admitted that they do not always consistently put it into practice, and that employees might have an alternative point of view. A second reason which managers provided in explaining their perception of a positive work environment related to organisational structures. Within small organisations, the fact that managers and owners are frequently working alongside their employees is seen to reduce the "us and them" factor. Within larger organisations, relatively flat organisational structures, and the fact that managers frequently have to fill-in for absent staff and at busy periods, is perceived as having the same effect. Conversely, where managers discussed examples of 
workplaces that they knew of or had experienced where a less positive workplace dynamic existed, they generally attributed this to absent managers, a less hands-on management style, or overly hierarchical structures. As one manager noted:

We try and treat our staff as equals. We've got to. We have to work side-by-side. (We) are hands-on employers. We work every day in this unit. It drives us insane! But we are on hands on - we don't sit back and own it and live in Queenstown and have a Manager in here running it, firing the shots. (Pub)

These sentiments were echoed by a manager employed by owners who lived nearby, but were not involved in the day-to-day running of the business:

\begin{abstract}
They don't often think about what they're going to say. And they build up inside them about a situation and then they tear strips off people and cause havoc. At the moment they're away and the staff are very relaxed, they're doing their jobs, and getting on well. As soon as they come back, the tension will be there. ... But it's very difficult to tell somebody, especially if they're the owners, that their approach is not quite right. (Motor Lodge)
\end{abstract}

The concept of "teams" was spontaneously used by almost half the managers and owners interviewed to describe their workplace environment. There has been considerable debate in the literature about what metaphor is being applied when managers describe their workplace as a team. In this industry, the concept incorporates notions of interdependent parts, of each member having a specific part to play, and of the success of the whole depending on the effectiveness of each of those parts. The previous chapter noted that managers look to recruit staff with an advanced level of interpersonal skills, and who "fit in" in the workplace. While their primary purpose in doing so is to employ staff who relate well to customers, they also recognise that these skills make a contribution to workplace dynamics. When discussing those employees who they considered hadn't worked 
out, interviewees frequently told stories of those who hadn't turned up for their shift, who turned up late, or who didn't "pull their weight". Many emphasised this as a necessary part of working as a team and noted that while personality factors are an important part of the service side of the business, basic operational requirements leads other range of characteristics to be regarded as equally important:

Some of the best people in the business, in the restaurant side, are the ones that relate the least to the customer. And they're the ones that everyone respects because they're great at prep, they clean up after themselves, they push the glasses to the back, they write up a lot of dockets and all that. And its almost without exception that the people that the customers like best are the ones that are a pain in the arse with their colleagues. Because they're putting all their energy into the customers, because they're people people. So I over the years have tried to accept that there are people out there who the customers love, and we clean up after them, then there's the people who the customers don't really relate to, but who are absolute great workhorses in this industry. And managers and colleagues tend to look at the qualities of those people who don't really come across to the punters much. And the punters just look at the guy that they think is fabulous because he leans over the bar and chats to them! (Restaurant)

A separate issue is whether the concept of teams is consistent with the reality of workplace hierarchies. Interviewees clearly did not see the two as being inconsistent. While they view themselves as treating their employees as having a valuable contribution to make at the workplace, they see no incongruity in their simultaneous belief the teams also require a leader whose function is direction and control. In their view, their managerial role is as integral to the business operation as any other:

We're all just part of $a$ team, assisting each other. ... I think everybody here realises that there's the management team, but that they don't ask them to do anything that they wouldn't be prepared to do themselves. (Cafe-Catering) 
It's sounds trite, because everyone says it, but team is far more important than anything. (Restaurant)

What I want to see here, and what I intend to do here is to build a very strong management team. A team that effectively presents the style of management and the style of service that we want; that gives it's employees training in the skills that they need to perform in that capacity, properly and efficiently. ... This industry is difficult to work in, and it's quite difficult because it's busy. But if you work as a team, it's a lot easier. (Cafe)

We started a new senior manager yesterday. And part of his initial briefing from me was the importance of everybody in the organisation regardless of what their wage rates were. If reception aren't doing a good job then the rest of us might as well pack up and go home. And they will only do a good job if we're supportive of them, encouraging and giving them information and that sort of thing. (Accommodation Hotel)

An additional aspect of the workplace dynamic is the frequency with which managers reported socialising with their employees or their employees socialising together as a group. Social events, whether formal or informal, were mentioned in all but three of the workplaces where interviews took place. While in larger organisations this is sometimes formally arranged by the organisation as a deliberate team-building strategy, more frequently it is informal and organised by employees themselves. This extent of socialising was used by managers to provide evidence for their belief that they got on well with their employees and that their employees got on well with each other:

So between the whole lot of us we are very sociable and if there is something on, we'll go out and do it together. So everybody is good friends with each other and I think that we've got that good feeling within the hotel. (Accommodation Hotel)

What we did for the last one and a half years is have outings together. Like we do our drinking together after work. And we did that on a quite frequent basis up to 
recently ... we have a very young staff. They are all 20,21 and they are very proud of taking their bosses out and showing them off. And they refer to ... they tell their friends that I'm their aunty. They find that very funny. (Restaurant)

Nevertheless, most managers admitted that their workplaces were not havens of consensus, tranquillity, and high productivity. Problems arose from time to time, both in their relationships with employees, and between employees themselves. In general, individuals (rather than work systems) were seen as the source of these problems. A small number of interviewees attributed this to simple personality clashes and the difficulties that arise when people work closely together day after day (including in one case the "natural" cattiness between women of different hair colouring). More commonly, however, they were seen to be the fault of "problem employees":

I think there are individuals who create problems. There're some who always think they're worth more than others, and those are the ones we try to avoid just as much as everyone else. (Bar-Restaurant)

The relationship is generally pretty good. But we have had, last year actually, four stirrers. Who weren't going to be happy with whatever we did. One of them made a great big fuss about the fact that there was no handcream in the garage, I had run out. And instead of coming to one of us, she just had to stir it up amongst the staff as if we were not good employers. (Holiday Park)

I never employ anyone where they say "They were a bastard to me and I've been hard done by". I avoid those people from experience, those people turn out to be the nightmare people. (Cafe)

\subsubsection{Communicating with employees}

The research also looked at communication between employers and employees as an aspect of the workplace dynamic. Survey questions asked about the methods 
used for communicating with employees; the frequency of communication, the areas in which information is communicated, and whether communication is a two-way or one-way process.

The most common methods for communicating with employees are direct discussions with employees as individuals, utilized by the vast majority of workplaces in all industry sub-sectors and size groups (see Figure 7.1). The use of 
Figure 7.1 Methods of communication

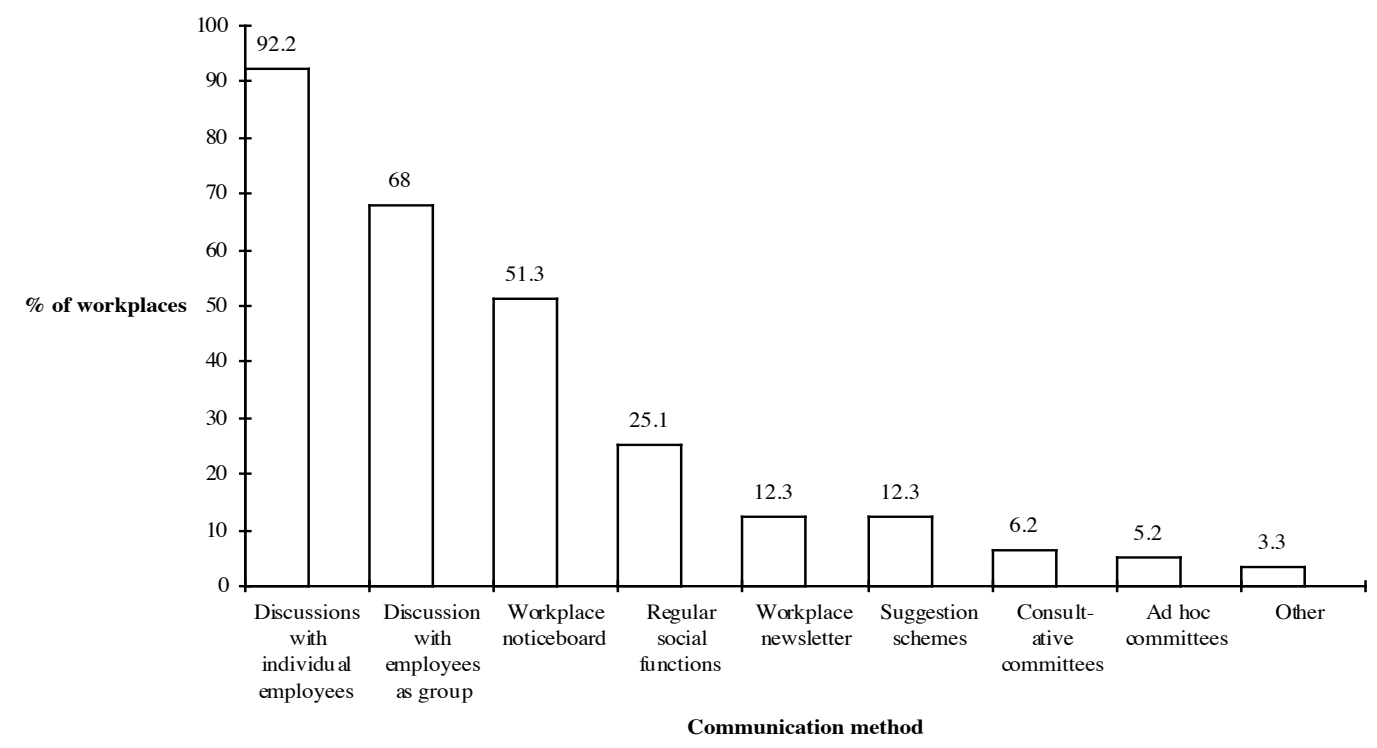

$\mathrm{N}=578$

other methods tends to be related to size - formal methods for communication are more common in workplaces employing more than 15 - 20 employees, and use of consultative or ad hoc committees is common only in organisations employing more than 40 employees. In terms of sub-sector, systematic forms of communication, such as company newsletters, suggestion schemes, and workplace noticeboards are common only in Accommodation Hotels, Fast Food Restaurants, and to a lesser extent Catering Companies. These were all workplaces which were more likely to be part of a broader organisational structure. In two-thirds of organisations, communication takes place on a "when and as-needed" basis, while in the remaining third, it is planned and on-going. The likelihood of this increases with increasing organisational size, and is most common in Accommodation Hotels, Fast Food Restaurants, Catering Companies and Educational Institutions. Planned and on-going communication is also more 
common in those workplaces where demand is predictable, and where it is expanding.

The importance of direct discussions with employees on an individual basis is underlaid by a preference for good interpersonal relationships with employees, emphasised in interviews. The hands-on management style adopted by managers (discussed further in Section 9.2) was felt to establish a very direct and personal relationship between them and their employees. Several managers referred to having an open-door policy and commented that having an active role in day-today operations allowed the opportunity for frequent and on-going communication. There were three notable features of this. The first was that managers place considerable emphasis on good communication as an indicator of effective workplace operation. In making decisions on labour-management issues, the justification for preferring people with whom they communicated well was that these people make a positive contribution to the workplace dynamic and also contribute to their ability to run their business:

I find it very difficult, I still do, to communicate with people who aren't proactively communicating with me. My chef and I get on really well, we have great dialogue, and he'd probably tell you that she's a great person to work with and we talk a lot. Because that's the way he is. But if I've got somebody who's difficult ... who's just a bit cut off, I find it very difficult to get through them. (Cafe-Restaurant)

Like if I can't talk to them I tend not to work very well with them. I tend to feel a bit hostile with them which is not very good. I have had some bad employees and because I haven't been able ... they've made so angry that I've not communicated with them well. It just got worse and worse and worse until I was just apoplectic. (Catering) 
Related to this is the view expressed by some managers that the quality of workplace communication is critical to their assessment of their own management skills. The ideal relationship between managers and employees is conceptualised as one in which there is no need for "third-party" intervention. This attitude is not held with the intent to exclude unions from the labour-management relationship, although it may have that effect. The need for any intermediaries (whether union officials, Human Resource staff, industry advisors and government officials) is seen to reflect a breakdown in trust and good communication:

(One employee) thought he wasn't getting paid right. I was quite annoyed, because he hadn't come to me first to find out. He came to me and said that he'd gone to the Labour Department and you should be doing this and you should be doing that. I didn't really appreciate it, and I told him in no uncertain terms that if I don't give a correct answer, or you don't think it's the correct answer, then you go to the Labour Department. It was underhanded. ... I said to him, if you want to go there you see me first. You go there if you don't think I've given you the right answer. (Motor Lodge)

You're not sitting there with a third person intervening. There are some employers that deserve to have that, I mean some of them are real bastards. But a lot of us aren't. And you know the trust that's required in your own workplace, and what the objective is, so you try to achieve that on a one-to-one relationship. (Licensed Club)

Managers also expressed a preference for informal and direct communication as a means of sorting out problems "before they festered" as one manager put it. The importance of immediacy as a cultural characteristic of the industry, spills over into the way that hiccoughs are sorted out, interpersonal problems are resolved, and mistakes are corrected. It is common for managers to express the view that open and honest communication is a prerequisite for a ensuring the continuance of a productive work environment. They consider it preferable to deal directly with interpersonal and communication problems, despite the potential difficulties: 
We always sort it out, it's not something that's ever on-going and left to really brew and brew until we have a big blow. We always sort it out. Say if I have a problem with someone in the kitchen, you've just got get out there and say it. You've got to say what the problem is because otherwise it's really hard to work together, and we are working closely together. ... I think if you're going to work as a team like that you've got to ... if you've got any problems you've got to get them out of the way and forget it and carry on. (Bar-Restaurant)

Managers often recognise the desirability of solutions being determined in a private forum, although they suggested operational constraints do not always allow this to happen. The emphasis which they place on good interpersonal relationships means that they are not always comfortable in taking a lead to resolve difficult or conflictual situations. The fact that they are able to direct employees to change their behaviour or attitudes is in direct conflict with their preferred view of themselves as easy-going and relaxed, and their workplaces as sites where managers and employees are equally valued. Some managers had a clear understanding of this contradiction and accepted it as part of their management role. Others (often those in smaller workplaces) found it difficult to negotiate and attempted to steer a middle path between their role as manager and their desire for good relationships with their employees. Examples of both types are given below:

It's not something I enjoy doing is critiquing people. But (the manager) might come up and tell she's done something and I butt in before she tells what she's done and tell her what I would've done. And she might go "Oh" and we will discuss what she did and the pluses and minuses of how she did it. The other day I actually took her out for a coffee because she was quite rude to the building manager and I felt that ... she was starting to get quite stressed and she was taking things on board a lot. So we went out and had lunch for about three hours. (Cafe-Catering) 
Once you put on the hat of being a manager, you're a manager the whole time. And some of these kids get a management opportunity and they might be managing on a Tuesday. And they want to take that hat off ... on a Wednesday. And I say to them you don't have that luxury any more. And they have to learn it the hard way, because of the way their colleagues deal with them. When you get into a management position, or a position of any responsibility or supervision or authority, you've got some standards by which you have to live. (Restaurant)

A final notable aspect of the direct communication with employees was the way in which managers saw this as being part of a very personal relationship which extends beyond the workplace. About a third of interviewees made comments which suggested that an integral part of their managerial role is pastoral care for their employees. The function of this belief is to prove to themselves and their employees that the emphasis which they place on interpersonal relationships was not cynical or instrumental:

We find that it's very easy for people to come to us when they've got problems, with other people in the workplace or with the way things work, or a personal problem that they want us to help them accommodate. And I think they usually get a pretty good response to that. (Restaurant)

I tend to be a bit of a person who is interested in the social side of things, so (when there are problems) I just try to find out ... what's going on for them. And people confide in me all their problems. I like that as well, and I find that the benefits from being sympathetic come back thousandfold. (Motor Lodge)

I've always maintained an open-door policy. If a staff member has a problem they come straight in. Whatever I'm doing, my problem takes second place to theirs. They get the open chance to air their problem, we can sit down and have a chat about it or whatever and they go away hopefully happy - if I haven't been able to solve the problem they'll go away knowing that I'm going to further investigate it. (Licensed Club) 
Interviewees saw their concern for the personal as the means by which they recognise their employees as human beings with lives outside the workplace. Personal considerations are not uncommonly taken into account when decisions are made on labour-relations matters. Two employers included questions about how families felt about "Mum taking a job" when interviewing applicants. The decision to dismiss an employee in one workplace had not been actioned after it was found out that she was pregnant. The decision to increase wages or not was sometimes influenced by what employers knew about their employees' financial circumstances. However well-intentioned, it is not difficult to interpret some aspects of this concern for the personal as undue management interference in the lives of their employees. It not infrequently results in restrictions employee behaviour at the workplace, whether they are on duty or not:

The bar staff are about the only ones that have a drink after work, which they pay for. I don't actually allow it to happen too often, because its too easy to become second nature, and before you know it its four o'clock in the morning before people are going home. And you've got the partners on the other side not very happy. I don't allow it because I've seen too much happen in the past with break-ups and booze and alcoholism and that sort of thing. (Motor Lodge)

Despite the prevalence of informal and direct communication, as noted earlier, systematic and formal methods are used in some organisations, mostly those that are larger than average in size, or are part of a larger organisation. Most common were regular meetings for shift or other managers. These varied in regularity from daily meetings in large hotels, to fortnightly or monthly meetings in other workplaces. In the very largest workplaces, multiple methods of communication are made use of, as is explained here by a manager in a large hotel: 
Every morning we have at nine o'clock briefing amongst the managers and they talk about what's going on in their departments for the day. We have weekly meetings which includes a steering committee meeting which is for the top echelon of management. And they discuss issues that are happening in the hotel, strategic issues those sorts of things. We have other committees, like we have an environmental committee, we have occupational health and safety, social clubs. Every month we have a management meeting where usually the managers of departments, people like myself go along and the boss sits there and he talks about what's going on in the hotel, sharing of information, how we've done for the month. All those sorts of things, and we talk about what's going on in our departments. And then every three months the boss has everybody from the whole hotel just come and he tells them about what is going on. (Accommodation Hotel)

Within medium sized workplaces, meetings commonly take the form of separate meetings for kitchen, front-of-house, and supervisory or management staff. In workplaces of all sizes and all industry subsectors, meetings of all staff in the workplace were less common and frequently difficult to arrange:

The problem is time and the amount of staff. How hard it is to rally them together. I mean I've given up on having full staff meetings. (Cafe)

We tried to instigate a fortnightly staff meeting, which perhaps was too much really. ... But it doesn't actually work in this environment because - two things: people don't work normal hours, so a lot of guys have Monday off, and getting them to come in Monday night and have a meeting because it's the only time we're closed, there was a bit of resentment. So I thought, well I'll pay them for half an hour for that, but that didn't make any difference, it was just a pain. People can't always make it. And also, I think unless you've got something really worthwhile to impart to them, then it's not worth it. (Cafe)

Despite the emphasis on constant communication within the industry, its nature and quality may fall short of managerial intentions. As can be seen from Figure 7.2, managers report a high degree of communication with employees on a range of issues. What is interesting about the pattern displayed in the graph is that some 
issues are more frequently the subject of discussion than others and that management seeks information from employees in smaller proportions than provide it. There was little variation among different parts of the industry in respect of management and employee communication, nor was there any

Figure 7.2: Information provided to and sought from employees

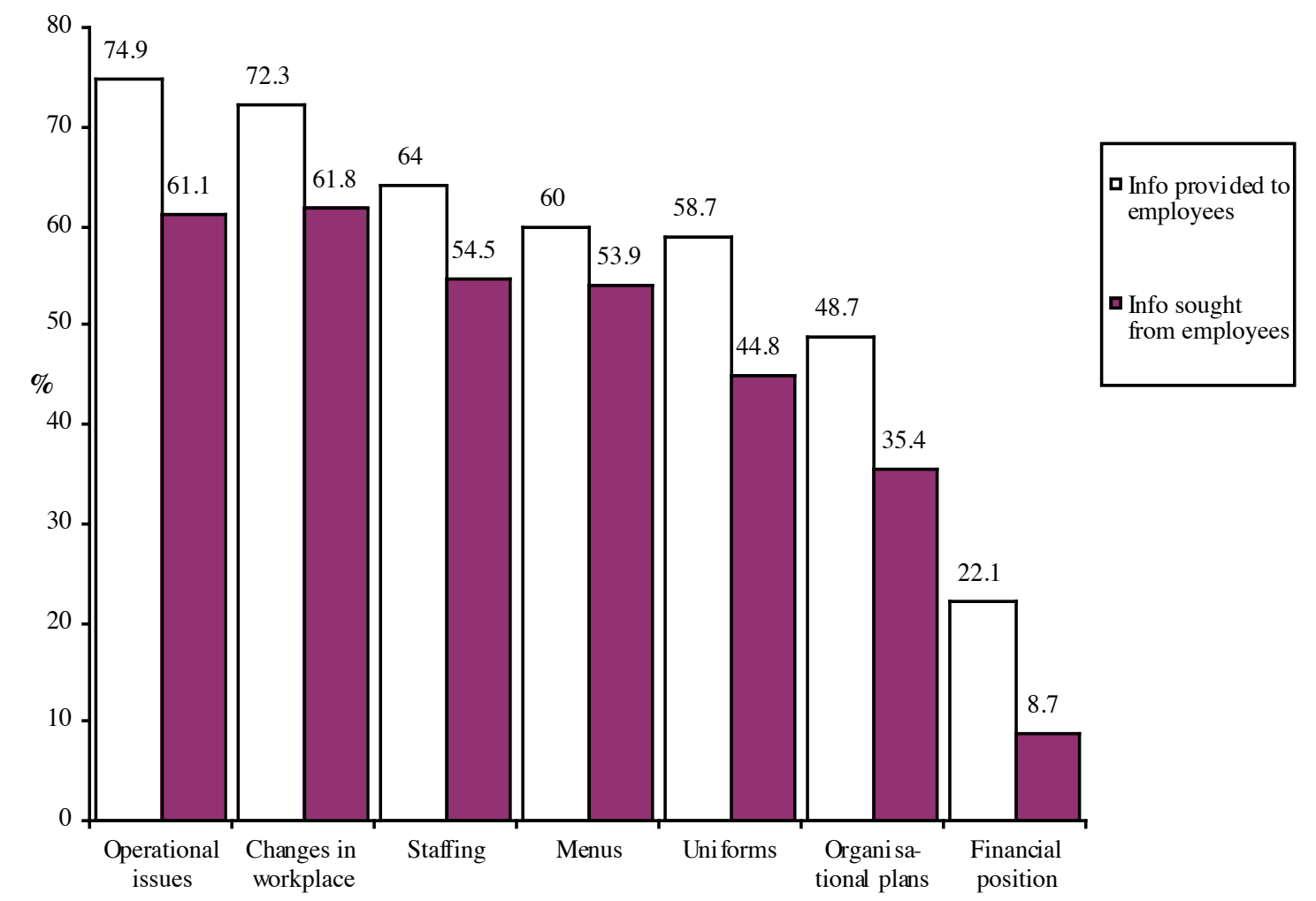
$\mathrm{N}=573$

association found between demand and competition variables and the extent and range of communication. The one exception to this was that workplaces experiencing contracting levels of demand were more likely than any others to provide information to employees on their financial position! In respect of size, 
while in general larger organisations tended to communicate with their employees more frequently and on a wider range of topics, this was uneven. The pattern of responses suggested the possibility that with increasing organisational size, systems for communication become more necessary but at the same time more complex.

Discussion on communications that took place in interviews described a similar picture. Managers are most likely to discuss the implementation of service standards, new menus, upcoming promotions, cleaning methods, new methods for payment, complaints and other operational questions than they are to discuss longer term issues that might impact longer term. In addition, most managers, when questioned, agreed that meetings were more akin to information-sharing than consultation. Two rationales were put forward for this pattern. The first, expressed by several managers, was a fear of raising employee expectations. As will be explored in further detail in Chapter 9, despite their emphasis on equality in interpersonal relationships at work, most managers draw a clear line between these and "running the business". Thus the scope of matters which they accept as being subject to employee influence is limited and they retain ultimate responsibility for business related decisions. The second reason for communication most commonly being a downwards phenomenon is their perception that staff generally have an instrumental orientation to work and are not particularly interested in making suggestions or thinking long-term about the business. 
If they come up with idea, or they've got input - yeah definitely we take on those ideas. A lot of them really can't be bothered though. They come to work and they do their job and then they disappear. (Cafe)

Well we always ask for suggestions. ... But we don't usually get a lot of results. Y'know people sort of think that that's our job so they don't really have very much to say about it. (Restaurant)

A number of managers also commented on the fact that for both managers and employees to get used to open communication as well as establishing a two-way process of communication takes some time, and requires an established level of trust. Those that had persisted, however, had found the rewards more than worth the effort:

It's probably two-thirds me telling them and a third back. In the past it hasn't been so beneficial to say "what do you think?" and get nothing from the floor. Whereas now I'm saying ... for example the last staff meeting we had we were developing a problem with our existing menu ... and this was causing some problem with customers. So we actually worked through, between the kitchen and the front staff, the way that we could ease that through, in terms of slowing the time that they got certain things like entrees, so there wasn't such a delay between entrees and mains. And we had quite a good discussion about that. And so the kitchen and front staff felt that they knew the next day, the things we could do together, to ease that problem. (Cafe-Restaurant)

When our chef came three years ago I was very keen on him having regular meetings with the staff. But he was a one-to-one man, he's not very comfortable with meetings. But I made him do it, and I went with him, and we went through subjects. Now I wouldn't have been to one of his for about a year. Except occasionally I come in at the end and just tell them things - like do you know we're building out the side and then they can ask me questions so that I'm available to them. But it's great to see him grow in that area, and he runs a great meeting now. (Restaurant)

\subsection{Summary and conclusions}


This chapter has drawn out a range of issues which show both similarities and differences to previous hospitality industry research described in Chapter 3. The continued high level of occupational segregation continues to be as relevant in New Zealand in the 1990s as has been suggested elsewhere, although recent and limited moves towards "cross-training" have been noted in some larger organisations. In addition, the two changes in work relations noted in other countries - increased routinisation of work in some areas of the industry, along with customisation and high quality customer service in others - is also relevant in New Zealand. The findings draw attention, however, to the fact that these changes have not occurred simply as a response to customer demand. Managers themselves play an important role in "educating" the customer about the service which they provide, and in this sense the relationship between managers and customers constitutes a two-way process. The most significant area of development drawn out from these findings is in the implications of these changes for the management process in the hospitality industry.

This chapter opened by expanding on the ideas raised at the conclusion of Chapter 6 on the importance of personal relationships for work relations in the industry. As can be seen from the material presented here, relationships between managers, staff and customers are critical in understanding not only work relations, but associated labour-management decisions. These findings take further the research findings on the industry summarised in Chapter 3. While pointing out to the importance of customers in work relations, previous research has not considered the way in which the "customer as manager" relationship affects the management 
process. By drawing attention to this, this chapter demonstrates the dilemma that managers are faced with in managing work relations. The contradiction which they seek to resolve is one in which they retain their managerial authority, while attempting to maintain interpersonal relationships with their staff that are based on the notion of interdependence of team members. The way in which these contradictions are resolved varies from workplace to workplace. In small businesses, it is reliant on the ability of the manager or owner to do so and will reflect the relative importance which they place on business requirements and staff relationships. In larger organisations, the necessity of developing a more systematic approach to labour-management decisions, together with the more hierarchical nature of these organisations creates a distance between managers and operational staff which makes these contradictions less acute. The importance of the personal and the way in which this spills over into labour relations decisions is the subject of the next chapter. 
Chapter 1: Introduction

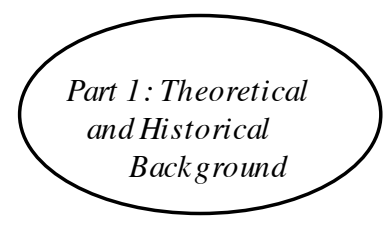

Chapter 2: Tourism and Hospitality Industry Development in New Zealand

Chapter 3: Employment, Work and Labour Relations in the Hospitality Industry

Chapter 4: The Framework for Analysis: Explaining Management Practice

Chapter 5: Research Approach and Methodology

Chapter 6: Employment Relations in the Hospitality Industry

Chapter 7: Work Relations in the Hospitality Industry

Chapter 8: Labour Relations in the Hospitality Industry

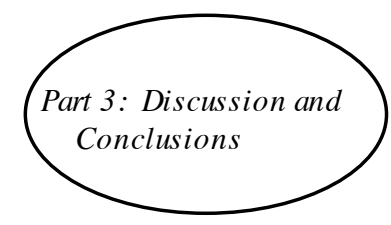

Chapter 9: Labour-Management Practice in the Hospitality Industry: Managing to Compete?

Chapter 10: Explaining Management Practice: Strategy, Environment and Social Action 


\section{Chapter 8: Labour Relations in the Hospitality industry}

\subsection{Introduction}

This final empirical chapter considers the nature of labour relations in the industry. In contrast to the topics covered in the previous two chapters, in the area of labour relations, the external constraints of industrial law place greater limitations on managerial action. Additionally, managers and employers were much less sure of themselves in describing the nature of their labour relations and the reasons for the choices they made. This chapter thus opens by setting the scene for what follows, by considering the nature of this uncertainty, and the sources of advice and help available for hospitality industry managers. The greater part of the chapter, set out in Sections 8.2 and 8.3, considers the nature and content of employment contracts and other working conditions in the industry. Section 8.4 briefly considers union presence in the industry and managers' attitudes to unions. The chapter ends by looking at dismissals. While in many respects this is a matter which might more properly be included in Chapter 6 , the importance of industrial law in influencing managerial behaviour in this area has determined its inclusion here.

\subsection{Managers as employers - getting advice}

As noted above, in the area of labour relations, the actions of managers and employers are constrained by the operation of industrial law which establishes a set of rights and obligations between employers and employees. The research uncovered a considerable amount of uncertainty, ignorance, and inaccuracy in 
employer perceptions of how the law (and interpretations of the law by the Courts) impacted on their businesses. Comments made in interviews uncovered examples of employers who believe that awards still existed, that the Hospitality Association standard contract is legally binding on the industry, that statutory conditions of employment (such as those set out in the Holidays Act) are mandatory (rather than minimum) conditions of work, that employee's wages may be unilaterally reduced if the employer is in financial difficulty, that the Courts automatically order the payment of three months' wages in any dismissal case, and that $90 \%$ (or more) of Personal Grievance cases are settled in favour of the employee. Of even greater concern is the fact that many of these misperceptions appear to have arisen on the basis of advice provided by lawyers, accountants, insurance companies, and other professional agencies. In the course of interviews, several employers commented that one of the reasons why they had been keen to participate in the research was to allow them an opportunity to seek advice on aspects of their labour relations practice or to clarify uncertainties which they had.

The way in which labour relations is approached in the industry as a whole can best be characterised as ad hoc and reactive. Several interviewees made comments which suggested a feeling of isolation in making decisions about labour relations matters. Unless they had friends or personal relationships with other employers and managers in the industry, the competitive nature of the industry limits the ability of managers to discuss common problems. ${ }^{1}$ What information they do get

\footnotetext{
${ }^{1}$ The only exception to this, noted below in Section 8.2, was in respect of Accommodation Hotels, whose managers and Human Resource Managers meet frequently, both formally and informally, to discuss employment and labour relations issues.
} 
on practice elsewhere in the industry (particularly on relative levels of wages) is more likely to come from employees than from any other source. While they might seek advice or assistance if they have a "problem", only a small number make any attempt to ascertain any more than their most basic obligations as employers or to establish procedures for keeping up to date with developments. Few interviewees had adopted a systematic approach to labour relations or aligned their labour relations practices to their business aims. In this sense, there is little evidence of what might be described as a "strategic" approach. The only exception to this was seen in large workplaces, such as Accommodation Hotels and Catering Companies, where dedicated Human Resource staff are employed. These staff, when interviewed, have a very clear understanding of the rationale for the labour relations choices made and of the advantages and disadvantages of doing so. The vast majority of other managers viewed the move to (for example) individual contracts, or the elimination of penal rates, as involving some kind of imperative brought about by the Employment Contracts Act. While some managers have some "gut" reaction about the choices available to them, they frequently do not have access to the information which would allow them to make an informed decision and are consequently reliant on their own notions of what they considered to be "fair".

In addition to the multi-industry Employer Associations representing employers in the wider economy, there are a number of industry associations operating in hospitality, including the Hospitality Association, the Food Services Association, the Motel Association, the Chartered Clubs Association, and the Holiday Parks 
Association. $68.4 \%$ of surveyed workplaces are members of at least one of these organisations, and just over $3 \%$ of workplaces (most likely to be workplaces employing more than 40 people) belonged to more than one organisation. Conversely, those workplaces with fewer than 10 employees were more likely to not belong to any external organisation. Comments made in interviews suggested that the reasons for this pattern related to the fact that small organisations did not consider membership to be good value for money. They perceived these organisations to be there to help them resolve "problems" and considered that if and when these arose they would be more likely to approach their lawyer or accountant for advice.

The organisations which employers were most likely to belong to were the Hospitality Association of New Zealand (29.5\% of workplaces), the Food Services Association (21.3\%) and the New Zealand Employers' Federation or one of its constituent Associations (17.9\%). Not surprisingly, there are sub-sectoral differences in the organisation that employers join. Hotels and Pubs are more likely than other industry sub-sectors to be members of the Hospitality Association (reflecting its history as the Hotel Association), Cafes and Restaurants are most likely to be members of the Food Services Association, and Motels and Licensed Clubs to be members of their respective industry associations. Those workplaces which belonged to the Employers' Federation tended to be larger than average (more than 40 employees) although several employers were aware of the links between the New Zealand Employers' Federation and the industry association to which they belonged. 
About a third of interviewees commented on the role of these organisations in keeping them up to date with developments in employment law through newsletters and seminars or in suggesting a preventative approach to aspects of labour relations. More commonly, however, the role of external organisations was perceived largely as providing advice on situations outside the expertise of the manager concerned. However, in over two-thirds of workplaces which responded to the survey, no outside organisation had been approached for advice in the previous year, presumably because no workplace problems had arisen that needed to be dealt with. Of the remainder, the most common issues on which advice had been sought from an external organisation were terms and conditions of employment (66\%), the operation of the Holidays Act (49.1\%), and dismissals (46.7\%). Their sources of advice were almost as likely to be their lawyer $(6.5 \%$ of workplaces) as the Employers' Federation (7.4\%) or the Hospitality Association (6.1\%). These patterns are again, however, associated with industry sub-sector and size. The Employers' Federation is most likely to be approached for advice from organisations employing more than 40 employees, including large Hotels and Catering Companies (who are also more likely to be members) and by those with fewer than five employees. The Hospitality Association is most likely to be the source of advice for medium sized Pubs and Hotels, while lawyers are most commonly used by Fast Food Restaurants and workplaces employing between 40100 employees. Workplaces employing fewer than 10 employees are not only less likely to belong to an outside organisation but are also less likely to have approached an outside organisation for advice. The explanations for this which 
arose in interviews were related partly to greater employment stability in smaller workplaces and partly to a preference for resolving conflict on an informal and personal basis.

From comments made in interviews, the quality of advice provided to employers in the industry would appear to be variable. While positive comments about each of the industry or employer organisations was the norm, all except one ${ }^{2}$ also received negative comments. Most of these were complaints about poor advice that had been received in the past. However, interview comments made it clear that Industry and Employers' Associations are considerably less likely to give wrong advice than some of the lawyers and employment consultants engaged by employers. The following three examples were perhaps the worst that arose but reflected a more general pattern of inaccurate information and guidance resulting in a misperception of the nature and impact of employment law:

\footnotetext{
We had an employee that we wanted to dismiss, and he was obviously very unhappy here. The manager and I sat down with him and talked to him about it. And he came back and he said "You're right, you guys are actually doing me a favour, I'm not happy here". But the next day I got a letter in the mail, saying that he was initiating legal proceedings against me because I hadn't done it properly. ... I went over to talk to (adviser) about what had happened and he said I was up for $\$ 8,000$ (in compensation). And he said that's where you're going to start at. He'd only been working for me for two months. (Cafe)
}

There is the situation now which we have been informed of, whereby if two staff members weren't getting on and one staff member decided to leave, because the first one was making her life hell, she has the right then to say that she was

\footnotetext{
2 The exception was the Food Services Association, which received glowing praise from those interviewees who were members. These, however, were all located in the top half of the North Island.
} 
(constructively dismissed), she left the job because she was forced to. (Motor Lodge)

I've been going to the (Business Advice Centre), they've been my advisors. .... And they just said that when you have your staff meeting, you can tell them that you can knock their wage down. Because you do not have to pay above the minimum wage, but I'm only paying them $\$ 7.60$. (Cafe)

The sections that follow in this chapter must be read in the light of the comments made above. Except for those in large organisations, the majority of owners and managers lack professional managerial training or education, and fewer still have an in-depth understanding of employment law and human resource management. While this does not necessarily make them "bad" managers, it does mean that they are vulnerable to individuals and organisations providing labour relations advice, and most are not in a good position to judge the quality of that advice. This leaves them exposed to inaccurate information about their rights and obligations, which can have considerable financial implications for their businesses. The consequences of this are evident in the final sections of this chapter.

\subsection{Employment contracts}

As noted in Chapter 2, the structure and content of employment contracts has been a matter for determination at the workplace since the Employment Contracts Act was passed in 1991. Overall, interviewees were positive about the effects of the Employment Contracts Act at their workplaces. Many, however, were confused about what it required of them in terms of their obligations to employees and the nature of the contracts applying at the workplace. A significant minority also appeared to be completely unaware of the change in legislation in 1991 and 
referred either to the award or to standard industry model contracts as being legally binding in the same way as awards were in the past. These issues, together with a discussion of the way in which contracts are negotiated in the industry, are explored below.

\subsubsection{The structure of employment contracts}

Both the survey and interviews looked at the nature and content of employment contracts in the industry. Of particular interest was whether employment contracts are written or verbal, and whether they are applied on a individual or collective basis (IECs and CECs). Amongst survey respondents, written contracts outnumbered verbal ones two to one, with $55.2 \%$ having written contracts and only $26.9 \%$ having verbal ones. A further $17.4 \%$ had a combination of the two. The existence of written, in preference to verbal contracts, was directly associated with size. Above average numbers of workplaces with fewer than 15 employees had verbal contracts, whereas more than two-thirds of workplaces with 15 or more employees had written contracts. ${ }^{3}$ Written contracts were also more common in workplaces where the level of demand was expanding and where it was predictable but were not associated with either levels of competition or critical success factors.

\footnotetext{
${ }^{3}$ In comparison, a recent survey undertaken for the Industrial Relations Service of the Department of Labour found that $34 \%$ of employees employed by surveyed employers were employed under single-employer CECs; $11 \%$ under multi-employer CECs; $34 \%$ under written IECs; $10 \%$ under informal IECs; $4 \%$ on combined IECs/CECs; and 6\% other (Colmar Brunton, 1997). Two other surveys of employment contracts are published on a regular basis (Harbridge and Crawford, 1997; Department of Labour, 1997) but as these primarily aim to collect mainly CECs, they are not considered a suitable basis for comparison.
} 
Survey respondents were also asked to select, from a range of alternatives, which situation best described the nature of the employment contracts at their workplace. The results are shown in Table 8.1. As can be seen from the table, the single most common category is the collective employment contract that is drawn up by management. The prevalence of individual contracts, however, is demonstrated by the fact that just under $44 \%$ of workplaces predominantly use IECs of various kinds (although these are of the standardised variety in almost half of these workplaces), and a further $17.6 \%$ have a mixture of individual and 
Table 8.1: Types of employment contracts

\begin{tabular}{|l|c|}
\hline Type of Employment Contract & \% of Workplaces \\
\hline All employees employed under a union-negotiated & 6.3 \\
\hline All employees employed under an employee- & 5.0 \\
negotiated CEC employed under a management- & 21.1 \\
\hline All employees empler & \\
determined CEC & 19.3 \\
\hline Standardised wages and conditions applied as an IEC & 7.1 \\
\hline All employees on individually negotiated IEC & 17.5 \\
\hline Most employees have similar conditions, but some & \\
individuals have negotiated different conditions & 17.6 \\
\hline Mix of CECs and IECs & \\
\hline Other & \\
\hline N 547 & \\
\hline
\end{tabular}

collective contracts. Individual contracts are common in workplaces of all sizes, but in workplaces employing fewer than 10 staff and in those where demand is not predictable they are more likely to be individually negotiated. Individually negotiated IECs are also more common in Restaurants then in any other industry sub-sector. Standardised individual contracts are most likely to be the predominant form of employment contract in medium-sized workplaces (30-39 employees), in Cafes and Fast Food Restaurants, and in workplaces where demand is predictable. Collective employment contracts are most likely to found 
in workplaces employing more than 40 staff, in Licensed Clubs and Catering Companies, and in workplaces experiencing predictable demand. As noted in Section 8.4 , it is notable that these industry sub-sectors continue to exhibit a relatively stronger union presence than others.

While the fixed-response nature of the survey questions forced respondents to indicate a specific type of contract, answers to the open-ended interview questions revealed a more complex picture. In four of the 38 interviews, the interviewees' immediate response to the question was that they did not have an employment contract at all, and three more were in the process of developing contracts for the first time. All of these workplaces employed fewer than 20 employees. In addition, several other employers commented that they were not clear about the distinction between an individual and a collective contract, or their remarks indicated a misunderstanding, or at least a lack of clarity between the two:

\footnotetext{
They are individual contracts. ... I prefer to see all my employees on one contract, and the best way to do that is when you bring on a new person is to say, "Look, to work here you have to be under the contract". Once they're here, to get them to sign it. So anyway, we have that in place, it's a written contract, they all have it. (Cafe)

It's an individual contract, but they all get the same one. A collective contract would be much easier ... but to be perfectly honest, I've never gone into looking at what's involved in that. (Cafe-Restaurant)
}

Few employers had actively considered either the structure or the content of the contract they had put in place. Those that had were exclusively large workplaces, or workplaces which were part of a larger organisation, most of which had either CECs or standardised IECs. In these cases, limiting the transaction costs of 
negotiating large numbers of individual contracts was inevitably a factor in this decision. However, a small number of managers interviewed also expressed the desire to ensure that employment contracts were consistent with business direction, and the creation of a culture centred around high quality and superior customer service. Managers at these workplaces recognised that the establishment of common conditions across worksites contributed in a positive way to this goal. In chain operations, or multi-establishment enterprises, the establishment of common conditions frequently involved suggestions for change being made from all workplaces and their consideration by a multi-workplace committee (discussed in further detail in Section 8.4). However, in the Fast Food and Accommodation Hotel sectors, consultation with other employers is also a key part of employer decision-making, and (as will be seen in Section 8.3) employment contracts right across the country are virtually identical. The Human Resource Manager of a large hotel describes the way in which this works in the following way:

\footnotetext{
Basically every hotel in (the city) operates under the same one - I've got copies of all of their contracts, as they have copies of mine. And when we come up to negotiate, we'll talk and chat, and make sure that we're paying around the same. So we have a collective employment contracts, and it's negotiated with the union. There are a few differences between hotels, but not many. They're all generic to that particular hotel. The differences between them are very minimal, very minor. And in fact as we negotiate, as one place brings something in, or modifies something, we find that we all do. Because we all operate the same way. (Accommodation Hotel)
}

In contrast, small and medium sized employers had put little systematic thought into ensuring congruence between the nature of their employment contract and their business strategy. While some managers clearly comprehended the consequences of constructive labour relations practices, the linkages could best be 
described as "instinctive" rather than the explicit and conscious understanding expressed by managers in larger organisations. Because small and medium sized organisations did not usually employ anyone with Human Resource or labour relations expertise, they looked outside the organisation for advice on contracts, and the most common way for contracts to be developed was after adaptation of a contract (including, in a small number of cases, adaptations which were less than statutory minimums $)^{4}$ that had been developed elsewhere. There are three main sources for employment contracts. A small number of employers had specifically asked their lawyers to draw up an employment contract or had contracted an employment consultant to do so. Others who had friends or personal contacts in other workplaces had simply picked up another employment contract and changed the name of the employer and employee parties. However, by far the most common has been the adoption of standardised and generic contracts put out by the Hospitality Association, the Food Services Association and the Chartered Clubs Association. The advantage of these contacts for employers are the fact that they are seen as being relevant for the industry, and are written in plain English, avoiding the perceived legalese of contracts drawn up by lawyers. In addition, the standardised contract is seen to eliminate the time needed to develop a workplace specific contract. One employer who had moved from his own contract to adopting the standard model explained:

When the (Act) first come in, the whole idea of it - I took to it with gusto. At (our other restaurant) we tried to do it ourselves and we had a committee, to-ed and froed, and it just took forever and ever and ever. And at the end of the day we ended up

\footnotetext{
${ }^{4}$ The cases referred to here were interviewees at two workplaces who, in discussing the way that they had adapted the Hospitality Association standard contract, mentioned in passing that they had increased eligibility for special leave to one year's employment. Under the Holidays Act, eligibility for special leave is established after six months continuous employment.
} 
with a lawyer helping out. So what we did at this place was get the HANZ and FANZ standard contracts which are actually quite good. And all we did was look through them and made some small adaptations for ourselves and banged them in. (Restaurant)

Confusion about the nature and structure of employment contracts was not limited to employers. Several employers noted that their employees had been resistant to signing contracts, not because of potential reduction in wages and conditions, but because they had a misunderstanding of the impact of an employment contract:

I think there is a lot of confusion. They don't know. They don't understand what the contract's for. They think that it's a contract, therefore I'm contracted for a certain amount of time. I don't think they understand that you've got to give us 5 days notice for leaving, but you can leave. (Cafe-Restaurant)

I suspect that there would be insurrection if I said "I'd like you all to sign an employment contract." There would be insurrection for sure. Because they're all incredibly young and naive. ... To them, if you say employment contract they say "Fascists! The Fascists are driving up (the street)!" So it's all done on the hoof. (Cafe)

Despite some confusion, and the perception that collective or standardised contracts were easier, most employers expressed a preference for individual employment contracts. When asked about the advantages of these contracts for them, most interviewees responded by suggesting that individual contracts promote a more direct and personal relationship with their employees. The perception that individual contracts are better for their staff was also frequently expressed:

There isn't really a reason why we did that except I do consider that I would like to deal with people individually. I don't know about other industries, but as far as my knowledge goes, I think that most people are better off dealing with me individually. 
But then I'm never unfair, and I never would be. And I think that the people that know me and that have worked here would know that. I've never had any problem with people wanting a collective, or even mentioning it. (Cafe)

So I prefer to go individual. I think we've got enough expertise on it to know the best way to work with the staff. (Licensed Club)

It's more of a personal contact with the staff member. ... Because we've got so few employees it's quite easy. And it treats them as a person, as an individual, rather than say “Okay, you're under the collective contract, here's a copy”. (Motel)

\subsubsection{The negotiation process}

The figures set out in Table 8.1 also provide some indication of the extent and type of negotiation in the industry. Only $11.3 \%$ of workplaces are covered by CECs that have been negotiated by either a union or an employee representative. Similarly, of those workplaces in which IECs were in place, only a small proportion were negotiated or partially negotiated. ${ }^{5}$ Nevertheless, interviews again revealed considerably more complexity than might be suggested by these facts. Firstly, in drawing up employment contracts, most employers considered that they had made a genuine attempt to ensure that existing employees were no worse off in terms of take-home pay and that the contract was fair. Secondly, most employers argued that they were quite happy to negotiate employment contracts with employees, but that employees themselves were largely uninterested in doing so. These two findings are explored in further detail below.

\footnotetext{
${ }^{5}$ These findings are similar to those patterns identified for the industry in a research project analysing CECs across the economy as a whole (Harbridge and Crawford, 1996, 1997). This shows that $56 \%$ of CECs in the industry do not list employee representatives in contrast to only $12 \%$ of all CECs. Conversely, only $5 \%$ of hospitality industry contracts list the union as a party to the contract in comparison with $52 \%$ of contracts in all industries. Thus the data here are consistent with national trends, but with a greater tendency towards IECs, and verbal or informal contracts than in the economy as a whole.
} 
In establishing employment contracts for the first time in the period after the Employment Contracts Act was passed in 1991, many employers commented that they found themselves at something of a loss in knowing how to go about doing this. Some solved the problem simply by continuing to offer wages and conditions of employment (although usually not penal rates or allowances) based on the old award. Others were keen to take advantage of the flexibility that the new Act provided them with and also saw this it as an opportunity to develop contracts that were shorter, expressed in clear language, and did not include provisions that had no relevance for their own workplace. There is no doubt that some employers interviewed saw the passage of the Act as a means of reducing their labour costs (particularly through the elimination of penal rates) and limiting union involvement at the workplace. While most stressed their concern to ensure that existing and long-tenured employees were treated fairly in the new contract, they were also keen to use the process to include provisions which better enabled them to improve the business:

We got our staff off the award and onto (the new contract) without any problems at all. Because at that time the club was really in quite a bad way ... and I think everybody was fairly conducive. It wasn't done out of fear or anything. I don't think any of them signed it because they were frightened they wouldn't have a job. But they could see the need for change. None of them were any worse off ... we just boosted up the hourly rate so that they were no worse off. I want to make that quite clear - nobody was worse off at any stage. (Licensed Club)

We have to admit we did want to position the Contract in a way that benefited us. Without though taking away necessarily any rights from them, or making it harder on them. ... So what we did was, we said to them ... what we want to do is actually work on an hourly rate, regardless of whether you are working weekdays or weekends, and this is how it will work. And we ended up putting up a comparison, 
this is what you've worked this year under the old system, this is what you will get in your hand if you do the same thing under a new system. What we did was that we then able to show that if the people ... with all those things taken into account - all awards, all weekends - that on average each worker was working for that amount of money which ever hour they worked. They could see that that rate was higher than the award, but lower than those penal rates that they were getting on the weekend. So all we said to them was, if I then took that hourly rate, which is higher than the award, and paid you that any hour of ... and we did the same roster again this year, you would actually get exactly the same as if you were on the award. Which they agreed to. (Motor Lodge)

In managers' view, their belief that the contract was fair provided them with a rationale for by-passing the negotiating process to some extent. Nevertheless most professed to provide continuing opportunities for negotiation, when the contract was renewed or when employees commenced work. In the majority of cases this took the form of the employer drawing up a contract and giving it to all employees, or providing a new employee with the standard contract, and asking them to take it away, read it over, and come back with suggestions if necessary. Nonetheless, there was a general perception that the negotiation of employment contracts, either individually or collectively, was a non-event. This was attributed to the fact that either there was little that was required to be changed, ${ }^{6}$ or that employees were not terribly interested themselves in the details of the employment contract:

Each year, in about February I just go down and just say "Does anyone want to look at the contract and make any amendments?" This year we had an amendment, I just forget what it was now. So we just got them together for five minutes and said

\footnotetext{
${ }^{6}$ This is also in line with findings from Colmar Brunton (1997). On the basis of interviews with employees, as well as the survey of employers, the most common reason given (by $51 \%$ of those with new employment contracts and $27 \%$ of those renewing their employment contracts) for nonnegotiation of a new or replacement contract was that there was no need for changes.
} 
"Right, I want to amend this, is everyone happy with that?" And so we drew up a new one and that was that. (Conference Centre)

I always hand it to them and say "This is your employment contract - read over it, make sure you understand it. If you're happy with it, sign it and put it back on my desk. If you're unhappy with it or you want to discuss it or change something, get back to me." And I've never had anyone get back to me on it. I don't think they read it to be quite honest. (Cafe)

The bargaining is not much of a real factor. I mean we set up a CEC, but in real terms, without dismissing its importance, when people join we just get them to sign the employment contract. I suppose at the start, if they don't like it, they can say “Well I don't like this". But they don't. In practical on-going terms, I haven't come across any waiter or bar-person who is particularly interested. (Restaurant)

\subsection{Wages and conditions in the industry}

Chapter 3 noted that the literature on wages and conditions of work in the hospitality industry frequently characterise these as inferior to those in other parts of the economy. This section considers the reality of those statements for New Zealand in the late 1990s. The findings presented here draw not just on interview data, but employment contracts collected from a number of sources, ${ }^{7}$ and published data on wages and conditions applying in other industries.

\subsubsection{The content of employment contracts}

Employment contracts in the industry are characterised by three features. Firstly they are minimal in the level of wages and conditions that are offered those

\footnotetext{
${ }^{7}$ Employment contracts applying at the workplaces where interviews took place were collected wherever possible. These were supplemented with others obtained from friends and acquaintances employed within the industry and the generosity of Professor Raymond Harbridge who allowed access to his data-base of contracts kept at Victoria University. In all, 62 contracts, all current at January 1997, were analysed according to a pre-determined range of variables. Contracts ranged from those covering an individual employee at a specific workplace to standard and generic contacts applying at a number of workplaces.
} 
employed under them and generally less comprehensive in scope than employment contracts in most other industries. Secondly, the fact that they are often adapted from contracts applying elsewhere in the industry (including standardised or generic contracts) means that there is a large degree of similarity between them and less variability on a workplace basis than in other industries. Finally, employment contracts in the hospitality industry include specifications of employee obligations to the employer (including behavioural requirements) which create a distinctive statement about the labour-management relationship. These are examined in further detail below.

Despite managers' concern to ensure fair treatment of employees, employment contracts in place in hospitality industry workplaces often provide little more in the way of conditions of work than those provided by statute. A range of provisions previously negotiated into awards applying in the industry at the time that the Employment Contracts Act was passed ${ }^{8}$ (including limits on the number of hours worked, shift allowances, penal rates, long service leave, and service allowances) have generally been phased out. There are exceptions to this general pattern, and some contracts (particularly those applying in large organisations) also include provisions for (for example) health and safety, redundancy, training guarantees, and allowances of various kinds. Analysis of the employment contracts available for scrutiny (mainly collective, but including some individuals)

${ }^{8}$ These were the New Zealand (with exceptions) Major Accommodation Hotel Industry Award; the New Zealand Hotels Premises Award; the New Zealand Tea-rooms and Restaurant Employees Award; the New Zealand Chartered Clubs and Licensed Clubs Employees Award; and the NonLicensed Motel, Private Hotel and Lodging Employees Award. 
suggests that the common "core" of conditions provided in a "typical" contract in the industry would include the conditions outlined in Table 8.2.

Interviewees frequently expressed a desire for new employment contracts to be written in plain and clear language, and the vast majority were, in fact, very easy to read. Those that are drawn up by lawyers, however, sometimes include unnecessarily complex legal phrasing (e.g., "The employer hereby offers to the employee the position referred to in the schedule hereto, on the terms and

\section{Table 8.2 Core employment conditions in employment contracts}

\begin{tabular}{|l|l|}
\hline Condition & "Typical" level \\
\hline Term of contract & One year or indefinite \\
\hline Hours of work & To be agreed; with employee agreement to be flexible. \\
in 7. & 30 minutes break after 5 hours. \\
\hline Breaks & $\begin{array}{l}\text { Hourly rate specified. (Across all contracts analysed } \\
\text { the lowest rate specified for an adult worker was } \$ 6.87 . \\
\text { The highest rate in any contract (for a skilled worker) }\end{array}$ \\
& was $\$ 16.75$ ) \\
\hline Overtime & Specified that payment is at ordinary rates. \\
\hline Annual Leave & As per Holidays Act (15 days annually). Where a 4th \\
& week is allowed, this is most commonly paid after 6 (or \\
\hline
\end{tabular}




\begin{tabular}{|c|c|}
\hline & more) years service. \\
\hline Statutory Holidays & $\begin{array}{l}11 \text { days. If worked, paid at ordinary time plus a day in } \\
\text { lieu. }\end{array}$ \\
\hline Special Leave & As per Holidays Act ( 5 days after 6 months). \\
\hline Parental Leave & $\begin{array}{l}\text { As per Parental Leave and Employment Protection } \\
\text { Act. }\end{array}$ \\
\hline $\begin{array}{l}\text { Abandonment of } \\
\text { employment }\end{array}$ & After 2 days without consent or authorisation. \\
\hline Discipline & Grounds for discipline and dismissal specified. \\
\hline PGs and Disputes & Procedure as specified in Employment Contracts Act. \\
\hline
\end{tabular}

conditions stipulated herein"). In general, the minimal nature of employment contracts was a deliberate action by employers. Their express purpose in doing so, from their point of view, was not to deprive employees of their employment rights, but rather to establish a document that is readily comprehensible to employees. The Human Resource Manager of a multi-site Catering Company explains his company's decision to move away from their comprehensive collective employment contract to a shorter individually based one:

We wrote a very simple document, one which retained all the amounts that they had always had from us that they've enjoyed and good leave provisions and everything else. But instead of having a document which is 30 pages long and 58 clauses, we've ended up with a double sided piece of paper. The front page just has all the details for that employee. Who the party to the contract is, what their role is, where they work, what their rate of pay is, what notice they have give and any special conditions. And a declaration saying that they will abide by the company house rules etc. The back page is the general terms and conditions that apply to all workers and that covers everything from the terms of payment, to leave provisions, 
terminations, that sort of thing. But it's a very brief contract. And it's the best thing we've ever done. Because the employees are now seeing it themselves and can participate in it. ... There's an opportunity for them to not only negotiate their own pay, and we talk to them about their rate of pay. ... And the special conditions that they were enjoying under a previous contract, or had a special need for, they can actually negotiate that. (Catering Company)

While the content of employment contracts is in contradiction to managers' express desire to ensure that their employees are treated well, it is important to note that comments made by managers made it clear that they saw employment contracts as being only one element in the employment relationship. To the extent that a contract was supplemented by a positive employer-employee relationship and a high level of trust, more comprehensive contracts were perceived as undermining (rather than contributing to) their relationship with employees:

It's pretty basic - stock, standard, stern. I've been to all sorts of seminars where people say they should be a lot more flexible, and a lot softer, and don't call it a contract, call it something else. But I think I'm soft enough in my other stuff that the contract can be quite cut and dry, so I'm quite happy to use the (generic) one. (CafeRestaurant)

I had contracts sent from the (industry) Association. And I think that goes far beyond what a contract should be. It's all legal jargon. If an employment situation has gone that far, it's hopeless anyway. ... I'd like something a lot simpler. I want to take out $80 \%$ of it. Basically what it should say is what your wage structure is; what is expected in terms of hours to be worked, and how the holidays will be handled, which is a problem for our industry. But that's basically it. (Restaurant)

Contracts in the industry are notable not only for what they leave out but also for what they include. It is striking that the most detailed clauses in many employment contracts are those which specify the behavioural standards which employees are required to adhere to, and the grounds for dismissal. These behaviours range from serious offences such as refusal to carry out lawful 
instructions, theft, consumption of drugs or alcohol during working hours, and violence or willful damage, through to insubordination, swearing and "criticism of club management" (Licensed Club contract). About a quarter of contracts also include confidentiality and restraint of trade clauses. While some of these simply draw employee attention to their duty of fidelity under common law, others go into substantial detail about employee obligations "... not to reveal any of the trade secrets, secret or confidential operations, processes or dealings, or any other information ... business, finances, customer lists, transactions, or affairs of the employer" (Motel contract). Given that the survey data found that few employers provide their employees with information about operational plans or the financial position of the workplace, these clauses are clearly excessive in their nature. A smaller number include an "employee loyalty" clause which, reminiscent of employment contracts from the turn of the century, requires employees to pledge "loyal, honest and trustworthy service to the employer at all times" in return for being treated with respect and dignity. A small number of contracts also contain a prohibition on employees being employed in other jobs. The significance of the specification of these standards was underlined in interviews when respondents were asked a general question about the content of their contracts. While some interviewees went on to specify the conditions of work that were provided for employees, a significant minority answered the question by referring to the rules that were established for employee conduct. One manager answered in the following way:

Things like procedures as far as how we do different things as regards handling of cash, and just conduct too, serious conduct regards to drinking alcohol on the premises, smoking or whatever, contraband on the premises, regards to assault. It does cover a numerous amount of things. And that's just more of an etiquette I 
suppose, to make sure everyone knows the rules and that they're following basic guidelines. It's making sure that everyone gets a fair deal at the end of the day, we say, "That's the rules and that's it". (Bar-Restaurant)

\subsubsection{Determining wages}

As in most industries, employment contracts are where wages are specified. Collective employment contracts in the hospitality industry tend to specify a single rate, rather than a range of rates, for each occupational classification. Wages in the industry are low. Starting rates in workplaces where interviews took place generally ranged from $\$ 8.50-\$ 9.50$ an hour rising up to around $\$ 13$ an hour for experienced and skilled waiting or bar staff in higher quality establishments. The average minimum adult rate in CECs in the industry at June 1997 was $\$ 327$, with only four other industry minor groups (agriculture, textile manufacturing, food retailing and other retailing) having a lower average minimum adult rate (Harbridge and Crawford, 1997). In addition, virtually all hospitality industry establishments pay a flat rate irrespective of the hour of the day or day of the week on which it is worked, and the vast majority have also eliminated overtime (i.e., working for more than 40 hours in a week) payments. On the other hand, youth rates are less common than in CECs in other industries (Harbridge and Crawford, 1997). Interviewees, when asked about youth rates, generally took the view that pay should be tied to experience and skill rather than age, and that if under 20-year olds were performing to the same standard then they would be paid the same rate of pay:

If you get someone who tells you how good they are, and you bring them in at $\$ 12$, you're putting them in, and I look at the kids on $\$ 12$ who are proven, who are training people, who are doing this and that. And I think well if this one doesn't measure up, we're out of whack. And my standard is can I look everyone in the eye 
and say, I'm comfortable with where you are in comparison with someone else.

(Restaurant)

Rates of pay as set out in the contract are only one element in the determination of pay rates for individuals. In general, employers openly indicated that the rate of pay to be paid to an individual employee was their unilateral decision. In answer to the survey question on how rates of pay were decided, only $29.8 \%$ of managers reported that this rate was negotiated. Negotiated rates of pay are, however, more common in Restaurants than in any other industry sector and in workplaces where demand is expanding and where it is predictable. In $42 \%$ of workplaces, the rate is decided by managers on their own, and in a further $28.2 \%$ of cases, the rate is standard. In establishing rates of wages for new employees, even employers who are open to negotiation, often err on the cautious side:

I had a big problem with employing people at ... I would bring people in who would think they were good, pay them fairly well, and it would turn out they were not very good. It's impossible to take someone's wages down, so now we bring everyone in very low and say well, you've got two weeks ... you're on this wage, and if I think you're worth it then I'll take you up and back-pay you for those two weeks; if not you stay at that wage. (Cafe)

There is negotiation when you employ people, because what they're really interested in is the rate of pay. We decide that individually. We're quite coy on the starting rate though, because you can't wind the clock back when you pay someone beyond their skill. (Restaurant)

While rates of pay are usually specified in employment contracts, and some employers pay all employees the same wage rate, most are happy to pay above contract rates in certain circumstances. In general this involves an assessment of whether the employee is "worth it". The same principle applies when deciding on 
pay increases. While these are sometimes applied in a uniform way across the workforce as a whole (usually only when a CEC is in place), by far the most significant influence on individual pay increases is employer assessment of individual performance. These are often subjective, and like recruitment decisions, based on gut instinct and negotiating power. In addition, the fact that employees are not uncommonly required to keep their rates of pay private involves a tacit admission that the rationale for their payment might conceivably be contested by other employees, and may not stand up to public scrutiny:

They are done in private obviously. It depends on where they've been, experience and what I would consider their vitality of work rate. You get a certain feel for people. There are people who will just stand there and smile and not talk. Other people be work a bit more. They'll get out and chat and make everybody feel really welcome. ... I normally ask them, what they think they're worth, and I'll sort of, we'll meet in the middle somewhere. (Licensed Club)

Well if they are performing, and they're contributing to the business then I'll say yes. And if they're not then I'll say no and that's it. There are no formal criteria, it's really on-the-job performance. (Bar-Restaurant)

All the larger employers, and those part of a larger organisation had a performance appraisal system in place which played a large part in determining the level of pay increase. Other employers did not have a systematic process for assessing performance, but had an informal set of criteria that they used for doing so. The yardstick that they used for doing this bore close resemblance to the comments they made about what they looked for when they recruited staff:

The main things are how they work in a team, what they're prepared to do to help the team, to build it and just how much they actually physically do. It's "Are you prepared to be part of the team or not?" (Restaurant) 
It's based on their reliability. And how eager they are to help out. And to work a little bit extra, like if they don't go until the job's finished. Somebody being conscientious and being good at their job, Being efficient and quick and their work being above standard. (Cafe-Restaurant)

I mean I've got a girl here, she'll never get a wage rise. I mean she's on good wages, she's on top rate of that contract, but she's always, you know, she's the type of woman that's always got to ask questions. She can't make a decision for herself and she'll never get any further. Unfortunately, that's the way life is. So, you know, she's on the top rate of the contract, but she's not on anything near the other staff, because other staff just run rings round her. I think it's fair that I can make that assessment as an employer and say okay that girl, she's good, she's attractive, very pleasant lady, she does her job. But still lacks a lot of confidence, still has to ask questions, still panics under pressure. (Pub)

The vast majority of employers in the industry wait for employees to initiate discussion on wage increases. In the words of one employer "When you think you're better come to me and we'll negotiate." Few adopted the more proactive approach taken by this restaurant manager:

We generally try to get to them before they get to us. Not that we try to keep ahead of them, but I always think it's nice to recognise people before they put the pressure on you. Just making a gesture, because they're doing really well, they've developed, they're doing this, they're doing that. (Restaurant)

Employers and managers are very aware of the relatively low wage rates paid in the industry. This arises not only from the fact that they have frequently come up through the industry themselves, but also because hospitality industry managers are poorly paid in contrast to managers in other industries. Several managers noted the linkages between low wages and the quality of service they were able to offer their customers:

When we started out we were paying, at the time I thought okay wages, but on an hourly rate especially with the front staff, we were only average, \$8-9 an hour. And 
we were getting quite inexperienced people for that amount of money because they were the only people who the job would appeal to. And I know that as we've increased the money, the quality of staff has improved. And I know that if I take it to the next level, especially say for managers, it will improve again. But we walk a very fine line with our wage costs; and through the winter, even with the people I've got now, my wage costs are far too high. (Cafe-Restaurant) 


\subsubsection{Beyond the contract - other working conditions}

Interviews revealed that conditions of work for employees in the industry include a range of benefits which are not specified in the contract of employment. These include tips, free or subsidised meals or drinks, and (in about half the workplaces) discounts on meals, accommodation, or use of facilities. In addition, a range of allowances previously specified in the award, where they exist at all, now more frequently have the status of "perks" provided at the employers' discretion. These include allowances (shoe, stocking, and laundry), and taxis home for early starts or late finishes. In addition to those benefits paid out on a regular basis, most employers suggested in interviews that a good working environment was a positive condition of employment for employees. For a significant minority of interviewees, an important part of this was the recognition they provided on an irregular basis to employees, either individually or collectively but usually in the form of a non-financial reward, as a token of their appreciation:

And I try and reward people at different times with either paid days off, or a gift, or something like that. (Cafe-Restaurant)

We also pay Christmas bonuses just because it's Christmas and it's a hard time of year, and it's busier than usual and everybody works harder than usual. And people are crabbier than usual, customers are crabby, so the people who are working fulltime over Christmas period generally gets a Christmas bonus. (Restaurant)

In summary, therefore, while managers in the industry generally see themselves as "good" employers, they have no understanding of the advantages of enshrining this in the employment contracts which apply to their staff, or are reluctant to do so. 


\subsection{Collective representation}

Given the analysis provided so far, and noting the desire of employers and managers to construct personal and direct relationships with their employees, the fact that there is little collective representation of employees in the industry is of no surprise. Survey respondents were asked about the percentage of employees at their workplace who were members of a union. Just over two-thirds of respondents replied that they employed no union members at all, and in only $3.6 \%$ of workplaces were more than $50 \%$ of employees unionised. Larger workplaces were more likely to contain union members, and Catering Companies and Licensed Clubs were the only industry sub-sectors likely to employ above average numbers of union members. Other factors indicate a low level of union activity in the industry. In the vast majority of workplaces, unions have a low profile. They had not attempted to enrol members and had not raised issues with employers on behalf of employees in the previous year. The part of the industry in which the predominant union in the industry (the Service Workers Union ${ }^{9}$ ) would appear to be most active is in Hotel Accommodation, where a quarter of workplaces had had contact with the union through issues being raised with employers, or where organising activity had taken place.

The attitudes of managers towards unions are hard to characterise. While only one interviewee was explicitly anti-union, employers generally express a preference

\footnotetext{
${ }^{9}$ Throughout the time that the research was being carried out, the official title of the union was the Service Workers Union of Aotearoa. This union was established in 1991 as an amalgamation of various regional unions representing Hotel, Hospital, Restaurants and Related Trades Employees; Cleaners, Caretakers, Lift Attendants and Watchmen; and Theatrical and Places of Amusement Employees. A further amalgamation has taken place in 1997, as this research was being written up. The union is now known as the New Zealand Service and Foodworkers Union.
} 
for a direct relationship with employees, rather than through a "third party" as noted earlier. In addition, a few were somewhat scathing of the level of union activity in the industry and the quality of service offered to employees. Two cafe managers, when asked about the frequency with which they saw the union, noted wryly that union officials usually came in as customers rather than as organisers, including one incident where a group of union organisers came in for lunch during a day-long strike! By and large, however, managers in the industry appeared to view unions with considerable indifference.

Those employers who employed union members and who had had contact with the union generally viewed it favourably. Several provided examples of situations in which union officials had represented employees to provide an amicable solution to workplace disputes, or where they had proactively sought advice from the union about potential problems. Nevertheless, even amongst employers with a positive view of the union, union representation is seen as being a thing of the past, and employer attitudes are best characterised as being tolerant rather than enthusiastic:

And this particular hotel is ... old, people have been here for (many) years. So you've still got that core belief, or feeling that they need the unions. Gradually we're changing that but it's a trust thing. And I think that after this period of years, it's hard for people to change and let go. (Hotel Accommodation)

She's a much older person, she's about 55; comes from the sort of background that my father would come from so she's very staunch union member. I mean, I don't have a problem with the union. But (she's) the representative, and she's really a very balanced woman. And I don't have a slightest problem with it. I don't really care if we have union or not. (Fast Food Restaurant) 
Despite the general lack of enthusiasm for unions, about half the interviewees believed there was still a place for them in the industry. Many had a poor opinion of management generally in the industry (discussed in further detail in Chapter 9), in a number of cases having experienced work themselves as employees before entering management ranks. Several interviewees related anecdotes of conversations that they had had with other managers, or situations in which employees had been treated badly, which led to their conviction that unions were needed to protect employees of "other" employers!

(Unions) are fine. I think that they are to protect the workers. But looking at it if I was an employee, I don't know that I would actually join a union if I was working for a person like me. But there are cases where you need them. (Holiday Park)

Other areas of management are okay, but the staff management thing is just awful. And it's hasn't improved. I've done consultancy work helping people set up cafes, helping them to organise it. And every single one of them I've walked away and thought "You bastard" Because I've seen the way they've talked to people. (Cafe)

Beyond having a role in protecting employees from "other" employers, the role of unions is often seen as limited. Interviewees conceded that unions had a role in negotiating wages and conditions but had the view that they voluntarily provided employees with the best possible wages and conditions and that union involvement would not result in any major improvements. In addition, union activity was to be kept strictly within the boundaries of those areas in which employers saw them as having a legitimate interest:

I do believe that at times they try to get involved where there is no need for them. Like this particular time round they were very interested in job descriptions and what people should and shouldn't be doing. Which really I don't believe is a union issue. It really has to be between the ... it's a business issue, and it's about the 
operation of the business, and the union should not be getting involved in the operation of the business. It's not what they're there for. (Hotel Accommodation)

In the absence of collective representation by unions, other forms of employee representation are being developed. While these are not yet common in the industry, they are usually present in large workplaces, or those that are part of a larger organisation. They frequently consist of various committees made up of employer and employee representatives for discussion and policy formation on issues such as health and safety, training, negotiation of the employment contract, and disputes and grievances. Employee representatives are rarely elected, however, but are more commonly "volunteers" or selected by management.

We use volunteers ... those that are interested, usually no coercion, and a lot of them. You'd be surprised at the people that want to be on - people that don't normally volunteer for anything else, but are really interested in that area. You know, chefs, kitchen hands, telephonists - people that you might not think would be interested because of the level of the job that they are doing. But we ask for volunteers and we say to them - look this is for your benefit, it's not only for the benefit of management. (Accommodation Hotel)

There's never any problems about finding a representative. What we try and do is to make sure we've got a really good cross-section of people. So we've got some older people, some younger people, some full-time and part-time workers, and we put up the list. If we select, we select the people basically so that we've got a spread of people, like we've a manager in there, because they're on the time card as well they're not all on salary. (Fast Food Restaurant)

\subsection{Discipline, dismissals and Personal Grievances.}

As noted at the beginning of this chapter, the topic of discipline and dismissals might more appropriately be dealt with in the part of this thesis dealing with employment relations. However as we will see, disciplinary procedures and the 
attitudes which employers have towards the disciplining and firing of staff are clearly influenced by the nature of employment law in New Zealand and the way in which this has been interpreted by the specialist institutions.

Employment contracts commonly specify the grounds on which employees may be disciplined or dismissed, as noted in the previous section. These are sometimes divided into the two area of "misconduct", for which disciplinary action may be taken, and "serious misconduct", which may justify summary dismissal. While only about half the contracts actually specified the procedure that would be used in the event of disciplinary action being taken, virtually all employers had a clear and accurate understanding of the requirements to have both justifiable reasons, and also to take action in a way which was procedurally fair. In most cases, this involved one or two verbal warnings, followed by a written one. The pervasive nature of such a textbook approach to discipline and dismissal may in part be attributable to the frequency with which such actions are taken in the industry. In addition, however, (and possibly in response to this frequency), the standard contract distributed by the Hospitality Association includes disciplinary procedures (including procedures to be used in the event of summary dismissal) in some detail. The generic contract includes not only the procedure to be used, but also a set of general principles to be followed, including the right of employees to representation, a requirement for specificity in the complaint, the necessity for impartial investigation, and the need for sufficient time for the employee to take corrective action. These details have been clearly influenced by Court interpretations of unjustified dismissal legislation. 
Interviewees were very explicit about the impact of these procedures on their behaviour. The need for evidence before disciplinary action can be taken (for example in cases of theft or pilfering) had led a sizable minority of employers to make use of hidden video cameras, surveillance by security personnel, or entrapment methods. Most perceived the procedural requirements imposed by the Courts to require an excessive period of time to put in place, and therefore had a low level of tolerance for employee behaviour which might in other circumstances be treated with a greater degree of liberalism:

\footnotetext{
The warning process is a long process, and when you know someone is not working out it can take easily on average about a month from when you've thought this isn't working to when you can get rid of them. So I start off quite early and sometime for quite trivial things, because I know how long it can take. (Cafe-Restaurant)
}

Despite the prevalence and understanding of procedures, these are not always followed in practice. In the case of casual employees, the solution was simply a question of not rostering them on. For permanent employees, a more common approach appeared to be having an informal discussion with the employee concerned. The way in which this was approached was frequently on the basis that the problem was with the employee, that they were not happy at work, or that they had a problem of some kind.

I've never actually used the words "fire" or "dismiss" etc. I convert them to think that perhaps they shouldn't be here, and I'm quite happy for them to stay here till they get a new job. And I will hunt for them if necessary. They all know that if they get called into this office here then they're in trouble. (Motor Lodge) 
In addition, while the procedure was seen to work in cases where a specific identifiable behaviour was at issue, it was not adequate for dealing with the more common problem of employees who did not relate well to customers, or did not work well with other employees:

Like if they aren't part of the team. People seem to get a rotten egg mentality about them and they sometimes just go bad, for whatever reasons. Sometimes it's personal to them, other times its something that happening in the environment. On-going laziness, its part of the bad egg syndrome ... they were flippant, they were glib, they would turn up late. With the front staff, there might be problems with customers, they've been rude, or just not going that extra distance. (Cafe-Restaurant)

I think its awful the things that you can never say to people. The amount of people that I just want to be honest with and say "Look this just is not working out, and I really can't see it working out." If it was me, that's how I'd like someone to say it to me. I go through this warning process, and I know that its not going to work out. And the best thing for them would be to go out and get another job. Or to do something that might suit them a bit better. Its only dragging it out for both of us. I try to get them to resign sometimes. But if I can't I can't. But it feels like a very dishonest process to me. I can't be honest with them, I can never say to them "You are not going to work out, I know that it never will.” It seems a bit harsh, but its true. (Cafe)

In cases where employers are concerned about the employee's relationship with customers, perceived difficulties in following the correct procedure sometimes leads employers to take pre-emptive action, even when they know that this might leave them exposed to the possibility of a Tribunal case:

We've had to write letters to staff members to give them written warnings. But the trouble is that they can actually cause havoc in here in the mean time, and it takes a good two or three months to get rid of someone. (Motor Lodge)

I had one that was so detrimental to the business and there was no way I could have got her out. So I just sacked her and said "Take me to court when you're ready." But it was settled outside. And it was settled for less than I would have paid in 
redundancy so it was worth it. She was virtually driving customers out the door with her attitude. And you can't say "Well I'll give you two weeks warning to fix your attitude up”, because by then you've lost $\$ 5,000$. Just in lost custom. (Restaurant)

Concerns about the approach taken by the Employment Court to the procedural aspects of disciplinary cases were expressed in about a third of interviews. ${ }^{10}$ While a high proportion of these were based on incorrect and exaggerated views of Court decisions (such as the proportion of cases that are settled in favour of employees, or the amounts awarded in compensation), they nevertheless have an impact on employer attitudes and behaviour in respect of discipline and dismissal. Their concern is based on a perception of increased legalism in the system, tempered with an acceptance of the necessity for some procedure to overturn unjustified actions by employers, which most recognised were a reality in the industry. However, the system was seen to impose greater costs on employers than employees (because of the availability of legal aid), and two employers had been in situations where they believed that an employee had taken deliberate action in order to provoke a dismissal and claim compensation. Most argued the

\footnotetext{
${ }^{10}$ Under New Zealand law, dismissals may be found to be unjustified either on substantive grounds, or if the procedure used to dismiss the employee did not follow the rules of natural justice. This latter feature has come under attack since the late 1980s, by business interests arguing that the Employment Court and Tribunal place excessive emphasis on procedure. In 1990, the initial draft of the Employment Contracts Bill contained a provision which would have instructed the Court to find in favour of employers where a dismissal would have been found to be justified but for procedural reasons. This was amended during the passage of the legislation to limit the extent of damages to be paid in situations where employee behaviour was felt to have contributed to the dismissal. Employers' groups such as the New Zealand Employers' Federation and the New Zealand Business Roundtable have continued to campaign against the unjustified dismissal aspects of the legislation in general, and the procedural fairness aspects in particular. The Agreement negotiated between the coalition parties forming the government at the time of writing (the New Zealand National Party and New Zealand First) includes a commitment to review decisions of the Employment Court and the Court of Appeal top ascertain whether personal grievance and procedural matters can be codified into legislation. Cabinet papers "leaked" from the Government in late 1997, suggest that the matter is under active consideration by Government, and that the view of the current Minister is that the procedural requirements of the law are too onerous for employers. Nevertheless, at the time of writing, no official policy position has been announced.
} 
need for the system to take greater account of workplace realities and their needs as employers:

I don't think the Employment Court ever looks at things and says "Now who was being fair here? What happened and what was fair and unfair?" Its all procedure, procedure, procedure. You'd think that at some point a mediator or a judge could decide "Okay this person was fair or they weren't." I mean it generally does come down to that. What we need is people who are familiar with employing people that could say "Well okay that was fair. They maybe didn't sign the warning, but they weren't being unfair." (Cafe)

\subsection{Summary and conclusions}

The pattern of labour relations depicted in New Zealand workplaces in the 1990s demonstrates considerable similarity to that which has been described in other countries. Key features of labour relations include the low level of wages and conditions for employees, the low level of union density and employee representation, and the prevalence of individual contracts of employment in preference to the establishment of mechanisms for collective bargaining. This study has also uncovered greater detail about employer rationales for this pattern. In particular, the centrality of interpersonal relationships between labour and management that has been emphasised as having an influence in the area of employment and work relations, is also seen to have an effect on labour relations. Employers express a clear preference for direct and personalised contracts of employment, even though wages an conditions of work may be exactly the same for all their employees. Nevertheless, as in the previously discussed areas of labour-management, the maintenance of this position places management in something of a dilemma. Placing higher value on some employees over others runs the risk of threatening their belief in the importance of team operations and 
of all employees making an equally valued contribution. On the other hand, competitive pressures require them to pay better than average wages to those employees who they see as making a contribution to the success of their workplace through the exercise of their skill. A second dilemma arises from the fact that as workplaces increase in size, they must find other ways of managing employees to ensure that the importance of personal relationships is not lost, despite the need for such organisations to adopt a more systematic approach to management. This is achieved through mechanisms such as an emphasis on individual employment contracts (albeit with standardised conditions) and seeking to involve employees in a variety of organisational decision-making forums, as well as the mechanisms mentioned in Chapter 7.

This chapter and the previous two have drawn attention to the dilemmas faced by managers in the industry in their attempts to establish a balance between their concern as managers to respond to market demands and competitive pressures on the one hand; and to maintain the quality of personal relationships with their employees which they see as desirable and necessary. In the final section of this thesis, we go on to explore these dilemmas in further detail. 
Chapter 1: Introduction

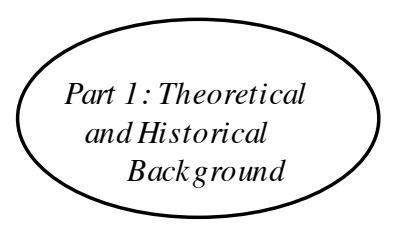

Chapter 2: Tourism and Hospitality Industry Development in New Zealand

Chapter 3: Employment, Work and Labour Relations in the Hospitality Industry

Chapter 4: The Framework for Analysis: Explaining Management Practice

Chapter 5: Research Approach and Methodology

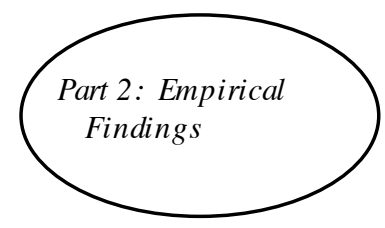

Chapter 6: Employment Relations in the Hospitality Industry

Chapter 7: Work Relations in the Hospitality Industry

Chapter 8: Labour Relations in the Hospitality Industry

Chapter 9: Labour-Management Practice in the Hospitality

Part 3: Discussion and Industry: Managing to Compete?

Chapter 10: Explaining Management Practice: Strategy, Environment and Social Action 


\section{Chapter 9: Labour-Management Practice in the Hospitality Industry: Managing to Compete?}

\subsection{Introduction}

In the final two chapters of this thesis, an attempt is made to draw together the theoretical and empirical material analysed previously to suggest a model of management action. This model locates managerial decisions and human resource practices firmly in a context in which market constraints and individual identity interact to influence management decisions. In order to do this, this chapter assesses management style and labour-management practice in the industry. It begins by describing interviewees' own accounts of their approach to management, focusing on three common features. The chapter then goes on to draw out the contradictions between managing staff and managing the business and to suggest the existence of four common patterns of labour-management practices. Finally, in Chapter 10, the findings are discussed in relation to the prevailing explanations of management practice summarised in Chapter 4.

\subsection{Reflections on management style}

As discussed in Chapter 5, the follow-up interviews were in large part designed to explore the rationales which management provided for their decisions and actions in the labour-management area. Managers were asked directly about their perceptions of management within the industry and about their own management style. Across all sub-sectors and in all size groups, interviewees were self- 
conscious about their management style, in the sense that they reflected on their decisions and the consequences which resulted. Few had any formal management training and commonly expressed reservations about their own management abilities. In addition, several (particularly those in small organisations) expressed uncertainty about how to improve their capabilities in these areas. Sources of external advice that were available to them often were perceived as not meeting the needs of the hospitality industry or small firms. Their reliance on "gut reaction" in making labour-management decisions was justified by a perceived lack of alternatives and a belief that the processes which they used in the past had worked well. As noted in the previous chapter, however, this meant that managers were sometimes vulnerable to poor and incorrect advice, particularly in the labour relations arena. The small size of many businesses limited the extent to which they were able to access competing sources of guidance, usually because of the costs associated with doing so. Nevertheless, their general outlook was that they were doing the best they could to manage their businesses:

I'm pretty slack! I probably shouldn't be too hard on myself, because I know that we'll do a lot more than many other restaurants our size will do. But I would say that our management style is probably a bit inconsistent to be perfectly honest, in that I think that the staff don't always know what is going on inside my head. I don't provide probably enough of a structure I suppose. And I could do more training. It's one of those things that I'd love to improve, it's just how to do it. I've now got an especially good friend who has got a lot of experience in the industry, and I will often talk to him about things. But it's just very difficult - no one else in the industry will talk to you very much. It's only by going to seminars and things; or reading ... but I just don't have time to read. It's really hard ... you sort of do things by trial and error. (Cafe-Restaurant)

I make a lot of mistakes. I probably don't put as much into it as I used to. I find I'm very tired now days. It's a very tiring industry. We try and get away at night now, 
whereas I used to stay on. And I find that the drinking side of things is a major problem. (Pub)

While some interviewees expressed a sense of isolation from other managers, many had a strong sense of being part of the hospitality industry, which they viewed as having peculiar characteristics in comparison to others. As noted in the previous chapter, while a number did not belong to any employer organisation, those that did were more likely to belong to the relevant industry association than to a multi-industry employer grouping. Interviews suggested that this reflected a sense of distinctiveness, and that managers' sense of identification lay within the industry, rather than with employers and managers in other industries. More than half of the interviewees attended industry seminars and read industry magazines as a means of networking as well as a source of information on legislative changes affecting them. Meetings and conferences also exposed them to the attitudes of their peers and competitors. These frequently shocked them and led them to assess the prevailing quality of management in the industry as poor. By far the most common criticism was in relation to staff management, which was perceived as overly autocratic. In general however, criticisms were directed at "other" managers. While interviewees believed that they themselves were good employers, and always treated their employees fairly, they believed that other managers in the industry would not be good to work for:

\footnotetext{
At the last meeting we were at, somebody said, and I thought this was absolutely awful: "Oh they're not people they're just cleaners". And I felt "I'm sorry, but $y^{\prime}$ know we're in the nineties". You can't speak to them like that. ... I don't agree with that I'm sorry. Everybody deserves to be respected. And I don't believe that if you don't respect your employees that they will respect you. (Holiday Park)
} 
There's a lot of prima donnas out there, there really is. I attended a function down in town ... and I had the opportunity to meet quite a few of the managers. ... People who I don't ... I don't know, I can't really say whether they should or shouldn't be managing, but if I was employing them they wouldn't have a job. (It's) just attitudes. They've got to get real. Some of the ideas that were being bandying around were so totally out touch it wasn't funny. (Licensed Club)

I think most of us would be fairly easy to get on with, but there are one or two that I would say would be extremely difficult to work for. You can just tell that with their manner. (Licensed Club)

\begin{abstract}
Absolutely hideous. There's a lot of people on power trips. There's a lot of owners of restaurants or head chefs, that have got the power to hire and fire. People that have come up through the apprentice chef route, and its absolutely hideous how they treat people and what they get away with. It's beyond me why people put up with it. (Cafe-Restaurant)
\end{abstract}

A second criticism of "other" managers in the industry arose from the massive growth in the industry over recent years. Redundancies and organisational downsizing in other sectors of the economy, combined with the New Zealand dream of owning one's own business was seen to have resulted in a flood of people setting up small cafes, restaurants or bars. These people were often looked down on by managers with industry experience. They were perceived as having a limited understanding of the industry, and of giving it a bad name:

I think there's a lot of people getting into the industry that want to buy a restaurant because they've got some money and they have no experience but they think it's an easy thing to get into. So if they've got a redundancy payout and they're not really trained to do anything else, they think "Well I'll buy a cafe, it'll be fun, it'll be a lifestyle thing and be enjoyable." And what they think they're buying is power over people. They're an employer now, but they've got no experience in how to treat people, no experience in managing people or in staff relations. (Cafe-Restaurant) 
There's a lot of new people out there that don't know much about the industry. I'm an old fashioned publican, I've been in this game a long time. The young fellow that used to work for me has got his own bar across the road now. .... I call them the cowboys of the industry. In another three or four years he won't probably be here. But that's what we've had to compete with. ... You know there's a lot of publicans in town, who've been here for years. We're the ones that have been the hard-core part of the industry over many many years and we're the ones now that are all suffering. You get your Fat Lady's Arms and Loaded Hogs and all these young people now doing things that we would never dream of doing. You know, two-for-one, drinks promotions and stuff ... things that I just don't do. Host responsibility plays a major part in it. (Pub)

Despite criticisms of their peers, interviewees tended to be considerably more sympathetic to their own shortcomings, often pointing to the difficult circumstances in which they operated. When asked directly about their management style, some common features emerged. A clear numerical majority could be described as fairly phlegmatic. When asked to describe their management style, the words which were used over and over again included “casual”, "relaxed”, "laid-back", “open", "easy-going”, and "informal”. The key features of the prevailing management style included a "hands-on approach" to management of the business; and an emphasis on personal relationships with employees, while at the same time taking a fairly resolute approach to discipline. At the same time, despite these commonalities, managers could be placed on a continuum in the extent to which they ranged from being highly autocratic to more participative. These common features are described in further detail below.

\subsection{1 "Being There"}


As noted in Chapter 3, studies of management in the hospitality industry have frequently drawn attention to its "hands-on" nature, with two commentators describing this as "being there" style of management (Guerrier and Lockwood, 1989c). It was notable that most managers in this current study described themselves in similar ways. Their work as managers involved not only the overall direction of the organisation or workplace but also included a good deal of operational activity. Chapter 6 described the managerial expectation that they and their senior staff operated as an "extra pair of hands", particularly at times when the workplace was busy or when employees were unexpectedly absent. Managers saw this as essential to their jobs. Firstly, it allowed them to better understand the operations. Several managers who were new to their particular workplace emphasised the necessity of working alongside employees to get a sense of how things were done and of refraining from making changes until they had had time to assess what things worked and what didn't. Interviewees also saw a hands-on management style as critical for achieving credibility with staff. The phrase "I would never ask my staff to do anything that I wouldn't do myself" was one which was repeated in a quarter of interviews and was a conscious aspect of managers' view of themselves as managers. While managers in small businesses often suggested that this style was necessitated by workplace size, the practice was also prevalent in larger organisations. Those who described themselves in this way, however, were sometimes ambivalent as to whether this was a totally worthwhile practice:

I try and set an example of leadership and not making demarcation lines by involving myself to a greater extent than I actually should. Like assisting staff with various tasks. I'll set chairs out on the conference room if it's needed, I will park cars, I will carry bags, I'll take room service trays. (Hotel Accommodation) 
I'm not going to get to know the feel of the hotel if I don't put the hours in at this stage of my job. And one or two people didn't like that, that I would be always around, and I'm probably more hands on than (the previous manager). Like yesterday, I mean it was a big job, we had to set the restaurant for 100 people, trestle tables and that sort of thing. And one of the receptionists said "But you are shifting trestle tables" and (another receptionist) said "Haven't you seen (manager) shift trestle tables before?" I said "Look the job's got to be done, I don't expect my staff anything that I'm not prepared to do myself'. Apart from cleaning toilets - I draw the line at that. I'll make beds if I need to, (but) I haven't had to do it here. I have great arguments with my husband because he reckons that I am too hands-on and I need to be more stand-offish, but that's not me. (Hotel Accommodation)

I can honestly say that nobody in this hotel has to perform any duties that I would not do myself. And I've proved that I can do them all myself by working in those areas alongside those people. People had no faith in the management of this hotel when I got here. They had no previous background of having experienced management around who would support them. They were basically a bunch of amateurs. And one day I came down and helped with breakfast when we were shortstaffed. It was very interesting to see the staff and their reaction in the kitchen to watch me work and they could see it with their own eyes that it was true, he can do it. Things started working from there on. (Hotel Accommodation)

A hands-on approach not only provided managers with a greater degree of credibility with their staff, but also contributed to their ability to control the labour process. A practical understanding achieved through hands-on involvement allowed them to direct operations with greater authority than an executive manager would be able to do. However, several managers noted that being so closely involved had its disadvantages. Apart from being exhausting and stressful, it also constrained their ability to look at the broader context in which they were operating. Most viewed the hands-on style of management as a matter of necessity rather than choice: 
I'd like more time. You can do everything, but whether you can do it well in the time that you've got is another matter. I mean, I'm expected to do all the marketing, and go and knock on doors, and then go off-site and come back at night and do a reception shift. And then have to sell a room at 2 o'clock in the morning. It can get a bit tiring, but then that's the way it is. (Motor Lodge)

\subsubsection{The personal is the industrial}

A theme arising at several points in Chapters 6-8 was the influence of personal relationships in labour-management decision making. Individual personalities (whether of employers or staff) are critical in explaining the selection of new staff, day-to-day workplace relationships, the allocation of rewards such as pay increases and training opportunities, and employee influence on managerial decisions. The quality of staff was foremost when it came to determining those factors which managers saw as being critical for competitive success, but criteria for assessing this are determined by managers alone. Given the extent of emotional labour in which a high proportion of staff are engaged in providing, it is inevitable that "personality management" is an important part of the labour process. Managers seek to undertake this through a variety of means. In making employment and promotion decisions they frequently rely on "gut instinct" and whether employees "fit in" or not. In day-to-day operations, employees may be encouraged (or required) to act in particular ways towards customers and may be prohibited from engaging in other types of behaviour. The workplace dynamic is closely affected by the extent to which all those working (both as operational staff and as managers) get on together, and individual contribution to the team operation is highly valued. Regular social events are also evidenced by employers as demonstrating close relationships between management and staff. The findings 
also demonstrated a preference for direct and personal forms of communication, including a dislike of any "third-party" interference in the employment relationship. Individual employment contracts were found to be more common in the industry than in others, and managers use these and other benefits where they can to reward individual employees.

The importance of personality in labour-management decisions is underscored by the exceptions where poor interpersonal skills are overlooked. For example, where technical skills are more important for job performance managers will sometimes put up with behaviour that would not be acceptable in other staff members. This is seen most clearly in respect of the ways in which chefs and cooks are viewed in the industry. Aggressive, abusive, temperamental and emotionally immature behaviour is tolerated from these individuals because it is viewed as associated with a creative and innovative personality necessary to produce a high quality product but the high quality service to customers must be delivered by staff with an entirely separate skill set.

The emphasis on the personal which arises out of the nature of the industry involves dilemmas for managers, as noted in the previous chapter. Because they are aware that employees are more likely to treat customers well if treated well themselves, managers place considerable emphasis on communication with employees. They see themselves as treating staff fairly, attempting to fit in with individual staff needs and being flexible. However, they are often less aware of 
the way in which they unconsciously balance these actions against operational needs and their own desire to maintain control and direction of the workplace. Resolving this dilemma involves skillful use of interpersonal relationships as a means of maintaining control. By managers' accounts, this is done through "finding a balance" between operational needs and the needs of employees. Most see themselves as prepared to be flexible but use the concept of "give and take" to describe the dynamic that is operating. The price of flexibility is their expectation that employees will "go the extra mile" if necessary. This approach is quite conscious for many employers, and they view it as an important way of achieving organisational flexibility:

I try to work around people as much as I can. Most of it is selfish really. I know that if I work around them then they'll work around me. (Cafe-Restaurant)

The "you scratch my back I'll scratch yours" approach provides greatest rewards to employees who they see as endeavouring to fit in with them. Examples from the empirical material already discussed include managers who gave first choice of the best shifts to favoured employees and those that negotiated individual benefits for employees who they considered to be "worth it". Conversely, employees that did not fit in or were perceived as being problematic in some way were rostered off, given less favourable hours or days on which to work, or managed out of the workplace. Several managers reported taking the approach adopted by the manager reported in Chapter 8, who never used the word "dismiss" but instead talked to his employees about whether they might not be "happier" working elsewhere. On the other hand, while management use of interpersonal 
skills was their preferred way to control employees, they were not averse to making use of direct authority where necessary, as will be seen below.

The importance of the interpersonal was as central in those workplaces which were larger than average as those that were small. These large workplaces, however, were faced with the additional challenge of creating a sense of closeness and individuality in the face of the more systematic and bureaucratic approach to labour-management which they adopted. In addition to some of the patterns described above that are common across all size groups (such as use of individual contracts and social gatherings), a variety of other mechanisms are used. In particular, most aspects of labour-management are devolved to managers at subunit level, (e.g., housekeeping, functions, portering) who have responsibility for rostering, performance appraisals, disciplinary complaints, and other day-to-day issues. The function of corporate human resource managers is to establish policy within which managers operate, to provide advice to managers on human resource issues and to promote and deliver training opportunities. In addition, as noted in Chapter 7, larger organisations frequently have multiple communication methods, and in one sense "overdo" the extent of information which they pass on to employees. These communication methods also often involve features which incorporate some form of individual involvement. The emphasis on individual employees, however, may be more symbolic than real - for example, addressing company newsletters to individual employees, or selecting individuals to represent employees on decision making bodies. Finally, the management style adopted in larger organisations frequently places considerable emphasis on the meeting the 
needs of individual employees by coaching and mentoring. These are the only workplaces in which training for supervisory and management staff takes place, and this training is based formally on policies of employee participation and empowerment. Workplaces may adopt a particular style of management in which these principles are central, or alternatively, training may be based on similar values without requiring managers to adopt any particular style. The two approaches are described below:

There's a lot of training that goes on and we have a very structured set of modules that we run. And we have a three-day "Train the Trainer" course. It's not actually when they come into a supervisory position - it's anyone who is going to be training front line staff members. Then after that we look at basically interviewing skills, if they're going to be interviewing people. Coaching and counseling skills; conducting an appraisal or performance development interview. ... We do a (management styles) course - and this is where the philosophy comes in. And although I've done numbers of these courses I've never done any like this. Basically you assess yourself and then you have 5 of your colleagues - peers, and people who know you at work assess you. Then off it goes and you sit down and colour in this little wheel that has basic quadrants of behaviour. And you've got desirable behaviour, and .... shall we say, not-so-desirable behaviour. And basically you come out and you see what your behavioural and your management style is as you assess yourself, and you see it as you have been assessed by 5 other individuals. And its quite in-depth. (Accommodation Hotel)

We put them through a group course which identifies their style and demonstrates to them other styles which can be used. I wouldn't say that we have a company culture as to any particular style. I'm not a great believer that you need one style for one company. Different styles can be used for different purposes depending on whether you're in a crisis or things are going very strongly. I guess our approach is more a coaching role than anything these days but certainly we use other techniques when required. The days are certainly here when the employer has to demonstrate that they have some feeling for their staff. Those days are long gone now when they're not doing that, even though I know that there are a number of employers that still operate like that. (Catering Company) 
In summary, the nature of the work performed in the hospitality industry means that interpersonal relationships are an integral part of the labour-management relationship.

\subsubsection{Management by imperative}

A third feature of labour-management reflects the way in which the product and service being purchased in the industry is consumed in an immediate way and cannot be stockpiled. Despite their emphasis on good interpersonal relationships, managers are also concerned to ensure that the balance in the labour-management relationship remains clearly in their favour. The main purpose of this is to ensure that employees act instantaneously to satisfy immediacy in customer demand when required. The directness with which the customer acts as a "proxy employer" often leads managers to adopt a more autocratic style of management than they might otherwise prefer:

I think what I've found with catering is that if something happens, it needs to be resolved straight away. If the meal is cold the meal is cold, its got to be heated, or its got to be re-served or whatever. Where in manufacturing you can do another re-run in three days time. (Catering Company)

I've always tried to be nice to my staff because I felt that that was the easiest way to deal with them. I do have difficulty throwing discipline into that. That's my hardest on-going battle. When I'm firm I'm very firm; and I say to people when they start with me, I will often be very firm and cut to the point, and probably quite cold when I tell you something; but if something needs to change in service, it needs to happen right then. You need to change how you're doing something and then we'll talk afterwards. (Cafe-Restaurant) 
While many employers professed to ensure that management decisions took employee concerns into account, most had a low tolerance for situations in which they felt that they were being disadvantaged. They viewed flexibility as something which had a place but which needed to be subjected to overall operational demands. When they put their foot down, they expected this to be respected, and were not averse to taking unilateral action if necessary. In addition, as noted in Chapter 8 , they initiated disciplinary action at an early stage rather than waiting for things to fester. The one manager who admitted dismissing an employee who he considered was losing him business was at one end of the continuum of a management style which was justified with reference to operational concerns:

(I'm) participative, bordering on autocratic! Which one I use is mainly based around time and resources. The problem with participation is that its very hard to see results. So if customer expectations and service requirements aren't being met, saying "Okay guys, how are we going to do it" isn't as good as "This is what I expect you to do". (Bar-Cafe)

(I like to) give the employees quite a degree of freedom, to express themselves. But then again as I say to them if they step out of line it won't be tolerated. And certain privileges may go, their hours may be in jeopardy. But we are pretty casual, I'm not a great disciplinarian. It works, it works pretty well. (Licensed Club)

While in most cases a willingness to take firm action to resolve conflict is perceived as restoring balance in favour of the employer, in other cases managers may be more autocratic than they are prepared to admit. Although "management by imperative" is most common in small firms, it is a style which is present in workplaces of all sizes. Some interviewees were aware of their own personal tendency to "bossiness" and argued that this reflected the high standards that they set for being successful in their businesses. In other cases, an autocratic approach 
was viewed as inherent in the management role. These managers were of the view that the task of "managing" allowed them to make unilateral decisions affecting employees in order to meet business requirements. In these cases, an autocratic style was not how they would describe themselves but was evident from what they said:

I've always told them where things were, and how I like things done, and that I was a difficult person to work for. And they have to accept that. I used to work with them in the kitchen, but now I've learned that they are better to work with my two stalwarts, because they're kinder people that I am. And I think that's worked very well. Because I'm bossy, and that's my reputation, and I think it's better, they feel more comfortable working with those two girls, and being told. (Catering)

I guess in a nutshell I want them to work as hard as $I$ do. You can't motivate staff to do the same thing that you want to do. They're often motivated by their wages, that is one of the major reasons for coming to work. ... But the reason for being here has got to be greater than a financial reward, they actually need to take pleasure and take pride in wanting to work here. Again, their morale was very low when I got here and they had no pride in what is a beautiful building really. They took it for granted really. So I used to make them walk round, and show them just how nice it was. And say, hey, look at this, this is a great place to work. Imagine if you had to work in a little tiny office with no windows. (Hotel Accommodation)

Despite these overall tendencies, managers' view of themselves is that they are "firm but fair", and they view these as being two sides of the same coin. "Fairness", however, does not imply giving way to employees on occasion, but the use of logic in management decision-making. Managers refer to changing practices for operational reasons as "making sense" and use this as the justification for many decisions which might otherwise be unpopular with employees:

I wanted something changed there a year or so ago. And people kicked and screamed about it. They didn't want to do it in the evening, they'd rather do this 
balance-up procedure in the morning. And I said, "No, the evening's better" because we had new electronic funds transfer system put in, and the most logical time for everything to happen was the evening. And they didn't want this to happen at all. They claimed that they were too busy in the evening. And I just over-rode them and said, "No, you're doing it in the evening and not the morning. You're going to have to change". And of course, it's done in the evening and it's not a problem. It was the logical way. (Motel Accommodation)

The provision or limitation of "perks" are also an important part of establishing or restoring balance in the relationship. While interviewees often discussed perks as a business cost, they also saw it as providing them with a tool in their arsenal for influencing employee behavior and essential element of the psychological contract which allowed them to remind employees of their managerial authority. One bar manager, for example, withdrew staff buying privileges following an incident in which several employees had become intoxicated after their shift had ended. In contrast, this manager describes her decision to continue staff access to post-mix machines, despite pressure from the hotel's accountant to tighten up on the practice:

And so I rang the union and I also rang (manager at another hotel) And he said to me ... if you tighten up, he said, they'll start to pinch it. And he said they just won't pinch soft drink, he said they'll pinch anything else going. He said providing it's not being abused and they are not filling great big huge 2 litre bottles to take home to friends and family, and it's a reasonable amount, he said just ride with it. (Accommodation Hotel)

In summary, therefore, interviews revealed that management style reflects the nature and operational characteristics of the industry. These include a very handson style of management, the importance of personal relationships in the establishment of a workplace culture into which customers are attracted, and the immediate nature of customer demand which results in a tendency towards a more 
autocratic style of management. These contradictions and dilemmas which managers face as a result of these common features are explored in further detail in the section below.

\subsection{Managing and competing: the Pushmepullyou manager}

A key task for managers in any industry involves simultaneously meeting customer needs, managing employees, and maintaining a viable cost structure. Watson (1994:33) describes this process as one of "strategic exchange" in which the managerial role involves orchestrating a series of exchanges with both internal and external parties. For managers in the highly competitive and labour intensive hospitality industry, this - like Dr Doolittle's Pushmepullyou - frequently involves managers looking in opposite directions to resolve competing demands. These demands are often experienced as being antithetical and irreconcilable. Some of the key issues in their attempts to do this are outlined below.

As noted in Chapter 5 of this thesis, most managers in the industry see the most significant factor in achieving competitive success as being quality of service or product offered. The labour-management practices most congruent with this involve those most likely to result in the recruitment and retention of staff with the requisite skills to deliver this quality. Evidence presented in Chapter 3 suggests the most common reasons for high levels of employee turnover are low wages, unfair treatment by employers, lack of job satisfaction and few opportunities for career development. Given this, the labour-management strategies most likely to deliver to employers the staff that would allow them to compete on the basis of 
quality would logically involve upwards competition in wages and conditions, due process in employer decision making, the development of an industry-wide internal labour market, and improved opportunity for employee involvement in workplace operation.

That these practices are not widespread within the industry suggests either that the perceived linkage between their application and quality as a competitive strategy does not work in practice; that managers misperceive the nature of the linkage; or that other factors are equally as important. The findings from this study suggest that the last factor is the most important of these, with price considerations acting as a counterweight to the importance of quality. The perceived trade off between cost and quality considerations that is sometimes suggested in the literature does not exist in managers perceptions of reality. Many workplaces seek to be competitive on both indices, and their management strategies attempt to achieve both these ends. Because the industry is engaged in service provisions, it is labour intensive. Thus, many of the difficulties faced in managing labour centre around the extent to which managers achieve business goals through the employment of skilled staff who are able to deliver the standard of service which they promote, and at the same time reduce labour costs. It is this central contradiction which lies at the heart of many of the incongruities of management beliefs and behaviour, and which helps to explain variation in management practices within the industry as a whole. 
This contradiction can be illustrated by considering the common features of management style within the industry described in the previous section and the way in which these are exhibited through patterns of employment, work and labour relations. The tension between staff quality and reduction of labour costs is perhaps most evident in patterns of employment relations. Theoretical perspectives on atypical employment suggest that these are utilised as a means of reducing labour costs, with labour being employed only when required. This results in the higher proportions of part-time and casual staff. However, many managers participating in this study faced limitations in attempting to do this. Casual staff are not perceived as being as committed to the organisation and thus do not provide the quality of customer service required. In addition, where quality is an important consideration, managers prefer to employ staff with existing customer service skills or technical (such as bar or kitchen) qualifications. These employees are perceived as being more likely to have the requisite interpersonal skills and better able to participate in a team. However, employees who have invested in industry-specific skills are more likely to have a career-orientation. Thus in order to attract these staff, employers are required to offer promotion prospects, hours of work and wages that are commensurate with these expectations.

Contradictions can also be seen in the extent to which employers are prepared to invest in staff training. While most are well aware of the advantages of doing so, the likelihood that employees will move on limits the extent to which employers believe that they will receive a return on this investment. Even in those 
organisations with formal programmes for cross-training and multi-skilling, participation is often limited to employees who are perceived as having the potential for a longer-term career in the industry, as opposed to those who are simply working in the area while completing an education or waiting for other work. The prevalence of on-the-job training and the fact that frequently it is only selected employees who are offered external or formal training, may be seen as a response by employers to improve quality while exercising caution to ensure that they do not significantly increase costs.

In the area of work relations, the nature of service provision involves its own contradictions which make management in this area particularly complex. As noted throughout this thesis, the centrality of interpersonal skills in the industry emanates from the nature of customer service, and selection and promotion decisions are commonly made on the basis of the employees' personality. Nevertheless, a tendency towards routinisation of service provision has been evident since the 1980s as a guarantee of both product and service quality within the industry. Routinisation may also serve as a means of reducing labour costs, since it lessens the degree of direct supervision that is required, and ensures a greater degree of predictability. It is notable that a considerable proportion of managers participating in this study had standardised job procedures, although they varied in the extent to which this had been done. Nevertheless, many employers were ambivalent about the limits of this routinisation. In particular, quality service was viewed as requiring a degree of personal authenticity which is seen as being inconsistent with increased routinisation. Employees who can 
provide this authentic service are seen as being few and far between, and managers expressed a willingness to offer these employees greater flexibility in hours of work, time off, and involvement in decision making as a means of improving the work environment for them individually.

Labour relations are also clearly affected by the contradiction between improved quality and reduced labour costs. Individual contracts are seen as a way of rewarding "good" employees, without increasing wages on a generalised basis to employees who do not have the required interpersonal skills. Collective contracts, on the other hand are seen to provide better conditions of work for "mediocre" employees who the employer might otherwise feel sanguine about losing. In addition, those workplaces concerned with quality are more likely than others to have comprehensive contracts of employment which include adequate leave provisions, training allowances and other conditions above those minimums provided for by legislation. While these provisions may increase labour costs, they are also seen by those employers that offer them to contribute to an overall employment package which allows them to attract employees with the requisite skills associated with the provision of superior quality.

In essence, therefore, the approaches taken to various aspects of labourmanagement reflect the ways in which employers individually resolve the contradictions between cost and quality. In doing so, they vary in the extent to which they focus on one or the other. The factors which influence their orientation include both objective and material factors such as workplace size, and industry 
and operational constraints. Nevertheless, the experience of managers in the industry and their perceptions of the interplay between their business and "the market" also have an influence on employer decision making. The effect of these factors is explored in the next section.

\subsection{Explaining management style}

Analysis of the data collected in this study suggests that four key considerations must be taken into account in explaining why a particular management style is adopted in a specific workplace. The first is workplace size, with larger workplaces being more likely to adopt formal practices in a range of areas. Secondly, operational constraints are critical. Of particular importance is the immediacy with which workplaces are required to respond to demands from customers; and in the quality of service that is being provided. Thirdly, a series of market based constraints arising out of increased competition as a result of industry deregulation is evident, although as discussed later, these are not as influential as the more immediate operational demands are. Finally, managers' own personal experiences and personal beliefs play a role in their choice of management style and their approach to labour-management. These are considered in greater detail below. 


\subsubsection{Size}

As noted in Chapter 1, a number of commentators have suggested that workplace size and structure are a key determinant of labour-management practices. This suggestion is supported by this current study. Not surprisingly, increasing size is associated with greater formalisation of policies in a range of areas. As noted above, larger than average workplaces are more likely to have adopted a systematic and policy-oriented approach to management style, and to provide management training for staff. In addition, as noted in Chapters $6-8$, increasing size is also associated with greater formalisation of policies for recruitment, selection, training and discipline, with the employment of full-timers and workers employed on a permanent basis, and with more comprehensive and collective employment contracts. While in most small firms labour-management decisions are made on an ad hoc basis, once workplace size reaches 15-20 employees, a greater degree of systematisation is evident. Human resource decisions in these workplaces are influenced by "custom", determined by what has worked for them in the past. While these are sometimes adapted from other workplaces, decisions in a range of areas are characterised by a degree of experimentation, practical business sense, and a focus on "workability". They vary in the extent, however, to which these are put down in writing or expressed as "policy". Very formal and written human resource policies are evident only in the very largest firms in the industry, or workplaces which are part of a larger organisation. A key feature of these are that they are influenced to a much greater extent by factors outside the workplace itself, including either corporate policies developed around a "brand" or practices adopted in other workplaces in a similar market niche (for example, 
the luxury hotel market). Despite the fact that these larger workplaces emphasise their distinctiveness, their human resource strategies have much more in common with each other than they do with the rest of the industry.

Size also has an influence on the nature of labour-management style, as well as the extent of formalisation. Managers in firms employing fewer than 20 employees rely largely on "gut instinct" and on direct and personal control of employees at the workplace. Decision making is frequently influenced by situational characteristics, including the nature, personality and skills of the individual employee. Managers of small businesses frequently described themselves as "autocratic" - or in the words of one cafe owner "the boss from hell"! At the other extreme, all of the very large workplaces (and those that were part of a larger organisation) had formally adopted a management philosophy centred on employee participation, coaching, and empowerment and also had a range of mechanisms in place to promote communication with employees.

The effect of size on management style and associated human resource practices is seen in these quotes from managers. The first is a manager who has worked in a number of workplaces in the industry. The second is the owner of business that had grown from one premise to three in a short space of time. Both suggest that the demands of increasing size necessitate greater systematisation and standardisation:

In a bigger hotel the demarcation line is much stricter than what it is in the smaller hotel. And lets face it, with 108 rooms privately owned, we're still relatively small to a chain hotel, where you have to follow the guidelines and you do the same whether 
you are in Quality Inn in Christchurch or Quality Inn in Auckland or elsewhere, wherever. (Accommodation Hotel)

As the time's gone by over the 4 years we've had to open another place up. We aren't obviously as hands on as what we used to be, but ... I think we've learnt a hell of a lot. That's obviously changed us and I think it's changed us for the good that's for sure. I think we're probably a bit more ... we probably demand more than in those days, because in those days we never worried about our percentages, we just rocked along and opened a bank account and everyone was having a good time, but obviously those things wouldn't last today. I've had to learn how businesses act. So we've had to put in systems and procedures, and guidelines to operate by. We know now what our percentages are; we know what we're making or not making. The way we were going before, I think that what we would be doing today is ... we would have crashed basically. (Bar-Restaurant).

\subsubsection{Operational constraints}

In addition to size, operational constraints have a substantive influence on the style which managers adopt in their workplaces. In discussing the effect of operational constraints, what is being referred to are what Marchington and Parker (1990) describe as "customer pressures" and include the patterns of demand (such as its predictability) experienced at an individual workplace. Although the industry as a whole is focused on service provision, the immediacy of consumption by customers and the quality of service that is being provided can vary from workplace to workplace; and even within workplaces. For example, in hotels, the tasks undertaken by housekeeping staff are less direct than those provided by the hotel receptionist. Similarly, staff employed by airline catering companies have a different relationship with the customer than staff employed by other catering companies to wait at functions. 
The impact of operational constraints can also be seen in the associations between demand variables and various labour-management practices. As noted in Chapter 5 , the vast majority of workplaces responding to the survey assessed the level of demand as being either stable or expanding, and two-thirds reported its variability as being predictable. These demand variables, more than other market related ones (such as levels of competition and critical factors for competitive success), are associated with different patterns of labour management. Workplaces where demand is expanding are more likely to employ a higher proportion of full-time and casual workers; to place greater emphasis on communication with employees and to communicate on a regular and on-going basis; to provide a range of ongoing training opportunities to higher proportions of employees; and to negotiate employment contracts individually with employees. Firms where demand is contracting, on the other hand, employ staff on irregular hours of work; are less likely to communicate with their employees except on matters related to their financial situation; communicate only as and when needed; are less likely to provide on-going training for their employees; and are more likely to have standardised and verbal contracts of employment. Similarly, workplaces where demand is predictable employ higher proportions of permanent staff and are more likely to have negotiated written contracts, while those where demand is unpredictable employ higher proportions of casual staff on verbal employment contracts. These associations suggest despite the concern of managers to compete on both quality and price grounds, there is some perceived trade off between the two. In particular, managers adopt more beneficial practices (for employees) at times when demand is expanding, but when this drops off, cost pressures are felt 
most quickly in relation to staff. Areas where expenditure is discretionary (such as in the area of on-going training) are likely to be the first reduced.

The close association between demand variables and more progressive labourmanagement practices, and the fact that almost half the survey respondents reported increasing demand also provide an explanation for the generally more positive findings on labour-management practices in the industry than might be expected from international research and anecdotal data. At the same time, the nature of quality as a competitive success factor also influences labourmanagement practices. A high proportion of interviewees made conscious connections between customer service and employee relations. A small number have introduced the notion that employees are "internal customers" and that the same standards of service which applied to paying customers are relevant to the way people were treated internally. Most, however, have a much more instinctive understanding that staff who had been treated badly could not be expected to provide quality customer service:

I remember sitting down and explaining to people "You know if you are going to yell at your chef, you're going to have him in a bad mood." ... And what do you think is going to happen? He's going to yell at the waiter, and the waiter's going to get shitty at the customer, and that is going to affect you. I don't think people believe it. I think they think it's a management right. Or they don't have the selfcontrol to stop it. Everybody has bad days, but you still can't treat people that way. (Cafe-Restaurant)

They (owners) don't often think about what they're going to say. They build up inside them about a situation and then they tear strips off people and cause havoc. At the moment they're away and the staff are very relaxed, they're doing their jobs, and getting on well. As soon as they come back, the tension will be there. Its just like 
getting told off. Some people don't handle it very well, and get surly or whatever after that, and the customer must get the result of that flak. (Motor Lodge)

If you provide the right environment, you'll have the right sort of people working for you. If you provide a crappy environment, in the end, the customer will get the result of that one way or another. So if you provide the right environment, with leadership and all the things that go with it - all these the other things that we talked about, if you like the intangible things - if you provide that, we believe any way, that the customer will get a good experience and that's the key. If you don't provide that, if you don't look after your people, then the people won't look after your customer. ... Because in the finish your customer's experiences are a reflection on the experience that your staff get. (Fast Food Restaurant)

The connections between customer service and management style require employers and managers to carefully consider their approach to labourmanagement. A number referred to the necessity of "leading by example" in their behaviour and attitudes. Several managers who had been in the industry for a considerable period of time commented that this required them to keep their tiredness and cynicism from their staff on the basis that "actions spoke louder than words":

If you relate it back to how we're running our business, we have to say and $d o$ the right thing. Its all very well to say, "Treat the customer right". Everyone says that. But we have to be seen to be doing that. I say to the managers, (staff) will pick up the worst traits you've got, not the best ones. They'll copy the worst thing you do. And its quite frightening when you look at it and you think "I've done that". So I have to start out with being bang on with how I deal with all the customers, even talking about them. Every now and then you drop your sandwich, and you think “God, I'm saying something that I shouldn't be saying, I should be saying, oh well, you know...” (Restaurant)

I say to any new person that comes into my area: we will be the last people that will break the rules, that will flaunt any rule or regulation. Because basically we are the ones enforcing a lot of the rules and regulations. We're the people that are saying "We want $100 \%$ ". So from the time you walk in to the time you walk out, we want 
quality. And basically we are not giving that if we don't lead by example. (Hotel Accommodation)

\subsubsection{Industry constraints}

In addition to the constraints impinging on individual workplaces, wider changes in the industry occurring since the 1980s are perceived as having an effect on management practices. While the vast majority of interviewees are positive about deregulation and consider that increased competition has made them "lift their game"; it has also made their job a lot harder than in the past. Increased competition for market share has meant that managers must adopt a more active approach to management, but as noted earlier, the simultaneous adoption of quality and price as critical success factors means that some trade-off between the two is common.

Industry constraints correspond to what Marchington and Parker (1990) describe as competitive pressures. They are distinguishable from operational pressures in that they are not experienced solely by individual workplaces, and are less tangible or measurable than customer demand. While $71 \%$ of survey respondents reported a high level of competition, there was little variation in patterns of employment, work and labour relations across different levels of competition. This suggests that the effect of competition had been felt in areas other than labour-management practices, such as the necessity for improved marketing, or increased attention being paid to the provision of additional entertainment facilities (such as live bands or cable television). Because increased competition has effects that are more difficult for managers to measure, the potential exists for 
managers to perceive competitive pressures differently. Some support for this suggestion was gathered from comments made in interviews which suggested that the actual extent and level of competition faced by different workplaces was less important than the attitude which managers adopted towards the environment in which they were operating. There is a qualitative difference between those managers who see the environment as being subject to their influence; and those who believe that it operates in ways outside their control. At one end of this continuum, managers view the market as having a determining influence on their operations. This approach is typified by the Pub manager in a provincial city, who in a quote earlier in the chapter was critical of the "cowboys" of the industry setting up new-style bars and restaurants. He described himself as "tired", and attributed this in large part to the pressures of competition. His comments here suggest a degree of ambivalence to the process of deregulation that has taken place:

... just the amount of licenses, it's just hard to handle. There's too many. What we're finding is there is no more patrons out there. So it's nice to have it liberalised, but also it's devastating for businesses. We wonder whether we're going to be in business next month. You know it's like that every month now. Whereas before it was ... you knew what you were looking at. I mean, and then they whack another bar around the corner and another here and another there, bang, bang, bang. The pie gets that small and we still have the ... overheads are going up. Wages have gone up, rates have gone up, booze keeps going up, so that in itself drives your customers away. (Pub)

At the other end of the continuum are organisations that take a much more dynamic approach. These managers express enthusiasm about the opportunities available to them through deregulation, and actively select a market segment in which to compete. They adopt a proactive approach to competition, seek to 
achieve excellence in a particular niche and see themselves as having a degree of influence over their customers. This frequently involves them in "educating" the market about what to expect from the product or service being supplied. The way in which Fast Food Restaurants have educated customers to expect a standardised food product in a short time frame has been addressed in the literature. However, the same practice is seen in restaurants who contrive to show their clientele the niceties of a fine dining experience, cafes who educate their customers about the superior quality of arabica beans, and luxury hotels who expect their guests to exhibit their "cultural capital" and behave with particular decorum. These features are illustrated in the following quotes:

There's far too many restaurants really, obviously. So we're competing for a pretty tight dollar. And you've got decor, you've got Steinlager ... I mean you can sell it anywhere, and the price can be a variation, but its the style you sell it with and the environment you put it in. And that comes down to the (staff) again doesn't it? Whether they are cheerfully going to take 5 bucks off you in this place for a Steinie or a Heineken. (Cafe-Restaurant)

So they come in and they say "Hello, how are you? Smoking or non-smoking? How are you off for time today?" Older women, you really have to slow that down. Because if you say to them "Would you like a drink?", they think you're trying to ram drinks down their throats. And when you say to someone "How are you off for time?" they'll say "What's wrong? Do you want the table?" And then we'll say, "No, what happened to good old service? We're just trying to find out how you want it" or "We're here till 1 in the morning, you can stay as long as you like". (Restaurant)

As noted earlier, it is managerial attitudes to competition (particularly whether managers take a defensive or pro-active approach to the market) rather than the level of competition per se which have the greatest effect on labour-management practices. Those who see the market as being outside of their control adopt an 
approach to human resources which is focused on cost-cutting. For example, they employ additional staff only when customer demand levels exceeds the ability of staff numbers to cope, they put little investment into staff training, and their expectations of staff are commensurate with the "adequate" levels of remuneration offered. Those that take a more active approach to the market are more likely to see staff as being critical to their competitive success. They invest more heavily in both initial and on-going staff training, are prepared to pay over the odds for good staff, and are more likely to view employment in the industry as a profession involving a degree of skill. Thus the impact of competition on labour-management practices is less direct than the impact of operational demands and customer pressure. 


\subsubsection{Personal experience and history}

While size, operational constraints, and perception of competitive demands all influence labour-management practices, it is also clear that managerial philosophy plays a role in the decisions of employers managing workplaces of similar sizes and operating in similar markets. Two particular influences on this (not always reinforcing or compatible) were noted. The first is the personal experience that many managers have had as employees within the industry. When asked why they did things in a particular way, interviewees frequently made reference to how they had felt as employees and the determining influence that this has had on their management style. To this extent, their management practices should be viewed as quite self-conscious:

I started this career working as a waiter, working in kitchens. And some of the incidents that have happened to me over my working career I wouldn't wish on anybody else. And I always felt that if I ever got into a position of authority where I was able to make decisions then I would do my level best to make sure that other people were treated fairly. (Accommodation Hotel)

I always say that it would be nice if people were more professional, but in a way I don't blame them. They get treated so badly when they go to work in these places, and they think "I wouldn't want to stay in this industry, its awful". And I don't blame them for wanting to get out. I did! That was why I got my own place. (CafeRestaurant)

The second influence is the very personal involvement that many smaller employers, often owner-operators, have with their businesses. While employers place great emphasis on good personal relationships with their employees, and even have a close personal relationship with them, they are not prepared to sacrifice the commitment and investment they have made in their businesses for 
the sake of a more harmonious work environment. They see the workplace as "belonging" to them and interpret employee behaviour in that light:

That they're caught stealing but because they weren't warned ... to me its just, we all know what's right and what's wrong, and stealing isn't right. If you're caught stealing you should be fired in my view, it shouldn't be a question of whether you followed the right procedure or not. I mean I have a business to run, I don't need people stealing from me. (Cafe)

And you get into a vicious cycle in so much as you're pulling people in at the last moment because things are turning out to be different from what you'd thought. You're not training them, so they're not doing the job probably, so you get more pissed off with them, they get more pissed off with you. So you haven't got the good work atmosphere. Plus from my own personal point of view some people have accused me of being negative and always harping on about my financial situation. In fact at one stage this girl that came to work for me in the kitchen said "It's just no fun working here", and I said "Well excuse bloody me, I am tens of thousands of dollars in debt". Well bluntly I could be liquidated as far as being a company goes, it's only because my creditors are being really good to me. I'm sorry it's not fun, at the moment all I'm trying to do is keep jobs for people and keep this operating. I'm not going to go around whistling, I'm that deep in the poo. And then they react to that type of reaction, and so it's really a no win situation for everybody. (Accommodation Hotel)

\subsection{Patterns of labour-management}

The combination of size factors, operational constraints, industry factors and the orientation of managers and owners within the industry gives rise to four general patterns of labour management within the industry. It is important to note, however, that these should be seen as archetypes, and that variation within these general patterns is considerable given the particular mix of factors applying at any individual workplace. Workplace or organisational size and employer attitudes about market conditions are the two axes on which these variations turn. These are, however, moderated by the managers' personal experience and managerial 
philosophy, and the extent of competition to which they are exposed. At extreme ends lie very large and very small operators, each with distinctive approaches. In between lie medium sized firms of between 15 and 100 employees. Although these workplaces have similar characteristics because of their size, a continuum of labour-management practices may be discerned. At the more traditional end of the spectrum, managers adopt what might be best described as "Business Before People” approach. Labour-management decisions are contingent on operational exigencies, and the needs of employees are seen as secondary to those of the business. In contrast, "Business Through People" managers are equally focused on operational issues but view employees as an integral part of this equation. Employees are recognised as the means by which competitive success can be attained, rather than an additional cost factor. Which approach is taken is partially explained by whether the employer views the market favourably and adopts a proactive approach to competition, or, whether they feel constrained by the operation of the market; but also by their own personal experiences and philosophy. Descriptions of the four types and some of the contradictions in the way they operate are outlined below, and set out diagrammatically in Figure 9.1.

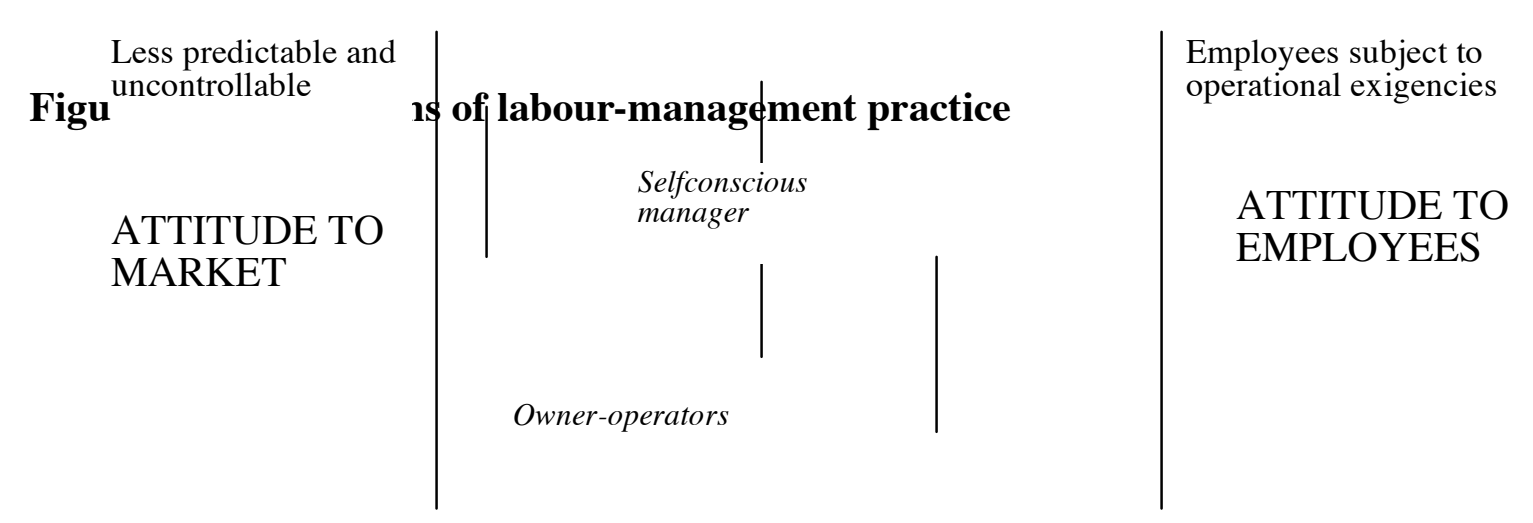




\subsubsection{The owner operator}

The small size of many businesses in the industry means that owner-operators and family businesses are common. Although some of these firms are in fact family owned, the term "family" is a qualitative description of how these managers see their businesses operating. For these employers, management of staff is largely contingent on their primary concern of running their business. They have become employers because they chose to go into business for themselves but have little formal expertise in areas outside their own experience, and are strongly influenced by pragmatism. A high proportion have not previously worked in the industry as employees, but are motivated by the opportunity to take greater control over their work lives. While employers in these businesses place considerable emphasis on meeting customer demands, and often seek out feedback, they generally do so on a reactive basis. Because of their size, the ability of these employers to engage in the type of environmental scanning that would allow them to take a more forward thinking approach is limited. Owner-operators will commonly be members of the relevant industry association (such as the Motel Association) which acts as their primary source of information and advice in labour-management matters, although lawyers and accountants also are commonly used.

More predictable and 
Labour-management practices in small workplaces reflect the personality of the individual owners, and it is rare for systems or policies to have been adopted. Staff are selected and assessed according to how well they relate to the manager and whether their approaches to work "match. This assessment is frequently made on the basis of how hard employees work in pursuit of the employers' business. While these employers have a strong sense that owning their own business allows them to direct their employees, they frequently avoid conflict, and seek out staff with whom they can develop a strong personal relationship. Employees who make the grade will be treated well, provided with considerable input into decision making and a degree of discretion and flexibility. The workplace dynamic that is built up, therefore, is strongly based on a preference for informality and is achieved through an emotional and psychological contract. Formal employment contracts are rare, and perceived as unnecessary.

The biggest challenge faced by these employers is if their expectations of this psychological contract are not met. When labour-management practices are reduced to a legal, rather than an emotional relationship, this necessitates their taking on a management role with which they are unfamiliar and unconfident. In doing this, they resort to seeking advice from outside sources, such as lawyers, industry associations, and informal contacts. Because the quality of these advisors is variable, they are frequently vulnerable to poor or inaccurate advice, which can leave them feeling that employment law, along with other management requirements, do not operate in favour of the small business person. 


\subsubsection{The self-conscious manager}

Increasing size requires a more professional approach to management, including greater systematisation of labour-management processes. As noted earlier in this chapter, this does not always involve the establishment of formal policies, but "custom and practice" will be established from practices used in the past. At one end of the continuum in the trade-off between operational constraints and concern for employees, labour-management practices can best be described as "Business Before People", and success is measured through a range of largely financial indicators. It is not uncommon for these managers to have had some management experience in other industries, with a significant minority coming into the industry from the Armed Forces. Like the managers of very small businesses, they have often deliberately chosen self-employment as an option but are strongly motivated by the desire for business success. They commonly had a stronger sense of themselves as "manager" than other interviewees, and they actively monitored business performance.

These managers are more likely than others to adopt the view that business success depends on responsiveness to customer demand. The customer is central in their orientation, and they actively seek quality improvements in their operations. The approach that they take, however, is frequently a "text-book" one. For example, they will commonly train staff in customer service routines and attempt to enforce adherence to these. In implementing changes at the workplace, they are active in keeping up with industry trends, but are more likely to imitate 
business strategies that have been proved successful elsewhere than they are to adopt an innovative approach.

The approach commonly leads employers to regard employees as a tool in their management arsenal and to place less need on employee needs and concerns. Accordingly, labour-management practices are based on reduction of costs and a requirement for employees to fit in with employers. While these employers view themselves as flexible in relation to their employees, the balance of the relationship is drawn heavily in their favour. The workplace dynamic is oriented towards the needs of the business, and these managers are less interested in the interpersonal aspects of their relationship with their staff as they are in employees fitting in with their business concerns and acting according to their directives. This is seen most clearly in relation to hours of work. In workplaces where this style is prevalent, employees are expected to work whatever hours are required of them, are prevented from nominating days or times at which they are not available for work, and may be called in at short notice to work. Employment contracts are based on minimum statutory conditions, as a means of reducing labour costs to the lowest possible level, although wages may be higher than this to meet market rates. Contracts are usually individualised as a means of controlling employees and providing above average conditions to employees as a reward for fitting in with their employer. Generally, this approach corresponds with the classical "unitarist" approach to management in which the authority of the employer is central in the firm. 
There are, nevertheless contradictions for managers in this approach. In particular, their lack of concern for employees in a labour intensive industry may result in lower levels of commitment and loyalty to the organisation; and higher levels of labour turnover. In addition to raising costs unnecessarily, this strategy also limits the sources of information through which employers can receive feedback on the success or otherwise of heir business. By relying solely on management initiated information sources, managers do not gain the benefit of feedback from their staff who are in much closer contact with their customers.

\subsubsection{The Industry Operator}

An alternative means by which management within the industry has been professionalised is the approach in which managers view employees as making a contribution towards the achievement of their business aims. These employers have a close sense of identification with the industry and understand it well. They view their employees as an integral part of the service being provided to their customers and can best be described as adopting a "Business Through People" approach. These managers share with family operators a concern for personal relationships and recognition of the importance of the psychological contract at the workplace, but their larger size necessitates a greater degree of systematisation of labour-management practices. These are based on establishing a balance between the needs of employees and employers, although they are careful not to subsume their business needs to those of employees. As one employer noted when discussing rostering arrangements, they are careful to ensure that the tail doesn't wag the dog, but within operational constraints they will make efforts to ensure 
that workplace relationships are more mutual. They are more likely, for example, to have systematic rostering provisions, to have instituted mechanisms for communication with employees, to have above average conditions included in the employment contact and to provide training for employees which is portable. Individual contracts are more common than collectives, but these are usually based on the belief that this is better for employees than as a means of manipulating or disadvantaging them.

These managers were more likely than any others to have a history in the industry, a strong sense of identification with it, and a commitment to improving its image and status. They actively monitor developments and take an energetic role in industry associations. The way in which these managers approach employees is based on their belief in the close association between customer service and labourmanagement practices. It is important to note, however, that the driver for this is a proactive attempt to overcome operational and industry constraints. Their businesses are more than simply a source of employment or an alternative career, but are integral to their sense of identity. It is not an exaggeration to say that these managers are passionate about what they do and that their workplaces are an extension of their personal enjoyment of eating and drinking and providing hospitality. Unlike other managers, they are more likely to be at the leading edge of trends, and to be pro-active in change.

While these workplaces are likely to have more harmonious relationships with their employees, there are still contradictions in the way they operate. In 
particular, while managers may seek a balance between their needs and those of employees, they may sometimes be perceived as inconsistent, particularly if they adopt a more autocratic approach from time to time as a means of restoring a perceived imbalance. In addition, the focus which these managers place on microlevel concerns may limit the extent to which they are able to bring a wider perspective to bear on their business operations.

\subsubsection{The Corporate}

As large players in an industry of small businesses, corporates (made up of large hotels and hotel chains, fast-food chains, and commercial catering companies) have a degree of leverage which enables them to establish a degree of stability in demand. Commercial catering companies, for example, may have standing orders with companies such as airlines, and large hotels may have guaranteed minimum levels of occupancy as a result of agreements with tour companies. In addition, corporates are of a size where a more active approach to advertising and marketing is better able to be absorbed. As a result, corporates operate in that part of the hospitality industry market which has a greater degree of predictability than any other. They have the luxury of being protected from sudden changes in demand in a way which is unavailable to other workplaces in the industry. This provides them with greater freedom from constraints in the choices that they make in respect of labour-management practices.

The very largest organisations participating in this study had adopted very similar approaches to labour-management. They were all committed to high quality in 
customer service and were large enough to be able to absorb the costs of providing for this. As noted earlier, these organisations were the only ones in the industry where a high degree of systematisation was evident, along with the development of a rudimentary internal labour market. Labour-management practices proceed according to established policies, which set out criteria and processes for selection and appraisal of staff, multiple mechanisms for employeemanagement communications, and training programmes. Employment contracts are usually collective, largely because transaction costs limit their ability to negotiate individual contracts. Nevertheless, these organisations profess a concern for individual employees. Conditions of employment are better in large organisations than elsewhere in the industry; in that they are more comprehensive than elsewhere and are guaranteed by contract.

The biggest contradiction for corporate employers in the industry is their desire to build a relationship with employees in what is essentially a large and bureaucratic organisation. As noted earlier in this chapter, this is achieved partly through symbolic means, but also through management philosophies which place considerable emphasis on individuals. It must be noted however, that the business orientation of these (often highly successful) firms is not compromised by their attention to human resource management practices. Instead, the balancing between the two involves a highly skilful management process which might perhaps be best compared to an iron hand in a velvet glove.

\subsection{Summary and conclusions}


This chapter has considered overall influences on labour-management practice in the industry, and the most prevalent styles of management. In summary, while a range of management styles exist across the industry as a whole, common features include a focus on a very hands-on management style, a direct and personal relationship with employees, and an emphasis on immediate and unquestioned responses to management directives. In returning to the material discussed in Chapter 4 , it is clear that economic conditions pertaining in the industry have an influence on the way in which firms make their labour-management decisions. However, both survey and interview data suggest that the operational constraints exerted by customer demand wield a more significant effect on labourmanagement practices than increased competition in the industry. This may be explained by the fact that although the industry has become more competitive, market share is increasing at the same time. The size of firms is also a critical influence in the type of management practices adopted. However, these factors do not in and of themselves completely explain the variety of practices existing in the industry. The personal backgrounds of managers, and their subjective perceptions of both market conditions and whether these are subject to influence also have a role to play. The implications of these findings are explored in the final chapter of this thesis, where we return to the subject of prevailing explanations of management practice. 
Chapter 1: Introduction

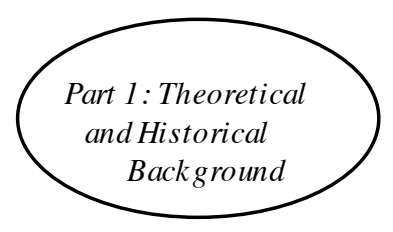

Chapter 2: Tourism and Hospitality Industry Development in New Zealand

Chapter 3: Employment, Work and Labour Relations in the Hospitality Industry

Chapter 4: The Framework for Analysis: Explaining Management Practice

Chapter 5: Research Approach and Methodology

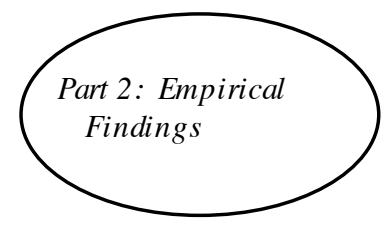

Chapter 6: Employment Relations in the Hospitality Industry

Chapter 7: Work Relations in the Hospitality Industry

Chapter 8: Labour Relations in the Hospitality Industry

Chapter 9: Labour-Management Practice in the Hospitality Industry: Managing to Compete?

Part 3: Discussion and Conclusions

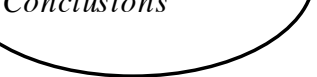

Chapter 10: Explaining

Management Practice: Strategy,

Environment and Social Action 


\section{Chapter 10: Explaining Management Practice: Strategy, Environment and Social Action}

\subsection{Introduction}

This final chapter returns to some of the theoretical debates covered in Chapter 4. In particular, prevailing explanations of management practice are examined with a view to considering their value in interpreting the findings of this study. The first section suggests that while theoretical models (such as those suggested by Gospel (1992) and Marchington and Parker (1990)), which place emphasis on changing demand and competition factors as an explanation of labourmanagement practices at firm level go some way to explaining contemporary practice, they neglect to consider the question of managerial agency. Both the social and political context in which managers operate and their individual and personal identities play an important part in the way that they play their roles, and contrive the process of "strategic exchange" between the needs of their customers and those of their employees. The second part of this chapter examines Gidden's concept of structuration as an analytical tool for establishing a theoretical link between materialist and interpretive explanations of organisational practice.

\subsection{Markets and social action as determinants of managerial practice}

As discussed in Chapters 1 and 4, Gospel (1992) has suggested that both labour and product markets constrain but do not determine labour-management practices and that these are mediated through the structure of the firm, its nature and the way in which work is organised. The extent to which these propositions are supported by the findings of the current study are explored below. 


\subsubsection{The influence of product markets}

The findings of the research make it clear that the nature of product markets is particularly influential in the determination of labour-management practices. The direction of these influences is not altogether clear however. In particular, Chapter 9 concluded that the predictability of demand, and whether demand was expanding or contracting had a greater influence on practice than levels of competition per se. For example, employment structures, the extent of training provided to employees, the proportion of employees provided with training, and the type of employment contract were all associated with aspects of demand; but there was little difference between workplaces on the basis of whether they experienced high levels of competition or not. An assessment of these findings against Marchington and Parker's (1990) theorisation of the linkages between product market considerations and labour-management patterns suggests the reasons for this. It will be recalled that they propose that degree of monopoly and degree of monopsony must both be taken into account when considering the impact of product markets. In the case of the hospitality industry in New Zealand in the 1990s, while the industry is highly competitive, aggregate demand is expanding both as a result of tourism growth and changing patterns of consumption in the domestic market, as discussed below.

Changes in the product market environment in the industry have been hugely significant over the past decade. Chapter 3 noted that deregulation of liquor licensing laws has resulted in the massive increase in the number of hospitality industry workplaces. In addition, despite the considerable up-front capital costs, barriers to entry into the hospitality industry market are lower than those experienced in other industries. Thus competitive pressures in the industry are considerable and have grown exponentially in recent years, providing customers 
with a ready source of alternatives from which to choose. While Marchington and Parker suggest that this might be expected to introduce constraints on managerial action, other relevant product market factors work in the opposite direction. In particular, the expanding market for hospitality industry services lessens the degree of competitive pressure than might otherwise be experienced and allows managers more room for manoeuvre in their labour-management practices. The expanding market has also seen the development of market niches in the industry, with businesses making a more active selection of that part of the market in which they wish to operate, and specialising within this. Thus the effect of competitive pressures in the industry may not constrain managers to the same extent as they would if the same level of competition was being experienced in a stable or contracting market, and may help to partially explain why competitive pressures were not associated with labour-management practices in the way that might otherwise have been expected.

Customer pressure exerts a related but separate effect. Marchington and Parker (1990) suggest that this may impact in a variety of ways, all of which are relevant in explaining the choices made by hospitality industry managers. Firstly, fluctuations in demand (whether on a daily, weekly or seasonal basis) and the extent to which demand is predictable clearly have a major impact. For example, predictability of demand was associated with employment structure and labour relations variables. Even though both the survey and interview findings suggested that demand is more predictable than is often assumed for the industry, at the same time managers recognise that it can be fickle and can change overnight. In addition, the "spot" nature of the service contracts that are entered into in the provision of hospitality industry services means that customers experience low or no transaction costs in moving their custom from one business to another. 
Employment structures are the most common way of protecting managers from a sudden fall in customer demand. High proportions of part-time workers and a supply of casuals allow greater flexibility in rostering if needed. High levels of labour turnover may provide managers with a buffer, allowing staff levels to be reduced without redundancy or dismissal costs should a drop in demand occur.

Throughout this thesis the centrality of customer demand in influencing labourmanagement practices has been noted. Both survey and interview material supported the notion of the customer as a new mechanism for workplace control (Heery, 1993). Of particular interest in the New Zealand situation is the increased emphasis on quality service. Both increasing numbers of international visitors and changing expectations among domestic consumers have put greater pressure on the industry to increase markedly the quality of service provision. This in turn has implications for the skills that employers look for in recruiting and rewarding staff. There is multiplying recognition in the industry of the level of skill required for many customer service jobs, although the implications of this have have not as yet fed through into labour relations practices.

The hospitality industry provides an excellent example of the linkages between 'competitive and customer pressures. As both have changed in New Zealand in the past decade, they have exerted considerable influence on labour-management practice. In part, this is as a result of the requirement for management practice to be congruent with the level of product and service quality that is being provided. The workplace culture that is being created for customers has spill-over effects for the type of labour-management practices that are implemented. For example, the range of small, inner city coffee houses that have grown in number in recent years garner their appeal to those seeking to participate in a particular experience 
in which caffeine intake has become part of 1990s urban culture. The style of service that is provided in such cafes is integral to this culture, and thus can be seen as a response to customer demand. In making labour-management decisions in a workplace of this type, managers are cognisant of the fact that unconscious customer demand for a cultural experience requires them to select staff who will contribute to this in the service encounter. The cafe style encounter can be contrasted with that which might be experienced in a provincial pub, a luxury hotel, a fast-food outlet, a fine dining restaurant, or a motel at a holiday resort. Each services a particular customer niche, and the customer expectations that form this niche make an essential contribution to the labour-management decisions that are made in that workplace.

\subsubsection{The influence of labour markets}

In addition to product market considerations, the findings of this research also support the notion of a linkage between labour markets and labour-management decisions. The direction of this influence can not be clearly discerned from these findings however. The labour market conditions existing at the present time include the fact that expansion has greatly increased labour demand over the past decades, and within New Zealand the industry is a major source of employment

growth. At the same time labour supply is not guaranteed. While there is a ready supply of those willing to work part-time (including students and those with responsibility for dependent family members), there is a decline in the number of new entrants onto the labour market, and the number of skilled staff is perceived as being limited relative to demand. According to neo-classical theories of labour market functioning, these conditions might be expected to result in improved wages and conditions of work in an attempt to attract employees into the workplace. It is true, as mentioned earlier, that there would appear to have been 
some shift in the status attached to work in the industry. Previously perceived as being unskilled and low-status, there is a greater perception now that work does in fact involve a considerable degree of skill and status in the public mind has improved, at least for some types of establishment. Changes in wages, hours and other conditions of work, job satisfaction and opportunities for employee involvement and development are much slower in coming. The research suggested that a small number of employers are conscious of these pressure and have taken some steps to attempt to address these problems. These efforts are, however, limited at the present time.

An alternative suggestion about the associations between labour markets and labour-management practices which is also consistent with the data is the linkage between labour market segmentation and managerial control strategies discussed in Chapter 4. It will be recalled that Edwards (1979) suggests that the segment of the labour market in which employers operated is established through management control strategies. The data here is consistent with Edwards' hypothesis. It is possible that the continued prevalence of an autocratic management style within the industry is a function of the fact that profitability can continue to be maintained through the continuation of direct control techniques. It is largely in relation to particular occupational groups where skill, education, and experience are required to a higher level (for example, for chefs, managers and receptionists), that a primary labour market has been established. Which ever way the direction of influence runs, however, a clear finding from the study is that if employers wish to attract the higher quality staff that they say they wish to attract then they will have to improve wages and conditions of work considerably in order to recruit and retain the staff they want. 


\subsubsection{Size and ownership}

A further influence on labour-management patterns to be confirmed in the study are size and ownership, inextricably linked in many ways. The vast majority of firms in the industry are small and independently owned. Those employing more than 50 employees are most often subsidiaries or franchises associated with or owned by large, often multi-national, corporations. The combination of these factors has a considerable influence on all aspects of labour-management relations discussed in this study, and are consistent with findings from other studies. As noted in Chapter 9, increasing size is associated with greater systematisation and bureaucratisation, including greater formality in employment practices, the establishment of formal mechanisms for employee involvement, prescriptive behaviour towards customers, and standardisation of wages and conditions. In contrast, smaller firms were more likely to operate informally, or on the basis of custom and practice, with the nature and personality of the individual manager having a determining influence on the nature of the workplace.

\subsubsection{Production technology and work organisation}

An additional feature of the industry found to have a significant influence on the nature of labour-management decisions has been the nature of production processes. Gospel (1992) suggests that this must consider not only the technology of production, but also the way in which work is organised. While technology has not been explicitly considered as part of this research, work organisation has been emphasised as highly influential in determining labour-management practices. As noted earlier in discussing customer pressures, of greatest significance in the hospitality industry is the way in which this is organised around service delivery. Chapter 7 in particular pointed to the way in which responses to customer pressures has resulted in two alternative strategies for the organisation of the work 
process. As was noted there, whether routinisation or customisation of customer service is adopted has implications for other labour-management decisions. Routinisation requires the selection of employees who can be trained to provide customer service and product in accordance with the specifications laid down by management. Individual personality factors are less critical than the necessity of implementing the specifications set out by managers, and training is very specific to the workplace. Those workplaces in which emphasis is placed on some degree of customisation are more likely to employ staff with a considerable degree of competence in interpersonal skills, and are more likely to respond to their needs as individuals through negotiation of individual contacts and payment of higher rates of pay.

While Gospel's (1992) model places considerable emphasis on market related factors (an emphasis which has been supported by the findings of this study) his admittance of the possibility of managerial choice within market constraints must also be re-emphasised. As noted in Chapter 4, however, the influence of historical, political and cultural factors is not considered in any detail by Gospel. The findings of this study suggest that these variables must be seen as critical in explaining variations between firms in similar market segments and facing similar constraints on their action. They are influential because managers do not simply respond as rational utility-maximising economic actors to market forces, but also in light of their multiple social identities. In addition, social and cultural factors including cultural conceptions of the managerial role and changing social attitudes about the place of the hospitality industry in the economy and society are relevant to explanations of labour-management decisions. 
Cultural conceptions about the role of a manager, and the influence of the ideology of managerial prerogative have been noted as influential in constructing managerial action. As was noted in Chapter 9, for a number of managers managerial prerogative is seen to emanate from the traditional justification of business ownership. This provides an ideological rationalisation of the "right" to direct and control employees. A second justification of managerial prerogative, however, is recognisably related to more recent legitimations of the managerial role. Deregulation of product and labour markets, and the resultant emphasis on the "manager's right to manage" has provided managers with the express right to make decisions in their own interests, although few articulated any direct linkage between changed labour-management practices and improved business efficiency. A key element of this new rhetoric is the desire of many employers to establish a much more direct relationship with their employees. Although few deliberately exploited the imbalance which is an inherent part of any hierarchical relationship, their lack of awareness about employees perceptions draws attention to the ways in which this relationship clearly benefits managers at the cost of employees.

Beyond the influence of social and cultural factors, individuals also approach the managerial task in a way which is consistent with their multiple social identities. Managers are not only managers but are also influenced by a range of other factors which influence their labour-management decisions. The way in which managers participating in this study approached their role, and in particular the way in which they spoke of themselves as managers bears close resemblance to Watson's (1994) description of managers as being "in search of themselves". The managerial process is one in which the way that managers seek to shape their organisations is very much a reflection of their personal priorities and how they themselves have been shaped as human beings. As discussed above, some 
managers are also small business persons, and bring to the managerial role a concern with their financial status and investment. Other managers are employees themselves, of multi-national corporates. The loyalty and commitment which they expect from the employees who they are responsible for is partly a reflection of what they perceive the organisation as asking from them individually. Managers also have a role through their past and present involvement in the industry. Frequently. their history as employees under other managers influences their current behaviour, either as the role model for their own behaviour or the example which they actively eschew. In addition to being managers, they are also active consumers within and observers of the industry. Unlike other industries where competitors may experience some difficulty in obtaining information about competitors, hospitality industry managers have open access to their businesses. Many go out of their way to find out what others are doing, to look at what is working and what is not, and to keep up with trends as they develop. This increases their awareness of different styles of management and workplace culture. Their experience as consumers within the industry also contributes to their perceptions of the strengths and weaknesses of their own operations, gives them a clear sense of what they like and why, and influences the way in which they approach the management task.

In summary therefore, evidence from the study supports both explanations of labour-management practices as being constrained by objective factors (such as levels of demand and competition, size and ownership, and technology) but also emphasises that these factors simply constitute the context in which managers make decisions. These are influenced equally by their personal identities and histories. We now go on to explore Gidden's concept of structuration as the means by which the perceived dichotomy between the two can be resolved. 


\subsection{Structuration and management action}

Chapter 4 adopted Giddens' theory of structuration as a means of resolving the theoretical impasse between agency and structure as competing explanations for social behaviour. This final section suggests that the stratification theory of action provides a useful model for considering the linkages between the impact of objective and subjective factors as influences on managerial decision-making in the hospitality industry. Four specific aspects of Giddens' theory have particular relevance in explaining labour-management practices in the hospitality industry. The first is the conception of human social activities as being recursive over time and space. Second is Giddens' insistence that social actors are by and large knowledgable about their actions and operate in a reflexive manner. At the same time, however, the stratification theory of action suggests that social actors may be influenced by unconscious motivations. Lastly, the existence of these unexplored and unconscious motivations may give rise to unintended consequences which later become acknowledged conditions of action. These are explored in further detail below.

It will be recalled that Giddens argued that the nature of social life is recursive. Social strucure has a dual nature - as well as forming the conditions of action, it also constitutes the conditions of its reproduction in space and over time. This duality of structure can be clearly illustrated in this dicussion of labourmanagement practices in the hospitality industry. Reference has been made to the way in which the industry in New Zealand in the 1990s displays many similarities to findings from studies in other countries at different time periods. These include the perception by managers that the industry is peculiar or unique in some way, in 
comparison to other industries and is exhibited by the way in which a distinctive industry "culture" has been produced and reproduced over time. The development of this culture is obviously in part a response to the nature of customer demand. However, the provision of service does not occur in an historical vacuum. The emergence of the hospitality industry from its earlier roots in domestic service have formed the context in which the nature of work and management have evolved. The remains of this tradition can be seen in the emphasis on managerial prerogative, the nature of the personal service that is provided to customers, the continued segregation of work according to occupation, and the status distinctions between work of various kinds.

At the same time, changes in the external environment interact with the culture that has served well in the past in a way which provides stimulus for its evolution to better meet the new conditions of increased competition. A consideration of the recent changes in the nature and structure of the industry in New Zealand can clearly be traced to regulatory and economic change. For example, concerns about the operation of the liquor industry dating back to the $1940 \mathrm{~s}$, culminated in deregulation of the industry in the 1980s, at the same time as growth in domestic and international tourism has occurred. The public perception of work in the industry has changed in response to these conditions. As noted in Chapter 2, in the immediate post- World War II period, the difficulties in attracting labour into the industry were attributed to the low status attached to service work, and the perception that it was demeaning in some way. Shifting social norms in respect of leisure activity and the changing status of the hospitality industry have resulted in an increase in the status of some aspects of hospitality industry work. These 
changes have not had a deterministic impact on the industry however. Managers adopt a range of different practices as they seek to gain best advantage for themselves. Change, although more rapid in the past decade, has not been revolutionary. Current practices in the industry are recognisable from the past, but have evolved in line with legislative and attitudinal reform. This must be seen as a result of the way in which managers seek to influence the environment in which they operate.

The recursive nature of social life, as well as the way in which it develops over time, leads into Giddens' stratification theory of action. As noted earlier, Giddens is insistent that managers are knowledgable about their actions. This leads them to behave reflexively, in actively monitoring their behaviour, practices, and intentions. Gidden's notes that "... actors not only monitor continuously the flow of their activities and expect others to do the same for their own; they also routinely monitor aspects, social and physical, of the contexts in which they move." (1984:5) People do not act as automatons but rather they act with intent, making choices which they can rationalise on the basis of past and current conditions. The conscious nature of managerial action is evident in the interview material collected in this study. Managers offered explicit rationales for all aspects of their labour-management decisions, including their reasons for selection of staff, the workplace dynamic they sought to create, the employment contracts under which their staff were engaged, and their management style. In large part, these rationales were based on the size of their workplace, and their perceptions of their influence over the environment in which they operate. Included in the range of circumstances which constitute this are regulatory 
constraints on employment and in relation to their operations, changing customer expectations and increased competition. While some adopt a passive stance in relation to outside forces, most see themselves as having an influence over at least some of these aspects. In particular, the notion of intent implies the possibility of alternative courses of action. Few managers saw themselves as being completely controlled by external events, even if they felt constrained by them, and most had adopted a particular approach from several which they saw as being available to them.

Giddens' stratification theory of action also, however, suggests that underneath the conscious level at which social actors are able to monitor and rationalise their actions lie unconscious motivations for the activities in which they engage. While actors can nearly always report on their intentions and reasons for acting in a particular way, they are almost never able to discuss their unconscious motivations. Again, the material gathered in this study suggests that managerial activity is as much a reflection of unconscious motivations and cognition as it is of discursive or practical consciousness. Two illustrations may be provided. The first is in relation to managerial explanations of continued occupational segregation in the industry. As noted in Chapter 7, these generally resorted to suggestions that the outcome resulted from employee preferences or immutable personality differences. Few managers, however, offered employees the opportunity to develop their skills in other occupations and those that had had experienced few difficulties in doing so. Thus it is suggested that the conscious reasons offered by managers for this state of affairs may be underpinned by unconscious beliefs based on historical operations and "the way things are". The 
second example is in relation to management defense of their sometimes autocratic direction of employees. This was commonly justified by operational concerns, based on the immediacy of meeting customer demand. However, at other points in the interviews, managers admitted that they made use of such a style in part as a way of controlling employees and ensuring that the balance of the labour-management relationship remained in their favour. Thus an autocratic style of management can be seen as reflecting assumed beliefs about managerial prerogative as much as it is a response to operational concerns. In addition, a wider notion of control often underlay much of how managers discussed the way in which their workplaces operated. In recognising the existence of external factors, managers attempted to check their influence. They sought to limit the impact of rapid changes in market demand by taking an active role in the niche in which they operated, and control over employees through labour-management practices which establish managerial prerogative as one of the central features of the employment relationship.

Finally, recognising unconscious motivations for action recognises the inevitability of unintended consequences. Because actions performed by managers may be unconsciously motivated, not all aspects may be intentional and they may have consequences which are undesirable. This may also occur if groups of individuals behave in the same way, giving rise to a wider pattern of unintended consequences. The traditional pattern of labour-management practices in the hospitality industry as a whole provides a good example of this. While it is individual employers who employ staff and pay wages, the way in which employers follow established practice has given rise to a wider pattern in the 
industry as a whole. Features of this include a cost structure which has traditionally relied on reducing labour costs as much as possible by paying low wages, employing staff under poor conditions of work, and limiting training investment. The consequence of this is to leave the industry in a position in the 1990s where it has been unable to retain the staff that it requires to deliver the quality of service and product on which it seeks to compete in the market place.

Giddens notes, however, that unintended consequences may come to form the acknowledged conditions of further action. The relevance of this for the hospitality industry may be seen in the way that individual managers are adapting their labour-management practices to industry conditions applicable in the 1990s. As noted throughout the empirical sections of this thesis, a number of managers in the industry, particularly those working for large organisations or who have been employed in the industry in the past, have become conscious over recent years of the ways in which past practice is limiting the industry's ability to meet the changing demands of customers for higher quality products and service. The recognition of this within the industry is resulting in gradual changes in employment practices towards those which have a greater likelihood of meeting the circumstances in which they industry is operating in the years approaching the turn of the century.

\subsection{Conclusions}

This thesis has looked at two particular aspects of management in the hospitality industry. Firstly it has described, from a managerial perspective, the patterns of employment, work and labour relations pertaining in the industry. Secondly, it has 
sought to uncover some of the rationales provided by managers for the patterns that exist. Its contribution to the body of knowledge is two-fold. In fulfilling the first objective, it covers in some depth labour-management patterns in an industry which is commonly ignored by scholars in the industrial relations and management disciplines. It also attempts to move beyond explanations of managerial behaviour based on simplistic assumptions of managers as either tools of international capital or all-knowing oracles responding perceptively to market forces. Instead it supports recent studies drawing attention to the complexities of the management process, and portrays managers as reasoned and intentioned, but all too human, social actors.

The availability of choices to managers in their decision-making draws attention to management as a political rather than an economic process. This conclusion is not a new one. Organisational theorists over the course of the twentieth century have argued that a model of organisational behaviour which relies essentially on the model of rational economic man ignores the realities of organisational decision-making. Workplaces are sites of social action in which market factors both influence and are influenced by the political environment, social and cultural changes, and the personal histories of individual working within them. Ignoring the impact of these factors is to risk viewing organisations as one dimensional associations where human action is largely predictable. To both understand and perhaps predict the actions of managers in labour-management matters, we must uncover the more complex influences on management behaviour and understand their actions in their own terms. To paraphrase the quote on which this thesis commenced, managers do not make their history under circumstances chosen by 
themselves, but under the circumstances directly encountered, given and transmitted from the past. 


\section{Appendix 1: Numbers of licences granted and average population}

\section{per licensed house 1894-19381}

\begin{tabular}{|c|c|c|}
\hline $\begin{array}{c}\text { Year ended } 31 \\
\text { March }\end{array}$ & $\begin{array}{l}\text { Number of } \\
\text { licenses granted }\end{array}$ & $\begin{array}{l}\text { Average number of } \\
\text { persons to each } \\
\text { licensed house }\end{array}$ \\
\hline 1894 & 1719 & 391 \\
\hline 1895 & 1579 & 434 \\
\hline 1896 & 1561 & 448 \\
\hline 1897 & 1538 & 464 \\
\hline 1898 & 1526 & 476 \\
\hline 1899 & 1524 & 487 \\
\hline 1900 & 1526 & 494 \\
\hline 1901 & 1522 & 504 \\
\hline 1902 & 1513 & 507 \\
\hline 1903 & 1504 & 529 \\
\hline 1904 & 1404 & 578 \\
\hline 1905 & 1415 & 583 \\
\hline 1906 & 1422 & 620 \\
\hline 1907 & 1367 & 660 \\
\hline 1908 & 1364 & 679 \\
\hline 1909 & 1364 & 687 \\
\hline 1910 & 1257 & 732 \\
\hline
\end{tabular}

\footnotetext{
${ }^{1}$ Figures on the total number of licenses were not published after 1930, but separate reporting of the figures for publicans and accommodation licenses shows that these remained stable through the 1930s, at 1032 and 192 respectively. From 1938, reports of the average number of people per licensed house remained the same, until such time as figures were no longer collected.
} 


\begin{tabular}{|c|c|c|}
\hline 1911 & 1248 & 803 \\
\hline 1912 & 1235 & 824 \\
\hline 1913 & 1218 & 852 \\
\hline 1914 & 1218 & 895 \\
\hline 1915 & 1207 & 911 \\
\hline 1916 & 1199 & 920 \\
\hline 1917 & 1183 & 918 \\
\hline 1918 & 1184 & 946 \\
\hline 1919 & 1156 & 964 \\
\hline 1920 & 1141 & 1062 \\
\hline 1921 & 1141 & 1062 \\
\hline 1922 & 1135 & 1069 \\
\hline 1923 & 1125 & 1125 \\
\hline 1924 & 1123 & 1146 \\
\hline 1925 & 1115 & 1182 \\
\hline 1926 & 1108 & 1263 \\
\hline 1927 & 1121 & 1274 \\
\hline 1928 & 1120 & 1291 \\
\hline 1929 & 1108 & 1320 \\
\hline 1930 & 1130 & 1303 \\
\hline 1931 & & 1243 \\
\hline 1932 & & 1253 \\
\hline 1933 & & 1263 \\
\hline 1934 & & 1273 \\
\hline
\end{tabular}




\begin{tabular}{|c|c|c|}
\hline 1935 & & 1281 \\
\hline 1936 & & 1301 \\
\hline 1937 & & 1300 \\
\hline 1938 & & 1330 \\
\hline
\end{tabular}




\section{Appendix 2: Questionnaire - Covering letter and reminder letter}

\section{October 1995}

\section{Employment Relations in Hotels, Cafes, and Restaurants.}

The Accommodation, Cafes and Restaurants sector is of substantial economic importance in New Zealand. It comprises some 11,000 workplaces and employs 77,500 employees (about $6 \%$ of the New Zealand labour force). Despite its economic significance, however, we know very little about employment relations in the industry. Improved knowledge would assist both employers and organisations involved in training for the industry, in knowing what practices are being used now; which ones work; and which could be improved.

To try to get some information on this issue I am approaching you as part of a sample of owners and managers of hotels, cafes, and restaurants to see if they will help by filling out a short questionnaire. It should take you no longer than 20 minutes to complete. I will be very grateful if you would fill it out and send it back by November 17 in the enclosed stamped addressed envelope.

The sample of employers for this survey has been selected by Statistics New Zealand. However, I must stress that Statistics New Zealand has not at any time given me the names or addresses of those in the sample. Instead I supplied the Department with the questionnaires, and they sent them out for me. Therefore your name, address, and business details have remained confidential to Statistics New Zealand.

When the survey is complete, I will analyse and summarise and write up the results. If you would like to receive a copy of this report you will need to provide me with your name and address (see page one of the survey). The information will also be made available to any industry organisation (such as the Hotel Association of NZ, the NZ Tourism Industry Association and the Hotel and Catering Industry Training Board) that would like to receive it. Needless to say, when this summary is sent out the results will be presented in such a way that no individual business will be identifiable. In addition, I would like to assure you that all questionnaires will be kept strictly confidential; and that no-one will have access to the data except myself and my research assistant.

Some employers have expressed concern that giving out this information may be in breach of the Privacy Act. I would like to assure you that this is not the case as the Act provides an exemption for information collected for the purposes of research and where no individual is able to be identified.

If you do not employ any staff; employ fewer than five staff; or have gone out of business; please tick here and return this letter in the enclosed stamped addressed envelope. 
If you have any queries in answering the questions, please do not hesitate to contact me.

Yours faithfully

\section{October}

\section{Employment Relations in Hotels, Cafes, and Restaurants.}

You may recall that I wrote to you two weeks ago asking you to fill in a questionnaire about employment relations in your organisation. This is being done as a survey of a random sample of owners and managers of hotels, cafes, and restaurants in New Zealand, selected from the Statistics New Zealand Business Directory.

According to our records your survey has not been returned. Although the names and addresses of all the people to whom the survey was sent have remained confidential to Statistics New Zealand, we included a number on each questionnaire, and a reminder letter is being sent to the addresses which correspond to the numbers for which we do not have completed questionnaires.

If you have since completed the questionnaire and sent it in, thank you very much, and please disregard this letter.

In case you have mislaid or lost your first copy of the questionnaire, I have included another one for you to complete. This should take you no longer than 20 minutes. When you have done so, I would be grateful if you would place it in the enclosed stamped addressed envelope and send it back to me by November 10.

If you have any concerns or queries about the questionnaire, please do not hesitate to contact me on 04 - 472-1000 extension 8574 (w) or 04 - 475-3500 (h).

If you do not employ any staff; employ fewer than five staff; or have gone out of business; please tick here and return this letter in the enclosed stamped addressed envelope.

Yours faithfully 
Rose Ryan

Lecturer 
Appendix 3: Questionnaire - Employment Relations in Hotels Cafes and Restaurants 


\section{Appendix 4: Survey Results - Frequency Tables}

Section 1 : Profile of respondent workplaces

Q.1-Main Activity carried out at respondent workplace

\begin{tabular}{|c|c|c|c|c|}
\hline Industry & Frequency & Percent & $\begin{array}{c}\text { Valid } \\
\text { Percent }\end{array}$ & $\begin{array}{c}\text { Cumulative } \\
\text { Percent }\end{array}$ \\
\hline Hotel accommodation & 78 & 13.3 & 13.3 & 13.3 \\
\hline Motel accommodation & 52 & 8.9 & 8.9 & 22.2 \\
\hline Pubs, taverns and bars & 93 & 16.1 & 16.1 & 38.3 \\
\hline Café & 97 & 16.6 & 16.6 & 54.9 \\
\hline Fast food restaurant & 27 & 4.6 & 4.6 & 59.5 \\
\hline Restaurant & 122 & 21.0 & 21.0 & 80.5 \\
\hline Licensed club & 54 & 9.2 & 9.2 & 89.7 \\
\hline Catering company & 26 & 4.4 & 4.4 & 94.1 \\
\hline Educational Institution & 17 & 2.9 & 2.9 & 97.0 \\
\hline Other & 17 & 3.0 & 3.0 & 100.0 \\
\hline
\end{tabular}

Source: Weighted data, 582 responses Missing cases: 0

Q.2 - Whether respondent workplace was part of a larger business or organisation

\begin{tabular}{|l|c|c|c|c|}
\hline & Frequency & Percent & $\begin{array}{c}\text { Valid } \\
\text { Percent }\end{array}$ & $\begin{array}{c}\text { Cumulative } \\
\text { Percent }\end{array}$ \\
\hline No & 413 & 70.9 & 71.2 & 71.2 \\
\hline Yes (unspecified) & 67 & 11.5 & 11.6 & 82.8 \\
\hline One of more than 10 & 54 & 9.3 & 9.3 & 92.1 \\
\hline
\end{tabular}




\begin{tabular}{|l|c|c|c|c|}
\hline branches in NZ & & & & \\
\hline $\begin{array}{l}\text { One of less than 10 } \\
\text { branches in NZ }\end{array}$ & 33 & 5.6 & 5.6 & 97.7 \\
\hline The only branch in NZ & 13 & 2.3 & 2.3 & 100.0 \\
\hline
\end{tabular}

Source: Weighted data, 582 responses. Missing cases: 2

Q.3 - Ownership of respondent workplace

\begin{tabular}{|l|c|c|c|c|}
\hline Ownership & Frequency & Percent & $\begin{array}{c}\text { Valid } \\
\text { Percent }\end{array}$ & $\begin{array}{c}\text { Cumulative } \\
\text { Percent }\end{array}$ \\
\hline Wholly NZ owned & 528 & 90.7 & 91.7 & 91.7 \\
\hline $\begin{array}{l}\text { Predominantly NZ owned } \\
\text { (51\% or more) }\end{array}$ & 9 & 1.5 & 1.6 & 93.3 \\
\hline Wholly foreign owned & 20 & 3.5 & 3.5 & 96.8 \\
\hline $\begin{array}{l}\text { Predominantly foreign } \\
\text { owned (51\% or more) }\end{array}$ & 14 & 2.3 & 2.4 & 99.1 \\
\hline $\begin{array}{l}\text { Equally NZ and foreign } \\
\text { owned }\end{array}$ & 5 & 0.9 & 0.9 & 100 \\
\hline
\end{tabular}

Source: Weighted data, 576 responses. Missing cases: 6

\section{Q.4 - Workplace location}

\begin{tabular}{|l|c|c|c|c|}
\hline Location & Frequency & Percent & $\begin{array}{c}\text { Valid } \\
\text { Percent }\end{array}$ & $\begin{array}{c}\text { Cumulative } \\
\text { Percent }\end{array}$ \\
\hline $\begin{array}{l}\text { Auckland, Hamilton, } \\
\text { Wellington, Christchurch } \\
\text { or Dunedin }\end{array}$ & 273 & 46.9 & 47.0 & 47.0 \\
\hline A smaller city & 121 & 20.7 & 20.8 & 67.8 \\
\hline A town & 123 & 21.1 & 21.2 & 89.0 \\
\hline A rural area & 64 & 11.0 & 11.0 & 100.0 \\
\hline
\end{tabular}

Source: Weighted data, 580 responses. Missing cases: 2 
Q.5 - Predictability of demand

\begin{tabular}{|l|c|c|c|c|}
\hline & Frequency & Percent & $\begin{array}{c}\text { Valid } \\
\text { Percent }\end{array}$ & $\begin{array}{c}\text { Cumulative } \\
\text { Percent }\end{array}$ \\
\hline Predictable & 397 & 68.2 & 69.3 & 69.3 \\
\hline Not predictable & 170 & 29.2 & 29.7 & 99.0 \\
\hline Other & 5 & 0.9 & 1.0 & 100.0 \\
\hline
\end{tabular}

Source: Weighted data, 573 responses. Missing cases: 9

\section{Q.6 - Stability of demand}

\begin{tabular}{|l|c|c|c|c|}
\hline & Frequency & Percent & $\begin{array}{c}\text { Valid } \\
\text { Percent }\end{array}$ & $\begin{array}{c}\text { Cumulative } \\
\text { Percent }\end{array}$ \\
\hline Expanding & 249 & 42.8 & 43.1 & 43.1 \\
\hline Stable & 274 & 47.0 & 47.4 & 90.6 \\
\hline Contracting & 53 & 9.2 & 9.3 & 99.8 \\
\hline Other & 1 & 0.2 & 0.2 & 100.0 \\
\hline
\end{tabular}

Source: Weighted data, 577 responses. Missing cases: 5

\section{Q.7 - Extent of competition}

\begin{tabular}{|l|c|c|c|c|}
\hline & Frequency & Percent & $\begin{array}{c}\text { Valid } \\
\text { Percent }\end{array}$ & $\begin{array}{c}\text { Cumulative } \\
\text { Percent }\end{array}$ \\
\hline Many competitors & 412 & 70.7 & 71.1 & 71.1 \\
\hline Few competitors & 154 & 26.5 & 26.7 & 97.8 \\
\hline No other competitors & 13 & 2.2 & 2.2 & 100.0 \\
\hline
\end{tabular}

Source: Weighted data, 580 responses. Missing cases: 2 
Q.8 - Most crucial factor for competitive success of respondent's business

\begin{tabular}{|l|c|c|c|c|}
\hline & Frequency & Percent & $\begin{array}{c}\text { Valid } \\
\text { Percent }\end{array}$ & $\begin{array}{c}\text { Cumulative } \\
\text { Percent }\end{array}$ \\
\hline Price & 68 & 11.6 & 11.6 & 11.6 \\
\hline $\begin{array}{l}\text { Quality of product or } \\
\text { service }\end{array}$ & 289 & 49.6 & 49.7 & 61.3 \\
\hline Quality of staff & 30 & 5.1 & 5.1 & 66.4 \\
\hline $\begin{array}{l}\text { Responsiveness to } \\
\text { customer requirements }\end{array}$ & 54 & 9.3 & 9.3 & 75.8 \\
\hline Advertising/Marketing & 12 & 2.0 & 2.0 & 77.8 \\
\hline $\begin{array}{l}\text { Providing a distinctive } \\
\text { product or service }\end{array}$ & 62 & 10.6 & 10.6 & 88.4 \\
\hline Location & 54 & 9.3 & 9.4 & 97.7 \\
\hline Other & 13 & 2.3 & 2.3 & 100.0 \\
\hline
\end{tabular}

Source: Weighted data, 581 responses. Missing cases: 1

Q.9 - Second most crucial factor for competitive success of respondent's business

\begin{tabular}{|l|c|c|c|c|}
\hline & Frequency & Percent & $\begin{array}{c}\text { Valid } \\
\text { Percent }\end{array}$ & $\begin{array}{c}\text { Cumulative } \\
\text { Percent }\end{array}$ \\
\hline Price & 127 & 21.8 & 21.9 & 21.9 \\
\hline $\begin{array}{l}\text { Quality of product or } \\
\text { service }\end{array}$ & 134 & 23.0 & 23.1 & 44.9 \\
\hline Quality of staff & 101 & 17.4 & 17.4 & 62.3 \\
\hline $\begin{array}{l}\text { Responsiveness to } \\
\text { customer requirements }\end{array}$ & 79 & 13.5 & 13.6 & 75.9 \\
\hline Advertising/Marketing & 19 & 3.3 & 3.3 & 79.2 \\
\hline $\begin{array}{l}\text { Providing a distinctive } \\
\text { product or service }\end{array}$ & 46 & 7.8 & 7.8 & 87.1 \\
\hline Location & 69 & 11.8 & 11.9 & 98.9 \\
\hline
\end{tabular}




\begin{tabular}{|l|l|l|l|l|}
\hline Other & 6 & 1.1 & 1.1 & 100.0 \\
\hline
\end{tabular}

Source: Weighted data, 581 responses. Missing cases: 1 
Q.10 - Respondents role within the organisation

\begin{tabular}{|l|c|c|c|c|}
\hline & Frequency & Percent & $\begin{array}{c}\text { Valid } \\
\text { Percent }\end{array}$ & $\begin{array}{c}\text { Cumulative } \\
\text { Percent }\end{array}$ \\
\hline Owner & 321 & 55.2 & 56.0 & 56.0 \\
\hline Most senior manager & 190 & 32.7 & 33.2 & 89.2 \\
\hline $\begin{array}{l}\text { HR/IR/Personnel } \\
\text { manager }\end{array}$ & 25 & 4.4 & 4.4 & 93.6 \\
\hline Franchisee & 5 & 0.9 & 0.9 & 94.5 \\
\hline Other & 32 & 5.5 & 5.5 & 100.0 \\
\hline
\end{tabular}

Source: Weighted data, 573 responses. Missing cases: 8

Q.11 - Length of time respondent has worked in this business, or for this organisation

\begin{tabular}{|l|c|c|c|c|}
\hline & Frequency & Percent & $\begin{array}{c}\text { Valid } \\
\text { Percent }\end{array}$ & $\begin{array}{c}\text { Cumulative } \\
\text { Percent }\end{array}$ \\
\hline Less than a year & 86 & 14.7 & 14.9 & 14.9 \\
\hline 1 year - less than 2 years & 80 & 13.7 & 13.9 & 28.7 \\
\hline $\begin{array}{l}\text { 2 years - less than 5 } \\
\text { years }\end{array}$ & 173 & 29.8 & 30.0 & 58.8 \\
\hline $\begin{array}{l}\text { 5 years - less than 10 } \\
\text { years }\end{array}$ & 121 & 20.8 & 21.0 & 79.7 \\
\hline 10 years or more & 117 & 20.1 & 20.3 & 100.0 \\
\hline
\end{tabular}

Source: Weighted data, 577 responses. Missing cases: 5

Q.12 - Length of time respondent has worked at this location or workplace

\begin{tabular}{|l|c|c|c|c|}
\hline & Frequency & Percent & $\begin{array}{c}\text { Valid } \\
\text { Percent }\end{array}$ & $\begin{array}{c}\text { Cumulative } \\
\text { Percent }\end{array}$ \\
\hline Less than a year & 101 & 17.4 & 17.6 & 17.6 \\
\hline 1 year - less than 2 years & 100 & 17.2 & 17.4 & 34.9 \\
\hline 2 years - less than 5 & 178 & 30.6 & 30.9 & 65.8 \\
\hline
\end{tabular}




\begin{tabular}{|l|c|c|c|c|}
\hline years & & & & \\
\hline $\begin{array}{l}5 \text { years - less than 10 } \\
\text { years }\end{array}$ & 116 & 20.0 & 20.2 & 86.0 \\
\hline 10 years or more & 80 & 13.8 & 14.0 & 100.0 \\
\hline
\end{tabular}

Source: Weighted data, 576 responses. Missing cases: 6 
Q.13 - Length of time respondent has worked in this industry

\begin{tabular}{|l|c|c|c|c|}
\hline & Frequency & Percent & $\begin{array}{c}\text { Valid } \\
\text { Percent }\end{array}$ & $\begin{array}{c}\text { Cumulative } \\
\text { Percent }\end{array}$ \\
\hline Less than a year & 39 & 6.7 & 6.8 & 6.8 \\
\hline 1 year - less than 2 years & 40 & 6.9 & 7.0 & 13.8 \\
\hline $\begin{array}{l}2 \text { years - less than 5 } \\
\text { years }\end{array}$ & 86 & 14.9 & 15.0 & 28.8 \\
\hline $\begin{array}{l}\text { 5 years - less than 10 } \\
\text { years }\end{array}$ & 125 & 21.5 & 21.8 & 50.6 \\
\hline 10 years or more & 284 & 48.9 & 49.4 & 100.0 \\
\hline
\end{tabular}

Source: Weighted data, 577 responses. Missing cases: 5

\section{Section 2: Hours of work}

Q.14 - Hours per day for which the workplace operates

\begin{tabular}{|l|c|c|c|c|}
\hline & Frequency & Percent & $\begin{array}{c}\text { Valid } \\
\text { Percent }\end{array}$ & $\begin{array}{c}\text { Cumulative } \\
\text { Percent }\end{array}$ \\
\hline 8 hours or fewer & 26 & 4.5 & 4.6 & 4.6 \\
\hline Between 8 and 12 & 132 & 22.6 & 22.8 & 27.4 \\
\hline 12 hours & 43 & 7.4 & 7.5 & 34.9 \\
\hline $\begin{array}{l}\text { More than 12 and up to } \\
20\end{array}$ & 223 & 38.3 & 38.6 & 73.5 \\
\hline $\begin{array}{l}\text { More than 20 but less } \\
\text { than 24 }\end{array}$ & 20 & 3.5 & 3.5 & 77.0 \\
\hline 24 hours & 86 & 14.8 & 15.0 & 92.0 \\
\hline Varies from day to day & 46 & 8.0 & 8.0 & 100.0 \\
\hline
\end{tabular}

Source: Weighted data, 577 responses. Missing cases: 5 
Q.15 - Days per week for which the workplace operates

\begin{tabular}{|l|c|c|c|c|}
\hline & Frequency & Percent & $\begin{array}{c}\text { Valid } \\
\text { Percent }\end{array}$ & $\begin{array}{c}\text { Cumulative } \\
\text { Percent }\end{array}$ \\
\hline Five days or fewer & 25 & 4.4 & 4.4 & 4.4 \\
\hline Six days & 77 & 13.3 & 13.4 & 17.8 \\
\hline Seven days & 423 & 72.7 & 73.3 & 91.1 \\
\hline $\begin{array}{l}\text { Varies from week to } \\
\text { week }\end{array}$ & 51 & 8.8 & 8.9 & 100.0 \\
\hline
\end{tabular}

Source: Weighted data, 577 responses. Missing cases: 5

Q.16 - Extent to which employees work regular hours of work

\begin{tabular}{|l|c|c|c|c|}
\hline & Frequency & Percent & $\begin{array}{c}\text { Valid } \\
\text { Percent }\end{array}$ & $\begin{array}{c}\text { Cumulative } \\
\text { Percent }\end{array}$ \\
\hline $\begin{array}{l}\text { Employees always work } \\
\text { regular and predictable } \\
\text { hours/days }\end{array}$ & 133 & 22.9 & 23.2 & 23.2 \\
\hline $\begin{array}{l}\text { Employee hours/days } \\
\text { vary on occasion }\end{array}$ & 213 & 36.7 & 37.1 & 60.3 \\
\hline $\begin{array}{l}\text { Employee hours/days } \\
\text { vary on a regular basis }\end{array}$ & 163 & 28.0 & 28.4 & 88.7 \\
\hline $\begin{array}{l}\text { Employee hours/days are } \\
\text { irregular and variable }\end{array}$ & 56 & 9.7 & 9.8 & 98.5 \\
\hline Other & 9 & 1.5 & 1.5 & 100.0 \\
\hline
\end{tabular}

Source: Weighted data, 575 responses. Missing cases : 7 
Q.17 - Employee flexibility to choose hours/days on which they work

\begin{tabular}{|l|c|c|c|c|}
\hline & Frequency & Percent & $\begin{array}{c}\text { Valid } \\
\text { Percent }\end{array}$ & $\begin{array}{c}\text { Cumulative } \\
\text { Percent }\end{array}$ \\
\hline Complete flexibility & 91 & 15.6 & 16.2 & 16.2 \\
\hline $\begin{array}{l}\text { Flexibility subject to the } \\
\text { convenience of } \\
\text { management }\end{array}$ & 313 & 53.7 & 55.7 & 71.8 \\
\hline Limited flexibility & 129 & 22.3 & 23.1 & 94.9 \\
\hline No flexibility & 27 & 4.6 & 4.7 & 99.6 \\
\hline Other & 2 & 0.4 & 0.4 & 100.0 \\
\hline
\end{tabular}

Source: Weighted data, 562 responses. Missing cases : 20

Q.18 - Employee ability to swap hours/days with co-workers

\begin{tabular}{|l|c|c|c|c|}
\hline & Frequency & Percent & $\begin{array}{c}\text { Valid } \\
\text { Percent }\end{array}$ & $\begin{array}{c}\text { Cumulative } \\
\text { Percent }\end{array}$ \\
\hline Yes & 313 & 53.8 & 54.3 & 54.3 \\
\hline Within limitations & 248 & 42.6 & 43.0 & 97.3 \\
\hline No & 14 & 2.5 & 2.5 & 99.8 \\
\hline Other & 1 & 0.2 & 0.2 & 100.0 \\
\hline
\end{tabular}

Source: Weighted data, 577 responses. Missing cases : 5 
Section 3: Employees

Q.19 - \% of permanent employees employed in respondent workplaces during the week of October 2-8 $1995^{2}$

\begin{tabular}{|c|c|c|c|c|}
\hline & Frequency & Percent & $\begin{array}{c}\text { Valid } \\
\text { Percent }\end{array}$ & $\begin{array}{c}\text { Cumulative } \\
\text { Percent }\end{array}$ \\
\hline No permanent employees & 25 & 4.3 & 4.9 & 4.9 \\
\hline $\begin{array}{l}1-9 \% \text { permanent } \\
\text { employees }\end{array}$ & 0 & 0.0 & 0.0 & 4.9 \\
\hline $\begin{array}{l}\text { 10-19\% permanent } \\
\text { employees }\end{array}$ & 5 & 0.9 & 1.0 & 5.8 \\
\hline $\begin{array}{l}\text { 20-29\% permanent } \\
\text { employees }\end{array}$ & 15 & 2.5 & 2.9 & 8.7 \\
\hline $\begin{array}{l}\text { 30-39\% permanent } \\
\text { employees }\end{array}$ & 27 & 4.6 & 5.2 & 13.9 \\
\hline $\begin{array}{l}\text { 40-49\% permanent } \\
\text { employees }\end{array}$ & 42 & 7.2 & 8.1 & 22.0 \\
\hline $\begin{array}{l}\text { 50-59\% permanent } \\
\text { employees }\end{array}$ & 0 & 0.0 & 0.0 & 22.0 \\
\hline $\begin{array}{l}\text { 60-69\% permanent } \\
\text { employees }\end{array}$ & 125 & 21.6 & 24.3 & 46.2 \\
\hline $\begin{array}{l}\text { 70-79\% permanent } \\
\text { employees }\end{array}$ & 35 & 6.0 & 6.8 & 53.0 \\
\hline $\begin{array}{l}\text { 80-89\% permanent } \\
\text { employees }\end{array}$ & 39 & 6.6 & 7.4 & 60.5 \\
\hline $\begin{array}{l}\text { 90-99\% permanent } \\
\text { employees }\end{array}$ & 5 & 0.8 & 0.9 & 61.4 \\
\hline All permanent employees & 200 & 34.3 & 38.6 & 100.0 \\
\hline
\end{tabular}

2 As actual numbers do not readily allow comparisons to be made between large and small workplaces, the tables included here have converted these into proportions of staff. All percentages for Tables for Q.19 have been calculated from raw data provided by respondents. 
Source: Weighted data, 577 responses. Missing cases : 5 
Q.19 - \% of casual employees employed in respondent workplaces during the week of October 2-8 1995

\begin{tabular}{|c|c|c|c|c|}
\hline & Frequency & Percent & $\begin{array}{c}\text { Valid } \\
\text { Percent }\end{array}$ & $\begin{array}{c}\text { Cumulative } \\
\text { Percent }\end{array}$ \\
\hline No casual employees & 200 & 34.3 & 39.8 & 39.8 \\
\hline $1-9 \%$ casual employees & 3 & 0.6 & 0.7 & 40.5 \\
\hline $\begin{array}{l}\text { 10-19\% casual } \\
\text { employees }\end{array}$ & 17 & 3.0 & 3.5 & 44.0 \\
\hline $\begin{array}{l}20-29 \% \text { casual } \\
\text { employees }\end{array}$ & 41 & 7.0 & 8.1 & 52.1 \\
\hline $\begin{array}{l}\text { 30-39\% casual } \\
\text { employees }\end{array}$ & 71 & 12.2 & 14.2 & 66.3 \\
\hline $\begin{array}{l}\text { 40-49\% casual } \\
\text { employees }\end{array}$ & 25 & 4.3 & 5.0 & 71.2 \\
\hline $\begin{array}{l}50-59 \% \text { casual } \\
\text { employees }\end{array}$ & 0 & 0.0 & 0.0 & 71.2 \\
\hline $\begin{array}{l}\text { 60-69\% casual } \\
\text { employees }\end{array}$ & 102 & 17.6 & 20.4 & 91.6 \\
\hline $\begin{array}{l}\text { 70-79\% casual } \\
\text { employees }\end{array}$ & 11 & 1.9 & 2.2 & 93.8 \\
\hline $\begin{array}{l}\text { 80-89\% casual } \\
\text { employees }\end{array}$ & 6 & 1.0 & 1.2 & 95.0 \\
\hline $\begin{array}{l}\text { 90-99\% casual } \\
\text { employees }\end{array}$ & 0 & 0.0 & 0.0 & 95.0 \\
\hline All casual employees & 25 & 4.3 & 5.0 & 100.0 \\
\hline
\end{tabular}

Source: Weighted data, 502 responses. Missing cases : 80 
Q.19 - \% of full-time employees employed in respondent workplaces during the week of October 2-8 1995

\begin{tabular}{|l|c|c|c|c|}
\hline & Frequency & Percent & $\begin{array}{c}\text { Valid } \\
\text { Percent }\end{array}$ & $\begin{array}{c}\text { Cumulative } \\
\text { Percent }\end{array}$ \\
\hline No full-time employees & 43 & 7.5 & 8.4 & 8.4 \\
\hline $1-9 \%$ full-time employees & 0 & 0.0 & 0.0 & 8.4 \\
\hline $10-19 \%$ full-time employees & 8 & 1.3 & 1.5 & 9.9 \\
\hline 20-29\% full-time employees & 45 & 7.8 & 838 & 18.7 \\
\hline $30-39 \%$ full-time employees & 109 & 18.7 & 21.1 & 39.8 \\
\hline $40-49 \%$ full-time employees & 97 & 16.6 & 18.7 & 58.5 \\
\hline $50-59 \%$ full-time employees & 0 & 0.0 & 0.0 & 58.5 \\
\hline $60-69 \%$ full-time employees & 169 & 29.0 & 32.7 & 91.2 \\
\hline $70-79 \%$ full-time employees & 6 & 1.1 & 1.2 & 92.4 \\
\hline $80-89 \%$ full-time employees & 8 & 1.3 & 1.5 & 93.9 \\
\hline 90-99\% full-time employees & 1 & 0.2 & 0.2 & 94.1 \\
\hline All full-time employees & 31 & 5.3 & 5.9 & 100.0 \\
\hline
\end{tabular}

Source: Weighted data, 517 responses. Missing cases : 65

Q.19 - \% of part-time employees employed in respondent workplaces during the week of October 2-8 1995

\begin{tabular}{|l|c|c|c|c|}
\hline & Frequency & Percent & $\begin{array}{c}\text { Valid } \\
\text { Percent }\end{array}$ & $\begin{array}{c}\text { Cumulative } \\
\text { Percent }\end{array}$ \\
\hline No part-time employees & 31 & 5.3 & 6.1 & 6.1 \\
\hline 1-9\% part -time employees & 1 & 0.2 & 0.2 & 6.4 \\
\hline $\begin{array}{l}\text { 10-19\% part-time } \\
\text { employees }\end{array}$ & 5 & 0.9 & 1.1 & 7.4 \\
\hline $\begin{array}{l}\text { 20-29\% part-time } \\
\text { employees }\end{array}$ & 6 & 1.0 & 1.2 & 8.6 \\
\hline $\begin{array}{l}30-39 \% \text { part-time } \\
\text { employees }\end{array}$ & 54 & 9.3 & 10.9 & 19.5 \\
\hline 40-49\% part-time & 45 & 7.7 & 8.9 & 28.4 \\
\hline
\end{tabular}




\begin{tabular}{|l|c|c|c|c|}
\hline employees & 0 & 0.0 & 0.0 & 28.4 \\
\hline $\begin{array}{l}\text { 50-59\% part-time } \\
\text { employees }\end{array}$ & 259 & 44.6 & 51.9 & 80.4 \\
\hline $\begin{array}{l}\text { 60-69\% part-time } \\
\text { employees }\end{array}$ & 46 & 7.9 & 9.1 & 89.5 \\
\hline $\begin{array}{l}\text { 70-79\% part-time } \\
\text { employees }\end{array}$ & 9 & 1.5 & 1.8 & 91.3 \\
\hline $\begin{array}{l}\text { 80-89\% part-time } \\
\text { employees }\end{array}$ & 0 & 0.0 & 0.0 & 91.3 \\
\hline $\begin{array}{l}\text { 90-99\% part-time } \\
\text { employees }\end{array}$ & 43 & 7.5 & 8.7 & 100.0 \\
\hline \begin{tabular}{l} 
All part -time employees \\
\hline
\end{tabular}
\end{tabular}

Source: Weighted data, 499 responses. Missing cases : 82

Q.19 - \% of female employees employed in respondent workplaces during the week of October 2-8 1995

\begin{tabular}{|l|c|c|c|c|}
\hline & Frequency & Percent & $\begin{array}{c}\text { Valid } \\
\text { Percent }\end{array}$ & $\begin{array}{c}\text { Cumulative } \\
\text { Percent }\end{array}$ \\
\hline No female employees & 7 & 1.1 & 1.2 & 1.2 \\
\hline $1-24 \%$ female employees & 14 & 2.4 & 2.6 & 3.8 \\
\hline $25-49 \%$ female employees & 106 & 18.3 & 20.0 & 23.8 \\
\hline $50-74 \%$ female employees & 205 & 35.2 & 38.5 & 62.3 \\
\hline $75-99 \%$ female employees & 115 & 19.8 & 21.6 & 83.9 \\
\hline $100 \%$ female employees & 86 & 14.7 & 16.1 & 100.0 \\
\hline
\end{tabular}

Source: Weighted data, 532 responses. Missing cases: 50

Q.19 - \% of male employees employed in respondent workplaces during the week of October 2-8 1995 


\begin{tabular}{|l|c|c|c|c|}
\hline & & & Percent & Percent \\
\hline No male employees & 86 & 14.7 & 16.1 & 16.1 \\
\hline $1-24 \%$ male employees & 136 & 23.3 & 25.5 & 41.6 \\
\hline $25-49 \%$ male employees & 220 & 37.9 & 41.4 & 83.1 \\
\hline $50-74 \%$ male employees & 70 & 12.0 & 13.1 & 96.2 \\
\hline $75-99 \%$ male employees & 14 & 2.4 & 2.6 & 98.8 \\
\hline $100 \%$ male employees & 7 & 1.1 & 1.2 & 100.0 \\
\hline
\end{tabular}

Source: Weighted data, 532 responses. Missing cases: 50 
Q.20 - Numbers of staff by ethnicity: NZ European

\begin{tabular}{|l|c|c|c|c|}
\hline & Frequency & Percent & $\begin{array}{c}\text { Valid } \\
\text { Percent }\end{array}$ & $\begin{array}{c}\text { Cumulative } \\
\text { Percent }\end{array}$ \\
\hline 0 NZ European employees & 5 & 0.9 & 1.0 & 1.0 \\
\hline 1-9 NZ European employees & 283 & 48.7 & 52.2 & 53.3 \\
\hline $\begin{array}{l}\text { 10-19 NZ European } \\
\text { employees }\end{array}$ & 154 & 26.5 & 28.3 & 81.7 \\
\hline $\begin{array}{l}\text { 20-29 NZ European } \\
\text { employees }\end{array}$ & 43 & 7.4 & 8.0 & 89.6 \\
\hline $\begin{array}{l}\text { 30-39 NZ European } \\
\text { employees }\end{array}$ & 25 & 4.3 & 4.7 & 94.3 \\
\hline $\begin{array}{l}\text { 40-49 NZ European } \\
\text { employees }\end{array}$ & 9 & 1.5 & 1.6 & 95.9 \\
\hline 50+NZ European employees & 23 & 3.8 & 4.0 & 100.0 \\
\hline
\end{tabular}

Source: Weighted data, 542 responses. Missing cases: 40

Q.20 - Numbers of staff by ethnicity: NZ Maori

\begin{tabular}{|l|c|c|c|c|}
\hline & Frequency & Percent & $\begin{array}{c}\text { Valid } \\
\text { Percent }\end{array}$ & $\begin{array}{c}\text { Cumulative } \\
\text { Percent }\end{array}$ \\
\hline 0 NZ Maori employees & 196 & 33.7 & 36.7 & 36.7 \\
\hline 1-9 NZ Maori employees & 303 & 52.0 & 56.6 & 93.3 \\
\hline 10-19 NZ Maori employees & 27 & 4.5 & 5.0 & 98.3 \\
\hline 20-29 NZ Maori employees & 6 & 1.0 & 1.1 & 99.4 \\
\hline 30-39 NZ Maori employees & 1 & 0.2 & 0.2 & 99.6 \\
\hline 40-49 NZ Maori employees & 0 & 0.0 & 0.0 & 99.6 \\
\hline 50+NZ Maori employees & 2 & 0.4 & 0.4 & 100.0 \\
\hline
\end{tabular}

Source: Weighted data, 535 responses. Missing cases: 47 
Q.20 - Numbers of staff by ethnicity: Pacific Islands

\begin{tabular}{|l|c|c|c|c|}
\hline & Frequency & Percent & $\begin{array}{c}\text { Valid } \\
\text { Percent }\end{array}$ & $\begin{array}{c}\text { Cumulative } \\
\text { Percent }\end{array}$ \\
\hline 0 Pacific Islands employees & 384 & 66.0 & 72.2 & 72.2 \\
\hline $\begin{array}{l}\text { 1-9 Pacific Islands } \\
\text { employees }\end{array}$ & 124 & 21.4 & 23.3 & 95.5 \\
\hline $\begin{array}{l}\text { 10- 19 Pacific Islands } \\
\text { employees }\end{array}$ & 15 & 2.7 & 2.9 & 98.5 \\
\hline $\begin{array}{l}\text { 20-29 Pacific Islands } \\
\text { employees }\end{array}$ & 4 & 0.7 & 0.7 & 99.2 \\
\hline $\begin{array}{l}30-39 \text { Pacific Islands } \\
\text { employees }\end{array}$ & 1 & 0.2 & 0.2 & 99.4 \\
\hline $\begin{array}{l}40-49 \text { Pacific Islands } \\
\text { employees }\end{array}$ & 0 & 0.0 & 0.0 & 100.0 \\
\hline $\begin{array}{l}50+\text { Pacific Islands } \\
\text { employees }\end{array}$ & 3 & 0.5 & 0.6 & 100.0 \\
\hline
\end{tabular}

Source: Weighted data, 532 responses. Missing cases: 50

Q.20 - Numbers of staff by ethnicity: Asian

\begin{tabular}{|l|c|c|c|c|}
\hline & Frequency & Percent & $\begin{array}{c}\text { Valid } \\
\text { Percent }\end{array}$ & $\begin{array}{c}\text { Cumulative } \\
\text { Percent }\end{array}$ \\
\hline 0 Asian employees & 403 & 69.3 & 76.1 & 76.1 \\
\hline 1-9 Asian employees & 118 & 20.3 & 22.4 & 98.5 \\
\hline 10-19 Asian employees & 8 & 1.4 & 1.5 & 100.0 \\
\hline
\end{tabular}

Source: Weighted data, 530 responses. Missing cases: 52 
Q.21 - Proportion of casual staff employed compared with 5 years ago

\begin{tabular}{|l|c|c|c|c|}
\hline & Frequency & Percent & $\begin{array}{c}\text { Valid } \\
\text { Percent }\end{array}$ & $\begin{array}{c}\text { Cumulative } \\
\text { Percent }\end{array}$ \\
\hline Bigger & 128 & 22.1 & 22.6 & 22.6 \\
\hline Smaller & 79 & 13.6 & 14.0 & 36.6 \\
\hline About the same & 162 & 27.9 & 28.6 & 65.2 \\
\hline Not applicable & 198 & 33.9 & 34.8 & 100.0 \\
\hline
\end{tabular}

Source: Weighted data, 568 responses. Missing cases: 14

Q.22 - Proportion of part-time staff employed compared with 5 years ago

\begin{tabular}{|l|c|c|c|c|}
\hline & Frequency & Percent & $\begin{array}{c}\text { Valid } \\
\text { Percent }\end{array}$ & $\begin{array}{c}\text { Cumulative } \\
\text { Percent }\end{array}$ \\
\hline Bigger & 160 & 27.5 & 28.1 & 28.1 \\
\hline Smaller & 79 & 13.6 & 13.9 & 42.0 \\
\hline About the same & 168 & 28.9 & 29.5 & 71.5 \\
\hline Not applicable & 162 & 27.9 & 28.5 & 100.0 \\
\hline
\end{tabular}

Source: Weighted data, 570 responses. Missing cases: 12

Q.23 - Proportions of workplaces employing listed occupation - female

\begin{tabular}{|l|c|c|c|c|c|c|c|c|c|c|}
\hline & \multicolumn{3}{|l|}{$\begin{array}{l}\text { Administrators } \\
\text { and Managers }\end{array}$} & \multicolumn{2}{l|}{$\begin{array}{l}\text { Clerical and } \\
\text { Reception }\end{array}$} & \multicolumn{2}{l|}{$\begin{array}{l}\text { Service and } \\
\text { Sales }\end{array}$} & \multicolumn{2}{l|}{$\begin{array}{l}\text { Elementary } \\
\text { occupations }\end{array}$} & \multicolumn{2}{l|}{ Professionals } \\
\hline & Freq. & $\%$ & Freq. & $\%$ & Freq. & $\%$ & Freq. & $\%$ & Freq. & $\%$ \\
\hline 0 & 276 & 50.3 & 355 & 65.6 & 51 & 9.3 & 325 & 61.0 & 505 & 94.7 \\
\hline $1-9$ & 271 & 49.2 & 178 & 33.0 & 334 & 61.0 & 189 & 35.5 & 28 & 5.3 \\
\hline $10-19$ & 3 & 0.5 & 4 & 0.8 & 103 & 18.7 & 11 & 2.1 & 0 & 0.0 \\
\hline $20-29$ & 0 & 0.0 & 3 & 0.5 & 30 & 5.5 & 4 & 0.8 & 0 & 0.0 \\
\hline $30-39$ & 0 & 0.0 & 0 & 0.0 & 17 & 3.1 & 2 & 0.3 & 0 & 0.0 \\
\hline $40-49$ & 0 & 0.0 & 0 & 0.0 & 4 & 0.8 & 1 & 0.2 & 0 & 0.0 \\
\hline
\end{tabular}




\begin{tabular}{|l|l|l|l|l|l|l|l|l|l|l|}
\hline $50+$ & 0 & 0.0 & 0 & 0.0 & 9 & 1.6 & 1 & 0.2 & 0 & 0.0 \\
\hline
\end{tabular}

Source: Weighted data, 533 responses. Missing cases: 49

Q.23 - Proportions of workplaces employing listed occupation - male

\begin{tabular}{|l|c|l|l|l|l|l|l|l|l|l|}
\hline & \multicolumn{3}{|l|}{$\begin{array}{l}\text { Administrators } \\
\text { and Managers }\end{array}$} & \multicolumn{2}{l|}{$\begin{array}{l}\text { Clerical and } \\
\text { Reception }\end{array}$} & \multicolumn{2}{l|}{$\begin{array}{l}\text { Service and } \\
\text { Sales }\end{array}$} & \multicolumn{2}{l|}{$\begin{array}{l}\text { Elementary } \\
\text { occupations }\end{array}$} & \multicolumn{2}{l|}{ Professionals } \\
\hline & Freq. & $\%$ & Freq. & $\%$ & Freq. & $\%$ & Freq. & $\%$ & Freq. & $\%$ \\
\hline 0 & 253 & 46.6 & 481 & 90.8 & 152 & 28.0 & 419 & 78.2 & 490 & 92.3 \\
\hline $1-9$ & 286 & 52.6 & 46 & 8.8 & 320 & 59.0 & 113 & 21.0 & 41 & 7.9 \\
\hline $10-19$ & 3 & 0.6 & 2 & 0.2 & 43 & 8.0 & 3 & 0.5 & 0 & 0.0 \\
\hline $20-29$ & 1 & 1.2 & 1 & 0.2 & 12 & 2.2 & 2 & 0.3 & 0 & 0.0 \\
\hline $30-39$ & 0 & 0.0 & 0 & 0.0 & 6 & 1.2 & 0 & 0.0 & 0 & 0.0 \\
\hline $40-49$ & 0 & 0.0 & 0 & 0.0 & 3 & 0.6 & 0 & 0.0 & 0 & 0.0 \\
\hline $50+$ & 0 & 0.0 & 0 & 0.0 & 6 & 1.0 & 0 & 0.0 & 0 & 0.0 \\
\hline
\end{tabular}

Source: Weighted data, 533 responses. Missing cases: 49

Q.24 - Workplaces employing under-20 year olds

\begin{tabular}{|l|c|c|c|c|}
\hline & Frequency & Percent & $\begin{array}{c}\text { Valid } \\
\text { Percent }\end{array}$ & $\begin{array}{c}\text { Cumulative } \\
\text { Percent }\end{array}$ \\
\hline No & 250 & 43.0 & 43.6 & 43.6 \\
\hline Yes & 324 & 55.7 & 56.4 & 100.0 \\
\hline
\end{tabular}

Source: Weighted data, 570 responses. Missing cases: 12

Q.25 - Proportion of under-20 year old employees compared to five years ago

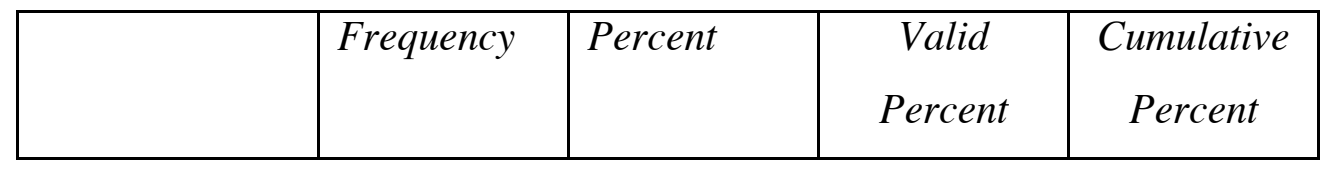




\begin{tabular}{|l|c|c|c|c|}
\hline More & 49 & 8.4 & 8.7 & 8.7 \\
\hline Fewer & 67 & 11.5 & 11.9 & 20.6 \\
\hline About the same & 138 & 23.7 & 24.5 & 45.0 \\
\hline Not applicable & 310 & 53.2 & 55.0 & 100.0 \\
\hline
\end{tabular}

Source: Weighted data, 563 responses. Missing cases: 19

Q.26 - Number of new employees commencing employment in previous 12 months

\begin{tabular}{|l|c|c|c|c|}
\hline & Frequency & Percent & $\begin{array}{c}\text { Valid } \\
\text { Percent }\end{array}$ & $\begin{array}{c}\text { Cumulative } \\
\text { Percent }\end{array}$ \\
\hline None & 30 & 5.2 & 5.3 & 5.3 \\
\hline $1-5$ & 278 & 47.8 & 48.6 & 53.9 \\
\hline $6-10$ & 98 & 16.8 & 17.1 & 71.0 \\
\hline $10-20$ & 96 & 16.5 & 16.8 & 87.8 \\
\hline More than 20 & 70 & 12.0 & 12.2 & 100.0 \\
\hline
\end{tabular}

Source: Weighted data, 572 responses. Missing cases: 10

Q.27 - Number of employees voluntarily resigning in previous 12 months

\begin{tabular}{|l|c|c|c|c|}
\hline & Frequency & Percent & $\begin{array}{c}\text { Valid } \\
\text { Percent }\end{array}$ & $\begin{array}{c}\text { Cumulative } \\
\text { Percent }\end{array}$ \\
\hline None & 70 & 12.0 & 12.2 & 12.2 \\
\hline $1-5$ & 312 & 53.5 & 54.4 & 66.6 \\
\hline $6-10$ & 92 & 15.8 & 16.1 & 82.7 \\
\hline $10-20$ & 65 & 11.2 & 11.3 & 94.0 \\
\hline More than 20 & 34 & 5.9 & 6.0 & 100.0 \\
\hline
\end{tabular}

Source: Weighted data, 573 responses. Missing cases: 9 
Q.28 - Number of employees dismissed or made redundant in previous 12 months

\begin{tabular}{|l|c|c|c|c|}
\hline & Frequency & Percent & $\begin{array}{c}\text { Valid } \\
\text { Percent }\end{array}$ & $\begin{array}{c}\text { Cumulative } \\
\text { Percent }\end{array}$ \\
\hline None & 402 & 69.1 & 70.9 & 70.9 \\
\hline $1-5$ & 160 & 27.4 & 28.1 & 99.0 \\
\hline $6-10$ & 2 & 0.4 & 0.4 & 99.4 \\
\hline $10-20$ & 0 & 0.0 & 0.0 & 99.4 \\
\hline More than 20 & 5 & 0.6 & 0.6 & 100.0 \\
\hline
\end{tabular}

Source: Weighted data, 568 responses. Missing cases: 14

Q.29 - Workplaces having work done under contract in previous 12 months

\begin{tabular}{|l|c|c|c|c|}
\hline & Frequency & Percent & $\begin{array}{c}\text { Valid } \\
\text { Percent }\end{array}$ & $\begin{array}{c}\text { Cumulative } \\
\text { Percent }\end{array}$ \\
\hline No & 390 & 67.1 & 68.3 & 68.3 \\
\hline Yes & 181 & 31.1 & 31.8 & 100.0 \\
\hline
\end{tabular}

Source: Weighted data, 572 responses. Missing cases: 10

\section{Section 4: Recruitment and Training}

Q.30 - Occupations for which vacancies have occurred in the previous 12 months

\begin{tabular}{|l|c|c|c|}
\hline & $\begin{array}{l}\text { Frequency } \\
\text { ("yes” } \\
\text { response) }\end{array}$ & $\begin{array}{l}\text { Percentage } \\
\text { of responses }\end{array}$ & $\begin{array}{c}\text { Percentage } \\
\text { of cases }\end{array}$ \\
\hline $\begin{array}{l}\text { No vacancies } \\
\text { in past year }\end{array}$ & 55 & 6.0 & 9.6 \\
\hline Administrators & 130 & 14.1 & 22.7 \\
\hline
\end{tabular}




\begin{tabular}{|l|c|c|c|}
\hline and Managers & & & \\
\hline $\begin{array}{l}\text { Service and } \\
\text { sales workers }\end{array}$ & 474 & 51.5 & 83.0 \\
\hline $\begin{array}{l}\text { Clerical and } \\
\text { reception }\end{array}$ & 99 & 10.8 & 17.4 \\
\hline Professionals & 13 & 1.5 & 2.4 \\
\hline $\begin{array}{l}\text { Elementary } \\
\text { employees }\end{array}$ & 136 & 14.7 & 23.7 \\
\hline $\begin{array}{l}\text { Trades } \\
\text { employees }\end{array}$ & 13 & 1.4 & 2.3 \\
\hline Total responses & 921 & 100.0 & 161.1 \\
\hline
\end{tabular}

Source: Weighted data, 572 responses. Missing cases: 10 
Q.31 - Recruitment methods used for filling vacancies

\begin{tabular}{|l|c|c|c|}
\hline & $\begin{array}{l}\text { Frequency } \\
\text { ("yes” } \\
\text { response) }\end{array}$ & $\begin{array}{l}\text { Percentage } \\
\text { of responses }\end{array}$ & $\begin{array}{c}\text { Percentage } \\
\text { of cases }\end{array}$ \\
\hline Advertising in local paper & 325 & 24.5 & 61.3 \\
\hline $\begin{array}{l}\text { Advertising in national } \\
\text { paper }\end{array}$ & 97 & 7.3 & 18.2 \\
\hline Word of mouth & 409 & 30.7 & 77.0 \\
\hline Internal promotion & 125 & 9.4 & 23.6 \\
\hline NZ Employment Service & 263 & 19.8 & 49.6 \\
\hline Recruitment agencies & 62 & 4.6 & 11.7 \\
\hline Position not filled & 8 & 0.6 & 1.5 \\
\hline Other & 42 & 3.1 & 7.9 \\
\hline Total responses & 1130 & 100.0 & 250.7 \\
\hline
\end{tabular}

Source: Weighted data, 530 responses. Missing cases: 52

Q.32 - Perceived success of recruitment methods used for filling vacancies

\begin{tabular}{|l|c|c|c|}
\hline & $\begin{array}{l}\text { Frequency } \\
\text { (“yes” } \\
\text { response) }\end{array}$ & $\begin{array}{l}\text { Percentage } \\
\text { of responses }\end{array}$ & $\begin{array}{c}\text { Percentage } \\
\text { of cases }\end{array}$ \\
\hline Advertising in local paper & 212 & 25.5 & 40.1 \\
\hline $\begin{array}{l}\text { Advertising in national } \\
\text { paper }\end{array}$ & 45 & 5.4 & 8.5 \\
\hline Word of mouth & 323 & 38.8 & 60.9 \\
\hline Internal promotion & 66 & 7.9 & 12.4 \\
\hline NZ Employment Service & 134 & 16.1 & 25.2 \\
\hline Recruitment agencies & 22 & 2.7 & 4.2 \\
\hline Position not filled & 3 & 0.4 & 0.6 \\
\hline Other & 28 & 3.4 & 5.3 \\
\hline Total responses & 832 & 100.0 & 157.1 \\
\hline
\end{tabular}

Source: Weighted data, 530 responses. Missing cases: 52 

Q. 33 - Average time taken for new employee to work to the standard of other employees

\begin{tabular}{|l|c|c|c|c|}
\hline & Frequency & Percent & $\begin{array}{c}\text { Valid } \\
\text { Percent }\end{array}$ & $\begin{array}{c}\text { Cumulative } \\
\text { Percent }\end{array}$ \\
\hline One day or less & 7 & 1.3 & 1.3 & 1.3 \\
\hline Less than a week & 111 & 19.1 & 19.5 & 20.8 \\
\hline $\begin{array}{l}\text { Between a week } \\
\text { and a month }\end{array}$ & 342 & 58.8 & 60.2 & 81.0 \\
\hline $\begin{array}{l}\text { Between a month } \\
\text { and three months }\end{array}$ & 85 & 14.7 & 15.0 & 96.0 \\
\hline $\begin{array}{l}\text { Three months or } \\
\text { more }\end{array}$ & 18 & 3.1 & 3.2 & 99.2 \\
\hline Other & 4 & 0.7 & 0.8 & 100.0 \\
\hline
\end{tabular}

Source: Weighted data, 568 responses. Missing cases: 14

\section{Q.34 - Information provided to newly recruited employees}

\begin{tabular}{|l|c|c|c|}
\hline & $\begin{array}{l}\text { Frequency } \\
\text { ( "yes” } \\
\text { response) }\end{array}$ & $\begin{array}{c}\text { Percentage } \\
\text { of responses }\end{array}$ & $\begin{array}{c}\text { Percentage } \\
\text { of cases }\end{array}$ \\
\hline $\begin{array}{l}\text { Information about the } \\
\text { company/business }\end{array}$ & 358 & 16.5 & 67.5 \\
\hline $\begin{array}{l}\text { Information about the } \\
\text { geographical layout of } \\
\text { the work area }\end{array}$ & 305 & 14.0 & 57.6 \\
\hline $\begin{array}{l}\text { Information about } \\
\text { their job }\end{array}$ & 517 & 23.8 & 97.5 \\
\hline $\begin{array}{l}\text { Information about } \\
\text { uniforms/appearance }\end{array}$ & 472 & 21.7 & 89.0 \\
\hline $\begin{array}{l}\text { Information about } \\
\text { employment } \\
\text { conditions }\end{array}$ & 485 & 22.3 & 91.5 \\
\hline
\end{tabular}




\begin{tabular}{|l|c|c|c|}
\hline None & 1 & 0.1 & 0.2 \\
\hline Other & 36 & 1.7 & 6.8 \\
\hline Total responses & 2175 & 100.0 & 410.0 \\
\hline
\end{tabular}

Source: Weighted data, 530 responses. Missing cases: 52

Q.35 - Person responsible for providing new employees with training

\begin{tabular}{|l|c|c|c|c|}
\hline & Frequency & Percent & $\begin{array}{c}\text { Valid } \\
\text { Percent }\end{array}$ & $\begin{array}{c}\text { Cumulative } \\
\text { Percent }\end{array}$ \\
\hline Manager & 402 & 69.0 & 69.8 & 69.8 \\
\hline Co-workers & 85 & 14.6 & 14.7 & 84.5 \\
\hline $\begin{array}{l}\text { Co-workers } \\
\text { and manager } \\
\text { jointly }\end{array}$ & 79 & 13.6 & 13.8 & 98.3 \\
\hline Other & 9 & 1.6 & 1.6 & 99.8 \\
\hline $\begin{array}{l}\text { No training } \\
\text { provided }\end{array}$ & 1 & 0.2 & 0.2 & 100.0 \\
\hline
\end{tabular}

Source: Weighted data, 576 responses. Missing cases: 6

Q.36 - Training provided to employees in the previous year

\begin{tabular}{|l|c|c|c|}
\hline & $\begin{array}{l}\text { Frequency } \\
\text { ("yes” } \\
\text { response) }\end{array}$ & $\begin{array}{l}\text { Percentage } \\
\text { of responses }\end{array}$ & $\begin{array}{c}\text { Percentage } \\
\text { of cases }\end{array}$ \\
\hline Kiwihost courses & 121 & 10.9 & 20.9 \\
\hline $\begin{array}{l}\text { On-the-job general } \\
\text { training }\end{array}$ & 463 & 41.8 & 80.2 \\
\hline $\begin{array}{l}\text { On-the-job specialist } \\
\text { training }\end{array}$ & 146 & 13.2 & 25.2 \\
\hline $\begin{array}{l}\text { Supervisory skills } \\
\text { training }\end{array}$ & 124 & 11.2 & 21.5 \\
\hline
\end{tabular}




\begin{tabular}{|l|c|c|c|}
\hline $\begin{array}{l}\text { Training at an external } \\
\text { institution }\end{array}$ & 142 & 12.9 & 24.7 \\
\hline None & 68 & 6.2 & 11.9 \\
\hline Other & 42 & 3.8 & 7.3 \\
\hline Total responses & 1106 & 100.0 & 191.7 \\
\hline
\end{tabular}

Source: Weighted data, 577 responses. Missing cases: 5 
Q.37 - Percentage of employees that have participated in training

\begin{tabular}{|l|c|c|c|c|}
\hline & Frequency & Percent & $\begin{array}{c}\text { Valid } \\
\text { Percent }\end{array}$ & $\begin{array}{c}\text { Cumulative } \\
\text { Percent }\end{array}$ \\
\hline None & 78 & 13.4 & 13.8 & 13.8 \\
\hline A quarter or less & 122 & 21.0 & 21.5 & 35.3 \\
\hline $\begin{array}{l}\text { Between a quarter and a } \\
\text { half }\end{array}$ & 60 & 10.0 & 10.6 & 45.9 \\
\hline About half & 51 & 8.8 & 9.1 & 55.0 \\
\hline $\begin{array}{l}\text { Between a half and three } \\
\text { quarters }\end{array}$ & 65 & 11.2 & 11.5 & 66.5 \\
\hline More than three quarters & 59 & 10.2 & 10.5 & 77.0 \\
\hline All & 130 & 22.4 & 23.0 & 100.0 \\
\hline
\end{tabular}

Source: Weighted data, 566 responses. Missing cases: 16

\section{$\underline{\text { Section } 5 \text { : Management and Employee Communication }}$}

Q.38 Methods currently used by managers to communicate with employees

\begin{tabular}{|l|c|c|c|}
\hline & $\begin{array}{l}\text { Frequency } \\
\text { ("yes” } \\
\text { response) }\end{array}$ & $\begin{array}{l}\text { Percentage } \\
\text { of responses }\end{array}$ & $\begin{array}{c}\text { Percentage } \\
\text { of cases }\end{array}$ \\
\hline Workplace noticeboard & 297 & 18.8 & 51.5 \\
\hline Workplace newsletter & 71 & 4.5 & 12.4 \\
\hline $\begin{array}{l}\text { Direct discussions with } \\
\text { employees individually }\end{array}$ & 533 & 33.8 & 92.6 \\
\hline $\begin{array}{l}\text { Direct discussions with } \\
\text { employees as a group }\end{array}$ & 393 & 24.9 & 68.3 \\
\hline Regular social functions & 145 & 9.2 & 25.2 \\
\hline Suggestion schemes & 71 & 4.5 & 12.3 \\
\hline Consultative committees & 36 & 2.3 & 6.2 \\
\hline
\end{tabular}




\begin{tabular}{|l|c|c|c|}
\hline Ad hoc committees & 30 & 1.9 & 5.3 \\
\hline Total responses & 1576 & 100.0 & 273.8 \\
\hline
\end{tabular}

Source: Weighted data, 576 responses. Missing cases: 6

Q.39 - Frequency of communication with employees

\begin{tabular}{|l|c|c|c|c|}
\hline & Frequency & Percent & $\begin{array}{c}\text { Valid } \\
\text { Percent }\end{array}$ & $\begin{array}{c}\text { Cumulativ } \\
\text { e Percent }\end{array}$ \\
\hline $\begin{array}{l}\text { Communication takes place } \\
\text { on a planned and on-going } \\
\text { basis }\end{array}$ & 185 & 31.9 & 32.1 & 32.1 \\
\hline $\begin{array}{l}\text { Communication takes place } \\
\text { when and as needed }\end{array}$ & 391 & 67.2 & 67.6 & 99.6 \\
\hline Other & 2 & 0.4 & 0.4 & 100.0 \\
\hline
\end{tabular}

Source: Weighted data, 579 responses. Missing cases: 3

Q.40 - Issues on which management supplies information to employees

\begin{tabular}{|l|c|c|c|}
\hline & $\begin{array}{l}\text { Frequency } \\
\text { ("yes” } \\
\text { response) }\end{array}$ & $\begin{array}{l}\text { Percentage } \\
\text { of responses }\end{array}$ & $\begin{array}{c}\text { Percentage } \\
\text { of cases }\end{array}$ \\
\hline Staffing & 366 & 15.7 & 64.0 \\
\hline Operational issues & 429 & 18.4 & 74.9 \\
\hline Menus & 343 & 14.7 & 60.0 \\
\hline Uniforms & 336 & 14.4 & 58.7 \\
\hline Organisational plans & 279 & 11.9 & 48.7 \\
\hline Changes in the & 414 & 17.7 & 72.3 \\
workplace & 127 & 5.4 & 22.1 \\
\hline $\begin{array}{l}\text { Financial position of } \\
\text { the workplace }\end{array}$ & 17 & 0.7 & 2.9 \\
\hline None & 23 & 1.0 & 4.0 \\
\hline Other & & & \\
\hline
\end{tabular}




\begin{tabular}{|l|c|c|c|}
\hline Total responses & 2332 & 100.0 & 407.4 \\
\hline
\end{tabular}

Source: Weighted data, 572 responses. Missing cases: 10 
Q.41 - Issues on which management seeks input from employees

\begin{tabular}{|l|c|c|c|}
\hline & $\begin{array}{l}\text { Frequency } \\
\text { " yes” } \\
\text { response) }\end{array}$ & $\begin{array}{l}\text { Percentage } \\
\text { of responses }\end{array}$ & $\begin{array}{c}\text { Percentage } \\
\text { of cases }\end{array}$ \\
\hline Staffing & 312 & 16.6 & 54.5 \\
\hline Operational issues & 350 & 18.6 & 61.1 \\
\hline Menus & 309 & 16.4 & 53.9 \\
\hline Uniforms & 257 & 13.7 & 44.8 \\
\hline Organisational plans & 203 & 10.8 & 35.4 \\
\hline Changes in the & 354 & 18.8 & 61.8 \\
workplace & & & 8.7 \\
\hline $\begin{array}{l}\text { Financial position of } \\
\text { the workplace }\end{array}$ & 50 & 2.7 & 6.7 \\
\hline None & 1880 & 100.0 & 328.1 \\
\hline Other & 38 & 2.0 & 1.2 \\
\hline Total responses & 7 & 0.4 & \\
\hline
\end{tabular}

Source: Weighted data, 573 responses. Missing cases: 9

\section{$\underline{\text { Section } 6 \text { : Industrial Relations }}$}

\section{Q.42 - Membership of industry organisations}

\begin{tabular}{|l|c|c|c|}
\hline & $\begin{array}{l}\text { Frequency } \\
\text { (“yes” } \\
\text { response) }\end{array}$ & $\begin{array}{l}\text { Percentage } \\
\text { of responses }\end{array}$ & $\begin{array}{c}\text { Percentage } \\
\text { of cases }\end{array}$ \\
\hline NZ Employers' Federation & 100 & 16.3 & 18.8 \\
\hline $\begin{array}{l}\text { Hotel/Hospitality Association } \\
\text { of NZ }\end{array}$ & 166 & 26.8 & 31.1 \\
\hline Motel Association of NZ & 54 & 8.8 & 10.2 \\
\hline Food Services Association & 120 & 19.4 & 22.5 \\
\hline Do not belong to any of these & 177 & 28.8 & 33.3 \\
\hline Total responses & 617 & 100.0 & 115.9 \\
\hline
\end{tabular}


Source: Weighted data, 532 responses. Missing cases: 50 
Q.43 - Organisations used for advice on industrial relations matters

\begin{tabular}{|l|c|c|c|}
\hline & $\begin{array}{l}\text { Frequency } \\
\text { (“yes” } \\
\text { response) }\end{array}$ & $\begin{array}{l}\text { Percentage } \\
\text { of responses }\end{array}$ & $\begin{array}{c}\text { Percentage } \\
\text { of cases }\end{array}$ \\
\hline Have not used any of these & 331 & 78.9 & 79.6 \\
\hline NZ Employers' Federation & 35 & 8.3 & 8.4 \\
\hline $\begin{array}{l}\text { Hotel/Hospitality Association } \\
\text { of NZ }\end{array}$ & 29 & 6.8 & 6.9 \\
\hline Motel Association of NZ & 3 & 0.8 & 0.8 \\
\hline Food Services Association & 22 & 5.2 & 5.3 \\
\hline Total responses & 420 & 100.0 & 101.0 \\
\hline
\end{tabular}

Source: Weighted data, 416 responses. Missing cases: 166

\section{Q.44 - Issues on which advice has been sought}

\begin{tabular}{|l|c|c|c|}
\hline & $\begin{array}{l}\text { Frequency } \\
\text { ("yes” } \\
\text { response) }\end{array}$ & $\begin{array}{l}\text { Percentage } \\
\text { of responses }\end{array}$ & $\begin{array}{c}\text { Percentage } \\
\text { of cases }\end{array}$ \\
\hline Rates of pay & 85 & 12.2 & 34.7 \\
\hline $\begin{array}{l}\text { Terms and conditions of } \\
\text { employment }\end{array}$ & 165 & 23.6 & 67.1 \\
\hline Negotiations with unions & 30 & 4.2 & 12.0 \\
\hline Dismissals & 116 & 16.7 & 47.4 \\
\hline Health and safety issues & 62 & 8.9 & 25.3 \\
\hline ACC matters & 45 & 6.5 & 18.5 \\
\hline Holidays Act & 122 & 17.5 & 49.9 \\
\hline Privacy Act & 39 & 5.6 & 16.0 \\
\hline Human Rights Act & 33 & 4.8 & 13.5 \\
\hline Total responses & 698 & 100.0 & 284.4 \\
\hline
\end{tabular}

Source: Weighted data, 246 responses. Missing cases: 336 

Q.45 - Nature of employment contracts

\begin{tabular}{|l|c|c|c|c|}
\hline & Frequency & Percent & $\begin{array}{c}\text { Valid } \\
\text { Percent }\end{array}$ & $\begin{array}{c}\text { Cumulative } \\
\text { Percent }\end{array}$ \\
\hline Written down & 313 & 53.8 & 55.2 & 55.2 \\
\hline Verbal & 153 & 26.2 & 26.9 & 82.1 \\
\hline $\begin{array}{l}\text { Combination written and } \\
\text { verbal }\end{array}$ & 98 & 16.9 & 17.4 & 99.4 \\
\hline Other & 3 & 0.6 & 0.6 & 100.0 \\
\hline
\end{tabular}

Source: Weighted data, 567 responses. Missing cases: 15

Q.46 - Types of employment contract

\begin{tabular}{|l|c|c|c|c|}
\hline & Frequency & Percent & $\begin{array}{c}\text { Valid } \\
\text { Percent }\end{array}$ & $\begin{array}{c}\text { Cumulative } \\
\text { Percent }\end{array}$ \\
\hline Union negotiated CEC & 34 & 5.9 & 6.3 & 6.3 \\
\hline $\begin{array}{l}\text { Employee negotiated } \\
\text { CEC }\end{array}$ & 27 & 4.7 & 5.0 & 11.3 \\
\hline $\begin{array}{l}\text { Management determined } \\
\text { CEC }\end{array}$ & 116 & 19.9 & 21.1 & 32.4 \\
\hline Standard IECs & 105 & 18.1 & 19.3 & 51.7 \\
\hline $\begin{array}{l}\text { Individually negotiated } \\
\text { IECs }\end{array}$ & 39 & 6.7 & 7.1 & 58.7 \\
\hline $\begin{array}{l}\text { Most with similar } \\
\text { conditions of } \\
\text { employment }\end{array}$ & 96 & 16.5 & 17.5 & 76.3 \\
\hline $\begin{array}{l}\text { Mixture of IECS and } \\
\text { CECs }\end{array}$ & 96 & 16.6 & 17.6 & 93.9 \\
\hline Other & 34 & 5.8 & 6.1 & 100.0 \\
\hline
\end{tabular}

Source: Weighted data, 547 responses. Missing cases: 35 
Q.47 - Determination of pay rates

\begin{tabular}{|l|c|c|c|c|}
\hline & Frequency & Percent & $\begin{array}{c}\text { Valid } \\
\text { Percent }\end{array}$ & $\begin{array}{c}\text { Cumulative } \\
\text { Percent }\end{array}$ \\
\hline $\begin{array}{l}\text { Employees paid } \\
\text { standard rate in contract }\end{array}$ & 162 & 27.8 & 28.2 & 28.2 \\
\hline $\begin{array}{l}\text { Pay rates are } \\
\text { individually negotiated }\end{array}$ & 171 & 29.5 & 29.8 & 58.0 \\
\hline $\begin{array}{l}\text { Pay rates are determined } \\
\text { by employer }\end{array}$ & 241 & 41.5 & 42.0 & 100.0 \\
\hline
\end{tabular}

Source: Weighted data, 574 responses. Missing cases: 8

Q.48 - Union membership at respondent workplace

\begin{tabular}{|l|c|c|c|c|}
\hline & Frequency & Percent & $\begin{array}{c}\text { Valid } \\
\text { Percent }\end{array}$ & $\begin{array}{c}\text { Cumulative } \\
\text { Percent }\end{array}$ \\
\hline None & 386 & 66.3 & 67.1 & 67.1 \\
\hline A quarter or less & 87 & 15.0 & 15.1 & 82.2 \\
\hline $\begin{array}{l}\text { Between a quarter and a } \\
\text { half }\end{array}$ & 10 & 1.8 & 1.8 & 84.0 \\
\hline About half & 5 & 0.9 & 0.9 & 84.9 \\
\hline $\begin{array}{l}\text { Between half and three } \\
\text { quarters }\end{array}$ & 8 & 1.3 & 1.3 & 86.2 \\
\hline More than three quarters & 5 & 0.9 & 0.9 & 87.1 \\
\hline All & 8 & 1.4 & 1.4 & 88.5 \\
\hline Don't know & 66 & 11.4 & 11.5 & 100.0 \\
\hline
\end{tabular}

Source: Weighted data, 575 responses. Missing cases: 7

Q.49 - Union attempts at enrolment in previous 12 months

\begin{tabular}{|c|c|c|c|c|}
\hline & Frequency & Percent & $\begin{array}{c}\text { Valid } \\
\text { Percent }\end{array}$ & $\begin{array}{c}\text { Cumulative } \\
\text { Percent }\end{array}$ \\
\hline
\end{tabular}




\begin{tabular}{|l|c|c|c|c|}
\hline No & 433 & 74.4 & 75.1 & 75.1 \\
\hline Yes & 61 & 10.4 & 10.5 & 85.6 \\
\hline Don't know & 83 & 14.2 & 14.4 & 100.0 \\
\hline
\end{tabular}

Source: Weighted data, 576 responses. Missing cases: 6 
Q.50 - Union raising issues with employer in previous 12 months

\begin{tabular}{|l|c|c|c|c|}
\hline & Frequency & Percent & $\begin{array}{c}\text { Valid } \\
\text { Percent }\end{array}$ & $\begin{array}{c}\text { Cumulative } \\
\text { Percent }\end{array}$ \\
\hline No & 521 & 89.6 & 90.4 & 90.4 \\
\hline Yes & 55 & 9.5 & 9.6 & 100.0 \\
\hline
\end{tabular}

Source: Weighted data, 576 responses. Missing cases: 6

Q.51 - Personal grievance proceeding in previous 12 months.

\begin{tabular}{|l|c|c|c|c|}
\hline & Frequency & Percent & $\begin{array}{c}\text { Valid } \\
\text { Percent }\end{array}$ & $\begin{array}{c}\text { Cumulative } \\
\text { Percent }\end{array}$ \\
\hline $\begin{array}{l}\text { No personal grievances } \\
\text { arisen in past 12 months }\end{array}$ & 505 & 86.8 & 87.9 & 87.9 \\
\hline $\begin{array}{l}\text { Resolved in discussions } \\
\text { with employee }\end{array}$ & 19 & 3.3 & 3.3 & 91.3 \\
\hline $\begin{array}{l}\text { Resolved with assistance } \\
\text { of a third party }\end{array}$ & 25 & 4.3 & 4.4 & 95.6 \\
\hline $\begin{array}{l}\text { Resolved at Grievance } \\
\text { Committee }\end{array}$ & 7 & 1.2 & 1.2 & 96.8 \\
\hline $\begin{array}{l}\text { Resolved in } \\
\text { Employment Tribunal }\end{array}$ & 1 & 1.8 & 1.8 & 98.7 \\
\hline $\begin{array}{l}\text { Resolved in } \\
\text { Employment Court }\end{array}$ & 7 & 1.1 & 1.2 & 100.0 \\
\hline Other & 0.2 & 0.2 & 98.8 \\
\hline
\end{tabular}

Source: Weighted data, 575 responses. Missing cases: 7 


\title{
Appendix 5: Covering letter to interviewees
}

\author{
(date)
}

(name and address)

Dear

Further to our telephone conversation, I am writing to confirm our interview arrangements for $\operatorname{xxxxxxx}$ at $\operatorname{xxxxxxxx}$.

There is no pre-set list of questions, but I have attached a list of the areas in which I am interested. While I will attempt to cover as much as possible in the time we have available, some issues may be more important or interesting to you than others.

As I noted on the phone, the interview will take between one and one and a half hours. I will be taping the interview to make notes afterwards, but the tapes will be erased at the end of the research. Everything that you say in the interview will be strictly confidential, and will not be reported in a way which would allow you to be identified.

I very much appreciate you making your time available and look forward to meeting you.

yours sincerely,

Rose Ryan 
Appendix 6: Interview schedule

\section{Employment and Labour Relations in hotels and restaurants: Interview schedule}

\section{Employment arrangements}

Numbers of employees.

Type of employment arrangement (full-time, part-time, permanent, casual, temporary).

Hours worked and variations in hours worked.

On-call employees.

\section{Working arrangements}

Turnover of staff.

Recruitment of staff.

Training, skills and careers within the industry.

Workplace communications.

Customer service.

\section{Labour relations}

Employment contracts.

Wages, conditions of work, "perks". 
Management style.

Representation and advice.

Dismissals and personal grievances. 


\section{Appendix 7 : Summary characteristics of interviewees}

1. Co-owner of holiday park in provincial town. Small employer (6 employees)

2. Co-owner of cafe in major city. Small employer (15 employees)

3. Co-owner of cafe in major city. Medium employer (26 employees).

4. Secretary-Manager of Licensed Club in major city. Small employer (10 employees)

5. Owner of cafe-restaurant in major city. Small - medium employer (20 employees)

6. Secretary-Manager of Licensed Club in major city. Small employer (15 employees).

7. Secretary-Manager of Licensed Club in provincial city. Medium employer (24 employees).

8. Secretary-Manager of Licensed Club in provincial town. Small employer (17 employees).

9. Co-owners of restaurant in major city. Small employer (14 employees).

10. Owner of catering company in major city. Small employer (3 employees plus a pool of casuals).

11. Manager of catering company in major city. Small employer (8 employees plus a pool of approximately 50 casuals).

12. Manager of Motor Lodge on out-skirts of major city. Medium employer ( 72 employees).

13. Co-owner of restaurant in provincial town, major tourist centre, Small employer (17 employees).

14. Owner of Motor Lodge on outskirts of major city. Medium employer (25 employees). 
15 Human Resource Manager of international hotel in major city. Large employer (253 employees).

16. Co-owner of bar-restaurant in major city. Medium employer (87 employees).

17 Human Resource Manager of international hotel in major city. Large employer (225 employees).

18. Co-owner of chain restaurant in major city. Medium employer (80 employees).

19. Manager of bar-restaurant in major city. Medium employer (35 employees).

20. Co-owner of restaurant in major city. Small employer (6 employees).

21. Manager of accommodation hotel in major city. Medium employer (60 employees).

22. Assistant manager of bar in a provincial city. Medium employer (20 employees plus casuals).

23. Manager of Fast Food restaurant in major city. Medium employer ( 95 employees).

24. Owner of Farm hospitality business, rural area. Small employer (5 employees).

25. Manager of bar in provincial city. Small employer (7 employees).

26. Owner of bar-cafe in provincial city. Small employer (11 employees).

27. Manager of accommodation hotel in major city. Medium employer (50 employees).

28. Assistant manager of restaurant in major city. Small employer (15 employees).

29. Co-owner of bar-hotel in rural area, tourist destination. Small employer (8 employees).

30. Owner of cafe - restaurant in major city. Medium employer (33 employees). 
31. Human Resource Manager of multi-location catering company. Large employer (2000+ employees in 130 locations).

32. Owner of restaurant in provincial city, tourist destination. Small employer (18 employees).

33. Co-owner of motel in major city. Small employer (15 employees).

34. Owner of cafe-restaurant in major city. Small - medium employer (20 employees).

35. Co-owner of motor lodge in provincial city. Small employer (14 employees).

36. Manager of Conference Centre and Holiday Park, rural area. Medium employer. (25 employees).

37. Owner of coffee lounge in small town. Small employer (5 employees).

38. General Manager and Accommodation Manager of hotel/hostel in major city. Medium employer (25 employees). 


\section{Bibliography}

Advisory, Conciliation and Arbitration Service (1980) Licensed Residential Establishment and Licensed Restaurant Wages Council, Report No 18, London: HMSO.

Anderson, G., Brosnan, P., Rea, D., and Walsh, P. (1992) "Labour market flexibility and the firm: A preliminary analysis of the workplace survey" in D. Blackmur (ed) Contemporary Australasian Trends in Industrial Relations Research Proceedings of the 6th Conference of the Association of Industrial Relations Academics of Australia and New Zealand, Queensland University of Technology, January 1992 pp.-12.

Ahlstrand, B. and Purcell, J. (1988) "Employee relations strategy in the multidivisional company", Personnel Review 17(3):3-11.

ALAC (1996) 1996 Fact Pack, Wellington, Alcohol Advisory Council, Alcoholic Liquor Advisory Council.

Aslan, A. and Wood, R. (1993) "Trade unions in the hotel and catering industry: the views of hotel managers", Employee Relations 15(2):61-70.

Astley, G. and Van de Ven, A. (1983) "Central perspectives and debates in organisation theory", Administrative Science Quarterly 28(2):245-273.

Atkinson, J. and Meager, N. (1986) New Forms of Work Organisation, IMS Report No 21, Brighton: Institute of Manpower Studies.

Austrin, T. (1994) "Positioning resistance and resisting position" in J. Jermier, D. Knights, and W. Nord (eds) Resistance and Power in Organisations, London: Routledge.

Bagguley, Paul (1990) "Gender and labour flexibility in hotels and catering", Service Industries Journal 10(4):737-747.

Baglin, Douglas and Austin, Yvonne (1984) New Zealand Pub Crawl, Beckett Stirling Ltd Auckland.

Baldacchino, G (1994) "Peculiar HRM practices: A case of the micro-state hotel", Tourism Management 15(1):46-58.

Baldacchino, G (1995) "Total Quality Management in a luxury hotel: a critique of practice", International Journal of Hospitality Management 14(1):67-78.

Barbee, C and Bott, V. (1991) "Customer treatment as a mirror of employee treatment", S.A.M. Advanced Management Journal 56(2):27-29.

Batstone, E. (1984) Working Order, Oxford: Basil Blackwell. 
Batstone, E. (1988) The Reform of Workplace Industrial Relations: Theory Myth and Evidence, Oxford: Clarendon Press.

Baum, Tom (1991) "The US and the UK: comparing expectations of management employees", Cornell Hotel and Restaurant Administration 32(2):79-84.

Beechey, V. (1987) Unequal Work, London: Verso.

Bell, R. and Winter, L. (1993) "Using marketing tools to improve employee relations", Cornell Hotel and Restaurant Administrative Quarterly 34(6):38-42.

Bendix, R. (1956) Work and Authority in Industry: Ideologies of Management in the Course of Industrialisation, London: John Wiley and Sons.

Blain, A.N. and Gennard, J. (1970) "Industrial relations theory - a critical review”, British Journal of Industrial Relations 8(3):389-407.

Boella, M. (1986) "A review of personnel management in the private sector of the British hospitality industry", International Journal of Hospitality Management 5(1):29-36.

Bogle, M. (1983) The Objectives and Performance of Licensing Trusts in New Zealand. Research Paper presented in partial fulfillment of the Degree of Master of Public Policy, Victoria University of Wellington.

Bollinger, Conrad (1959) Grogs Own Country, Wellington: Price Milburn and Co.

Bonn, A.M. and Forbinger, L.R. (1992) "Reducing turnover in the hospitality industry: an overview of recruitment, selection and retention", International Journal of Hospitality Management 11(1):47-64.

Boreham, P., Lafferty, G. and Whitehouse, G. (1996) "Training careers and numerical flexibility: equity implications in hospitality and retailing", Journal of Industrial Relations 38(1):3-21.

Bowen, D and Lawler, E (1992) "The empowerment of service workers: what, why, how and when?", Sloan Management Review 33(3):31-39.

Braverman, H. (1974) Labour and Monopoly Capital, New York: Monthly Review Press.

Bremner, Julie (1990) "Barrett's Hotel: the Victorian rendezvous" in D. Hamer and R. Nicholls The Making of Wellington 1800-1914, Wellington: VUW Press.

Brighton Labour Process Group (1977) "The capitalist labour process", Capital and Class, 1: 3-26.

Brosnan, P., Horwitz, F. and Walsh, P. "Non-standard employment in Australia, New Zealand and South Africa: results from a workplace survey". Paper 
presented at the Globalisation of Production and the Regulation of Labour conference, University of Warwick, England, 11-13 September 1996.

Brown, R. (1992) Understanding Industrial Organisations: Theoretical Perspectives in Industrial Sociology, London: Routledge.

Brown, W. and Wright, M. (1994) "The empirical tradition in industrial relations Research”, British Journal of Industrial Relations 32(2):153-164.

Bryant, C. and Jary, J. (1991) "Introduction: coming to terms with Giddens" in C. Bryant and D. Jary Giddens' Theory of Structuration: A Critical Appreciation, London: Routledge.

Brymer, R., Perrewe, P., and Johns, T. (1991) "Managerial job stress in the hotel industry", International Journal of Hospitality Management 10(1):47-58.

Burawoy, M. (1979) Manufacturing Consent, Chicago: University of Chicago Press.

Burrell, G. and Morgan, G. (1979) Sociological Paradigms and Organisational Analysis, Portsmouth: Heinemann.

Butler, S. and Skipper, J. (1981) "Working for tips: an examination of trust and reciprocity in a secondary relationship of the restaurant organisation", The Sociological Quarterly 22(1):15-27.

Callus, R., Morehead, A., Cully, M. and Buchanan, J. (1991) Industrial Relations at Work, Canberra: Australian Government Publishing Service.

Cappelli, P. and McKersie, R. (1987) "Management strategy and the redesign of workrules”, Journal of Management Studies 24(5):441-462.

Cassell, P (ed) (1993) The Giddens Reader, Stanford, California: Stanford University Press.

Cavaness, J and Manoochehri, G (1993) "Building quality into services", S.A.M. Advanced Management Journal Winter 1993:4-15.

Chamberlain, N (1948) The Union Challenge to Management Control, New York: Harper and Brothers.

Chandler, A. (1962) Strategy and Structure, Cambridge: MIT Press.

Chandler, A. and Daems, H. (1980) "Introduction" in A. Chandler and H. Daems (eds) Managerial Hierarchies: Comparative Perspectives on the Rise of the Modern Industrial Enterprise, Cambridge, Massachusetts: Harvard University Press.

Child, J. (1972) "Organisational structure, Environment and Performance: The Role of Strategic Choice”, Sociology 6(1):1-22. 
Child, J. (1985) "Managerial Strategies, New Technology and the Labour Process" in D. Knights, H. Wilmott and D. Collinson (eds) Job Redesign: Critical Perspectives on the Labour Process, London: Gower.

Chitiris, Leonidas (1990) "Who are the work-motivated managers in the hotel industry?", International Journal of Hospitality Management 9(4):293-304.

Chivers, T.S. (1972) Chefs and Cooks: A Study in the Sociology of Occupations, Unpublished $\mathrm{PhD}$ thesis, University of London.

Clark, Mona (1993) "Communications and social skills: perceptions of hospitality managers", Employee Relations 15(2):51-60.

Clegg, H. (1975) "Pluralism in industrial relations" British Journal of Industrial Relations 13(3)309-316.

Clegg, H. (1979) The Changing System of Industrial Relations in Great Britain, Oxford: Basil Blackwell.

Clegg, S. (1994) "Power and Institutions in Organisation Theory" in J. Hassard and M. Parker (eds) Towards a New Theory of Organisations, London: Routledge.

Cobble, D.S. (1991) Dishing It Out: Waitresses and the Unions in the Twentieth Century, Urbana and Chicago: University of Illinois Press.

Cockburn, C. (1983) Brothers: Male Dominance and Technological Change, London: Pluto Press.

Colmar Brunton (1997) A Survey of Labour Market Adjustment under the Employment Contracts Act, Prepared for Department of Labour Industrial Relations Service, Wellington.

Commission on Industrial Relations (1971) The Hotel and Catering Industry, Part 1, Hotels and Restaurants, Report No. 23, London: HMSO.

Commission on Industrial Relations (1973a) Industrial Relations at Establishment Level: A Statistical Survey, CIR Study No. 2, London: HMSO.

Commission on Industrial Relations (1973b) The Role of Management in Industrial Relations, Report No. 34, London: HMSO.

Cowan, J. (1907) New Zealand or Aotearoa: Its Wealth and Resources, Scenery, Travel Routes, Spas and Resorts, Wellington: Department of Tourist and Health Resorts.

Coyle, M.P., and Dale, B.G. (1993) "Quality in the hotel industry: a study", International Journal of Hospitality Management 12(2):141-153. 
Craig-Smith, S.J. and Fagence, M. (1995) "Tourism Training Needs in the AsiaPacific Region", Annals of Tourism Research 22(3):703-704.

Crompton. R. and Sanderson, K. (1990) Gendered Jobs and Social Change, London, Unwin Hyman Ltd.

Croney, P (1988) An Investigation into the Management of Labour in the Hotel Industry, Unpublished MA thesis, University of Warwick.

Cully, M. and Marginson, P. (1995) The Workplace Industrial Relations Surveys: Donovan and the Burden of Continuity, Warwick Papers in Industrial Relations No 55, Industrial Relations Research Unit, Coventry: University of Warwick.

Cyert, R. M. and March, J. (1963) The Behavioural Theory of the Firm, New Jersey: Prentice-Hall.

Dann, D (1990) "The nature of managerial work in the hospitality industry", International Journal of Hospitality Management 9(4):319-333.

Davidson C. and Bray, M. (1994) Women and Part-time Work in New Zealand, Christchurch: New Zealand Institute of Social Research and Development.

Deery, Stephen and Purcell, John (1989) "Strategic choices in industrial relations management in large organisations", Journal of Industrial Relations 31(4):459477.

Department of Labour (1997) Contract, Volume 23 November 1997.

Dey, I. (1989) "Flexible 'parts' and rigid 'fulls': the limited revolution on worktime patterns", Work Employment and Society 3(4):465-490.

Doeringer, P.B. and Piore, M.J. (1971) Internal Labour Markets and Manpower Analysis, Massachusetts: Heath Lexington Books, D.C. Heath and Company.

du Gay, P. and Salaman, G. (1992) "The cult[ure] of the customer", Journal of Management Studies 29(5):615-633.

Duncan, Ian, James, Doug, Ngan, T., and Hamilton, S. (1994) Tourism Investment in New Zealand: Opportunities and Constraints, Research Monograph No 63, Wellington: New Zealand Institute for Economic Research.

Dunlop, J. (1958/1993) (revised edition) Industrial Relations Systems, Boston: Harvard University Press.

Edwards, R.C. (1973) "The Social Relations of Production in the Firm and Labour Market Structure" in R.C. Edwards, M. Reich and D.M. Gordon (eds) Labour Market Segmentation Lexington: D.C. Heath and Co.

Edwards, R.C. (1979) Contested Terrain: The Transformation of Work in the Twentieth Century, New York: Basic Books. 
EEO Trust (1997) Annual Report 1997, Auckland: EEO Trust.

Feifer, M (1985) Tourism in History: From Imperial Rome to the Present, New York: Stein and Day.

Ferguson, S. (1985) Class at the Margins: the Canterbury Hotel Workers Union 1908-1970, Unpublished M.A. Thesis, University of Canterbury.

Ferner, A. (1988) Governments, Managers and Industrial Relations: public enterprises and their political environments, Oxford: Basil Blackwell.

Fernie, S. and Woodland, S. (1995) "HRM and workplace performance using WIRS3 - a reply to McCarthy", Industrial Relations Journal 26(1):65-68.

Fine, G. (1990) "Organisational time: temporal demands and the experience of work in restaurant kitchens", Social Forces, 69(1):95-114.

Fine, G. (1996) "Justifying work: occupational rhetorics as resources in restaurant kitchens", Administrative Science Quarterly 41(1):90-115.

Flanders, A.(1970) Management and Unions: the theory and reform of industrial relations, London: Faber and Faber.

Fox, A. (1966a) "Managerial ideology and labour relations", British Journal of Industrial Relations 4(3):366-378.

Fox, A. (1966b) Industrial Sociology and Industrial Relations, Research Paper 3, Royal Commission on Trade Unions and Employers Associations, London: HMSO.

Fox, A. (1974) Beyond Contract, London: Faber and Faber.

Fox, A. (1979) "A note on industrial relations pluralism" Sociology 13(1):105109.

Friedman, A. (1977a) "Responsible Autonomy versus Direct Control over the Labour Process", Capital and Class 1:43-57.

Friedman, A. (1977b) Industry and Labour: Class Struggle at Work and Monopoly Capitalism, London: MacMillan.

Fryer, G. (1976) Auckland Hotel Workers Union 1908-1914, Unpublished M.A. Long Essay, History Department, University of Auckland.

Gabriel, Y. (1988) Working Lives in Catering, London: Routledge.

Gamble, P. and Jones, P. (1991) "Quality as a strategic issue" in R. Teare and A. Boer (eds) Strategic Hospitality Management: Theory and Practice for the 1990s, London: Cassell. 
Gardner, K. and Wood, R. (1991) "Theatricality in food service work", International Journal of Hospitality Management 10(3):267-278.

Geary, J. (1992) "Employment flexibility and human resource management", Work Employment and Society 6(2):251-70.

Giddens, A. (1982) Profiles and Critiques in Social Theory, London: The MacMillan Press.

Giddens, A. (1984) The Constituion of Society, Cambridge: Polity Press.

Giddens, A. (1991) "Structuration theory: past, present and future" in C. Bryant and D. Jary Giddens' Theory of Structuration: A Critical Appreciation, London: Routledge.

Gilbert, D. and Joshi, I. (1992) "Quality Management and the tourism and hospitality industry" in C. Cooper and A. Lockwood (eds) Progress in Tourism, Recreation and Hospitality Management, London: Bellhaven Press.

Gilson, C. and Wagar, T. (1996) "Workforce reduction in Australia and New Zealand" Human Resource Management Journal 6(2):88-.

Glennie, M. (1991) "Service management and quality assurance: a systems approach", Cornell Hotel and Restaurant Administrative Quarterly 21(1):26-35.

Gosche, M (1992) "The Impact of the Act on Unions and Bargaining Agents", Paper presneted to a seminar entitled The Employment Contracts Act: One Year On, Wellington: Victoria University of Wellington, May 1992.

Gospel, H. (1983) "New Managerial Approaches to Industrial Relations: Major Paradigms and Historical Perspective", Journal of Industrial Relations 25(2):162183.

Gospel, H. (1992) Markets, Firms and the Management of Labour in Modern Britain, Cambridge: Cambridge University Press.

Gospel, H. and Littler, C. (eds) (1983) Management Strategy and Industrial Relations: an historical and comparative study, London: Heinemann Educational Books.

Guerrier, Y. (1987) "Hotel managers careers and their impact on hotels in Britain", International Journal of Hospitality Management 6(3):121-130.

Guerrier, Y. and Lockwood, A. (1989a) "Core and peripheral employee in hotel operations", Personnel Review 118(1):9-15.

Guerrier, Y. and Lockwood, A. (1989b) "Managing flexible working in hotels", Service Industries Journal 9(3):406-419. 
Guerrier, Y. and Lockwood, A. (1989c) "Developing hotel managers - a reappraisal”, International Journal of Hospitality Management 8(2):82-89.

Guerrier, Y. and Lockwood, A. (1990) "Managers in hospitality: a review of current research", in C. Cooper (ed) Progress in Tourism, Recreation and Hospitality Management ,London: Bellhaven Press.

Guest, D. (1987) "Human resource management and industrial relations", Journal of Management Studies 24(5):503-521.

Guest, D. (1990) "Human resource management and the american dream", Journal of Management Studies 27(4):377-397.

Hakim, C. (1990) "Core and periphery in employers' workforce strategies: Evidence from the 1987 E.L.U.S. survey", Work Employment and Society 4(2):157-188.

Hales, C. (1987) "Quality of work life, job redesign and participation in a service industry: a rose by any other name?", Service Industries Journal 7(3):253-273.

Hall, E. (1993a) "Waitering/Waitressing: engendering the work of table servers", Gender and Society 7(3):329-346.

Hall, E. (1993b) "Smiling deferring and flirting: doing gender by giving 'good service", Work and Occupations 20(4):452-471.

Harbridge, R. and Crawford, A. (1996) "The Employment Contracts Act and Collective Bargaining Patterns: A Review of the 1995/96 year" in Harbridge, R., Cawford, A. and Kiely, P. Employment Contracts: Bargaining Trends and Employment Law Update, Wellington: Industrial Relations Centre, Victoria University of Wellington.

Harbridge, R. and Crawford, A. (1997) "The Employment Contracts Act and Collective Bargaining Patterns: A Review of the 1996/97 year" in Harbridge, R., Cawford, A. and Kiely, P. Employment Contracts: Bargaining Trends and Employment Law Update, Wellington: Industrial Relations Centre, Victoria University of Wellington.

Harbridge, R. and Honeybone, A. (1994) "The Employment Contracts Act and Collective Bargaining Patterns: A Review of the 1993/94 year" in Harbridge, R., Cawford, A. and Kiely, P. Employment Contracts: Bargaining Trends and Employment Law Update Wellington: Industrial Relations Centre, Victoria University of Wellington.

Harbridge, R. and Hince, K. (1994) A Sourcebook of New Zealand Trade Unions and Employee Organisations, Wellington: Industrial Relations Centre, Victoria University of Wellington. 
Hargreaves, Ray (1992) Barmaids, Billiards, Nobblers and Rat-Pits - Pub Life in Goldrush Dunedin, Dunedin, Otago Heritage Books.

Hawkins, Richard (1984) "Employee theft in the restaurant trade: forms of ripping off by waiters at work" Deviant Behaviour 5,1-4.47-69.

Heery, E. (1993) "Industrial relations and the customer", Industrial Relations Journal 24(4):284-295.

Heymann, K. (1992) "Quality management: a ten-point model” in Cornell Hotel and Restaurant Adminstration 33(5):50-55.

Hochschild, A. R. (1983) The Managed Heart: Commercialisation of Human Feeling, California, University of California Press.

Hotel and Catering Economic Development Committee (1969) Staff Turnover, National Economic Development Office, London, HMSO.

Hotel and Catering Training Company (1994) Employment Flows in the Catering and Hospitality Industry, London: Hotel and Catering Training Company.

Hunter, L., McGregor, A., MacInnes, J., and Sproull, A. (1993) "The 'flexible firm': strategy and segmentation", British Journal of Industrial Relations 31(3):383-407.

Hyman, R. (1974) "Inequality, ideology and industrial relations", British Journal of Industrial Relations 12(2):171-190.

Hyman, R. (1978) "Pluralism, procedural consensus and collective bargaining", British Journal of Industrial Relations 16(1):16-40.

Hyman, R. (1995) "The historical evolution of British industrial relations", in P. Edwards (ed) Industrial Relations: Theory and Practice In Britain, Oxford: Blackwell.

Ichniowski, C., Delaney, J., and Lewin, D. (1989) "The new resources management in US workplaces: is it really new or is it only non-union?", Relations Industrielles 44(1):97-119.

Jermier, J., Knights, D. and Nord, W. (eds) (1994) Resistance and Power in Organisations, London: Routledge.

Johnson, K. and Mignot, K. (1982) "Marketing trade unionism to service industries: an historical analysis of the hotel industry", Service Industries Review 2(3):5-23.

Jones, P and Davies, A (1991) "Empowerment: a study of general managers of four-star hotel properties in the UK", International Journal of Hospitality Management 10(3):211-217. 
Jurgeleit, M.D. (1973) "Figuratively Speaking", Papers presented to the News Media Forum of the New Zealand Liquor Industry Council, Russley Hotel, Christchurch, April 30-May 2 1973, pp 10-28.

Justice Department (1974) Submission to Royal Commission on Licensing, Wellington, Justice Department.

Katz, H. (1993) "The decentralisation of collective bargaining: a literature review and comparative analysis", Industrial and Labour Relations Review 47(1):3-22.

Kaufman, B. (1993) The Origins and Evolution of the Field of Industrial Relations in the United States, Ithaca: ILR Press.

Keenoy, T. and Anthony, P. (1992) "HRM: Metaphor, Meaning and Morality" in Blyton, P. and Turnbull, P. (eds) Reassessing Human Resource Management, London: Sage.

Kelliher, C. and Johnson, K. (1987) "Personnel management in hotels - some empirical observations", International Journal of Hospitality Management 6(2):103-108.

Kelliher, C. and McKenna, S. (1987) "Contract caterers and public sector catering", Employee Relations 9(1):8-13.

Kerr, C. (1978) "Industrial relations research: a personal retrospective" Industrial Relations 17(2):131-142.

Kinnie, N. (1985) "Changing management strategies in industrial relations", Industrial Relations Journal 16(4):17-24.

Kinnie, N. (1987) "Bargaining within the enterprise: centralised or decentralised?", Journal of Management Studies 24(5):463-477.

Kinnie, N. (1989) "Patterns of industrial relations management", Management Decision 27(4):113-118.

Knights, D. and Collinson, D. (1985) "Redesigning work on the shopfloor: a question of control or consent?" in D. Knights, H. Willmott and D. Collinson (eds) Job Re-design: Critical Perspectives on the Labour Process Aldershot: Gower Publishing Company.

Knights, D. and Wilmott, H. (1986) (eds) Gender and the Labour Process, Aldershot: Gower Publishing Company.

Kochan, T. and Cappelli, P. (1984) "The transformation of the industrial relations and personnel function" in P. Osterman (ed) Internal Labour Markets, Cambridge, Massachusetts: MIT Press.

Kochan, T.A., Katz, H., and McKersie, R.B. (1994) The Transformation of American Industrial Relations, Ithaca, New York: ILR Press. 
Kochan, T., McKersie, R. and Cappelli, P. (1984) "Strategic choice and industrial relations theory", Industrial Relations 23(1):16-39.

Kohl, John P. and Stevens, David B. (1989) "Recruitment policies and practices of restaurants, hotels and clubs: a study of the personnel procedures of hospitality firms", Hospitality Education and Research Journal 13(2):45-50.

La Pointe, E. (1992) "Relationships with waitresses: gendered social distance in restaurant hierarchies",Qualitative Sociology 15(4):377-393.

Lashley, C (1995a) "Towards an understanding of employee empowerment in hospitality services", International Journal of Catering and Hospitality Management 7(1):27-32.

Lashley, C (1995b) "Empowerment through delayering: a pilot study at McDonald's restaurants", International Journal of Catering and Hospitality Management 7(2/3):29-35.

Legge, K. (1988) Personnel Management in Recession and Recovery: A Comparative Analysis of What the Surveys Say, Bradford: MCB University Press.

Legge, K. (1989) "Human Resource Management: a critical analysis” in J. Storey (ed) New Perspectives on Human Resource Management, London: Routledge.

Legge, K. (1995) Human Resource Management: Rhetorics and Reality, Hampshire: MacMillan Press.

Leidner, R. (1993) Fast Food Fast Talk, Berkeley: University of California Press.

Lennon, J. and Wood, R (1989) "The Sociological analysis of hospitality labour and the neglect of accommodation workers", International Journal of Hospitality Management 8(3):227-235.

Leonard, B. (1992) "HR Policies ensure the Mirage won't vanish", HR Magazine June 1992: 85-97, 91.

Lind, C. (1994) Pubs, Pints and People: 50 Years of the Invercargill Licensing Trust, Invercargill: Invercargill Licensing Trust.

Liquor Review Advisory Committee (1997) Liquor Review: Report of the Advisory Committee, Wellington: Ministry of Justice.

Littler, C. (1982) The Development of the Labour Process in Capitalist Societies, London: Heinemann.

Littler, C. (1985) "Taylorism, Fordism and job design" in D. Knights, H. Willmott and D. Collinson (eds) Job Re-design: Critical Perspectives on the Labour Process, Aldershot: Gower Publishing Company. 
Littler, C. (1987) "Labour Process Literature - A Review 1974-1986" in K. Hince and A. Williams. (eds) Contemporary Industrial Relations in Australia and New Zealand, Proceedings of the Biennial Conference of the Association of Industrial Relations Academics of Australia and New Zealand.

Littler, C. and Salaman, G. (1982) "Bravermania and beyond: recent theories of the labour process", Sociology 16(2):251-269.

Lloyd, P. J. (1964) The Economic Development of the Tourist Industry in New Zealand, Research Paper No 6, Wellington: New Zealand Institute of Economic Research.

Loveridge, Ray (1983) "Labour market segmentation and the firm" in John Edwards, Chris Leek, Ray Loveridge, Roger Lumley, John Mangan, Mick Silver (eds) Manpower Planning: Strategy and Techniques in an Organisational Context, Chichester, John Wiley and Sons.

Loveridge, R. and Mok, A. (1979) Theories of Labour Market Segmentation : A Critique, The Hague: Martinus Nijhoff Social Sciences Division.

Lucas, R. (1991a) "Remuneration practice in a wages council sector: some empirical observations in hotels", Industrial Relations Journal 22(4):273-285.

Lucas, R. (1991b) "Promoting collective bargaining: Wages Councils and the hotel industry", Employee Relations 13(5):3-11.

Lucas, R. (1993) “Ageism and the UK hospitality industry", Employee Relations 15(2): 33-41.

Lucas, R. (1995) Managing Employee Relations in the Hotel and Catering Industry, London: Cassell.

Lucas, R. (1996) "Youth, gender and part-time employment: implications in the labour process" Paper presented to 14th annual International Labour Process conference, Aston University, 27-29 March 1996.

Lyon, P. Taylor, S. and Smith, S. (1994) "McDonaldization: a reply to Ritzer's thesis", International Journal of Hospitality Management 13(2):95-99.

Macaulay, I. and Wood, R. (1982) "Hotel and catering industry employee's attitudes towards trade unions", Employee Relations 14(3):20-28.

MacCannell, D. (1976) The Tourist: A New Theory of the Leisure Class, New York: Schocken Books.

MacInnes, J. (1988) “The question of flexibility”, Personnel Review 17(3):12-15.

MacFarlane, A. (1982) "Trade union growth, the employer and the hotel and restaurant industry", Industrial Relations Journal 13(4):29-43. 
MacKay, Duncan (1992) Frontier New Zealand: The Search for Eldorado 18001920, Auckland: Harper Collins.

Manicas, P. (1987) A History and Philosophy of the Social Sciences, Oxford: Basil Blackwell.

Marchington, M. (1990) "Analysing the links between product markets and the management of employee relations", Journal of Management Studies 27(2):111132.

Marchington, M. (1996) "Shopping down different aisles: a review of the literature on human resource management in food retailing", Journal of Retailing and Consumer Services 3(1):21- 32.

Marchington, M. and Harrison, E. (1991) "Customers, competitors and choice: employee relations in food retailing”, Industrial Relations Journal 22(4):286-299.

Marchington, M. and Parker, P. (1990) Changing Patterns of Employee Relations, Hemel Hempstead: Harvester Wheatsheaf.

Marginson, P., Edwards, P., Martin, R, Purcell, J., and Sisson, K. (1988) Beyond the Workplace: Managing Industrial Relations in Multi-Establishment Workplaces, Oxford: Basil Blackwell.

Mars, G. and Nicod, M. (1984) The World of Waiters, London: Allen and Unwin.

Mars, Gerald and Peter Mitchell. (1976) Room for Reform?: A Case Study of Industrial Relations in the Hotel Industry, Prepared for the Open University, Industrial Relations Course Team, Milton Keynes : Open University Press.

Marx, K. (1938) Capital: A Critical Analysis of Capitalist Production, London: George Allen and Unwin Ltd.

Marx, K. (1870) "The Eighteenth Brumaire of Louis Bonaparte" in Feuer, L.S. (ed) (1959) Marx and Engels: Basic Writings on Politics and Philosophy, Anchor Books: New York.

Maurice, M., Sellier, F. and Silvestre, J-J. (1986) The Social Foundations of Industrial Power, Cambridge, Massachusetts: MIT University Press.

McCarthy, W. (1994) "Of hats and cattle: or the limits of macro-survey research in industrial relations”, Industrial Relations Journal 25(4):315-322.

McGraw, P. and Palmer, I (1990) "Reluctant conscripts? Small business management attitudes to employee relations in travel agencies", Journal of Industrial Relations 32(4):513-522.

McLoughlin, I. and Gourlay, S. (1994) Enterprise Without Unions: Industrial Relations in the Non-Union Firm, Buckingham: Open University Press. 
Millward, N. (1994) The New Industrial Relations? London: Policy Studies Institute.

Millward, N. and Hawes, W. (1995) "Hats, cattle, and IR research: a comment on McCarthy", Industrial Relations Journal 26(1):69-73.

Millward, N. and Stevens, M. (1986) British Workplace Industrial Relations 1980-84, Aldershot: Gower.

Millward, N., Stevens, M., Smart, D. and Hawes, W. (1992) Workplace Industrial Relations in Transition, Aldershot: Dartmouth Publishing.

Ministry of Commerce (1996) Post-Election Brief to the Incoming Government, Wellington: Ministry of Commerce.

Ministry of Justice (1996) Liquor Review 1996: A Discussion Paper, Wellington: Ministry of Justice.

Mintzberg, H. (1978) "Patterns in strategy formation", Management Science 24(9):934-948.

Mitchell, P. (1988) "The structure of labour markets in the hotel and catering industry: what do employment law cases indicate?", The Service Industries Journal 8(4):470-487.

Morris, T. and Wood, S. (1991) "Testing the survey method: continuity and change in British industrial relations", Work Employment and Society 5(2):259282.

Nailon, P. (1982) "Theory in hospitality management", International Journal of Hospitality Management 1(3):135-143.

Nankervis, A. R. (1993) Productivity, Service Excellence and Innovation in Southeast Asian Hotels: A Report on an International Study, Sydney: University of Western Sydney.

National Development Conference (1969) Report of the Tourism Committee to the National Development Conference, Wellington.

NEDO (National Economic Development Conference) (1969) Staff Turnover, London: HMSO.

New Zealand Institute of Economic Research (1997) New Zealand Industry Outlook, Wellington: NZIER.

New Zealand Official Yearbooks: (various years) Wellington, New Zealand Government.

New Zealand Tourism Board (1993) Tourism in New Zealand: Strategy and Progress, Wellington: New Zealand Tourism Board. 
New Zealand Tourism Board (1995) New Zealand Tourism Awards: Entry Form, Wellington: New Zealand Tourism Board.

New Zealand Tourism Department (1990) Brief to the Incoming Minister of Tourism, November 1990.

New Zealand Tourist and Publicity Department (undated) Education and Training for the New Zealand Tourism Industry, Wellington: Tourist and Publicity Department.

New Zealand Tourist Industry Federation (1984) "Tourism and New Zealand". Submission to the Economic Summit Conference 1984, Wellington: Parliament House.

Newman, E. (1993) Waiting for Change: A Case Study of Employment in the Restaurant Industry, Unpublished MA thesis, University of Warwick.

Nikolich, M. and Sparks, B. (1995) “The hospitality service encounter: the role of communication", Hospitality Research Journal 19(2):43-56.

Nolan, P. and Walsh, J. (1995) "The structure of the economy and labour market" in P. Edwards (ed) Industrial Relations: Theory and Practice in Britain, Oxford: Blackwell Publishers Ltd.

OECD (1993) Tourism Policy and International Tourism in OECD Countries 1990-91, Paris: Organisation for Economic Cooperation and Development.

Osterman, Paul (1987) "Choice of employment systems in internal labour markets", Industrial Relations 26(1):46-67.

Palmer, G. (1968) "Chronicle: negotiations and agreements: inter-union dispute in the Torquay hotel industry", British Journal of Industrial Relations 6(2):250.

Paules, G. (1991) Dishing it Out: Power and Resistance among Waitresses in a New Jersey Restaurant, Philadelphia: Temple University Press.

Perry, M., Davidson, C. and Hill, R. (1995) Reform at Work: Workplace Change and the New Industrial Order, Auckland: Longman Paul.

Pettigrew, A. (1985) The Awakening Giant: Continuity and Change at ICI, London: Blackwell.

Pickard, J. (1995) "Food for Thought", People Management 5 October 1995.

Pickering, J.F., Greenwood, J.A., and Hunt, D. (1971) The Small Firm in the Hotel and Catering Industry, Committee of Inquiry on Small Firms, London: HMSO. 
Piore, M. (1973) "Notes for a theory of labour market stratification" in R.C. Edwards, M. Reich and D.M. Gordon (eds) Labour Market Segmentation, Lexington: D.C. Heath and Co.

Piore, M. and Sabel, C.F. (1984) The Second Industrial Divide - Possibilities for Prosperity, New York: Basic Books.

Pollert, A. (1987) "The 'flexible firm': a model in search of reality (or a policy in search of a practice)?", Warwick Papers in Industrial Relations No 19 Industrial Relations Research Unit, University of Warwick.

Pollert, A. (1988a) “The 'flexible firm': fixation or fact?", Work Employment and Society 2(3):281-316.

Pollert, A. (1988b) “Dismantling flexibility”, Capital and Class Vol 34:42-75.

Pollert, A. (1991) "The orthodoxy of flexibility" in A. Pollert (ed) Farewell to Flexibility, Oxford: Basil Blackwell.

Price, L. (1993) "The limitations of the law in influencing employment practices in UK hotels and restaurants", Employee Relations 15(2):16-24.

Prus, Robert and Vassilakopoulos, Steve (1979) "Desk clerks and hookers: hustling in a shady hotel" Urban Life 8(1):52-71

Purcell, J. (1987) "Mapping management styles in employee relations", Journal of Management Studies 24(5) 533-548.

Purcell, J. and Ahlstrand, B. (1993) Strategy and Style in Employee Relations, Oxford: Oxford University Press.

Purcell, J. and Sisson, K. (1983) "Strategies and practice in the management of industrial relations" in G.S. Bain (ed) Industrial Relations In Britain, Oxford: Basil Blackwell.

Ralston, R. (1989) The Changing Nature of Personnel Management in the hotel and catering industry, Unpublished MSc thesis, University of Manchester.

Ransom, S.; Hinings, B. and Greenwood, R. (1981) "The structuring of organisational structures" Administrative Science Quarterly 25(1):1-17.

Rees, G. and Fielder, S (1992) "The services economy, sub-contracting and the new employment relations: contract catering and cleaning" , Work Employment and Society 6(3):347-368.

Reich, M, Gordon, D.M. and Edwards, R.C. (1973) "A theory of labour market segmentation”, American Economic Review 63(2):359-365. 
Revelly, J.W. (1996) Registering Interest: Work, Employment and Industrial Relations on the Waterfront in New Zealand 1953-93 , Unpublished PhD Thesis, University of Canterbury.

Riley, M. (1985) "Some social and historical perspectives on unionisation in the UK hotel industry", International Journal of Hospitality Management 4(3):99104.

Riley, M. (1991) "An analysis of hotel labour markets" in C. P. Cooper (ed) Progress in Tourism Recreation and Hospitality Management, Vol 3 University of Surrey, London: Bellhaven Press.

Riley, M. (1992) "Functional flexibility in hotels - is it feasible?", Tourism Management 13(4):363-367.

Riley, M. (1993) "Back to the future: lessons from the free market experience", Employee Relations 15(2):8-15.

Riley, M. (1994) "Industrial relations in the hotel and catering industry" in C. Cooper (ed) Progress in Hospitality and Catering Research,Vol. 6 University of Surrey, London: Bellhaven Press.

Ritzer, G. (1993) The McDonaldization of Society, Newbury Park: Pine Forge Press.

Ritzer, G. (1996) "The McDonaldization Thesis", International Sociology 11(3):291-308.

Roethlisberger, F. and Dickson, W. (1939) Management and the Worker, Cambridge, Massachusetts: Harvard University Press.

Ross, Malcolm (1896) “A Scenic Wonderland”, New Zealand Official Yearbook Vol 4.

Ross. G (1995) "Management Values, work preference ideals and personality needs as predictors of hospitality industry employee career anchors", Hospitality Research Journal 18(3)/19(1):61-79.

Royal Commission on Licensing (1974) The Sale of Liquor In New Zealand Report of the Royal Commission to Inquire into and Report upon the Sale of Liquor in New Zealand, Wellington: Government Printer.

Royal Commission on Licensing (1946) Report of the Royal Commission on Licensing, Wellington: Parliamentary Paper H-38, 1946.

Rubery, J. (1994) “The British Production Regime: a societal-specific system?", Economy and Society 23(3):335-354.

Ryan, R. (1992) "Flexibility in New Zealand workplaces: a study of Northern employers" New Zealand Journal of Industrial Relations , 17(2):129-147. 
Salmon, C. (1992) The Unexplored Avenue: The Standardisation of Bar Work, Unpublished M.A. thesis, University of Warwick.

Samenfink, W. (1994) "A qualitative analysis of certain interpersonal skills required in the service encounter", Hospitality Research Journal 17(2):3-15.

Saunders, C. (1981) Social Stigma of Occupations: The Lower Grade Worker in Service Occupations, Hants.: Gower Publishing Company.

Saunders, I.W. and Graham, W.A. (1992) "Total Quality Management in the hospitality Industry", Total Quality Management 3(3):243-255.

Shamir, B. (1975) A Study of Working Environments and Attitudes to Work of Employees in a Number of British Hotels, Unpublished $\mathrm{PhD}$ thesis, London, London School of Economics.

Shamir, B. (1978) "Between bureaucracy and hospitality - some organisational characteristics of hotels", Journal of Management Studies 15(3):285-307.

Shamir, B. (1981) "The workplace as community: the case of British hotels", Industrial Relations Journal 12(6):45-56.

Sheehy, T. (1971) "Staff Recruitment and Training", in papers presented at the News Media Form of the National Council of the Licensed Trade, Mon Desire Hotel, Takapuna, April 26-28, 1971, pp99-105.

Silverman, D. (1970) The Theory of Organisations, London: Heinemann Educational Books.

Silverman, D. (1994) "Re-writing the theory of organisations" in J. Hassard and M. Parker (eds) Towards a New Theory of Organisations, London: Routledge.

Simms, J., Hale, C. and Riley, M (1988) "Examination of the concept of internal labour markets in UK hotels", Tourism Management 9(1):3-12.

Simon, H. (1957) (2 ed) Administrative Behaviour, New York: The Free Press.

Sisson, K. (1993) "In Search of HRM", British Journal of Industrial Relations 31(2):201-210.

Sisson, K. and Marginson, P. (1995) "Management systems, structure and strategy" in P. Edwards (ed) Industrial Relations: Theory and Practice in Britain, Oxford: Blackwell Publishers.

Slattery, P. (1983) "Social scientific methodology and hospitality management", International Journal of Hospitality Management 2(1):9-14.

Sparks, B. (1994) "Communicative aspects of the service encounter", Hospitality Research Journal 17(2):39-50. 
Sparks, B., Bradley, G. and Callan, V (1995) "The impact of staff empowerment and communication style on customer evaluations", Paper presented to National Hospitality and Tourism Conference, Melbourne, 1995.

Statistics New Zealand (1993) New Zealanders At Work, Wellington: Statistics New Zealand.

Statistics New Zealand (various years) Business Activity Statistics, Wellington: Statistics New Zealand.

Storey, J. (1976/77) "Workplace collective bargaining and managerial prerogatives", Industrial Relations Journal 7(3):40-55.

Storey, J. (1983) Managerial Prerogative and the Question of Control, London: Routledge.

Storey, J and Sisson, K. (1993) Managing Human Resources and Industrial Relations, Buckingham: Open University Press.

Strauss, G. and Feuille, P. (1978) "Industrial relations research: a critical analysis" in Industrial Relations 17(3):259-277.

Sturdy, A. (1992) "Clerical Consent: 'Shifting' Work in the Insurance Office" in A. Sturdy, D. Knights and H. Wilmott (eds) Skill and Consent: Contemporary Studies in the Labour Process, London: Routledge.

Sturdy, A., Knights, D. and Willmott, H. (1992) "Introduction: skill and consent in the labour process" in A. Sturdy, D. Knights and H. Wilmott (eds) Skill and Consent: Contemporary Studies in the Labour Process, London: Routledge.

Sutch, W (1966) Quest for Security in New Zealand 1840-1966, Wellington: Oxford University Press.

Taylor, F. W. (1947) Scientific Management, New York: Harper.

Taylor, S. and Lyon, P. (1995) "Paradigm lost: the rise and fall of McDonaldization", International Journal of Hospitality Management 7(2/3):6468.

Thompson, J.W. (1973) "Comments on the Survey", in Papers presented at the News Media Form of the New Zealand Liquor Industry Council, Russley Hotel, Christchurch, April 30-May 2 1973, pp 38-41.

Thompson, P. (1989) (2 ed) The Nature of Work, Basingstoke: Macmillan Education Ltd.

Thompson, P. and McHugh, D. (1990) Work Organisations, London: Macmillan. 
Thurley, K. and Wood, S. (1983) "Business strategy and industrial relations strategy", in K. Thurley and S. Wood (eds) Industrial Relations and Management Strategy, Cambridge: Cambridge University Press.

Timo, N. (1993) "Employment relations and labour markets in the Tourism and Hospitality Industry", International Journal of Employment Studies 1(1):33-50.

Tolliday, S. and Zeitlin, J. (1985) (eds) Shop Floor Bargaining and the State: Historical and Comparative Perspectives, Cambridge: Cambridge University Press.

Tourism Advisory Council (1978) Report of the Personnel and Training Committee, Tourism Conference, 15-16 August 1968.

Townley, B. (1994) Reframing Human Resource Management, London: Sage.

Tracey, J.B. and Tews, M. (1995) "Training effectiveness: accounting for individual characteristics" Cornell Hotel and Restaurant Administration Quarterly.

Urry, J. (1990) The Tourist Gaze: Leisure and Travel in Contemporary Society, London: Sage Publications Ltd.

Walby, S. (1986) Patriarchy at Work, Oxford: Polity

Walsh, K. (1995) "Quality through markets: the new public sector management" in Wilkinson, A and Wilmott, H. (eds) Making Quality Critical: New Perspectives on Organisational Change, London: Routledge.

Walsh, T. (1991) "Flexible employment in the retail and hotel trades", in A. Pollert (ed.) Farewell to Flexibility, Oxford: Blackwell.

Watkins, E (1992) "How Ritz-Carlton won the Baldrige Award", Lodging Hospitality November 1992 pp22-24.

Watson, T. (1994) In Search of Management: Culture, Chaos and Control in Managerial Work, London: Routledge.

Whipp, R. (1992) "Human resource management, competition and strategy: some productive tensions" in P. Blyton and P. Turnbull (eds) Reassessing Human Resource Management London: Sage Publications Ltd.

Whittington, R. (1992) "Putting Giddens into action: social systems and managerial agency”, Journal of Management Studies (29(6):693-712.

Whittington, R. (1993) What is Strategy and Does It Matter?, London: Routledge.

Whittington, R. (1994) "Sociological pluralism, institutions and managerial agency" in J. Hassard and M. Parker (eds) Towards a New Theory of Organisations, London: Routledge. 
Whyte, W. F. (1948) Human Relations in the Restaurant Industry, New York: McGraw Hill Book Company.

Whyte, W., Hamilton, E. and Wiley, M. (1965) Action Research for Management: A Case report on research and action in Industry, Homewood, Illinois: Richard D. Irwin Inc and the Dorset Press.

Williams, Claire (1986) "Domestic flight attendants in Australia: a quasioccupational community?", Journal of Industrial Relations 28(2):237-251.

Williams, Peter and Hunter, Michael (1992) "Supervisory hotel employee perceptions of management careers and professional development requirements", International Journal of Hospitality Management 11(4):347-358.

Williamson, O. E. (1975) Markets and Hierarchies, New York: The Free Press.

Wilmott, H. (1981) "The Structuring of Organisational Structure: A Note", Administrative Science Quarterly 25(3):470-474.

Willmott, H. (1994) "Bringing agency (back) into organisational analysis: responding to the crisis of (post)modernity" in J. Hassard and M. Parker (eds) Towards a New Theory of Organisations, London: Routledge.

Winchester, D. and Bach, S. (1995) "The State: the public sector" in Edwards, P. (ed) Industrial Relations: Theory and Practice in Britain, Oxford, Blackwell Publishers Ltd.

Wood, R. (1992a) Working in Hotels and Catering, London: Routledge.

Wood, R. (1992b) "Deviants and misfits: hotel and catering labour and the marginal worker thesis", International Journal of Hospitality Management 11(3):179-182.

Wood, R. (1993) "Status and hotel and catering work: theoretical dimensions and practical implications", Hospitality Research Journal 16(3):3-15

Wood, R. (1994a) "Hotel culture and social control", Annals of Tourism Research 21(1):65-80.

Wood, R. (1994b) "Some theoretical perspectives on hospitality", in A. Seaton (ed) Tourism: the State of the Art, Chichester: John Wiley and Sons.

Wood, R. (1995) Labour in the Hotel and Catering Industry: Update 1995, Glasgow, The Scottish Hotel School, University of Strathclyde.

Wood, S. (1989) "The transformation of work?" in S. Wood (ed) The Transformation of Work?, London: Unwin Hyman.

Wood, S. and Elliot, R. (1977) “A Critical Evaluation of Fox's Radicalisation of Industrial Relations Theory", Sociology 11(1):105-125. 
Wood, S. and Kelly, J. (1982) "Taylorism, responsible autonomy and management strategy" in S. Wood (ed) The Degradation of Work?, London: Hutchinson.

Wood, S. and Pedlar, M (1978) "On losing their virginity: the story of the strike at the Grosvenor Hotel Sheffield", Industrial Relations Journal 9(2):15-37.

Worland, D. and Wilson, K. (1988) "Employment and labour costs in the hospitality industry: evidence from Victoria, Australia", International Journal of Hospitality Management 7(4):363-377.

Worsfold, P. (1989) "Leadership and managerial effectiveness in the hospitality industry", International Journal of Hospitality Management 8(2):145-155.

Worsfold, P and Jameson, S. (1991) "Human resource management: a response to change in the 1990s", in R. Teare and A. Boer (eds) Strategic Hospitality Management: Theory and Practice for the 1990s, London: Cassell.

Wright, C. (1995) The Management of Labour: A History of Australian Employers, Australia: Oxford University Press.

Wynne, J. (1993) "Power relationships and empowerment in hotels", Employee Relations 15(2):42-5.

Yaw, Debrah (1994) "Management of operative staff in a labour-scarce economy: the views of human resource managers in the hotel industry in Singapore", AsiaPacific Journal of Human Resources 32(1):41-60.

Zaccarelli, H. (1985) "Is the hospitality industry turning its employees on - or off?", International Journal of Hospitality Management 4(1):123-124.

Zimbalist, A. (1979) Case Studies on the Labour Process, New York: Monthly Review Press. 